\title{
Geology of the Alpha Regio (V-32) Quadrangle, Venus
}

\author{
by
}

\author{
Erin Bethell
}

A thesis submitted to the Faculty of Graduate and Postdoctoral Affairs in partial fulfillment of the requirements for the degree of

Doctor of Philosophy

in

Earth Sciences

Carleton University

Ottawa, Ontario

(C) 2021

Erin Bethell 


\section{ABSTRACT}

This thesis presents a 1:2,500,000 geological map of the Alpha Regio (V32) quadrangle, Venus. Nearly 40,000 lineaments and 77 geological units were mapped. Several fracture belts have been identified. Plains material, previously mapped as several global units, was divided into 27 units and some were linked to discrete sources. Several corona-sourced volcanic flows were recognized. Cross-cutting relationships reveal a complex geological history throughout which numerous processes have overlapped.

Fatua Corona is associated with a radiating graben-fissure system 1700 $\mathrm{km}$ in length that swings in trend from radiating to sub-parallel. The structures are inferred to overly dykes, which represent an estimated $57,000 \mathrm{~km}^{3}$ of magma. The dyke trends were used to establish the regional stress field orientation (NNESSW maximum compressive stress). Two hypotheses are proposed to explain the forces contributing to this stress field: 1) extension in the DercetoQuetzalpetlatl belt, or 2) ridge push from the Alpha-Lada belt.

Giant circumferential dyke swarms on Earth resemble the circumferential graben-fissure systems of coronae. Characteristics of circumferential grabenfissure systems in the V-32 quadrangle are catalogued and compared with terrestrial circumferential dyke swarms. Based on this new mapping of circumferential systems, several coronae are shown to be much larger than previously described, notably Thermuthis Corona $(330 \mathrm{~km}$ to $1250 \mathrm{~km}$ in diameter). 
The high coverage of stereo-derived topography data in this region has enabled the characterization of wrinkle ridge morphometry. The ridges are $\sim 10$ $\mathrm{km}$ wide with $\sim 100 \mathrm{~m}$ of relief and mostly asymmetric. Modeling of the underlying thrust faults suggests they are planar, dip $30^{\circ}$, reach depths of $\leq 5 \mathrm{~km}$, are blind to depths of $\geq 2 \mathrm{~km}$, and have accommodated $\sim 200 \mathrm{~m}$ of dip-slip. These results support thin-skinned deformation. Wrinkle ridge density is negatively correlated with crustal thickness, supporting previous models linking the magnitude of strain to the swell-push body force combined with crustal thickness. The strain appears to be specifically related to mantle downwelling along Eistla Regio.

The results of this research have been used to identify landing site targets in the V-32 quadrangle for the Venera-D mission. Five targets are suggested in plains material, digitate volcanic flows, and corona-sourced flows. 


\section{ACKNOWLEDGEMENTS}

First and foremost, I would like to thank my supervisors, Dr. Richard Ernst and Dr. Claire Samson, for taking me on as their student. They have steadfastly guided me through this project and helped shape me into the scientist I am today.

I would like to extend my sincere thanks to several mentors that I have been fortunate enough to have throughout my graduate studies. Dr. Eric Grosfils kindly hosted me at his institution (Pomona College) for a week to teach me about finite element modeling software. While I did not ultimately use this software in my thesis, I learned so much from the visit and was able to apply this knowledge to other areas of my research. Dr. Kenneth Buchan and I had numerous discussions about coronae on Venus and circumferential dyke swarms on Earth, and these conversations were critical in developing the fourth chapter of my thesis. I owe a great debt to Dr. Simon Hanmer, who provided extensive feedback on the fifth chapter of my thesis. Dr. Hanmer's comments and suggestions greatly improved the content of this chapter and expanded my knowledge on wrinkle ridges and structural geology in general. Special thanks go to Dr. Giorgio Ranalli, my "grand-supervisor", who has been an excellent mentor to me during this project and provided crucial comments that helped refine the third chapter.

I would also like to thank the USGS Astrogeology Science Center for providing me with a GIS package for my study area, and Dr. Alberto Jiménez- 
Díaz for providing me with crustal and effective elastic thickness datasets for Venus.

I am grateful for my Venusian colleagues from Carleton, including Jamie Graff, Sara Khawja, Jennifer Lee, and Sarah Davey. They have all helped me in some manner along the way, whether that was editing conference abstracts and presentations, or joining me for coffee breaks and commiserating about the stresses of graduate school. I would also like to recognize the various participants in Venus Working Group meetings over the years, particularly the groups from Mount Royal (led by Dr. Katherine Boggs) and Wesleyan University (led by Dr. Martha Gilmore). Great thanks go to them for listening to my various presentations throughout the years and providing me with extensive feedback.

Finishing my thesis in the midst of an unprecedented global pandemic was not an easy feat, and the support of my friends, whether virtually or in person (restrictions permitting), made the last year bearable. Thank you all for sharing in my passions and introducing me to new ones, including beading circles, bouldering, hiking, and circus. I would like to specifically thank Jade, who has been an incredible emotional support, and Dana and Christjahn, who very quickly became some of my closest friends, and with whom many meals and laughs have been shared over the past year. I would also like to thank my oldest friends, the T.R.E.E team - Tessa, Robyn, and Erica, who have shared in my ups and downs over the last 15 years. 
I would not be where I am today without the support of my family, especially my parents, grandparents, sister, and niece. Thank you all for always believing in me, even when I did not believe in myself.

Last but certainly not least, there are no words that can express how grateful I am for my partner, Nico, who has been by my side throughout this entire journey. Through all of the good and bad days, he has been my number one supporter, shoulder to cry on, and provider of iced cappuccinos. 


\section{TABLE OF CONTENTS}

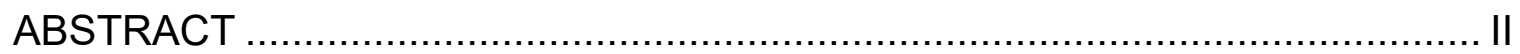

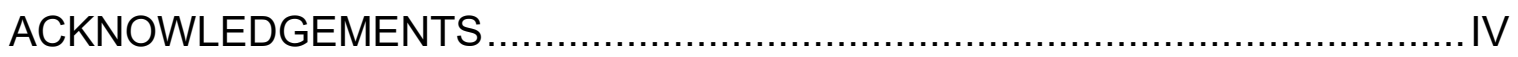

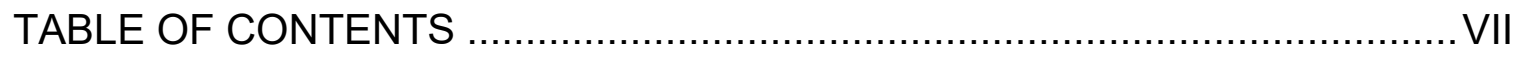

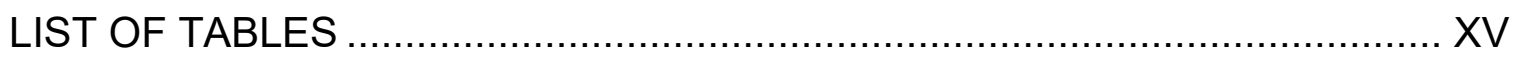

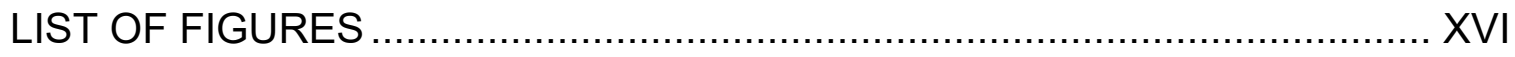

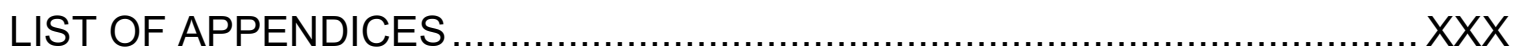

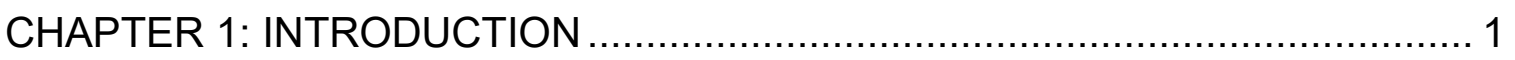

1.1 Venus: Earth's Sister Planet .......................................................... 1

1.2 Overview of Venus' Geology ...................................................... 2

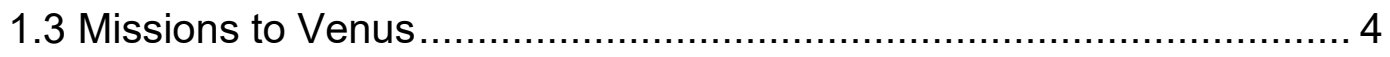

1.3.1 Synthetic Aperture Radar (SAR) ……......................... 5

1.4 Study Area: The Alpha Regio (V-32) Quadrangle ............................. 6

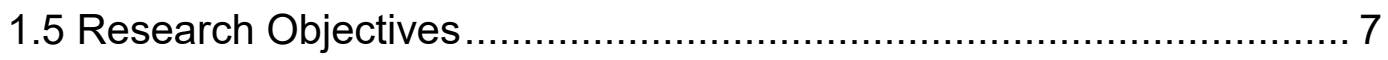

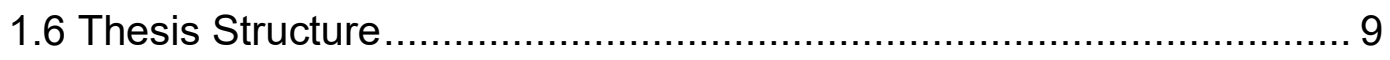

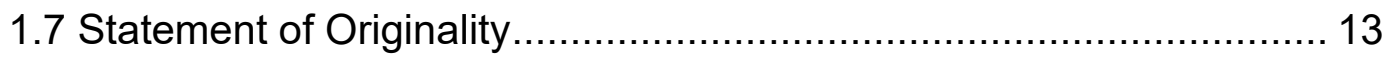

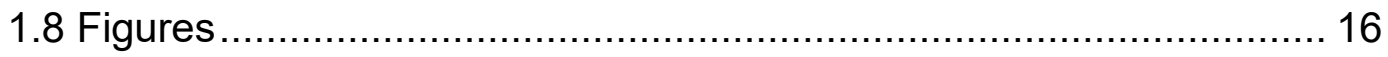

CHAPTER 2: GEOLOGICAL MAP OF THE ALPHA REGIO (V-32)

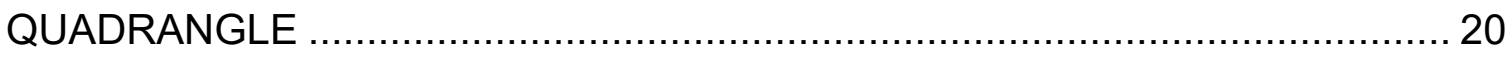




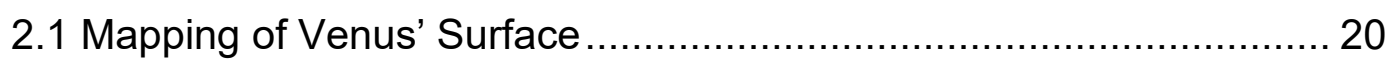

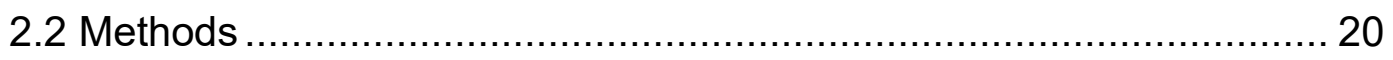

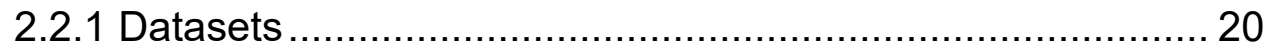

2.2.2 Geological Mapping Procedures .................................... 21

2.2.2.1 Linear and Point Features ................................... 21

2.2.2.2 Geological Units ................................................ 24

2.3 Overview of the Main Geological Features .................................... 26

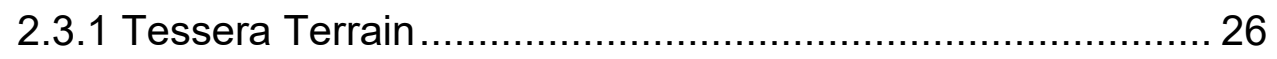

2.3.2 Chasmata and Fracture Belts....................................... 28

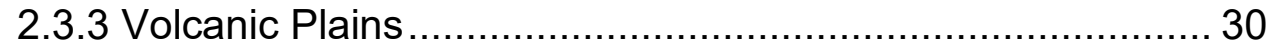

2.3.3.1 Mapping Strategies for Plains Material........................... 32

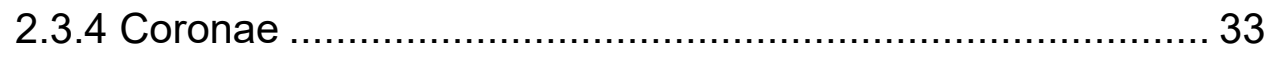

2.3.4.1 Summary of Corona Formation Models ................. 36

2.3.4.2 Atargatis Corona................................................. 40

2.3.4.3 Kuan-Yin Corona ................................................... 42

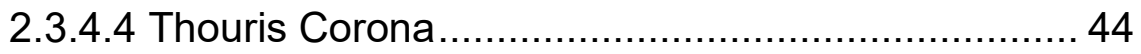

2.3.4.5 Fatua Corona .................................................... 46

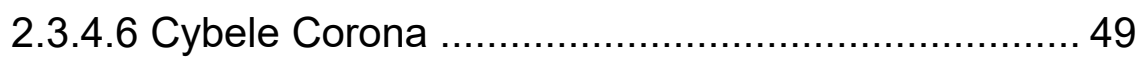


2.3.4.7 Heng-o Corona .................................................... 51

2.3.4.8 Thermuthis Corona ............................................... 52

2.3.5 Volcanic Edifice and Flow Material.................................... 53

2.3.5.1 Digitate Flows ................................................. 53

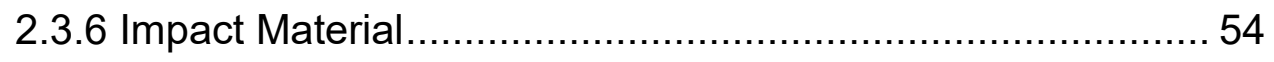

2.3.6.1 Graham Patera: A Low-Angle Bolide Impact? ........ 56

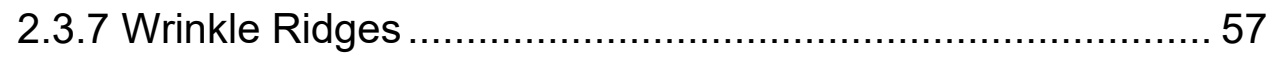

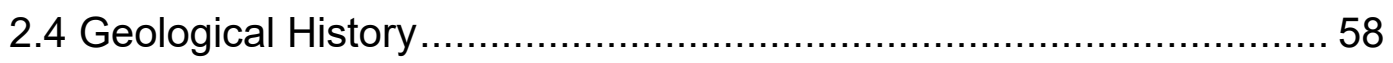

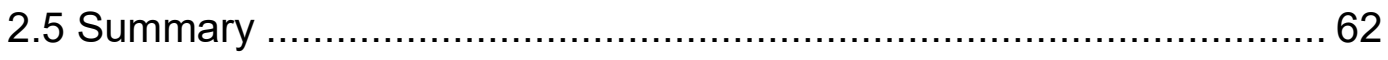

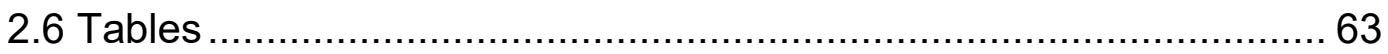

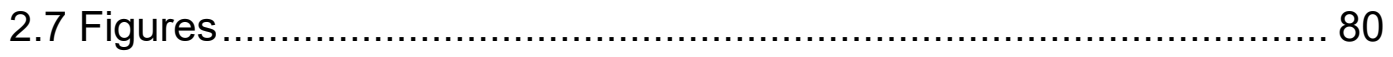

CHAPTER 3: GRABEN-FISSURE SYSTEMS ASSOCIATED WITH FATUA

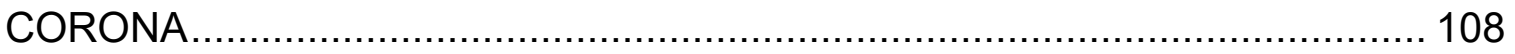

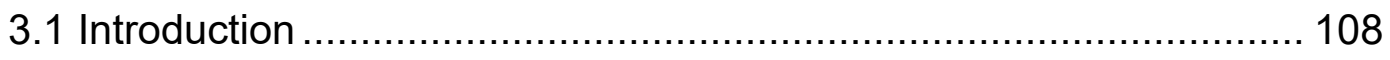

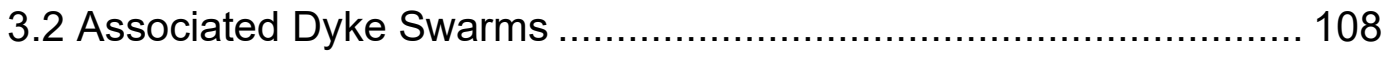

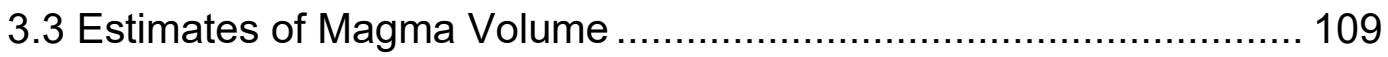

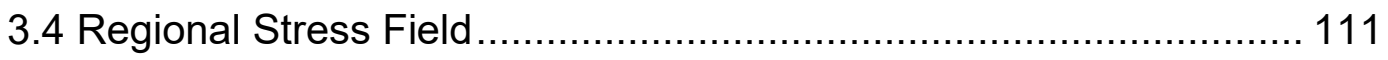

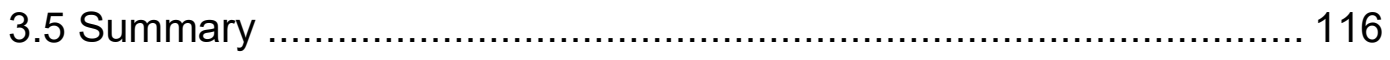

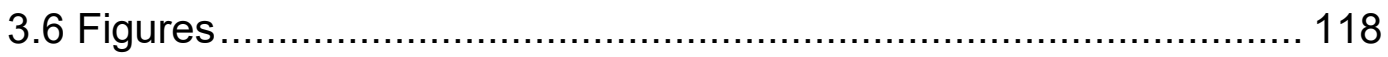

$\mathrm{IX}$ 
CHAPTER 4: INSIGHTS ON CORONAE FROM GEOLOGICAL MAPPING.... 123

4.1 Coronae on Venus as Analogues to Large Igneous Provinces (LIPs)

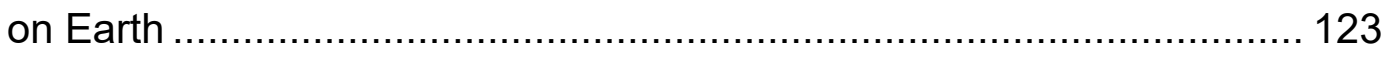

4.1.1 Coronae: Unique to Venus? ......................................... 123

4.1.2 Dyke Swarms on Venus .............................................. 125

4.1.2.1 Giant Circumferential Dyke Swarms................... 126

4.1.3 Characteristics of Circumferential Graben-Fissure

Systems Associated with Coronae ................................ 127

4.1.3.1 Arc Length ................................................ 128

4.1.3.2 Minimum and Maximum Diameter ....................... 129

4.1.3.3 Minimum and Maximum Annulus Width .............. 131

4.1.3.4 Distribution with Respect to Corona Topography . 131

4.1.3.5 Relationship with Radiating Graben-Fissure Systems 133

4.1.3.6 Association with Magmatic Features .................. 134

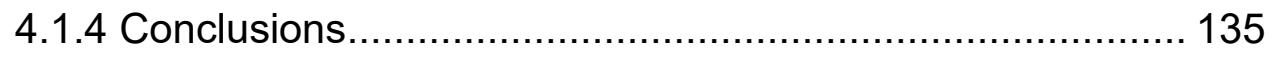

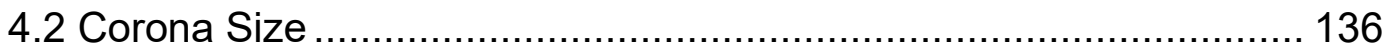

4.2.1 Evaluating Corona Size ................................................. 136 
4.2.2 Re-Evaluating the Structure of Thermuthis Corona: The Second Largest Corona on Venus?

4.2.2.1 Topography 139

4.2.2.2 Structural Trends

4.2.2.3 Evidence for an Increased Maximum Diameter .... 141

4.3 Conclusions 135

4.4 Tables 144

4.6 Figures 146

CHAPTER 5: ANALYSIS OF VENUSIAN WRINKLE RIDGE MORPHOMETRY USING STEREO-DERIVED TOPOGRAPHY: A CASE STUDY FROM SOUTHERN EISTLA REGIO. 152

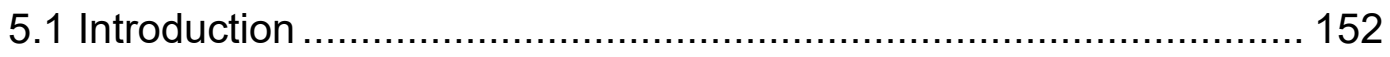

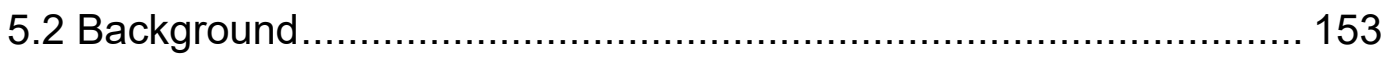

5.2.1 Models for Planetary Wrinkle Ridge Formation ................. 153

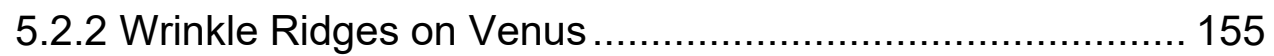

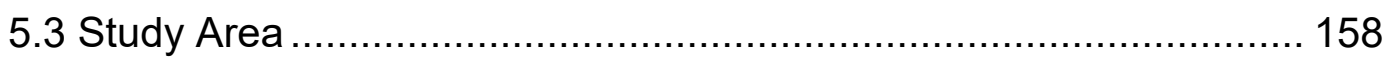

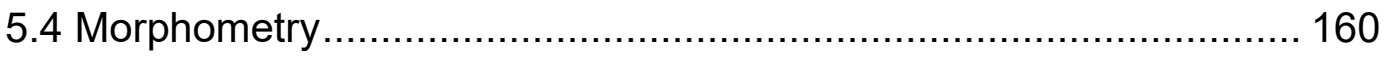

5.4.1 Datasets and Construction of Topographic Profiles ........... 160

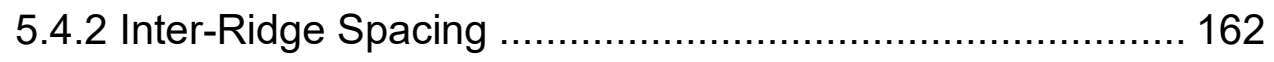


5.4.3 Width 164

5.4.4 Height 166

5.4.5 Shape 167

5.5 Modeling Fault Geometry. 169

5.5.1 Model Construction 169

5.5.2 Modeling Results. 171

5.6 Discussion 173

5.6.1 Comparison with Ridge Belts 173

5.6.2 Thrust Fault Geometry 174

5.6.2.1 Thick- vs. Thin-Skinned Deformation 174

5.6.2.2 Comparison with an Exposed Wrinkle Ridge in Melas Chasma, Mars 175

5.6.2.3 Associated Synclines 176

5.6.2.4 Secondary Peaks and Crenulations 177

5.6.2.5 Elevation Offsets 177

5.6.3 Regional Strain 178

5.6.4 Regional Tectonic Setting 178

5.7 Conclusions 183

5.8 Tables 185 
5.9 Figures 186

CHAPTER 6: EVALUATION OF LANDING SITE TARGETS IN THE V-32 QUADRANGLE 201

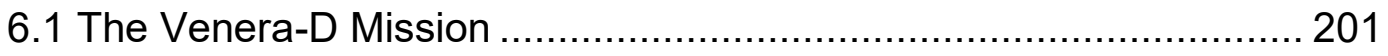

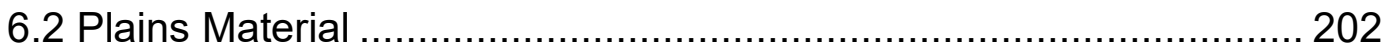

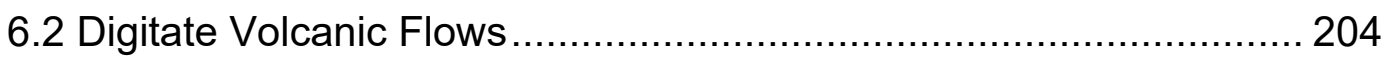

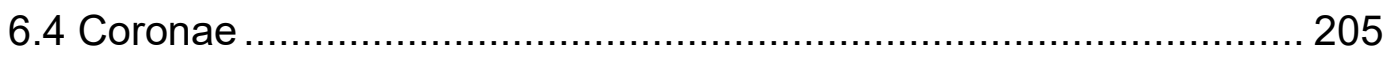

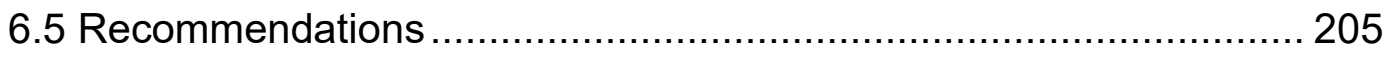

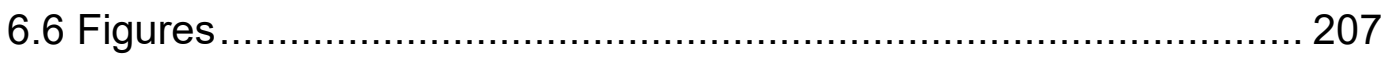

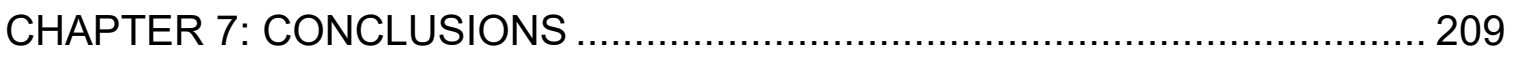

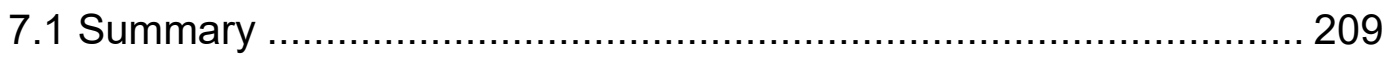

7.2 Recommendations for Future Work …...................................... 213

7.2.1 Detailed Geological Mapping of Venus ........................... 214

7.2.2 Stress and Relative Age Indicators in the Vicinity of the AlphaLada and Derceto-Quetzalpetlatl Extensional Belts ................... 215

7.2.3 Comparisons Between Coronae and Giant Circumferential

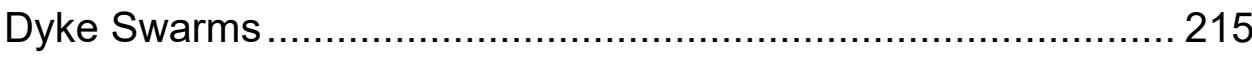

7.2.4 Analysis of Wrinkle Ridge Morphometry Using Stereo-Derived

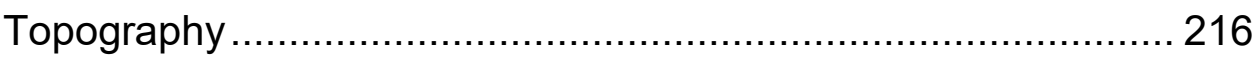


REFERENCES . 


\section{LIST OF TABLES}

Table 2.1: Classification of structural systems in the Alpha Regio (V-32) quadrangle. 63

Table 2.2: Main characteristics of geological units in the V-32 quadrangle. 65

Table 4.1: Characteristics of circumferential graben-fissure systems associated with coronae in the V-32 quadrangle 144

Table 4.2: Maximum diameters for coronae in the V-32 quadrangle and Thermuthis Corona (located partially in the neighbouring V-33 quadrangle). The percentage difference between the estimates of this study and others are also included. 145

Table 5.1: Calculations of average slope (in degrees) along fore- and backslopes for a representative subset of 20 de-trended wrinkle ridge profiles. 


\section{LIST OF FIGURES}

Figure 1.1: Global geological map (1:10,000,000 scale) of Venus, modified after Ivanov and Head (2011). The location of the V-32 quadrangle is shown by the orange box.

Figure 1.2: Magellan instrument geometry: A) observing geometry of the spacecraft for the three modes of operation: SAR imaging, altimetry, and radiometry, and B) SAR image acquisition geometry. After Ford et al.

Figure 1.3: Simplified schematic of the effect of surface roughness on radar wave scattering. For a smooth surface, the incident radar wave (red arrow) is scattered as a specular reflection (blue arrow) and the surface appears dark on the resultant SAR image. For a rough surface, the incident radar wave (red arrow) is scattered as a diffuse reflection in multiple directions (blue arrows) and the surface appears bright on the resultant SAR image.

Figure 1.4: Left-looking SAR basemap with superimposed labels showing the location of major named geological features in the V-32 quadrangle. Lara Crater $\left(2.9^{\circ} \mathrm{E}, 4.2^{\circ} \mathrm{S}\right)$ is not labelled on the map due to its small size $(<5$ $\mathrm{km})$

Figure 2.1: Geological mapping status of 1:5 million scale Venus quadrangles (as of March 2021). Modified after schematic from the International Astronomical Union (IAU)/USGS/NASA 
Figure 2.2: Examples of SAR images (left) and superimposed mapping (right) of the two main types of linear features, extensional structures $(A, B$; image centred on $\left.19.1^{\circ} \mathrm{E}, 20.4^{\circ} \mathrm{S}\right)$ and wrinkle ridges (C,D; image centred on $\left.16.0^{\circ} \mathrm{E}, 2.0^{\circ} \mathrm{S}\right)$

Figure 2.3: Schematic cross-sections of the interpreted geometries of structures mapped in this study. A) Geometries of extensional structures, modified after Grosfils and Head (1994b): i) graben, ii) fissure, and iii) fracture. B) Hypothetical geometries of wrinkle ridges interpreted to represent anticlines and thrust faults, modified after Okubo and Schultz (2004): i) primary thrust, and ii) secondary forethrusts and backthrusts

Figure 2.4: Examples of the three geometry classes for structural systems: A) circumferential about a focal point (yellow star), B) radiating from a focal point (yellow star), and C) linear.

Figure 2.5: Map showing each structural system (represented by different colours) in the V-32 quadrangle: A) graben-fissure systems, and B) wrinkle ridges. 84

Figure 2.6: Left-looking SAR images and corresponding geological maps of examples of the types of geological units: lithodemic $(A, B)$ and material (C,D). A) Fracture Belt Unit 1 (bf1; centred at $\left.10.2^{\circ} \mathrm{S}, 1.2^{\circ} \mathrm{E}\right)$, a lithodemic unit; B) geological map corresponding to A; C) Unsourced Flow Material Unit 2 (fu2; centred at $21.6^{\circ} \mathrm{S}, 13.6^{\circ} \mathrm{E}$ ), a material unit; and D) geological map corresponding to $\mathrm{C}$ 
Figure 2.7: Left-looking SAR images of examples of the major geological units within the category 'Volcanic Edifice and Flow Materials'. A) Shield Volcano Apron Material (va; image centred on $25.7^{\circ} \mathrm{E}, 19.0^{\circ} \mathrm{S}$ ); B) Shield Volcano Field (vf; image centred on $29.7^{\circ} \mathrm{E}, 15.2^{\circ} \mathrm{S}$ ); C) Steep-Sided Dome Material (sd; image centred on $9.8^{\circ} \mathrm{E}, 0.9^{\circ} \mathrm{S}$ ); D) Dewi-Ratih Chasma Material (fDR; image centred on $0.9^{\circ} \mathrm{E}, 7.8^{\circ} \mathrm{S}$ ); E) Dzalarhons Mons Flow Material (fDM; image centred on $29.6^{\circ} \mathrm{E}, 0.3^{\circ} \mathrm{S}$ ); F) Brynhild Fossae Flow Material (fBF; image centred on $22.9^{\circ} \mathrm{E}, 24.7^{\circ} \mathrm{S}$ ); G) Digitate Flow Material (fd; image centred on $9.4^{\circ} \mathrm{E}, 17.5^{\circ} \mathrm{S}$ ); and H) Unsourced Flow Material (fu; image centred on $\left.15.0^{\circ} \mathrm{E}, 20.6^{\circ} \mathrm{E}\right)$ 86

Figure 2.8: Left-looking SAR images of examples of the major geological units within the category 'Corona Material'. A) Heng-O Corona Flow Material $\left(\mathrm{cmH}\right.$; image centred on $\left.0.6^{\circ} \mathrm{E}, 1.1^{\circ} \mathrm{S}\right)$; B) Atargatis Corona Interior Material (ciA; image centred on $\left.9.5^{\circ} \mathrm{E}, 8.8^{\circ} \mathrm{S}\right)$; C) Atargatis Corona Fractured Material (cfA; image centred on $9.2^{\circ} \mathrm{E}, 8.1^{\circ} \mathrm{S}$ ); D) Kuan-Yin Corona Flow Material (cmK; image centred on $11.2^{\circ}$ E, $\left.4.4^{\circ} \mathrm{S}\right)$; E) Kuan-Yin Corona Interior Material (ciK; image centred on $10.3^{\circ} \mathrm{E}, 4.1^{\circ} \mathrm{S}$ ); F) KuanYin Corona Fractured Material (cfK; image centred on $9.8^{\circ} \mathrm{E}, 4^{\circ} 1^{\circ} \mathrm{S}$ ); $\mathrm{G}$ ) Thouris Corona Fractured Material (cfT; image centred on $13.0^{\circ} \mathrm{E}, .6 .7^{\circ} \mathrm{S}$ ); H) Fatua Corona Flow Material (cmF; image centred on $\left.19.5^{\circ} \mathrm{E}, 14.0^{\circ} \mathrm{S}\right)$; I) Fatua Corona Interior Material (ciF; image centred on $17.8^{\circ} \mathrm{E}, 16.3^{\circ} \mathrm{S}$ ); J) Fatua Corona Fractured Material (cfF; image centred on $18.0^{\circ} \mathrm{E}, 16.3^{\circ} \mathrm{S}$ ); K) Cybele Corona Interior Material (ciC; image centred on $20.6^{\circ} \mathrm{E}, 8.0^{\circ} \mathrm{S}$ ); 
L) Cybele Corona Fractured Material (cfC; image centred on $21.3^{\circ} \mathrm{E}, 7.1^{\circ}$

S); and M) Corona-Like Feature Material (ci; image centred on $18.6^{\circ} \mathrm{E}, 4.6^{\circ}$

S). 87

Figure 2.9: Left-looking SAR images of examples of the major geological units within the category 'Plains Material'. A) Smooth Plains Material (ps; image centred on $17.6^{\circ} \mathrm{E}, 5.5^{\circ} \mathrm{S}$ ); B) Intermediate Plains Material (pi; image centred on $\left.15.7^{\circ} \mathrm{E}, 22.2^{\circ} \mathrm{S}\right)$; C) Mottled Plains Material (pm; image centred on $18.5^{\circ} \mathrm{E}, 23.2^{\circ} \mathrm{S}$ ); D) Densely Fractured Plains Material (pf; image centred on $9.0^{\circ} \mathrm{E}, 0.6^{\circ} \mathrm{S}$ ); E) Ridged Plains Material (pr; image centred on $\left.17.1^{\circ} \mathrm{S}, 1.4^{\circ} \mathrm{S}\right)$; and F) Intratessera Plains Material (pt; image centred on $\left.3.9^{\circ} \mathrm{E}, 20.3^{\circ} \mathrm{S}\right)$ 89

Figure 2.10: Left-looking SAR images of examples of the major geological unit (Fracture Belts) within the category 'Structural Terrains' (image centred on $\left.1.8^{\circ} \mathrm{E}, 10.9^{\circ} \mathrm{S}\right)$ 90

Figure 2.11: Left-looking SAR images of examples of the major geological units within the category 'Tessera Material'. A) Tessera Margin Material (tm; image centred on $7.6^{\circ} \mathrm{E}, 14.7^{\circ} \mathrm{S}$ ); and B) Tessera Terrain (tt; image centred on $\left.1.9^{\circ} \mathrm{E}, 24.2^{\circ} \mathrm{S}\right)$. 91

Figure 2.12: Left-looking SAR images of examples of the major geological units within the category 'Impact Material'. A) Impact Crater Material (im; image centred on $11.8^{\circ} \mathrm{E}, 11.0^{\circ} \mathrm{S}$ ); and B) Impact Crater Halo (ih; image centred on $\left.17.8^{\circ} \mathrm{E}, 12.4^{\circ} \mathrm{S}\right)$. 92 
Figure 2.13: Thematic maps showing the distribution of the categories of geological units superimposed on a left-looking SAR basemap. A) Volcanic edifice and flow material; B) corona material; C) plains material; D) structural terrains; E) tessera material; and F) impact material. 93

Figure 2.14: Relative proportions, by percentage of surface area covered, of geological units in the V-32 quadrangle, arranged by: A) each unit category; B) units within the volcanic edifice and flow material category; C) major units within the corona material category; D) major units within the plains material category; E) major units within the tessera material category; and F) major units within the impact material category. 94

Figure 2.15: Fracture Belt Unit 1 (bf1), associated with Dewi-Ratih Chasma ( $0^{\circ}$ $\left.20^{\circ} \mathrm{S}, 0^{\circ}-9^{\circ} \mathrm{E}\right)$. A) Left-looking SAR image; and B) extent of the mapped bf1 unit and associated structures. See accompanying geological map for other mapped units and structures.

Figure 2.16: Fracture Belt Unit $3(\mathrm{bf} 3)\left(6^{\circ}-14^{\circ} \mathrm{S}, 11^{\circ}-19^{\circ} \mathrm{E}\right)$. A) Left-looking SAR basemap; and B) extent of the mapped bf3 unit and associated structures. See accompanying geological map for other mapped units and structures.

Figure 2.17: Example of mapping of plains units and the use of cross-cutting relationships of structures (NNW trending extensional structures) to define separate units (images centred on $19.1^{\circ} \mathrm{E}, 1.4^{\circ} \mathrm{S}$ ). A) Left-looking SAR

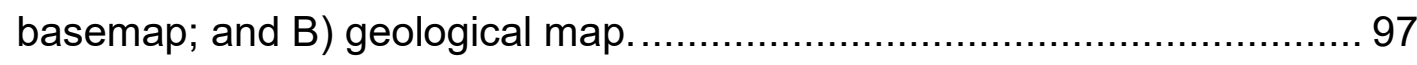


Figure 2.18: Atargatis Corona: A) Left-looking SAR image; B) geological map; C) stereo-derived topography showing location of profile line for D; and D) stereo-derived topographic profile (MPR = Mean Planetary Radius).

Figure 2.19: Kuan-Yin Corona: A) Left-looking SAR image; B) geological map; C) stereo-derived topography showing location of profile line for $D$; and $D$ ) stereo-derived topographic profile (MPR = Mean Planetary Radius). 99

Figure 2.20: Thouris Corona: A) Left-looking SAR image; B) geological map; C) stereo-derived topography showing location of profile line for D; and D) stereo-derived topographic profile (MPR = Mean Planetary Radius) $\ldots . . . .100$

Figure 2.21: Fatua Corona: A) Left-looking SAR image; B) geological map; C) stereo-derived topography showing location of profile line for D; and D) stereo-derived topographic profile $($ MPR $=$ Mean Planetary Radius $) .. . . . .101$

Figure 2.22: Cybele Corona: A) Left-looking SAR image; B) geological map; C) stereo-derived topography showing location of profile line for $D$; and D) stereo-derived topographic profile (MPR = Mean Planetary Radius). ...... 102

Figure 2.23: Map of Digitate Flow Material Units superimposed on left-looking SAR image (centred on $6.2^{\circ} \mathrm{E}, 16.6^{\circ} \mathrm{S}$ ). The inferred flow direction of these volcanic flows is represented by the yellow arrow. 103

Figure 2.24: Map of the two wrinkle ridge systems of radiating (blue) and circumferential (red) geometry identified in association with Thermuthis Corona (to the east). 104 
Figure 2.25: SAR images displaying examples of the major cross-cutting relationships in the V-32 quadrangle. A) Embayment of tessera terrain (tt; below, radar-bright) by plains material (pi1; above, radar-dark) (image centred on $8.4^{\circ} \mathrm{E}, 20.4^{\circ} \mathrm{S}$ ); B) embayment of NNW-SSE trending extensional structures within a fracture belt (bf1) by plains material (ps1) (image centred on $3.1^{\circ} \mathrm{E}, 12.5^{\circ} \mathrm{S}$ ); C) NNW-SSE trending extensional structures within a fracture belt (bf3) cross-cutting circumferential extensional structures associated with Thouris Corona (image centred on $\left.\left.13.5^{\circ} \mathrm{E}, 7.6^{\circ} \mathrm{S}\right) ; \mathrm{D}\right)$ radiating extensional structures associated with Fatua Corona cross-cutting plains material (pi1) (image centred on $18.1^{\circ} \mathrm{E}, 20.5^{\circ}$ S); E) Smooth Plains Material Unit 4 (ps4; above, relatively radar-dark) truncating NNW-SSE trending extensional structures in the adjacent relatively radar-bright Ridged Plains Material Unit 3 (pr3; below, relatively radar-bright), indicating different relative ages for plains material (image centred on $15.9^{\circ} \mathrm{E}, 2.5^{\circ} \mathrm{S}$ ); and $\mathrm{F}$ ) relatively recent volcanic flow material (fd4) overlying NE-SW trending regional wrinkle ridges (image centred on

$\left.8.2^{\circ} \mathrm{E}, 18.8^{\circ} \mathrm{S}\right)$ 105

Figure 2.26 (part 1): Full stratigraphic column showing relative ages of all geological units and structural systems. 106

Figure 2.26 (part 2): Full stratigraphic column showing relative ages of all geological units and structural systems. 107

Figure 3.1: Regional map showing the location of the Alpha-Lada and DercetoQuetzalpetlatl extensional belts, their intersection (at Astkhik Planum), 
Fatua Corona, and the Brynhild Fossae (radiating graben associated with Fatua Corona).

Figure 3.2: Map of structures associated with Fatua Corona and the Alpha-Lada extensional belt: A) structural map depicting the relationships between graben-fissure systems associated with Fatua Corona (radiating (red) and circumferential (blue)) and extensional structures within the Alpha-Lada extensional belt (black); B) map depicting the structures in map A (grey) and superimposed orientations of the maximum compressive stress (black arrows).

Figure 3.3: The Mackenzie radiating dyke swarm: A) map of the generalized distribution of Mackenzie radiating dykes (after Day et al., 2008); B) map of modeled maximum compressive stress orientations along the trajectory of the Mackenzie dykes (after Hou et al., 2010).

Figure 4.1: Hypothetical cross section of a corona through analogy with large igneous provinces (LIPs) on Earth. The corona topography represented in the model is of topographic subtype $3 b$ (rim surrounding interior dome) from the classification scheme of Smrekar and Stofan (1997). Modified after the model for terrestrial LIPs by Ernst et al. (2019). The circumferential dykes in this model are represented as cone sheets; the actual dip of possible circumferential dykes, and whether they are more likely to be cone sheets or vertical dykes, is unknown. The magmatic underplate is depicted as the same size of the plume head; in reality, it may not extend across the entire 
plume head or there may be several regions of magmatic underplating (Ernst et al., 2019) 146

Figure 4.2: The 1385 Ma Lake Victoria giant circumferential dyke swarm, associated with the Kunene-Kibaran LIP, in East Africa on Earth. After Mäkitie et al. (2014) and Buchan and Ernst (2016).

Figure 4.3: Schematic drawing of the characteristics of circumferential grabenfissure systems and dyke swarms. Fatua Corona (centre coordinates $17.7^{\circ}$ $\mathrm{E}, 16.3^{\circ} \mathrm{S}$ ) is shown as an example

Figure 4.4: Examples of magmatic features associated with circumferential graben-fissure systems of coronae: A) volcanic flows origination from circumferential graben associated with Fatua Corona (centre coordinates $\left.17.7^{\circ} \mathrm{E}, 16.3^{\circ} \mathrm{S}\right)$; B) steep-sided dome and a tholus in the annulus of Fotla Corona (centre coordinates $163.5^{\circ} \mathrm{E}, 58.5^{\circ} \mathrm{S}$ ), as well as a chain of shield volcanoes along the southern margin; C) channelized features emanate from circumferential graben associated with Cybele Corona (centre coordinates $20.7^{\circ} \mathrm{E}, 7.5^{\circ} \mathrm{S}$ ); and D) pit crater chains associated with the circumferential graben-fissure system around Qakma Corona (centre coordinates $\left.207.1^{\circ} \mathrm{E}, 35.5^{\circ} \mathrm{N}\right)$. 149

Figure 4.5: Graphical comparisons between maximum size estimates for coronalike features on Venus and Earth: A) comparison of estimates from this study, Stofan et al. (1992), and Crumpler and Aubele (2000) for coronae in the V-32 quadrangle and Thermuthis Corona (located partially in the 
neighbouring V-33 quadrangle); B) maximum diameters of giant circumferential dyke swarms on Earth as presented by Buchan and Ernst (2019). Labels refer to either the name of the dyke swarm or its associated

LIP. 150

Figure 4.6: Maps and topographic profiles of the extended map area around Thermuthis Corona. A) Map of structures interpreted to be associated with Thermuthis Corona. WRL1 and other structures which have been mapped but are not associated with the corona have been omitted from the map; B) Composite image of colourized Magellan altimetry data superimposed over a Magellan SAR (C3-MIDR) basemap. The line extending from $A$ to $A^{\prime}$ corresponds to the topographic profile in C. The accompanying legend was obtained courtesy of the USGS Astrogeology Science Center; C) Topographic profile of Thermuthis Corona along the A to A' line shown in B. The elevations on the vertical axis are relative to Mean Planetary Radius (MPR), which is approximately $6051 \mathrm{~km}$. 151

Figure 5.1: Examples of wrinkle ridges set to similar scales: A) NNW-SSE trending wrinkle ridges in the volcanic plains of northern Eistla Regio, Venus; B) NNW-SSE trending wrinkle ridges in northern Lunae Planum, Mars; C) NNE-SSW trending wrinkle ridges northeast of Nicollet Crater, the Moon; D) E-W trending wrinkle ridges southeast of Gaudi Crater, Mercury.

Figure 5.2: Location of the study area (left-looking SAR image) in relation to Eistla Regio. Dashed lines within Eistla Regio are contours of the geoid 
anomaly, with a contour interval of $10 \mathrm{mGal}$. Volcanic centres

corresponding with major geoid highs within Eistla Regio are labelled. ... 187

Figure 5.3: Wrinkle ridges mapped in the study area. The 40 wrinkle ridges selected for topographic analysis are outlined in red. The green line (oriented N-S and constructed through the centre of the study area along $15^{\circ} \mathrm{E}, 14^{\circ} \mathrm{N}-25^{\circ} \mathrm{S}$ ) represents the line along which the profiles in Figure 5.6 were constructed (A-A' from north to south) and corresponds to the transect used for measuring wrinkle ridge spacing in Figure 5.7. The inset map to the right shows the distribution of circumferential (orange) and radial (blue) wrinkle ridges associated with Thermuthis Corona. The brown box

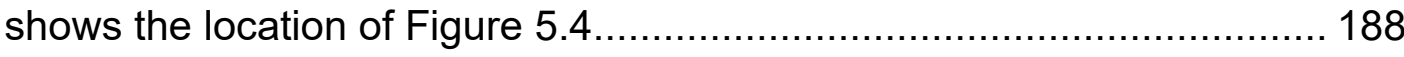

Figure 5.4: Map of the 40 wrinkle ridges selected for topographic analysis with superimposed labels. The location of this figure within the broader study area is shown in Figure 5.3. 189

Figure 5.5: Examples of raw topographic profiles (left) and their locations on leftlooking SAR images (right) for four of the studied wrinkle ridges (R2, R4, $\mathrm{R} 6$, and R7). All profiles are oriented with the right side toward the southeast. Vertical exaggerations (VE) for the profiles are as follows: R2 = 34.6x VE, R4 = 28.6x VE, R6 = 33x VE, and $R 7=26.1 \times \mathrm{VE}$. 190

Figure 5.6: Profiles of various parameters across the study area: stereo-derived topography (black), Bouguer gravity anomaly (red), mapped wrinkle ridge 
density (blue), crustal thickness (green), and effective elastic thickness (purple).

Figure 5.7: Distribution of wrinkle ridge spacing: A) wrinkle ridge spacing against latitude, and B) frequency histogram of wrinkle ridge spacing measurements. 192

Figure 5.8: Comparison between A) the density of mapped wrinkle ridges (in $\mathrm{km} / \mathrm{km}^{2}$ ), B) the Bouguer gravity anomaly (in $\mathrm{mGal}$ ) in the study area, and C) the location of salient geological features. Location 1, the corridor of high wrinkle ridge density, is shown by the dashed lines on A and B. 193

Figure 5.9: Histograms and statistics for morphometric parameters of wrinkle ridges: A) width, B) height, C) elevation offset, and D) skewness. Reported for each parameter are the number of profiles studied, the average value, the interquartile range (IQR), and minimum ( $\min )$ and maximum (max) values. 194

Figure 5.10: Comparison of morphometric data for wrinkle ridges on Venus (from this study and Kreslavsky and Basilevsky (1998)) with morphometric data for wrinkle ridges on the Moon and Mars. Data for Lunar wrinkle ridges is from Golombek et al. (1991) and Yue et al. (2015). Data for Martian wrinkle ridges is from Golombek et al. (1991), Plescia (1993), and Plescia (1991). 
Figure 5.11: Examples of topographic profiles of wrinkle ridges illustrating the three shape categories: A) asymmetric (R6, verging to the southeast), B) symmetric (R16), and C) double (R15). 196

Figure 5.12: Schematic diagrams showing the range of faulting parameters considered in this study: A) a surface-breaching fault with a shallow dip; B) a surface-breaching fault with a steep dip; C) a surface-breaching fault with a listric geometry; D) a blind fault with a shallow dip; E) a blind fault with a steep dip; and F) a blind fault with a listric geometry..... 197

Figure 5.13: Sensitivity diagrams for the different faulting parameters: A) dip, B) depth to the lower fault tip, C) depth to the upper fault tip, and D) planar versus listric geometries. Unless otherwise stated, faulting parameters are set to a dip of $30^{\circ}$, a depth to the upper fault tip of $0 \mathrm{~km}$, a depth to the lower fault tip of $5 \mathrm{~km}$, a slip magnitude of $200 \mathrm{~m}$ and a planar fault geometry. 198

Figure 5.14: Comparison between the average topographic wrinkle ridge profile (red) and the best fitting modeling result (dashed line). The average topographic profile is shown only in the immediate vicinity of the wrinkle ridge where de-trending was conducted.

Figure 5.15: Comparison between left-looking SAR images of ridge belt and wrinkle ridge deformation: A) Lukelong Dorsa ((Frank and Head, 1989); image centred at $180^{\circ} \mathrm{E}, 71^{\circ} \mathrm{N}$ ), and $\mathrm{B}$ ) wrinkle ridges deforming volcanic plains in the study area (image centred at $15.5^{\circ} \mathrm{E}, 0.6^{\circ} \mathrm{N}$ )..................... 200 
Figure 6.1: Landing site attainability arcs for the Venera-D mission. The attainability arc for December $5^{\text {th }}, 2026$ is shown by the dashed red line, and the outline of the V-32 quadrangle is shown by the orange box. Attainability arcs for December $9^{\text {th }}, 2026$, and December $17^{\text {th }}, 2026$, are shown by the green and yellow dashed lines, respectively. The map is in a Mollweide projection with a central meridian of $0^{\circ}$. Modified after Venera-D Phase II Final Report (2019). 207

Figure 6.2 Landing site targets and their locations in the V-32 quadrangle. Targets $A$ and $B$ are located in plains material. Targets $C$ and $D$ are located in a digitate volcanic flow field, and Target $E$ is located in a corona-sourced volcanic flow. Red circles outline $300 \mathrm{~km}$ diameter landing circles. 208 


\section{LIST OF APPENDICES}

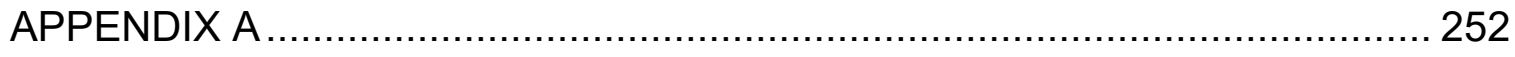

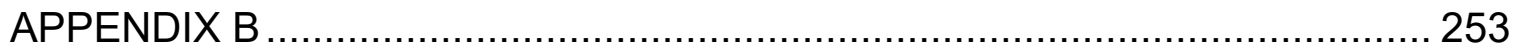

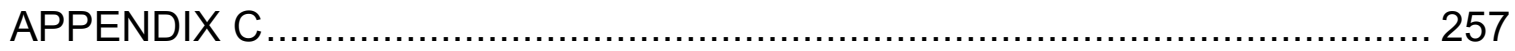




\section{CHAPTER 1: INTRODUCTION}

\subsection{Venus: Earth's Sister Planet}

Venus, the second planet from the Sun, is the most Earth-like planet in the solar system. Earth and Venus are similar in numerous ways, notably in size and mass: Venus has a mean radius of 0.95 Earths and a mass of 0.82 Earths (Colin, 1983). As a result, the mean densities of Venus $\left(5.243 \mathrm{~g} / \mathrm{cm}^{3}\right)$ and Earth $(5.51$ $\mathrm{g} / \mathrm{cm}^{3}$ ) are very similar, reflecting similarities in the bulk compositions of the planets (Colin, 1983). However, the two planets differ in significant ways. Venus has a thick, dense atmosphere, with a composition of approximately $96.5 \% \mathrm{CO}_{2}$, 3.5\% $\mathrm{N}_{2}$, and only 20 ppm $\mathrm{H}_{2} \mathrm{O}$ (Von Zahn et al., 1983; Donahue and Russell, 1997). The predominantly $\mathrm{CO}_{2}$ composition of its atmosphere, and the planet's proximity to the Sun, have created a 'runaway greenhouse' effect. This greenhouse effect has contributed to a high average surface temperature of approximately $464^{\circ} \mathrm{C}(737 \mathrm{~K})$ (Donahue and Russell, 1997). The surface also has a high atmospheric pressure of approximately 92 bar (Donahue and Russell, 1997). Venus also has a slow, retrograde rotation period of 243 Earth-days, and possesses no intrinsic magnetic field.

Despite the drastic differences between Venus' and Earth's present-day surface conditions, there is a growing body of evidence suggesting that Venus may have been even more Earth-like earlier in its history. Climate modeling suggests that Venus' surface temperatures could have remained habitable until at least 715 million years ago (Way et al., 2016). A commonly accepted theory 
invoked to explain the transition in climate from habitable Earth-like to hothouse conditions is that the emplacement of large igneous provinces (LIPs), commonly observed across Venus' surface, contributed significant amounts of volcanic gases (mainly $\mathrm{CO}_{2}$ ) and kickstarted the transition to the runaway greenhouse climate observed today (Way and Del Genio, 2020). One of the key pieces of evidence lending credence to the idea of a previously habitable Venus is the high deuterium (heavy hydrogen) to hydrogen isotopic ratio (120 times that of Earth's) observed in the atmosphere by the Pioneer Venus mission (Donahue et al., 1982). The abundance of the heavy isotope deuterium relative to hydrogen implies that a significant amount of Venus' initial hydrogen was lost. If Venus initially had a higher water content and conditions favourable to liquid water, there may have been water oceans on the surface. Geological evidence supporting this theory includes the presence of potential fluvial erosional channels (Khawja et al., 2020) and layering (either volcanic or sedimentary in nature; Byrne et al., 2021) in some of Venus' oldest terrains.

\subsection{Overview of Venus' Geology}

Venus' impact cratering record suggests that its overall surface is relatively geologically young. While impact craters are present on the surface of Venus, the impact cratering record is not as extensive as on other planetary bodies such as Mars, the Moon, and Mercury. Venus' dense $\mathrm{CO}_{2}$ atmosphere creates an atmospheric filtering effect, where smaller meteors burn up in the atmosphere and never reach the surface. The result is a rapid decrease in the density of craters with diameters less than $35 \mathrm{~km}$ (Schaber et al., 1992). Venus in 
general has very few impact craters (approximately 940) (McKinnon et al., 1997). The apparently random spatial distribution of impact craters points toward extensive resurfacing. Various authors have used the cratering record to estimate the approximate mean age of the surface; these estimates range from approximately 0.2 to $1 \mathrm{Ga}$ (e.g., Kreslavsky et al., 2015, and references therein). Most models proposed to explain Venus' resurfacing fall between two broad endmember categories: 1) global resurfacing models, where resurfacing over a relatively short timescale has occurred globally at least once (e.g., Bullock et al., 1993; Turcotte et al., 1999; Romeo and Turcotte, 2009; Kreslavsky et al., 2015); and 2) equilibrium (or 'steady state') resurfacing models, where resurfacing occurs continuously, at similar rates to impact crater formation (e.g., Phillips et al., 1992; Guest and Stofan, 1999; Bjonnes et al., 2012).

The surface of Venus is characterized by tectonism and volcanism. Globally distributed, Earth-like plate tectonics do not appear to have occurred throughout the portion of Venus' history that can be observed at the surface (e.g., Solomon et al., 1992; Phillips and Hansen, 1994; Nimmo and McKenzie, 1998). Instead, intraplate-style magmatism and tectonism have dominated. Surface features on Venus include expansive lava fields, shield volcanoes, large individual volcanoes, and tectono-magmatic structures such as coronae (discussed in Section 2.3.4). Features on Venus are relatively well preserved, as the lack of water and low surface wind speed $(0.3-1.0 \mathrm{~m} / \mathrm{s})$ produce little erosion (Saunders et al., 1991). Regardless, some aeolian features are present, including wind streaks, yardangs, and dune fields (Greeley et al., 1992). The vast 
majority of the surface (approximately $80 \%$ ) is covered by volcanic plains (discussed in Section 2.3.3; Figure 1.1; Basilevsky and Head, 2000a, 2003). The remaining $20 \%$ of the surface is populated by moderately to highly deformed terrains, such as mountain and ridge belts (discussed in Section 5.6.1), rift zones and fracture belts (discussed in Section 2.3.2), and tessera terrain (discussed in Section 2.3.1; Figure 1.1; Basilevsky and Head, 2000, 2003).

\subsection{Missions to Venus}

Venus has a long history of exploration, from the early Mariner, Venera, VEGA, Pioneer Venus, and Magellan missions to the more recent Venus Express (2006-2014) and Akatsuki (currently active) missions (e.g., Sonett, 1963; Colin, 1980; Saunders et al., 1992; Basilevsky et al., 2007; Svedhem et al., 2009; Nakamura et al., 2011). The Magellan mission of the National Aeronautics and Space Administration (NASA) collected the most complete dataset (to date) of the surface of Venus, including the following products: synthetic aperture radar (SAR), altimetry, radiometry, and gravity data (Phillips and Hansen, 1991). The Magellan mission was launched from the Kennedy Space Center on May 4th, 1989 and entered Venus orbit on August 10th, 1990, beginning its first mapping orbit six days later (Tanaka, 1994). The mission reached its end on October 12th, 1994, when contact with the spacecraft was lost following its entry into the atmosphere.

The following information about Magellan's mapping cycles has been summarized from Ford et al. (1993) and Tanaka (1994). The sensor on the 
Magellan spacecraft was a single instrument that collected radar data in three modes (SAR imaging, radiometer, and altimeter modes) that operated in bursts (Figure 1.2A). The spacecraft executed a total of six cycles around Venus, including three radar mapping cycles and a cycle dedicated to collecting gravity data (Cycle 4). The first mapping cycle had the radar antenna positioned in a leftlooking sense, with incidence angles varying between $16^{\circ}$ and $45^{\circ}$, and captured SAR images covering $83.7 \%$ of Venus' surface. Cycle 2 was performed to fill in the gaps left from Cycle 1, as well as to conduct right-looking radar mapping at a near-constant incidence angle of about $25^{\circ}$, resulting in $54.5 \%$ surface coverage. The final radar mapping cycle, Cycle 3, was dedicated to left-looking radar mapping at incidence angles smaller than Cycles 1 and 2 for the purpose of generating stereographic SAR images in combination with Cycle 1 data. Cycle 3 covered $22.8 \%$ of Venus' surface. The three mapping cycles brought the total coverage of SAR images to $98.3 \%$ of Venus' surface, at a maximum resolution of $75 \mathrm{~m} / \mathrm{pixel}$.

\subsubsection{Synthetic Aperture Radar (SAR)}

Radar technology is used to image the surface of Venus as the thick and opaque Venusian atmosphere shrouds the surface from visible light. The Magellan SAR data, along with the accompanying datasets, is used for geological mapping of Venus due to its completeness and higher resolution when compared with other earlier radar datasets. The SAR sensor generates its own illumination through bursts of microwaves (at a wavelength of $2.385 \mathrm{GHz}$ ) and then measures the echoes reflected from the surface (Ford et al., 1993; Tanaka, 
1994). The appearance of SAR images is dependent on the properties of the surface, as well as the incidence angle and look direction (i.e., left or right) of the radar sensor (Figure 1.2B). The brightness (i.e., reflectivity) of SAR images is mostly a function of changes in slope and the roughness of the geological surface (Ford et al., 1993). Slopes which face toward the sensor will appear relatively bright and shortened, whereas slopes which face away from the sensor will appear relatively dark and elongated. Neglecting large variations in topographic slope and for incidence angles greater than $20^{\circ}$ but less than $60^{\circ}$, radar brightness is dominated by surface roughness at the scale of the radar wavelength: geological surfaces with high roughness will produce more backscatter than smooth surfaces, translating into more radar-bright areas on radar images (Figure 1.3). Brightness can also be affected by intrinsic material properties, such as the permittivity of the material; materials with high dielectric constants will produce increased radar backscatter.

\subsection{Study Area: The Alpha Regio (V-32) Quadrangle}

The Alpha Regio (V-32) quadrangle extends from $0^{\circ}$ to $25^{\circ} \mathrm{S}$ latitude and $0^{\circ}$ to $30^{\circ} \mathrm{E}$ longitude and covers an area of approximately $7,600,000 \mathrm{~km}^{2}$ (Figure 1.1). This quadrangle hosts several coronae and numerous other tectonomagmatic features. There are five named coronae: Atargatis, Cybele, Fatua, Kuan-Yin, and Thouris (Figure 1.4), as well as an additional unnamed corona-like structure located approximately $60 \mathrm{~km}$ northwest from the annulus of Cybele Corona. There are also volcanic flows, and circumferential and radiating extensional lineaments that may be attributed to Heng-O (in the neighbouring Sif 
Mons (V-31) quadrangle, to the northwest) and Thermuthis Coronae (in the neighbouring Scarpellini (V-33) quadrangle, to the west). Other major geological features include the extensive Alpha Regio and the smaller Minu-Anni tessera terrains, Dewi-Ratih Chasma, Dudumitsu Dorsa, Brynhild Fossae, Graham Patera, and Banumbirr Vallis (Figure 1.4). Several impact craters are also present throughout the map area: Lara, Vanessa, Linda, Rebecca, Xantippe, Leslie, Frank, Karen, Carreno, Paige, Tiffany, Andami, and Adamson (Figure 1.4). The largest impact crater is Carreno, with a diameter of approximately 60 $\mathrm{km}$.

The V-32 quadrangle is situated in an area of low-lying volcanic plains (Tinatin Planitia), evidenced by the altimetry and geoid data, with the exception of the Alpha Regio highland. A large proportion of the quadrangle is dominated by coronae and their associated structures and volcanic units. Other notable tectonic domains include many densely spaced NNW-SSE trending extensional structures surrounding Dewi-Ratih Chasma along the western boundary of the quadrangle, and a regional system of ENE-WSW trending, relatively long and closely spaced wrinkle ridges that are prevalent in the northern half of the quadrangle.

\subsection{Research Objectives}

The research objectives of this thesis are as follows:

- Produce a 1:2,500,000 scale geological map of the V-32 quadrangle (Chapter 2). 
- Propose a geological history for the V-32 quadrangle, integrating both geological units and structures, using the principles of cross-cutting relationships (Chapter 2).

- Determine the regional stress field at the time of emplacement of the radiating dyke swarm associated with Fatua Corona and provide hypotheses for the underlying tectonic mechanism(s) (Chapter 3).

- Evaluate the potential designation of Fatua Corona as a large igneous province (LIP) by estimating the total igneous volume and comparing it with the Mackenzie radiating dyke swarm on Earth (Chapter 3).

- Evaluate the characteristics of circumferential graben-fissure systems associated with coronae on Venus in the context of a comparison with giant circumferential dyke swarms associated with LIPs on Earth (Chapter $4)$.

- Discuss implications of detailed geological mapping at the full resolution of the Magellan data on estimating the maximum diameter of coronae (Chapter 4).

- Characterize the morphometry of wrinkle ridges in southern Eistla Regio (including the V-32 and part of the Sappho Patera (V-20) quadrangles), including width, height, and shape, using stereo-derived topography (Chapter 5).

- Model thrust fault geometries that approximate the average morphometry of the studied wrinkle ridges (Chapter 5). 
- Propose a model to explain the distribution of wrinkle ridges in the V-32 quadrangle and southern Eistla Regio (Chapter 5).

- Propose landing site targets in the V-32 quadrangle for future lander missions to Venus, with a focus on the upcoming Venera-D mission (Chapter 6).

\subsection{Thesis Structure}

This thesis contains seven chapters. Chapter 1 provides an overview of Venus and the geology of its surface, including descriptions of previous missions to Venus and the data products returned by these missions. Particular emphasis is given to the Magellan mission and its datasets, which were predominantly used in this thesis. Chapter 1 also includes an outline of the research objectives of this thesis and background information on the study area, the V-32 quadrangle.

Chapter 2 consists of the results of a 1:2,500,000 scale geological mapping study of the V-32 quadrangle. In this chapter, each of the main geological features in the study area are described in detail. The results of this mapping study are summarized in a synthesis of the geological history of the region integrating both geological units and structures. An abbreviated version of Chapter 2 has been published in the Journal of Maps (reference below). For publication 1, E.M. Bethell produced the map and wrote the manuscript. R.E. Ernst provided feedback on the mapping and scientific results, and R.E. Ernst and C. Samson provided valuable comments that helped revise the manuscript. 
1) Bethell, E.M., Ernst, R.E., and Samson, C. (2019b). Geology of the Alpha Regio (V-32) Quadrangle, Venus. Journal of Maps, 13 (2), p. 474486. Doi: https://doi.org/10.1080/17445647.2019.1614489

Chapter 3 investigates Fatua Corona, a tectono-magmatic feature contained within the V-32 quadrangle, in greater detail. Two hypotheses are proposed to explain the interaction between radiating dykes associated with the corona and two extensional belts to the south. It is also compared with the Mackenzie radiating dyke swarm on Earth. Chapter 3 has been presented at the Lunar and Planetary Science Conference (reference below). For abstract 2, E.M. Bethell conducted the mapping and wrote the abstract. R.E. Ernst provided feedback on the mapping and scientific results. R.E. Ernst, C. Samson, and K.L. Buchan provided valuable comments that helped revise the abstract. K.L. Buchan also provided useful information on terrestrial dyke swarms.

2) Bethell, E.M., Ernst, R.E., Samson, C., and Buchan, K.L. (2017).

Detailed Mapping of Graben-Fissure Systems Associated with Fatua Corona, Venus: Implications for Magmatism and the Regional Stress Field. Lunar and Planetary Science Conference XLVIII, abstract 2177.

Chapter 4 explores potential Earth analogues of coronae in the form of LIPs, and in particular, the giant circumferential dyke swarms associated with some of them. Characteristics of coronae relevant to these comparisons are discussed, with the coronae of the V-32 quadrangle used as examples. In addition, a re-analysis of the maximum diameter of Thermuthis Corona is 
presented through geological mapping. Material in Chapter 4 has been presented in two abstracts at the Lunar and Planetary Science Conference (references below). For abstract 3, E.M. Bethell wrote the abstract. R.E. Ernst and K.L. Buchan provided useful information about terrestrial dyke swarms. R.E. Ernst, C. Samson, and K.L. Buchan provided valuable comments that helped revise the abstract. For abstract 4, E.M. Bethell conducted the mapping and wrote the abstract. R.E. Ernst aided in the interpretation of the mapping results. R.E. Ernst and C. Samson provided valuable comments that helped revise the abstract.

3) Bethell, E., Ernst, R.E., Samson, C., and Buchan, K.L. (2016). Circumferential Graben-Fissure Systems of Venusian Coronae as Possible Analogues of Giant Circumferential Dyke Swarms on Earth. Lunar and Planetary Science Conference XLVII, abstract 1471.

4) Bethell, E.M., Ernst, R.E., and Samson, C. (2019a). Re-Evaluating the Structure of Thermuthis Corona Through Detailed Geological Mapping: The Second Largest Corona on Venus? Lunar and Planetary Science Conference $L$, abstract 1462 .

Chapter 5 contains a study on the morphometry of wrinkle ridges in the $\mathrm{V}$ 32 quadrangle and a portion of the neighbouring V-20 quadrangle using stereoderived topography data. Data including wrinkle ridge width, height, and shape are presented. Fault geometry is tested using an elastic dislocation model. Chapter 5 is currently in preparation for submission for publication and preliminary results from this chapter were presented at the Lunar and Planetary 
Science Conference (reference below). For abstract 5, E.M. Bethell conducted the mapping, collected and analyzed the data, and wrote the abstract. R.E. Ernst and C. Samson reviewed the results and provided valuable comments that helped revise the abstract.

5) Bethell, E.M., Ernst, R.E., and Samson, C. (2020). Morphometry of Wrinkle Ridges, Southern Eistla Regio, Venus. Lunar and Planetary Science Conference LI, abstract 1278.

Chapter 6 includes a survey of potential landing site targets in the V-32 quadrangle for future missions (with a focus on the upcoming Roscomos-led Venera-D mission). These landing site targets were proposed at the Venera-D Venus Modeling Workshop and the Venera-D Landing Site Workshop (references below). Finally, a summary of the results of this thesis is provided in Chapter 7 and recommendations for future work are discussed. For abstract 6 , E.M. Bethell conducted the analysis of landing site targets and wrote the abstract. R.E. Ernst provided scientific feedback on and aided in the final selection of landing site targets. R.E. Ernst and C. Samson provided valuable comments that helped revise the abstract. For abstract 7, R.E. Ernst and C. Samson oversaw the writing process, in which all co-authors participated. E.M. Bethell contributed text and figures pertaining to coronae and the $\mathrm{V}-32$ quadrangle as a landing site target. J. Lee, S. Khawja, J. Graff, and S. Davey provided text and figures on large volcanic flow fields, tessera terrain, rift systems, and volcanic centres, respectively. 
6) Bethell, E., Ernst, R.E., and Samson, C. (2019c). Evaluation of Landing Site Targets in the Alpha Regio (V-32) Quadrangle. Venera-D Landing Site Selection and Cloud Habitability Workshop, Space Research Institute (IKI), Russia.

7) Ernst, R.E., Samson, C., Bethell, E., Lee, J., Khawja, S., Graff, J.R., and Davey, S. (2018). Venera-D Landing Site Selection Based on Detailed Geological Mapping Using Magellan Radar Images. Proceedings of the Venera-D Venus Modeling Workshop, p. 139-143.

Due to the significant overlap between references for each chapter, a reference list for the entire thesis is provided following Chapter 7. After the reference list, three appendices are included. Appendix A is attached to this thesis as a supplementary file and includes the 1:2,500,000 scale geological map of the V-32 quadrangle discussed in Chapter 2. Appendix B includes data for the topographic profiles of wrinkle ridges discussed in Chapter 5. Appendix C includes the model data discussed in Chapter 5.

\subsection{Statement of Originality}

Previous geological mapping of Venus' surface has mostly been completed at global or regional scales. This thesis includes the first detailed geological mapping study of the Alpha Regio (V-32) quadrangle and is also one of few maps to be produced at a scale smaller than 1:5,000,000. Numerous previously unrecognized units were mapped, notably in the volcanic plains, 
where subtle variations in SAR properties and interactions with geological structures were carefully analyzed.

Detailed mapping of the radiating dyke swarm (represented by grabenfissures at the surface) associated with Fatua Corona allowed for the determination of the area's regional stress field. This thesis provides the first hypotheses to explain the driving forces responsible for the orientation of the regional stress field. In addition, the mapping conducted in this thesis has allowed for the first estimate of the magmatic volume of Fatua Corona's radiating dykes and volcanic flows.

This thesis provides the first characterization of the coronae within the $\mathrm{V}$ 32 quadrangle from the perspective of LIPs and their magmatic plumbing systems. This builds upon recent research from R.E. Ernst and K.L. Buchan that proposed coronae on Venus have a terrestrial analogue as LIPs with circumferential dyke swarms. This new context has permitted the development in this thesis of a geometric criteria that can be used to rigorously characterize and compare coronae and their terrestrial analogues. Additionally, the detailed mapping in this thesis of circumferential graben-fissure systems in the V-32 quadrangle has resulted in the re-evaluation of corona diameters, in some cases by several hundreds of kilometres. When compared with the diameters reported by Stofan et al. (1992), the largest increases were observed for Fatua Corona (310 km to $870 \mathrm{~km})$ and Thermuthis Corona (330 km to $1250 \mathrm{~km})$. 
This thesis includes the first morphometric measurements of wrinkle ridges on Venus obtained from topography data. Original elastic dislocation models of thrust fault geometry were created to match the observed wrinkle ridge morphometry. The results of this thesis were also able to provide analytical support for previous models of contractional strain on Venus.

The research presented in this thesis allowed for the identification of potential landing site targets in the V-32 quadrangle for future missions. 


\subsection{Figures}

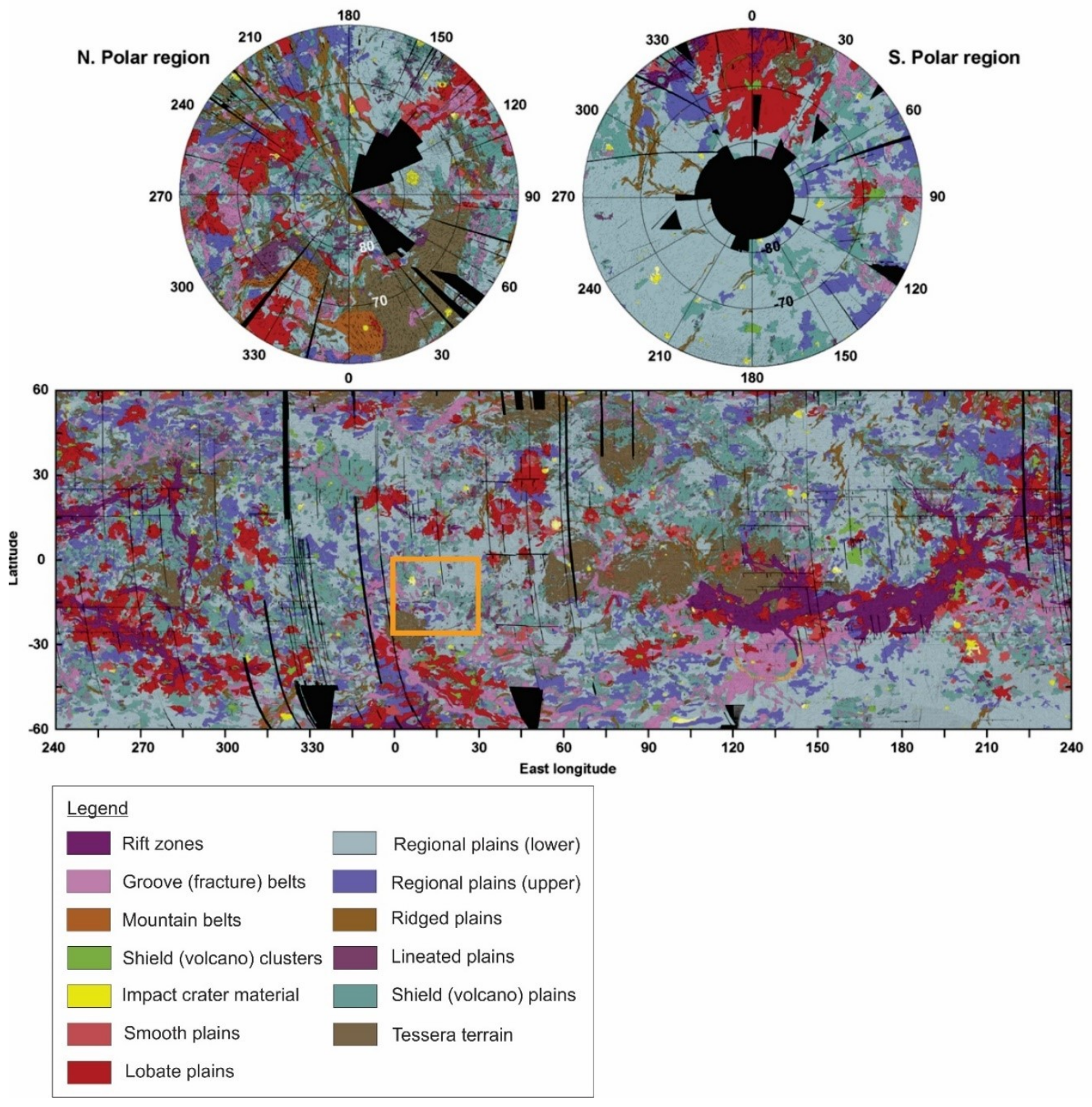

Figure 1.1: Global geological map (1:10,000,000 scale) of Venus, modified after Ivanov and Head (2011). The location of the V-32 quadrangle is shown by the orange box. 


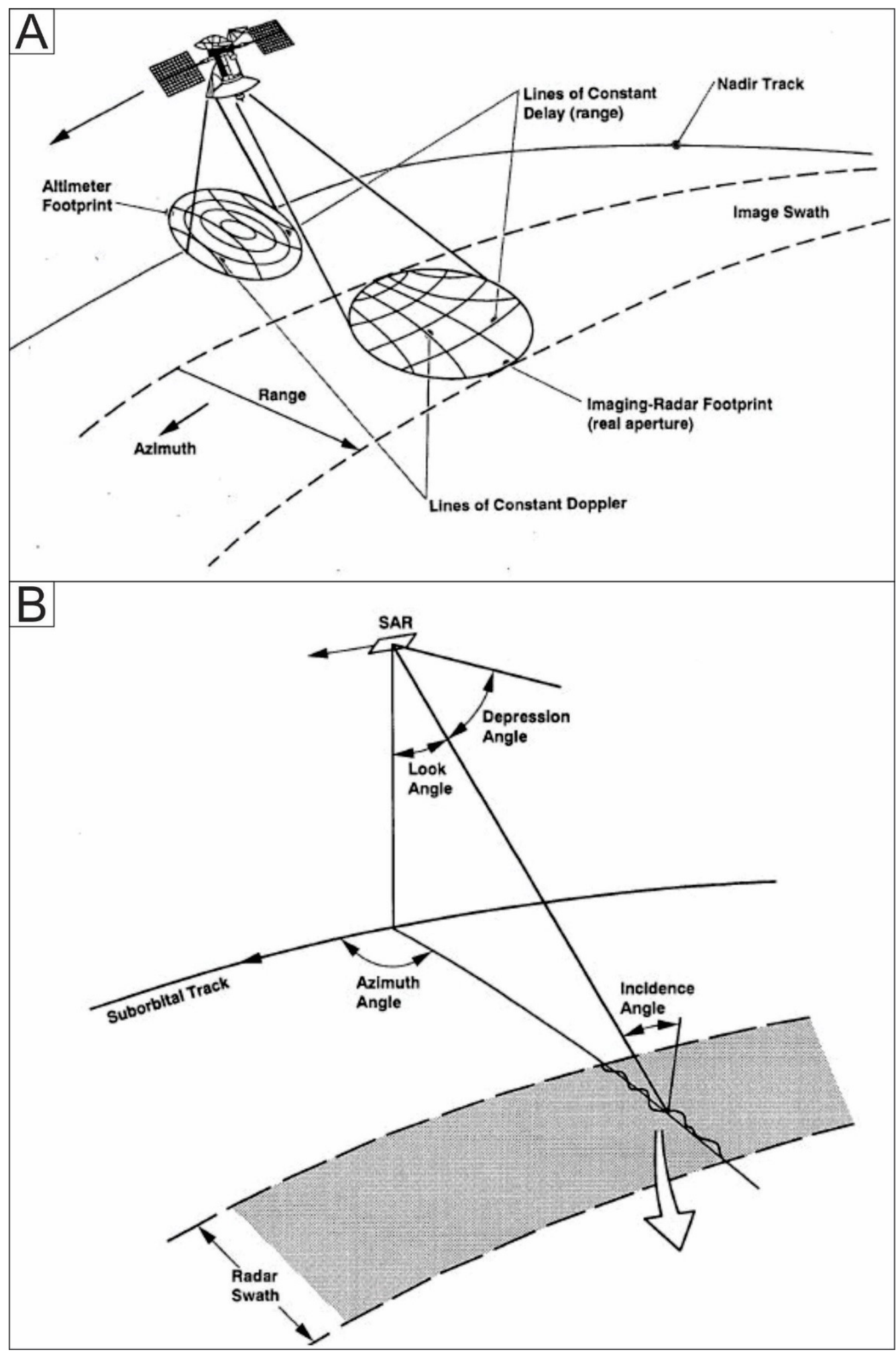

Figure 1.2: Magellan instrument geometry: A) observing geometry of the spacecraft for the three modes of operation: SAR imaging, altimetry, and radiometry, and B) SAR image acquisition geometry. After Ford et al. (1993). 
Smooth surface

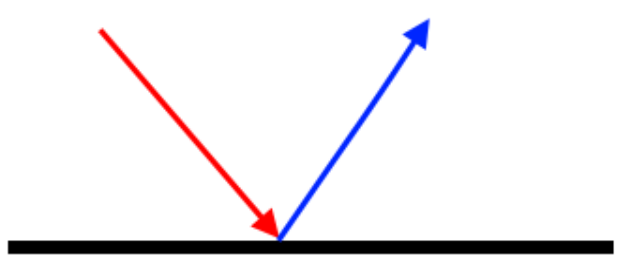

No reflection back to the sensor Appears dark
Rough surface

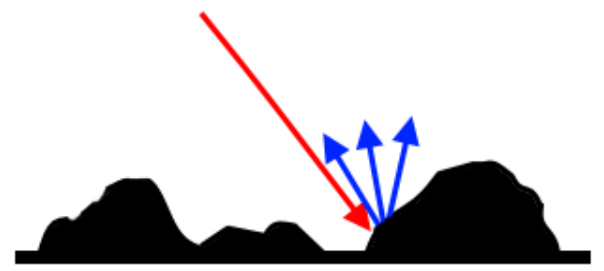

Rough surface produces reflection back to the sensor Appears bright

Figure 1.3: Simplified schematic of the effect of surface roughness on radar wave scattering. For a smooth surface, the incident radar wave (red arrow) is scattered as a specular reflection (blue arrow) and the surface appears dark on the resultant SAR image. For a rough surface, the incident radar wave (red arrow) is scattered as a diffuse reflection in multiple directions (blue arrows) and the surface appears bright on the resultant SAR image. 


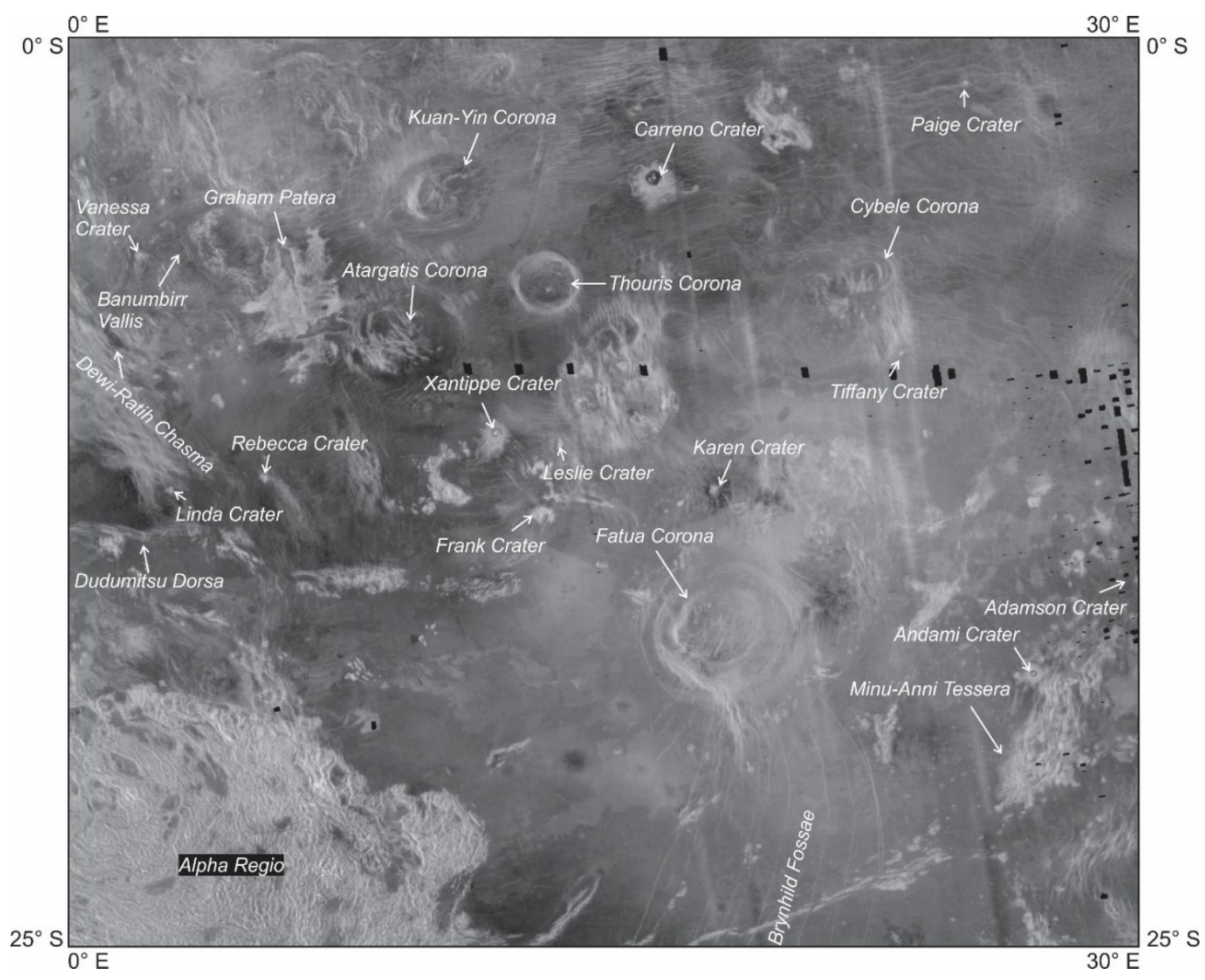

Figure 1.4: Left-looking SAR basemap with superimposed labels showing the location of major named geological features in the V-32 quadrangle. Lara Crater $\left(2.9^{\circ} \mathrm{E}, 4.2^{\circ} \mathrm{S}\right)$ is not labelled on the map due to its small size $(<5 \mathrm{~km})$. 


\section{CHAPTER 2: GEOLOGICAL MAP OF THE ALPHA REGIO (V-32) QUADRANGLE}

\subsection{Mapping of Venus' Surface}

Many of the previous mapping efforts on Venus have been conducted at relatively large scales. The surface of Venus has been divided into 62 quadrangles. At present, regional-scale geological maps for 33 of these quadrangles have been published by the United States Geological Survey (USGS) in collaboration with NASA, most at a scale of 1:5,000,000 (Figure 2.1; USGS, n.d.). Other mapping studies have been conducted at scales smaller than 1:5,000,000 (e.g., Hansen and Phillips, 1993; Copp et al., 1998; Grindrod and Guest, 2006; Studd et al., 2011; Graff et al., 2018). For example, detailed geological mapping of graben-fissure systems by Ernst et al. (2003) at a scale of 1:250,000 in the Beta Regio and Guinevere Planitia regions of Venus identified five times as many systems than were previously identified from mapping conducted at larger scales.

This chapter consists of the results of a 1:2,500,000 scale geological mapping study of the Alpha Regio (V-32) quadrangle. The accompanying geological map is included in Appendix A.

\subsection{Methods}

\subsubsection{Datasets}

The primary datasets used for this map were collected during NASA's Magellan mission. A map package for the $\mathrm{V}-32$ quadrangle consisting of 
Magellan datasets (stereo- and left-looking SAR FMAPs (mosaicked full resolution basic image data records (F-BIDRs)), C3-MIDRs (compressed mosaicked image data records), and the Global Topographic Data Record (GTDR)), and an ArcGIS database were provided by the USGS Astrogeology

Science Center. Additionally, a stereo-derived topography dataset generated by Herrick et al. (2012) using Magellan Cycle 1 and Cycle 3 left-looking data was used. The stereo-derived topography has increased the resolution of the Magellan topography dataset from an original horizontal resolution of approximately $10-20 \mathrm{~km}$, to a horizontal resolution of approximately $1-2 \mathrm{~km}$ and a vertical resolution of approximately 100 m (Ford and Pettengill, 1992; Herrick et al., 2012). This newly derived topography dataset covers approximately $20 \%$ of the surface of Venus, and $50 \%$ of the V-32 quadrangle. However, due to inconsistencies in the absolute elevation values along the boundaries of the FBIDRs, the stereo-derived topography data was primarily used for analysis of relative elevation values and generalized morphologies of features. Other specific details about the Magellan mission and its various datasets can be found in Saunders et al. (1992), Ford et al. (1993), and Tanaka (1994).

\subsubsection{Geological Mapping Procedures}

\subsubsection{Linear and Point Features}

Linear features such as graben, fissures, fractures, and wrinkle ridges appear as bright lines on grayscale SAR images (Figure 2.2). These bright lines represent reflections from the left or right wall of the feature, depending on the 
look direction of the SAR sensor. Linear features were mapped along the illuminated side; for the V-32 quadrangle, the left-looking SAR dataset was primarily used for mapping as there is no right-looking SAR dataset for this area. Interpretations were supplemented with stereo left-looking data where available. Linear features were described as small $(<30 \mathrm{~km}$ long, a few km wide; typically localized) or large (> $30 \mathrm{~km}$ long, a few to tens of $\mathrm{km}$ wide; typically of regional extent). Extensional structures, generally expressed as narrow troughs and scarps, were grouped into two categories based on their geometry: 1) graben, defined as having observable 'floors' bounded by inward angling scarps (Figure 2.3Ai; Grosfils and Head, 1994b) and 2) other extensional structures, including: fissures (Figure 2.3Aii; defined as features that have a ' $V$-shaped' geometry (Grosfils and Head, 1994b), fractures (Figure 2.3Aiii; defined as features limited to the near-surface (Grosfils and Head, 1994b)), and normal faults. Groups of extensional structures (comprising graben, fissures, and fractures) that share a common geometry (and often an inferred genetic relationship) have been referred to as 'graben-fissure systems' (e.g., Ernst et al., 2003; Grosfils and Head, 1994a, 1994b; Studd et al., 2011). Low-amplitude, sinuous ridges, known as wrinkle ridges, were also mapped. Wrinkle ridges are thought to be contractional in origin (Figure 2.3B; e.g., Bilotti and Suppe, 1999; McGill, 1993). Due to the nature of the illumination of features in SAR images, extensional structures and wrinkle ridges can be differentiated by tonal contrast. Scarps associated with extensional structures display sharp tonal contrasts, whereas the tonal contrast associated with wrinkle ridges is more gradual (Suppe and 
Connors, 1992). The along-strike morphology of these features is also different; wrinkle ridges are typically more sinuous (McGill, 1993). Due to the complex structural fabric that is characteristic of tessera terrain, only representative structures were mapped within this unit; these structures were grouped broadly into ridges (e.g., fold crests), and troughs and fractures (e.g., graben, fissures, scarps). Canali and sinuous rilles, interpreted to represent channels formed by lava (Williams-Jones et al., 1998), were also mapped as linear features. A representative number of linear features, consistent with the map scale, were mapped.

Systems of linear structures were classified as circumferential, radiating, or linear, based on their overall geometry (Figure 2.4). They were then numbered and assigned labels (Table 2.1). A total of twenty-five graben-fissure systems were identified in the V-32 quadrangle, including eight circumferential, six radiating, and eleven linear systems (Figure 2.5A). Among these, fourteen (circumferential and radiating) graben-fissure systems were associated with coronae or corona-like features, and seven (linear) graben-fissure systems were associated with fracture belts. Five wrinkle ridge systems were identified, including two circumferential, one radiating, and two linear systems (Figure 2.5B).

Other features, such as small volcanic edifices, colles (small hills or knobs), and pit craters, were mapped as point features. Small volcanic edifices may include shields, domes, and cones, as defined in Guest et al. (1992); the outlines of associated summit craters with diameters larger than approximately 
$2 \mathrm{~km}$ were mapped. Pit craters, defined as quasi-circular, shallow, and steep depressions (Bleamaster and Hansen, 2001; Wyrick et al., 2004) were mapped individually, though they often occur in chains. The outer rims of impact craters were also mapped.

\subsubsection{Geological Units}

Detailed information on the procedures used for geological mapping on Venus can be found in Tanaka (1994) and Ford et al. (1993). Geological units were defined on the basis of their brightness, as well as their relationship with other units and structures. Geological units fall within two main categories: material (i.e., the unit is characterized by its primary features) and lithodemic (i.e., the unit is characterized by secondary, post-emplacement features) (Hansen and López, 2018). In some cases, units could be defined solely based on their distinct SAR and textural properties; these represent material units (Figure 2.6C,D; e.g., relatively young, undeformed lava flows). In other cases, post-emplacement features and structures were pervasive enough that material units could not be defined. Within these areas, post-emplacement features and structures were used to define units and these represent lithodemic units (Figure 2.6A,B; e.g., fracture belts). Units are referred to as 'intensely deformed' where there is a high density of secondary structures. Units with mostly similar characteristics were distinguished as sub-units of a major unit in the following scenarios: 1) where there were only minor differences in characteristics (such as radar brightness), 2) where units were separated by large distances and could not be confidently correlated with each other, or 3) where units were interpreted 
to have similar modes of origin (e.g., distinct volcanic flows associated with a single corona or plains material with abundant wrinkle ridges). Contacts between adjacent geological units were grouped into two categories: 1) certain, where clear boundaries between units could be discerned, and 2) uncertain, where clear boundaries between units could not be discerned. Flow outlines are superimposed on map units where boundaries of individual volcanic flows were observable on SAR images but could only be partially traced.

Geological units were grouped into the following categories, based on their inferred mode of formation: 1) volcanic edifice and flow material (Figure 2.7), defined as localized units identified as distinct volcanic flows; 2) corona material (Figure 2.8), defined as units associated with the formation of coronae; 3) plains material (Figure 2.9), defined as regional units with no identified source(s); 4) structural terrains (Figure 2.10), defined as units characterized by post-emplacement structures; 5) tessera material (Figure 2.11), defined as units associated with tessera terrain; and 6) impact material (Figure 2.12), defined as units related to the formation of impact craters.

The properties of the geological units identified in this study, including their abbreviations and descriptions, are summarized in Table 2.2. The map extent and relative proportion of the surface area covered by each category of geological units are shown in Figures 2.13 and 2.14, respectively. 


\subsection{Overview of the Main Geological Features}

\subsubsection{Tessera Terrain}

Tessera terrain is characterized by its high radar brightness, relatively high relief in comparison with its surroundings, and intense deformation patterns consisting of intersecting networks of ridges, scarps, troughs, and other lineaments (Hansen and Willis, 1996, 1998; Gilmore and Head, 2000). It is considered the oldest stratigraphic unit on Venus and comprises approximately $8 \%$ of the surface (Ivanov and Head, 1996; Basilevsky and Head, 2000b). There are two major tessera regions in the quadrangle: Alpha Regio (1300 by $1500 \mathrm{~km}$, with an average elevation of $1 \mathrm{~km}$ above the surrounding plains; Bindschadler et al., 1992; Bender et al., 2000; Gilmore and Head, 2000) and Minu-Anni Tessera (composed of multiple blocks, the largest being 220 by $500 \mathrm{~km}$, with an average

elevation of several hundred metres above the surrounding plains), along with numerous smaller outcrops of tessera terrain of varying size (termed 'tessera inliers'). Notable occurrences include a sequence of tessera inliers outcropping in an E-W direction along the Dudumitsu Dorsa ridge belt, within the outer uplifted rim of Fatua Corona, and a few strongly elongated NE-SW trending ridge-like tessera structures originating from the margins of Alpha Regio in the southern region of the quadrangle. Tessera terrain in the quadrangle is almost always contained within areas of regionally or locally elevated topography, typically a few hundred metres to several kilometres above the surrounding areas. Tessera material covers approximately $12 \%$ of the quadrangle and has been mapped as 
two major units: tessera terrain (tt) and tessera margin material (tm) (Figure 2.13E, 2.14E).

Alpha Regio has been divided into three different regions by Senske et al. (1991): northern Alpha, southern Alpha, and western Alpha. Bindschadler et al. (1992) classified structures within Alpha Regio into five types: 1) N-S broad linear troughs and ridges spaced 20-30 km apart, likely formed by E-W compression; 2) fine ridges and troughs spaced $3 \mathrm{~km}$ apart, overprinting broad structures and mimicking their orientations, likely formed subsequent to broad structures and also by compression; 3) linear disruption zones of troughs, scarps, and lineaments trending W-NW or E-NE, shear component likely; 4) broad, arcuate ridges with variable orientations and discontinuities that are confined to westcentral Alpha Regio and are associated with linear disruption zones; and 5) $5 \mathrm{~km}$ wide graben spaced 1-10 km apart, trending NW-SE, that truncate all structures. The V-32 quadrangle contains roughly the northern half of the highland region. Although the mapping approach herein involved only mapping generalized structures (i.e., ridges and troughs) due to the extremely complex deformational nature of tessera terrain, major structural trends were identified. The structural trends identified here align well with those described by Binschadler et al. (1992). Approximately the northern half of Alpha Regio is dominated by NNE-SSW trending ridges and minor troughs, and NE-SW to ENE-WSW trending troughs. The central area of Alpha Regio, located at the southwestern corner of the quadrangle, is dominated by ENE-WSW trending broad ridges, and is located along a linear disruption zone identified by Bindschadler et al. (1992). 
Intratessera plains material (pt) within Alpha Regio was also mapped, which has been previously determined to constitute $8 \%$ of the surface area of the highland, and frequently contains volcanic vents, shield volcanoes, and fissures (Gilmore and Head, 1994; Gilmore and Head, 2000).

\subsubsection{Chasmata and Fracture Belts}

Rift zones and fracture belts, frequently interpreted to represent zones of extension, are characterized by numerous closely spaced extensional lineaments (e.g., graben, half-graben/normal faults, fractures) of similar orientation (Hansen et al., 1997; Tanaka et al., 1997). The main distinction between these two features is based on their topographic expression: rifts and their associated chasmata (steep, elongated valleys) are mainly topographic troughs, whereas fracture belts are mainly topographic highs (hundreds of metres to $>1 \mathrm{~km}$ above

the surrounding areas) (Hansen et al., 1997; Tanaka et al., 1997; Basilevsky and Head, 2000b). Previous workers have interpreted age differences between these features: rifts, chasmata and their associated structures are suggested to be younger than the regional plains, and fracture belts are suggested to be older than the regional plains (Head and Basilevsky, 1998; Basilevsky and Head, 2000a, 2000b).

At least two distinct and prominent zones of closely spaced extensional structures are present in the V-32 quadrangle. Dewi-Ratih Chasma trends NNWSSE and is located along the western edge of the quadrangle, where it extends into the neighbouring Carson ( $V-43)$ quadrangle to the west. The chasma itself is 
approximately $30 \mathrm{~km}$ wide, $450 \mathrm{~km}$ long, and has an elevation of approximately $200 \mathrm{~m}$ below the surrounding areas. The chasma is flanked by regions of extensional structures that are elevated a few hundred metres above the surrounding plains. The entire Dewi-Ratih system, including its extension into neighbouring quadrangles, has maximum dimensions of approximately $450 \mathrm{~km}$ wide and $1150 \mathrm{~km}$ long. This lithodemic unit has been classified as the DewiRatih fracture belt (Figure 2.15; Fracture Belt Unit 1 (bf1)). The change in relief observed at Dewi-Ratih Chasma is significantly smaller than what is observed at other features identified as chasmata on Venus, which typically have troughs with elevations up to a few km below the surrounding areas (Senske et al., 1992). For example, Devana Chasma, a rift system associated with the Beta Regio and Phoebe Regio volcanic rises, reaches depths of approximately $2.5 \mathrm{~km}$ beneath the surrounding plains (Kiefer and Swafford, 2006). Thus, the extensional zone associated with Dewi-Ratih Chasma is categorized here as a fracture belt due to the small size of the chasma itself and the overall uplifted topography of the system when compared with the surrounding areas. The interior of the chasma has been flooded by volcanic flows (fDR) that range in appearance from moderately bright (fDR1) to dark (fDR2) on SAR images. Flows belonging to fDR truncate extensional structures in bf1 in some areas. Extensional structures in bf1 are also truncated and sometimes embayed by surrounding plains material, especially ps1.

A second, unnamed, fracture belt (Figure 2.16; Fracture Belt Unit 3 (bf3); centred at $9.7^{\circ} \mathrm{S}, 15.0^{\circ} \mathrm{E}$ ) is present in the central region of the $\mathrm{V}-32$ 
quadrangle. It is approximately $350 \mathrm{~km}$ wide and $430 \mathrm{~km}$ long, with the long axis and extensional structures oriented NNW-SSE. This fracture belt stands a maximum of approximately $775 \mathrm{~m}$ above the surrounding plains. Unlike bf1, bf3 does not appear to be associated with a central trough. The margins and interior topographic lows of bf3 are flooded by plains material (ps1, pi1, pi7, and pf3). These younger plains units also truncate and sometimes embay most of the extensional structures associated with the belt.

Several other minor fracture belts have been mapped (Fracture Belt Units 2, 4-6 (bf2, bf4-6)). While associated with numerous extensional structures, these structural terrains are not as regionally extensive or as heavily deformed as the units described above.

\subsubsection{Volcanic Plains}

Volcanic plains cover approximately $80 \%$ of the surface of Venus (Basilevsky and Head, 2000a; Basilevsky and Head, 2003). In their global geological map of Venus, Ivanov and Head (2011) subdivide these volcanic plains into the following units: densely lineated plains, ridged plains, shield plains, regional plains (further subdivided into a lower unit and an upper unit), smooth plains, and lobate plains (Figure 1.1). In the V-32 quadrangle, Ivanov and Head (2011) mapped the majority of the volcanic plains as shield plains, and lower and upper regional plains.

While the boundaries of geological units mapped herein are generally consistent with the global mapping of Ivanov and Head (2011), mapping revealed 
several localized material and lithodemic units that were previously grouped as part of the global regional plains units. In this study, many volcanic units (e.g., the shield plains and lobate plains of Ivanov and Head (2011)) were also linked to their sources, such as individual coronae (e.g., Fatua Corona Flow Material $(\mathrm{cmF})$ ) or volcanic edifices (e.g., Dzalarhons Mons Flow Material (fDM)). Volcanic units Digitate Flow Material Units 1-4 (fd1-4) overlie adjacent extensional structures and wrinkle ridges and are particularly recent and undeformed by secondary processes. Some channel-like features are present within these relatively young volcanic flows.

Plains material covers approximately $55 \%$ of the quadrangle and has been mapped as 6 major units, with 26 sub-units (Figure 2.13C, 2.14D). Plains units were mapped based on both their radar properties and the presence of secondary structures. The major plains units include: 1) smooth plains material, which includes plains units that appear dark on radar images, indicating low surface roughness; 2 ) intermediate plains material, which includes plains units that have an intermediate radar backscatter, and likely represents units with intermediate surface roughness; 3) mottled plains material, which includes plains units that have a mottled texture comprised of numerous localized and overlapping flows of varying radar backscatter; 4) densely fractured plains material, which includes plains material that has been extensively deformed by extensional structures; 5) ridged plains material, which includes plains material that has been extensively deformed by wrinkle ridges; and 6) intratessera plains material, which includes plains material located within tessera terrain. 


\subsubsection{Mapping Strategies for Plains Material}

Many previous mappers have mapped plains material as generalized, regional units. In particular, in their global 1:10,000,000 scale map of Venus, Ivanov and Head (2011) mapped most of the plains material in the V-32 quadrangle as shield plains (Accruva Formation), and lower (Rusalka Formation) and upper (Ituana Formation) regional plains. The mapping approach of this study attempted to resolve as many sub-units as possible within the extensive plains material, based on subtle differences in radar properties but, most importantly, by using the relationships of these plains units with the various identified structural systems. Rather than grouping all mapped materials with similar radar properties into singular regional units, units with similar properties that were separated by large distances (sometimes thousands of kilometres) were also distinguished as separate sub-units as these materials cannot be confidently geologically correlated using the available data.

For example, Ivanov and Head (2011) mapped the plains in the region bounded by $\left(16^{\circ} \mathrm{E}, 0^{\circ} \mathrm{N}\right.$ to $\left.23^{\circ} \mathrm{E}, 3^{\circ} \mathrm{S}\right)$ as the lower regional plains (Rusalka Formation). In the attempt of this study at more detailed mapping, the plains material in this region has been subdivided into three distinct units: Ridged Plains Material Unit 3 (pr3), Ridged Plains Material Unit 4 (pr4) and Smooth Plains Material Unit 1 (ps1) (Figure 2.17). Both pr3 and pr4 are characterized by pervasive wrinkle ridge deformation (belonging to WRL1) and intermediate radar backscatter, and ps1 is distinguished as being relatively radar-dark. Within pr4 are also many NNW-SSE trending extensional structures (belonging to GFL7). 
These structures in pr4 are abruptly truncated by ps 1 , suggesting that ps 1 is distinctly younger than pr4 and has flooded and obscured GFL7. Unit pr4 is distinguished from pr3 also based upon the presence of the structures in GFL7. North of the uppermost boundary of the V-32 quadrangle (at $0^{\circ} \mathrm{N}$ ), in the Sappho Patera (V-20) quadrangle, a contact between pr3 and pr4 is observed, where pr3 also clearly truncates structures in GFL7.

The recognition of subtle differences in the surface properties and relative ages of Venus' volcanic plains is relevant to the debate on the style of Venus' resurfacing, namely whether the resurfacing was catastrophic (resurfacing of the entire planet over a short duration) or steady state (continuous, more localized resurfacing) (refer to Section 1.1).

\subsubsection{Coronae}

Coronae, quasi-circular tectono-magmatic features first described by Barsukov et al. $(1984,1986)$, have been a subject of great interest since the time of the Venera 15/16 missions (Grindrod and Hoogenboom, 2006). Coronae are partly characterized by their topographic expression, which most commonly includes an uplifted rim surrounding an interior depression (approximately $25 \%$ fo the population, Smrekar and Stofan, 1997). However, this topographic expression can be diverse, complex, or non-existent. In addition to the topographic expression, many coronae are also characterized by an annulus of extensional lineaments that form a circumferential graben-fissure system around the magmatic centre (Stofan et al., 1991; Stofan et al., 1992). Coronae may also 
be associated with radiating graben-fissure systems, which in some cases, can extend thousands of kilometres from the centre (e.g., Grosfils and Head, 1994a,b, 1995, 1996; Ernst et al., 1995; Studd et al., 2011). Many radiating graben-fissure systems, especially those that extend significantly beyond the central region of coronae, are likely underlain by dyke swarms (e.g., Grosfils and Head, 1994a, 1994b; refer to Section 4.1.2). The average diameter of coronae has been reported as approximately $200-300$ km (Stofan et al., 1992; Crumpler and Aubele, 2000; Stofan et al., 2001). In this thesis, similar features that have been termed 'novae' and 'arachnoids' are considered to be in the same class of features as coronae (e.g., Stofan and Head, 1988; Hamilton and Stofan, 1996; Krassilnikov and Head, 2003). Novae have been interpreted to represent a subclass of radiating graben-fissure systems whose focal region is preserved (Studd et al., 2011).

Coronae are associated with volcanism and volcanic features, including volcanic flows, steep-sided volcanic domes, and shield volcanoes (which may also be present in chains or 'shield fields') (Stofan et al., 1991; Stofan et al., 1992; Smrekar and Stofan, 1997; Stofan et al., 2001). Many studies have focused on characterizing and cataloguing coronae and corona-like features on a global scale. Initial cataloguing by Pronin and Stofan (1990) using Venera-15/16 SAR data identified 36 coronae and corona-like features on the surface of Venus. Further cataloguing efforts, using the more complete and higher resolution Magellan SAR and topography data, brought the total number of coronae to 362 (Stofan et al., 1992). Re-assessment of coronae and corona-like features, and 
further detailed analysis, has expanded the total number of coronae to 515 (Stofan et al., 2001). Coronae have also been divided into types based on multiple attributes, including their topographic profile, morphology of the annulus, association with volcanism, etc. (Smrekar and Stofan, 1997; Stofan et al., 2001).

Coronae are a predominant feature in the $\mathrm{V}-32$ quadrangle, with their radiating and circumferential graben-fissure systems comprising major structural features and their associated volcanic flow material covering a significant portion of the surface (10\%) (Figure 2.13B, 2.14C).

All the coronae in the V-32 quadrangle are associated with a circumferential graben-fissure system contained within the annulus. The maximum diameter of the associated circumferential graben-fissure system has been chosen herein to define the maximum diameter of coronae (refer to Section 4.2.1; Bethell et al., 2016; Bethell et al., 2019a). The detailed structural mapping presented here has significantly increased the observed diameters of coronae from initial estimates within the global corona catalogue by Stofan et al. (1992). For instance, Fatua Corona is described by Stofan et al. (1992) as morphological type 'concentric double-ring' and volcanic category 2 (moderate volcanic activity), with a maximum diameter of $310 \mathrm{~km}$ and a maximum annulus width of $85 \mathrm{~km}$. Based on the mapping of this study, the maximum diameter of all circumferential graben-fissures within the annulus is, however, approximately $870 \mathrm{~km}$.

Radiating graben-fissure systems have also been identified; at least four coronae, including Kuan-Yin, Atargatis, Cybele, and Fatua, are associated with a 
radiating system. The radiating systems associated with Kuan-Yin, Atargatis, and Cybele are concentrated within the central regions of the coronae. The largest radiating system in the quadrangle is associated with Fatua Corona and extends for a maximum distance of $1700 \mathrm{~km}$ from the centre; this system includes the Brynhild Fossae of the neighbouring Kaiwan Fluctus (V-44) quadrangle, to the south (Bethell et al., 2017).

Units associated with coronae have been grouped into three categories: 1) corona fractured material, representing regions of mainly extensional deformation associated with the formation of the corona and comprising the area known as the annulus; 2) corona interior material, representing volcanic material localized in the interior of coronae, often associated with numerous small $(<10 \mathrm{~km}$ in diameter) volcanic constructs; and 3) corona flow material, representing volcanic flow material, sourced from coronae that extends beyond the annulus (and often for hundreds of kilometres outward).

\subsubsection{Summary of Corona Formation Models}

Many different models have been proposed to explain the formation of coronae. Formation models for coronae from the literature have been compiled and compared by Grindrod and Hoogenboom (2006). The compilation of Grindrod and Hoogenboom (2006) will be summarized below, with the addition of more recent models.

One of the first explanations for the formation of coronae on Venus was proposed by Nikolaeva et al. (1986), who suggested they were impact craters 
modified by secondary processes such as volcanism and tectonism. Volcanism would be facilitated in this model by a weakened and thinned post-impact lithosphere. Multiple more recent studies, including Vita-Finzi et al. (2005) and Hamilton (2005), have also proposed impact-related formation models. However, these models fail to explain the lack of transitional forms between pristine and modified impact craters that would be expected with an impact model. They also cannot explain the complex tectonics and topography associated with most coronae, clustering of coronae along rift zones, or the extremely large sizes of some coronae (Stofan and Head, 1990; Price et al., 1996; Copp et al., 1998).

Terrestrial ring-dyke intrusion was proposed as an analogue to corona formation by Masursky (1987). Ring-dyke complexes on Earth resemble the annulus of concentric fractures observed at many coronae on Venus, and often possess surrounding ridges similar to the uplifted rim of coronae (Masursky, 1987). However, this hypothesis has been criticized for a few reasons: the ridge morphology on Earth is generated through differential erosion (which is not a significant process on Venus), ring-dyke complexes do not possess the outer topographic low or 'moat' seen at many coronae, and ring-dyke complexes do not reach the large sizes of many coronae. The ring dykes could, however, represent the eroded equivalent of the annulus structures observed on Venus.

Lithospheric subduction has also been proposed as a formation model by Sandwell and Schubert (1992) for the very large corona-like features (e.g., Artemis, with a diameter of approximately $2600 \mathrm{~km}$ ). Schubert et al. (1994) demonstrated, using gravity data, that the observed depths of compensation of 
four large coronae were consistent with subduction of the lithosphere, or largescale reverse faulting (underthrusting). Detailed mapping of these coronae and corona-like features has found inconsistencies with this interpretation, as many coronae and corona-like features (including Artemis) have associated extensive radiating graben-fissure systems that would not be expected to form as a result of subduction (Hansen and Phillips, 1993; Hansen and Olive, 2010). Davaille et al. (2017) presented an analogue model wherein subduction is triggered by a mantle plume and found that the results of their model were consistent with geological and geophysical observations at Artemis and Quetzalpetlatl coronae.

Sinking mantle diapirs, induced by a phase change and/or cooling at the base of the lithosphere, have been proposed as a model of corona formation by Stofan et al. (1987) and Stofan et al. (1991). However, this model could not account for the observed variances in topography. This model also predicts dominant central compression, which is not observed at coronae (Stofan et al., 1991; Grindrod and Hoogenboom, 2006).

The most consistent and widely accepted models of corona formation involve buoyant mantle plumes or mantle diapirs (i.e., a mantle plume lacking a tail) (e.g., Barsukov et al., 1984, 1986; Basilevsky et al., 1986; Stofan et al., 1987; Stofan and Head, 1990; Stofan et al., 1991; Janes et al., 1992; Stofan et al., 1992). The generalized corona formation model proposed by Stofan et al. (1992), later revised by Squyres et al. (1992), includes three steps: 1) a rising (thermal) mantle diapir induces doming of the crust, radial extension, and volcanism; 2) the diapir impinges on and spreads radially outward at the base of 
the lithosphere, creating a plateau; and 3) gravitational relaxation occurs as the diapir cools, resulting in central collapse and the formation of the annulus and its associated fractures. The three-stage evolutionary model can account for the observed topographic profiles of most coronae, but the predicted stresses do not appear to be sufficient to generate the concentric fracturing observed at many coronae (Grindrod and Hoogenboom, 2006; Dombard et al., 2007). These upwelling models, including the three-step model, have been further supported by numerical modeling (e.g., Stofan et al., 1991; Janes et al., 1992). However, subsequent detailed mapping studies have demonstrated that corona formation may be non-linear; there are likely multiple, alternating episodes of uplift and annulus formation (e.g., Copp et al., 1998; López et al., 1999; Bethell et al., 2016). Some coronae appear to have never undergone the uplift phase (Stofan et al., 1997).

Dombard et al. (2007) have proposed a magmatic loading model for coronae. In this model, mantle plumes impinging on the base of the thermal lithosphere generate zones of partial melting, which lead to magmatic loading (underplating) of the crust and formation of coronae. Dombard et al. (2007) demonstrated through finite element simulations that the magmatic loading model can account for the wide range of corona diameters, the annulus of concentric fractures, and a simple topographic profile similar to many coronae. However, thorough testing of this model is required in order to attempt to generate the wide range of simple and complex topographic profiles that are observed in association with coronae. 
Recent thermomechanical modeling of a variety of mantle plumelithosphere interactions (including lithospheric dripping, short-lived subduction, plume embedding, and magmatic underplating) has been able to explain a number of the characteristics of coronae (Gülcher et al., 2020). In addition to the variety of plume-lithosphere interactions considered, the authors suggest coronae display a variety of evolutionary stages, with 37 coronae that are potentially currently active (Gülcher et al., 2020).

\subsubsection{Atargatis Corona}

Atargatis Corona (Figure 2.18) was characterized in the global corona catalogue of Venus by Stofan et al. (1992) as an asymmetric corona of category $2 r$ (moderate associated volcanism, embayed by regional plains), with a maximum diameter of $410 \mathrm{~km}$ and a maximum annulus width of $45 \mathrm{~km}$. The maximum diameter of all mapped structures is estimated to be approximately $540 \mathrm{~km}$, and the maximum diameter of the outer topographic rim at approximately $350 \mathrm{~km}$. The topographic signature of Atargatis Corona is characterized by an interior dome that is 100 by $175 \mathrm{~km}$ in diameter, surrounded by an outer rim with a diameter ranging between $20-50 \mathrm{~km}$. This outer rim is more prominently observed on the northeastern edge of the corona. Atargatis Corona can be classified as topographic sub-type $3 \mathrm{~b}$ (rim surrounding interior dome), following the topographic classification scheme used by Smrekar and Stofan (1997). 
The maximum width of the annulus structures, based on mapping of GFC3, is approximately $90 \mathrm{~km}$. The annulus extends for $270^{\circ}$ around the center; a small $160 \mathrm{~km}$ wide section towards the north and a larger $270 \mathrm{~km}$ wide section towards the southeast of the corona do not contain any visible structures. In these regions, structures associated with the corona in GFC3 and GFR3 have likely been embayed by smooth plains material (ps1). Areas of embayment by plains material correspond to topographic lows around the corona. There is a zone of intense tectonism and quasi-radial fracturing, corresponding to GFR3, in the interior of Atargatis Corona that is concentrated in the interior topographic dome. The interior dome and its associated fracturing are slightly offset to the west from the centre of the annulus.

Very few volcanic constructs are observed in the interior. A few small, localized radar-bright flows are observed emanating from structures in GFR3 in the interior and in GFC3 in the annulus and may represent eruptions from underlying dykes. Several areas of radar-dark material are present in the interior of the corona, concentrated south of the interior dome; these have been mapped as the unit Atargatis Corona Interior Material (ciA). It is currently unclear whether these radar-dark areas represent volcanism associated with the corona itself, or darker areas of volcanic flooding by ps1. No flow material units were observed in association with Atargatis Corona; possible flows sourced from the corona may have been obscured by the later plains material that embays the corona. On the southeast flank is a cluster of several volcanic edifices and pit craters. Many of these volcanoes are superimposed over wrinkle ridges in WRL1, suggesting they 
are relatively young features and are not likely to be related to the formation of Atargatis Corona.

\subsubsection{Kuan-Yin Corona}

Kuan-Yin Corona (Figure 2.19) has a slightly ovoid shape. It was classified by Stofan et al. (1992) as a concentric corona of volcanic category $2 r$, with a maximum diameter of $250 \mathrm{~km}$ and a maximum annulus width of $70 \mathrm{~km}$. The maximum diameter of the topographic rim and of structures estimated from the mapping herein are 400 and $530 \mathrm{~km}$, respectively. The topographic signature is characterized by an inner topographic high 210 by $20 \mathrm{~km}$ in diameter, surrounded by a moat-like depression 40 to $50 \mathrm{~km}$ wide, and an exterior rim 30 to $60 \mathrm{~km}$ wide. The centre of the interior dome is at an elevation of $465 \mathrm{~m}$, whereas the exterior rim is at an elevation of $500 \mathrm{~m}$ on the southwestern side and $75 \mathrm{~m}$ on the northern side. Kuan-Yin Corona likely belongs to topographic sub-type 6 (outer rise, trough, rim, inner low) of Smrekar and Stofan (1997). Stofan et al. (1992) likely measured the diameter of the interior dome only; it is more evident in the stereo-derived topography dataset that there is an exterior moat and rim surrounding the interior dome.

Annulus structures (GFC2) begin and are most concentrated within the exterior rim of the corona, but in some areas extend up to $280 \mathrm{~km}$ away from the centre. Mapping of GFC2 reveals a maximum annulus width of $160 \mathrm{~km}$, although the annulus could potentially be divided into two groups, an inner and outer ring, based on the spacing of the structures. An inner set of closely spaced (1-2 km 
apart) graben-fissures are concentrated along the exterior rim of the corona, and an outer set of more widely spaced (5-40 km apart) graben-fissures extend significantly past the exterior rim. The annulus extends for an estimated $300^{\circ}$ around the centre; a small section to the southeast of the corona is devoid of circumferential structures. A radiating graben-fissure system (GFR2) is contained within the interior dome of the corona and may extend for at least $460 \mathrm{~km}$ away from the centre, towards the northwest. The geometry of GFR2 is only truly radiating in the centre of the interior dome, and it transitions to a more linear NWSE trending geometry (mapped as GFL2) that is most concentrated in the exterior topographic rim. In the annulus of the corona, structures in GFR2 and GFL2 cross-cut structures in GFC2, suggesting that GFC2 is relatively older than GFR2 and GFL2. Wrinkle ridges belonging to WRL1 diverge around the interior dome of the corona and cross-cut GFR2 and GFC2, suggesting that the wrinkle ridges formed subsequently to the corona. This age determination is consistent with the interpretations of McGill (1993), who suggested based on the geometry of wrinkle ridges in the area that Kuan-Yin and Thouris Corona formed prior to or concurrently with the wrinkle ridges.

Within the central interior dome of the corona are tens of small volcanic constructs. The interior dome and moat of the corona are relatively radar-dark and an increase in radar brightness is observed at the exterior rim. The radardark interior of the corona, mapped as Kuan-Yin Corona Interior Material (ciK), may represent volcanism sourced from the various volcanic constructs in the interior, but may also represent flooding of the interior by later plains volcanism. 
At least two possible volcanic flow units were mapped in association with KuanYin: Kuan-Yin Corona Flow Material Units 1 and 2 (cfK1 and cfK2, respectively). Unit cfK 1 is a relatively small flow with relatively radar-bright margins, originating from the edge of the annulus (mapped as Kuan-Yin Corona Fractured Material (cfK)) and extending no more than $20 \mathrm{~km}$ north. Unit cfK2 also appears to have originated along the northern edge of the annulus (cfK), but extends for much further distances from the annulus (up to $140 \mathrm{~km}$ ) and enters a wide topographic trough along the eastern edge of the corona. Both flow material units cfK1 and cfK2 obscure GFC2, as well as some structures in GFR2, GFL2, and WRL1.

\subsubsection{Thouris Corona}

Thouris Corona (Figure 2.20) is a near-circular corona classified by Stofan et al. (1992) as morphological type concentric/caldera and volcanic category 2 , with a maximum diameter of $290 \mathrm{~km}$ and a maximum annulus width of $20 \mathrm{~km}$. Thouris Corona could be classified as topographic subtype 4 (rim surrounding depression) of Smrekar and Stofan (1997). The maximum width of the topographic rim is $40 \mathrm{~km}$, and the maximum diameter of the interior depression is $140 \mathrm{~km}$, corresponding to a maximum total diameter of $220 \mathrm{~km}$ based on topography alone.

The maximum width of the annulus and its associated structures (mapped as GFC4) is nearly $60 \mathrm{~km}$, and the total diameter measured using these structures yields an estimate of $235 \mathrm{~km}$, which is lower than the maximum diameter catalogued by Stofan et al. (1992). Structures in GFC4 extend for $360^{\circ}$ 
around the centre and are concentrated in the uplifted rim of the corona. There is no apparent radiating graben-fissure system associated with Thouris Corona. Structures in GFC4, as well as the interior topographic low of the corona, are flooded and embayed by plains material (ps1). Linear structures in GFL4 crosscut structures in GFC4 in the annulus of Thouris Corona. The system of structures mapped as GFL4 appear to be related to the extensional structures contained within Fracture Belt Unit 3 (bf3), which is located $60 \mathrm{~km}$ southwest of Thouris Corona's rim. Structures within bf3 have the same trend, and it appears the relatively low-lying region between Thouris and bf3 has been embayed by plains volcanism (ps1). The plains appear to have obscured the continuation of extensional structures in GFL4 between the annulus of Thouris Corona and bf3. The NE-SW trending structures in GFL4 therefore do not appear to be related to the formation of the corona, but to an extensional event occurring post-formation of Thouris Corona. Regional wrinkle ridges belonging to WRL1 are also present surrounding the annulus and within the interior of the corona. A direct crosscutting relationship between these wrinkle ridges (WRL1) and structures associated with the corona (GFC4) was not observed. However, based on their geometry, McGill (1993) interpreted the wrinkle ridges to be younger or equivalent in age to Thouris.

The interior depression of Thouris Corona is relatively radar-dark, resembling the plains material (ps1) that surrounds it. At least two separate volcanic constructs are present in the interior, a caldera approximately $7 \mathrm{~km}$ in diameter is located in the central region, and another possible caldera 
approximately $4 \mathrm{~km}$ in diameter is located on the northeastern edge of the interior and is cut by structures in GFC4. A few small, relatively young volcanic flows of intermediate radar brightness (which overly some of the wrinkle ridges in WRL1) are observed within the interior that likely originate from the central caldera.

It is unclear whether Thouris should be classified as a true corona (Squyres et al., 1992). The nearly perfectly circular ring of extensional structures and the relatively simple topographic signature, consisting of an upraised rim surrounding an interior depression, resemble classic caldera morphology. However, the diameter $(235 \mathrm{~km})$ of Thouris Corona is much larger than even the largest known caldera on Earth (Lake Toba, with dimensions of $100 \mathrm{~km}$ by 40 km) (Chesner and Rose, 1991).

\subsubsection{Fatua Corona}

Fatua Corona (Figure 2.21) is described by Stofan et al. (1992) as morphological type concentric double ring and volcanic category 2 , with a maximum diameter of $310 \mathrm{~km}$ and a maximum annulus width of $85 \mathrm{~km}$. The topography (from the centre outward) is characterized by an inner low with dimensions of $120 \mathrm{~km}$ by $75 \mathrm{~km}$, surrounded by a circular topographic high 250 $\mathrm{km}$ in diameter, which is further surrounded by a moat $25-40 \mathrm{~km}$ wide, and an exterior rim $20-80 \mathrm{~km}$ wide. The total diameter of the topography, measured using the exterior rim, yields a maximum estimate of $420 \mathrm{~km}$. The topography of the interior high is complex when viewed in profile; the interior contains several highs and lows. Fatua Corona's topographic signature resembles topographic 
subtype 5 (outer rise, trough, rim, inner high) of Smrekar and Stofan (1997)'s topographic classification system.

Fatua Corona is associated with a complex range of structures. The annulus, mapped as GFC5, extends nearly $360^{\circ}$ around the centre. The annulus can be subdivided into two parts: an inner ring focused along the southwest portion of the exterior rim (GFC5a), and an outer ring which extends significantly outward from the exterior rim and completely encircles the centre (GFC5b). GFC5a varies in width from 20 to $40 \mathrm{~km}$, and GFC5b varies significantly in width, from $25 \mathrm{~km}$ to sections over $295 \mathrm{~km}$ wide with continuous, closely spaced extensional structures. A few circumferential graben in GFC5b extend as far as $410 \mathrm{~km}$ away from the centre. Thus, the maximum diameter of all annulus structures is approximately $870 \mathrm{~km}$. This estimate is significantly larger than the diameter recorded by Stofan et al. (1992), who likely measured the diameter of the exterior topographic rim.

Fatua Corona is also associated with an extensive radiating grabenfissure system (GFR4). The interior high of the corona contains extensional structures that transition in geometry from radiating to circumferential. The radiating graben, mapped as GFR4, originate at the southern outer edge of GFC5a; many of these radiating graben extend further south, beyond the outermost graben of GFC5b and reach maximum distances of $1700 \mathrm{~km}$ away from the corona's centre. Another set of radiating graben, also mapped as GFR4, originate from the northeastern edge of GFC5b and reach lengths of up to 600 $\mathrm{km}$ outward from the annulus. The extent of these radiating graben, which reach 
well beyond the uplifted region of the corona, as well as their association with numerous volcanoes and fissure-style flows along their strike, strongly suggests that they are the surface expression of an underlying dyke swarm. Approximately $450 \mathrm{~km}$ south of the centre of Fatua Corona, GFR4 gradually changes trend from approximately radiating to a subparallel linear orientation that trends NE-SW.

Hundreds of volcanic constructs are present in the interior of Fatua Corona. A few of these volcanoes have localized radar-bright aprons of flows surroundings their flanks; those that are visible at the 1:2,500,000 scale of the map have been mapped as the unit Shield Volcano Apron Material (va). The interior of the corona contains material with a different texture than the surrounding plains (pi1), and this material has lobate margins in some areas (particularly along the eastern side of the topographic moat); these textures are especially emphasized in the stereo left-looking SAR data. The interior material has been mapped as Fatua Corona Interior Material Unit 1 (ciF1; intermediate to moderately radar-bright) and Fatua Corona Interior Material Unit 2 (ciF2; intermediate radar-brightness) and is interpreted to represent flow material sourced from volcanic constructs and extensional structures in the interior topographic high of the corona. Hundreds of volcanoes are also present in the areas surrounding the corona to the northwest and east, and are also clustered along structures in GFR4. The northwestern cluster of volcanoes and their associated flows are particularly dense and have been mapped as the units Shield Volcano Field Units 2a and 2b (vf2a and vf2b, respectively). Three possible flow units were mapped in association with Fatua Corona, including 
Fatua Corona Flow Material Units 1,2, and $3(\mathrm{cmF} 1, \mathrm{cmF} 2$, and $\mathrm{cmF} 3$, respectively). Originating at the southeastern edge of the annulus, cmF1 extends for over $600 \mathrm{~km}$ southeast. Using the present topography and the orientation of lobate margins on the flow, the flow direction of $\mathrm{cmF} 1$ was determined to be likely southeast. Unit cmF1 obscures structures in GFC5 but is cross-cut by some radiating graben. Units $\mathrm{cmF} 2$ and $\mathrm{cmF} 3$ originate at the northeastern edge of the annulus; $\mathrm{cmF} 2$ underlies $\mathrm{cmF} 3$. Unit $\mathrm{cmF} 3$ obscures and embays structures in GFC5, has distinct lobate margins, and extends for nearly $450 \mathrm{~km}$ northeast. Based on this information and the topography, the plausible flow direction of $\mathrm{cmF} 2$ and $\mathrm{cmF} 3$ was northeast. Due to both units having similar points of origin and morphology, both $\mathrm{cmF} 2$ and $\mathrm{cmF} 3$ are interpreted to be genetically linked, representing different generations of volcanism, with cmF2 being the older flow.

\subsubsection{Cybele Corona}

Cybele Corona (Figure 2.22) is classified as a concentric type corona of volcanic category 2 with a maximum diameter of $480 \mathrm{~km}$ and a maximum annulus width of $55 \mathrm{~km}$ (Stofan et al., 1992). The topography is complex and asymmetric; it is characterized by an irregularly shaped interior dome, surrounded by an interior depression, and an exterior rim composed of multiple rings in the shape of two adjoining semi-circles. The smaller semi-circle is located in the northeastern quadrant and has a maximum diameter of $180 \mathrm{~km}$ and a maximum width of $50 \mathrm{~km}$; the larger semi-circle, which makes up the bulk of the structure, has a maximum diameter of $450 \mathrm{~km}$. The highest and most prominent point of the interior dome has dimensions of 40 by $60 \mathrm{~km}$ and is 
located towards the eastern side of the corona. Cybele Corona would be classified as topographic subtype 5 (outer rise, trough, rim, inner high) of Smrekar and Stofan (1997)'s classification scheme.

The morphology of the annulus and its corresponding system of structures (GFC6) reflect the asymmetry observed in the topography. Multiple annuli are present, which correspond to the multiple rings of the exterior rim. There is a larger annulus with a maximum diameter of $670 \mathrm{~km}$ (mapped as GFC6a) that circumscribes the entire structure, and a smaller annulus (in the northeastern quadrant) with a maximum diameter of $290 \mathrm{~km}$ (mapped as GFC6b). Crosscutting relationships indicate that GFC6b is older than GFC6a. The highest peak of the interior dome is the focal point of a radiating graben-fissure system (GFR5), that is concentrated in the eastern half of the corona, particularly in a region $230 \mathrm{~km}$ wide along the southeastern portion of GFC6a. A few graben from GFR5 extend for a significant distance $(450 \mathrm{~km})$ from this focal point. An interesting observation is that the focal point for GFR5 is offset significantly from the focal point of GFC6a. Cross-cutting relationships between GFR5 and the annuli reveal that GFC6a is older than GFR5, however, cross-cutting relationships between GFC6b and GFR5 are ambiguous. Most relationships suggest that GFC6b is younger than the radiating system (GFR5). Several orientations of wrinkle ridges are present in the vicinity of Cybele Corona. Some circumscribe the corona (mapped as WRC2) and appear to be primary structures generated during the formation of the corona, and others are part of a regional system (mapped as WRL1). Wrinkle ridges in WRL1 are cross-cut by structures 
in GFR5. These same wrinkle ridges clearly cross-cut and are younger than GFC6a. The age relationship between WRL1 and GFC6b is unclear.

Tens of small volcanic constructs and pit craters are present within the interior of the corona. Many volcanoes have summit craters on the order of 1-2 $\mathrm{km}$ in diameter, but a few have visible flanks with diameters as large as $15 \mathrm{~km}$. There are a few calderas with crater diameters up to $10 \mathrm{~km}$. Localized flows of varying radar brightness commonly surround these interior volcanoes. Cybele Corona does not appear to have been embayed by plains material. The material in the interior of the corona embays extensional structures in Cybele Corona Fractured Material (cfC) (including both GFR5 and GFC6) and covers the wrinkle ridges. The material within the corona has been mapped as Cybele Corona Interior Material ( $\mathrm{ciC}$ ) and is interpreted to represent volcanic material, possibly sourced from the volcanoes in the interior, that is associated with the formation of the corona.

\subsubsection{Heng-o Corona}

Although most of Heng-o Corona (centred at $355^{\circ} \mathrm{E}, 2^{\circ} \mathrm{N}$ ) is located in the Sif Mons (V-31) quadrangle, some structures that may be attributed to Heng$\mathrm{o}$ are present in the $\mathrm{V}-32$ quadrangle. Only the structures contained within the $\mathrm{V}$ 32 quadrangle will be discussed here.

Heng-o Corona was classified by Stofan et al. (1992) as morphological type concentric and volcanic category $2 r$, with a maximum diameter of $1060 \mathrm{~km}$ and a maximum annulus width of $85 \mathrm{~km}$. In the northeastern corner of the V-32 
quadrangle, there are multiple arcuate graben that appear to be part of a circumferential graben-fissure system (mapped as GFC1) centred on Heng-o Corona. These graben are located $270 \mathrm{~km}$ from the main annulus that circumscribes Heng-o (which is concentrated on an uplifted topographic rim associated with the corona). Several graben at near-perpendicular angles to the circumferential system extend for distances over $650 \mathrm{~km}$ to the southeast and may represent a radiating graben-fissure system (mapped as GFR1) originating at Heng-o. A relatively young flow of intermediate radar brightness, mapped as Heng-O Corona Flow Material $(\mathrm{cmH})$ and which has been interpreted to be associated with Heng-o, cross-cuts and overlies most of the extensional structures in the area. It is located in the region between the main annulus of Heng-o Corona and the circumferential and radiating structures contained within the $\mathrm{V}-32$ quadrangle. This suggests that the annulus of extensional structures around Heng-o may have initially been more extensive, and relatively topographically low areas outside of the corona's rim were later covered by younger volcanics.

\subsubsection{Thermuthis Corona}

Thermuthis Corona (centred at $33^{\circ} \mathrm{E}, 8^{\circ} \mathrm{S}$ ) is located just outside of the V-32 quadrangle (200 $\mathrm{km}$ to the east), in the neighbouring Scarpellini (V-33) quadrangle. It was classified by Stofan et al. (1992) as a corona of morphological type concentric and volcanic category 2, with a maximum diameter of $330 \mathrm{~km}$ and a maximum annulus width of $60 \mathrm{~km}$. A much larger, arcuate set of extensional structures (mapped as GFC8), wide troughs and wrinkle ridges 
(mapped as WRC1) that coincide with a broad topographic rise of the same shape are located at the eastern edge of the quadrangle. These structures continue eastward into V-33 and encircle nearly $270^{\circ}$ around Thermuthis Corona. The corona is also associated with systems of radiating extensional structures (GFR6) and wrinkle ridges (WRR1), which trend perpendicularly to GFC8 and WRC1.

\subsubsection{Volcanic Edifice and Flow Material}

Volcanic edifice and flow material cover approximately $11 \%$ of the quadrangle and are mapped as 8 major units, with 20 sub-units (Figure 2.13A, 2.14B). Major units within this category include fields of shield volcanoes (vf) and their associated flow aprons (va), volcanic flows within Dewi-Ratih Chasma (fDR), volcanic flows emanating from Dzalarhons Mons (fDM), fissure-style flows

emanating from graben within the Brynhild Fossae (fBF), digitate flows (fd), and localized volcanic flows with clear margins but no identified source(s) (fu).

\subsubsection{Digitate Flows}

An approximately $1400 \mathrm{~km}$ long series of layered digitate volcanic flows is located in the central western area of the quadrangle (Figure 2.23). Where possible, individual flows were mapped, but were grouped into four generalized sub-units based on their radar brightness: digitate flow material units 1 (fd1; radar-bright); 2 (fd2; intermediate radar brightness); 3 (fd3; radar-dark); and 4 (fd4; moderately radar-dark to intermediate radar brightness). The combined surface area of these flows is $426,589 \mathrm{~km}^{2}$; they cover $2 \%$ of the surface area of 
the V-32 quadrangle. With the assumption of a $10 \mathrm{~m}$ flow thickness (Roberts et al., 1992), the total volume would be $4,266 \mathrm{~km}^{3}$. However, the full extent of the flows is not represented here as they extend into the neighbouring V-43 (Carson) quadrangle to the west. Based on the topography and the morphology of flow lobes, the general flow direction is interpreted here to be roughly eastward. At present, no source has been identified for these flows, although they may belong to a much larger flow field extending across the $\mathrm{V}-32$ and $\mathrm{V}-43$ quadrangles. This system of digitate flows is at the scale of a fluctus (great flow field), and has a larger surface area than some well-known fluctüs (e.g., Mylitta Fluctus with a surface area of $300,000 \mathrm{~km}^{2}$ (Roberts et al., 1992), or Ningyo Fluctus with a surface area of $180,000 \mathrm{~km}^{2}$ (Head et al., 1992)).

\subsubsection{Impact Material}

Thirteen named impact craters are contained within the V-32 quadrangle: Lara (not shown on the accompanying map in Appendix A, due to its limited extent of $<5 \mathrm{~km}$ ), Vanessa, Linda, Rebecca, Xantippe, Leslie, Frank, Karen, Carreno, Paige, Tiffany, Andami, and Adamson. Units associated with impact cratering processes include Impact Crater Material (im) and Impact Crater Halo (ih). These units comprise approximately $2 \%$ of the surface area of the quadrangle (Figure 2.13F, 2.14F).

There are 3 craters in the V-32 quadrangle that possess a complex crater morphology with an outer rim and central uplift: Carreno, Xantippe, and Rebecca. The largest of the named impact craters is Carreno Crater, which has a diameter 
of approximately $50 \mathrm{~km}$. Carreno Crater has the morphology of a complex crater, with a rim and central uplift. Outflow deposits surround the crater and extend outward from the rim, reaching maximum distances of approximately $115 \mathrm{~km}$ from the crater rim. The floor of the crater is radar-dark and smooth. Deposits associated with the crater overly all adjacent wrinkle ridges, signifying that the bolide impact producing the crater occurred post-wrinkle ridge development.

Xantippe Crater has a diameter of approximately $40 \mathrm{~km}$ and is also associated with outflow deposits extending large distances from the crater's rim. These outflows are most extensive to the southwest, reaching maximum distances of over $150 \mathrm{~km}$ from the outer rim. Xantippe Crater also has a relatively smooth, radar-dark floor and its ejecta and outflow deposits cross-cut and overlie adjacent wrinkle ridges and extensional structures. The Xantippe impact therefore also likely occurred post-wrinkle ridge development.

The smallest of the complex craters is Rebecca Crater, with a diameter of approximately $10 \mathrm{~km}$. It is associated with minor outflow deposits extending up to $15 \mathrm{~km}$ from the crater's rim. Unlike the other complex craters described above, the floor of Rebecca Crater appears rough and rubbly in texture and is relatively radar-bright.

The remaining 10 named impact craters in the V-32 quadrangle are simple craters (i.e., lacking the central uplift of a complex crater). In order from the smallest to largest crater diameters, these are: Lara $(3 \mathrm{~km})$, Paige $(7 \mathrm{~km})$, Linda 
(7 km), Leslie (7 km), Tiffany (7 km), Vanessa (10 km), Karen (11 km), Adamson

$(27 \mathrm{~km})$ Frank $(28 \mathrm{~km})$, and Andami $(29 \mathrm{~km})$.

\subsubsection{Graham Patera: A Low-Angle Bolide Impact?}

Graham Patera, located approximately $170 \mathrm{~km}$ northwest from the annulus of Atargatis Corona, is an oblong depression that is approximately 110 $\mathrm{km}$ long and $30 \mathrm{~km}$ wide. The floor of the depression is relatively radar-dark and mostly smooth in texture, but It is surrounded by mottled, relatively radar-bright material with lobate margins that radiates outward from the depression towards the southeast. This lobate material covers and cross-cuts all nearby units and structures. The depression itself reaches depths up to approximately 350 metres in its centre and is surrounded by a rim that is approximately 100 metres in relief relative to its surroundings. The rim has a radar-bright, rubbly texture and is irregular and hummocky in morphology.

The morphology of the Graham Patera described above resembles that of impact craters in the V-32 quadrangle and elsewhere on Venus, however, the shape of the depression is highly ellipsoidal compared to most impact craters. Ellipsoidal craters are thought to form from bolide impacts at shallow incidence angles (e.g., Gault and Wedekind, 1978; Collins et al., 2011; Elbeshausen et al., 2013).

Although the feature type "patera" is defined by the International Astronomical Union (IAU) Working Group for Planetary System Nomenclature (WGPSN) as "an irregular crater, or a complex one with scalloped edges" and 
does not assign any genetic connotation to the term, features on Venus are generally only named "paterae" if they have a volcanic origin. Debate surrounding the assignment of the term to a crater-like feature named "Cleopatra" provides an example. Initially named Cleopatra Patera, this feature was originally interpreted by Masursky et al. (1980) as a volcanic caldera near the summit of Maxwell Montes. Some workers later debated the volcanic origin of this feature, instead preferring an impact origin (Peterfreund et al., 1984). Later analysis of the Cleopatra structure using Magellan data led to a re-interpretation of the feature as an impact crater (Basilevsky et al., 1991). The feature was then re-named "Cleopatra Crater". Similarly, the feature "Graham Patera" is suggested herein to be changed to "Graham Crater", due to its probable impact origin.

\subsubsection{Wrinkle Ridges}

Wrinkle ridges are prevalent throughout the $\mathrm{V}-32$ quadrangle and are mostly concentrated in the volcanic plains units. A few discrete trends are observed. A regional system of relatively long (>100 km), closely spaced ENEWSW trending wrinkle ridges is prevalent throughout the northern half of the quadrangle. The density and spacing of these wrinkle ridges increase and decrease toward the north, respectively. Regionally ENE-WSW trending wrinkle ridges diverge around regions of high topography (e.g., the outer rim of Kuan-Yin Corona) and converge into regions of low topography (e.g., the interior of Thouris Corona) (McGill, 1993). A system of circumferential wrinkle ridges is present in the northeastern corner of the quadrangle, intersecting with a third system of 
approximately perpendicular wrinkle ridges that possess a radial geometry (Figure 2.24).

Wrinkle ridges are widely interpreted to be the surface expression of thrust faults and associated anticlines (e.g., Golombek et al., 1991; McGill, 1993, 2004; Bilotti and Suppe, 1999; Schultz, 2000; Okubo and Schultz, 2004). Bilotti and Suppe (1999) identified the ENE-WSW trending wrinkle ridges as belonging to a system circumscribing Eistla Regio in their global mapping of wrinkle ridges. Wrinkle ridges in the V-32 quadrangle are discussed in detail in Chapter 5.

\subsection{Geological History}

Tessera materials (including Tessera Terrain (tt) and Tessera Margin Material (tm)) are the oldest units in the V-32 quadrangle. The precursor terrain for tessera materials is unknown; it has been deformed by multiple tectonic events. The nature of the tectonic events that created the observed deformation patterns is currently unknown, however, the deformation is clearly polyphase, and there were likely several phases of both extensional and contractional deformation. The margins of tessera terrain are always embayed by younger volcanic units and are frequently cross-cut by younger structures (Figure 2.25A). The presence of numerous small tessera inliers throughout the quadrangle may indicate that the tessera terrain is akin to a regional 'basement' terrain. Tessera margin material is interpreted to represent tessera terrain that has been flooded by younger volcanic units 
Although fracture belts (bf1-6), as lithodemic units, do not conform to conventional laws of stratigraphy (Hansen and López, 2018; North American Commission on Stratigraphic Nomenclature, 2005), the material comprising these units must also be relatively old. This is evidenced by the cross-cutting relationships of their defining extensional structures, which are consistently embayed by surrounding units and cross-cut by younger fractures (Figure 2.25B). Fracture belt units are also generally preserved in regions of elevated topography. Extensional structures in fracture belts also cross-cut tessera materials, suggesting that at least the deformation characterizing these units is younger than tessera materials. Many of the extensional structural systems and their associated fracture belt units, including GFL1/bf1, GFL2/bf3, and GFL4/bf3, share roughly NW-SE to NNW-SSE orientations. The similar age between these features, along with their similar trends, suggests that an early period of extension in the ENE-WSW direction occurred. The extensive nature of the DewiRatih system (bf1), along with its association with a central chasma and more than 8000 mapped extensional structures, suggests the system formed under regional extension. Many aspects of its morphology resemble extensional zones found elsewhere on Venus (e.g., rift zones in the Beta-Atla Themis region or the Alpha-Lada and Derceto-Quetzalpetlatl extensional belts). The Dewi-Ratih system is classified herein as a fracture belt due to its overall elevated topography, which is not typical of rift zones. This extensional event contributed to the formation of at least two major fracture belts identified in the quadrangle, GFL1/bf1 and GFL4/bf3. Other minor fracture belts and associated extensional 
systems, such as GFL8/bf4, GFL9/bf3, and GFL10/bf6 possess different trends or are separated by large enough distances that they likely represent separate extensional events that also occurred early in the V-32 quadrangle's geological history.

Units classified as plains material display a range in relative ages (Figure 2.25E). The majority of plains material units (including the most areally extensive units, Smooth Plains Material Unit 1 (ps1) and Intermediate Plains Material Unit 1 (pi1)) are both younger than tessera terrain and mostly younger than the extensional structures defining fracture belts. The majority of plains material units are also relatively older than many localized volcanic units. Some plains material units (including Smooth Plains Material Units 4-5 (ps4-5) and Intermediate Plains Material Units 2-3 (pi2-3)) are interpreted to have formed relatively late.

Corona materials also display a range in relative ages. For instance, Thouris Corona Fractured Material (cfF) is cross-cut by the extensional structures characterizing Fracture Belt Unit 3 (bf3) and is therefore relatively older (Figure 2.20C). A few coronae (Atargatis, Kuan-Yin, and Thouris) display evidence for embayment by plains material. Flow material that is interpreted to be associated with Kuan-Yin Corona (cmK1 and cmK2) overlies the same plains material (pr3) that floods the corona's structures and interior, which could indicate that the bulk of the corona's activity occurred pre-plains emplacement, but that some activity continued post-plains emplacement. Other coronae, such as Fatua, have interiors that are not embayed by plains material, and are associated with structures that cross-cut plains material (Figure 2.25D). Cross-cutting 
relationships demonstrate that volcanic units and structures associated with coronae mostly predate the formation of wrinkle ridges.

Many of the units classified as volcanic edifice and flow material are younger than the majority of the plains material units, and most of which have been subsequently deformed by wrinkle ridges. A few of these units, particularly Digitate Flow Material Units 1 and 3 (fd1,3) overlie all nearby units and cross-cut all observed structures (including wrinkle ridges; Figure 2.25F).

While wrinkle ridges are concentrated in volcanic plains material, they cross-cut most units and structures, suggesting their formation is one of the most recent events to occur in the quadrangle. Based on cross-cutting relationships between the different wrinkle ridge trends, the regional ENE-WSW trending wrinkle ridges appear to be younger than both the circumferential and radial wrinkle ridges in the northeastern corner of the V-32 quadrangle. Based on the varying ages and geometries of these wrinkle ridge systems, each is interpreted to represent an episode of contractional deformation related to different orientations of the maximum compressional stress. The V-32 quadrangle therefore records a history of polyphase contractional deformation, with at least three separate generations.

A summary of the geological history displaying the relative ages of the geological units and structural systems defined here is presented in the style of a stratigraphic column in Figure 2.26. 


\subsection{Summary}

This mapping study represents the first detailed geological map produced for the Alpha Regio (V-32) quadrangle, and one of few maps of areas on Venus to be produced at a scale of 1:2,500,000. Detailed mapping of the $V-32$ quadrangle has revealed a complex tectono-magmatic history. In total, 39,523 lineaments were mapped, including 29,837 extensional structures and 8,266 wrinkle ridges. Among the mapped extensional structures, 11 linear, 6 radiating, and 8 circumferential graben-fissure systems were identified. Five wrinkle ridge systems were identified, including 2 linear, 1 radiating, and 2 circumferential systems. At least two distinct extensional zones are present, which are defined as fracture belts that represent relatively old lithodemic units. A total of 77 units (including sub-units) were mapped. Twenty-seven of these units have been classified as plains material. Mapping of volcanic units and structures (including radiating and circumferential graben-fissure systems, and wrinkle ridges) associated with the five named coronae and one corona-like structure contained within the V-32 quadrangle has significantly extended the previously estimated size of these features. Three pervasive regional-scale wrinkle ridge trends (of ENE-WSW, circumferential, and radial trends) were identified by this mapping study, of which at least two were not previously identified. 


\subsection{Tables}

Table 2.1: Classification of structural systems in the Alpha Regio (V-32) quadrangle.

Graben-fissure systems

\begin{tabular}{|c|c|c|c|}
\hline System & Orientation & Associated Feature & Location in the Map Area \\
\hline GFC1 & Circumferential & Heng-o Corona & Northwest corner \\
\hline GFC2 & Circumferential & Kuan-Yin Corona & Centred on $\sim 10^{\circ} \mathrm{E}, 4^{\circ} \mathrm{S}$ \\
\hline GFC3 & Circumferential & Atargatis Corona & Centred on $\sim 8^{\circ} \mathrm{E}, 8^{\circ} \mathrm{S}$ \\
\hline GFC4 & Circumferential & Thouris Corona & Centred on $\sim 13^{\circ} \mathrm{E}, 7^{\circ} \mathrm{S}$ \\
\hline GFC5a & Circumferential & Fatua Corona & Centred on $\sim 18^{\circ} \mathrm{E}, 16.5^{\circ} \mathrm{S}$ \\
\hline GFC5b & Circumferential & Fatua Corona & Centred on $\sim 18^{\circ} \mathrm{E}, 16.5^{\circ} \mathrm{S}$ \\
\hline GFC6a & Circumferential & Cybele Corona & Centred on $\sim 21^{\circ} \mathrm{E}, 7^{\circ} \mathrm{S}$ \\
\hline GFC6b & Circumferential & Cybele Corona & Centred on $\sim 21^{\circ} \mathrm{E}, 7^{\circ} \mathrm{S}$ \\
\hline GFC7 & Circumferential & $\begin{array}{l}\text { Unnamed corona-like } \\
\text { feature }\end{array}$ & Centred on $\sim 18.6^{\circ} \mathrm{E}, 5.2^{\circ} \mathrm{S}$ \\
\hline GFC8 & Circumferential & Thermuthis Corona & Eastern edge \\
\hline GFR1 & Radiating & Heng-o Corona & Northwestern corner \\
\hline GFR2 & Radiating & Kuan-Yin Corona & Centred on $\sim 10.5^{\circ} \mathrm{E}, 4^{\circ} \mathrm{S}$ \\
\hline GFR3 & Radiating & Atargatis Corona & Centred on $\sim 8.5^{\circ} \mathrm{E}, 8.5^{\circ} \mathrm{S}$ \\
\hline GFR4 & Radiating & Fatua Corona & Centred on $\sim 18^{\circ} \mathrm{E}, 16.5^{\circ} \mathrm{S}$ \\
\hline GFR5 & Radiating & Cybele Corona & Centred on $\sim 22^{\circ} \mathrm{E}, 7^{\circ} \mathrm{S}$ \\
\hline GFR6 & Radiating & Thermuthis Corona & Eastern edge \\
\hline GFL1 & Linear; NNW-SSE & $\begin{array}{l}\text { Dewi-Ratih Chasma } \\
\text { (bfl) }\end{array}$ & Western edge \\
\hline GFL2 & Linear; NW-SE & $?(\mathrm{bf} 2)$ & $\sim 7.5^{\circ} \mathrm{E}, 2^{\circ} \mathrm{S}$ \\
\hline GFL3 & Linear; N-S to NNW-SSE & ? & $\sim 8^{\circ} \mathrm{E}, 10^{\circ} \mathrm{S}$ \\
\hline GFL4 & Linear; NNW-SSE & ? (bf3) & $\sim 15^{\circ} \mathrm{E}, 9^{\circ} \mathrm{S}$ \\
\hline GFL5 & Linear; NNE-SSW & ? & $\sim 14^{\circ} \mathrm{E}, 5^{\circ} \mathrm{S}$ \\
\hline GFL6 & Linear; NW-SE & ? & $\sim 16^{\circ} \mathrm{E}, 3.5^{\circ} \mathrm{S}$ \\
\hline GFL7 & Linear; N-S to NNW-SSE & ? & $\sim 22^{\circ} \mathrm{E}, 5^{\circ} \mathrm{S}$ \\
\hline GFL8 & $\begin{array}{l}\text { Linear; various } \\
\text { orientations }\end{array}$ & $?$ (bf4) & $\sim 22^{\circ} \mathrm{E}, 12.5^{\circ} \mathrm{S}$ \\
\hline GFL9 & $\begin{array}{l}\text { Linear, NE-SW to ENE- } \\
\text { WSW }\end{array}$ & $?(\mathrm{bf} 3)$ & $\sim 12.5^{\circ} \mathrm{E}, 12.5^{\circ} \mathrm{S}$ \\
\hline GFL10 & Linear, NNW-SSE & $?$ (bf6) & $\sim 29^{\circ} \mathrm{E}, 12^{\circ} \mathrm{S}$ \\
\hline GFL11 & $\begin{array}{l}\text { Linear; various } \\
\text { orientations }\end{array}$ & $?$ (bf5) & $\sim 27.5^{\circ} \mathrm{E}, 22.5^{\circ} \mathrm{S}$ \\
\hline
\end{tabular}


Wrinkle ridge systems

\begin{tabular}{|c|c|c|c|}
\hline System & Orientation & Associated Feature & Location in the Map Area \\
\hline WRC1 & Circumferential & Thermuthis Corona & Eastern edge \\
\hline WRC2 & Circumferential & Cybele Corona & $\sim 22^{\circ} \mathrm{E}, 7^{\circ} \mathrm{S}$ \\
\hline WRR1 & Radiating & Thermuthis Corona & Eastern edge \\
\hline WRL1 & $\begin{array}{l}\text { Linear; ENE-WSW, } \\
\text { circumferential around Eistla } \\
\text { Regio on a regional scale }\end{array}$ & Eistla Regio? & Northern half \\
\hline WRL2 & Linear; E-W & $?$ & Southern quarter \\
\hline
\end{tabular}

Footnotes:

$\mathrm{GF}=$ Graben-fissure system

$\mathrm{WR}=$ Wrinkle ridge system 
Table 2.2: Main characteristics of geological units in the V-32 quadrangle.

VOLCANIC EDIFICE AND FLOW MATERIAL UNITS

\begin{tabular}{|c|c|c|c|c|c|c|}
\hline $\begin{array}{l}\text { Unit } \\
\text { label }\end{array}$ & Unit name & $\begin{array}{c}\text { Type } \\
\text { locality }\end{array}$ & Radar properties & Description & Cross-cutting relationships & $\begin{array}{c}\text { Associated } \\
\text { Feature }\end{array}$ \\
\hline va & $\begin{array}{l}\text { Shield Volcano } \\
\text { Apron Material }\end{array}$ & $\begin{array}{c}26.3^{\circ} \mathrm{E} \\
16.7^{\circ} \mathrm{S}\end{array}$ & $\begin{array}{l}\text { Varies; bright to dark } \\
\text { radar backscatter. }\end{array}$ & $\begin{array}{l}\text { Consists of the material } \\
\text { comprising and } \\
\text { surrounding individual } \\
\text { volcanic edifices. }\end{array}$ & $\begin{array}{c}\text { Varies, most visible } \\
\text { volcanoes and their } \\
\text { associated deposits overlie } \\
\text { other map units. }\end{array}$ & $\begin{array}{l}\text { Small volcanic } \\
\text { edifices, shield } \\
\text { volcanoes }\end{array}$ \\
\hline vf & $\begin{array}{l}\text { Shield Volcano } \\
\text { Field }\end{array}$ & - & - & $\begin{array}{c}\text { Regions of densely } \\
\text { clustered shield } \\
\text { volcanoes. }\end{array}$ & - & - \\
\hline vf1 & Unit 1 & $\begin{array}{l}17.3^{\circ} \mathrm{E} \\
12.8^{\circ} \mathrm{S}\end{array}$ & $\begin{array}{l}\text { Intermediate to } \\
\text { moderately dark } \\
\text { radar backscatter. }\end{array}$ & $*$ & $\begin{array}{l}\text { Embays or partially embays } \\
\text { GFL4 and GFR4. Embays } \\
\text { GFL6 and GFL7. Cross-cut } \\
\text { by WRL2. }\end{array}$ & - \\
\hline $\mathrm{vf} 2_{\mathrm{a}}$ & Unit 2a & $\begin{array}{l}21.0^{\circ} \mathrm{E} \\
15.1^{\circ} \mathrm{S}\end{array}$ & $\begin{array}{l}\text { Moderately dark to } \\
\text { dark radar } \\
\text { backscatter. }\end{array}$ & $*$ & $\begin{array}{l}\text { Embays or partially embays } \\
\text { GFC5b. Embays GFL8. }\end{array}$ & $\begin{array}{c}\text { GFC5b; Fatua } \\
\text { Corona? }\end{array}$ \\
\hline $\mathrm{vf} 2_{\mathrm{b}}$ & Unit $2 b$ & $\begin{array}{l}22.0^{\circ} \mathrm{E} \\
15.3^{\circ} \mathrm{S}\end{array}$ & $\begin{array}{l}\text { Intermediate to } \\
\text { moderately bright } \\
\text { radar backscatter. }\end{array}$ & $*$ & $\begin{array}{c}\text { Partially embays GFC5b. } \\
\text { Cross-cut by WRL2, } \\
\text { WRR1, and WRC1. }\end{array}$ & $\begin{array}{c}\text { GFC5b; Fatua } \\
\text { Corona? }\end{array}$ \\
\hline vf3 & Unit 3 & $\begin{array}{c}29.6^{\circ} \mathrm{E} \\
15.5^{\circ} \mathrm{S}\end{array}$ & $\begin{array}{l}\text { Intermediate radar } \\
\text { backscatter with } \\
\text { moderately dark } \\
\text { patches. }\end{array}$ & $*$ & $\begin{array}{l}\text { Partially embays GFL10. } \\
\text { Cross-cut by WRL2. }\end{array}$ & - \\
\hline sd & $\begin{array}{c}\text { Steep-Sided Dome } \\
\text { Material }\end{array}$ & $\begin{array}{l}9.8^{\circ} \mathrm{E} \\
0.9^{\circ} \mathrm{S}\end{array}$ & $\begin{array}{c}\text { Intermediate radar } \\
\text { backscatter. }\end{array}$ & $\begin{array}{l}\text { Material associated with } \\
\text { steep-sided dome } \\
\text { structures, interpreted to } \\
\text { form as a result of the } \\
\text { eruption of viscous lava. }\end{array}$ & Varies/uncertain. & $\begin{array}{l}\text { Steep-sided } \\
\text { domes }\end{array}$ \\
\hline fDR & $\begin{array}{c}\text { Dewi-Ratih Chasma } \\
\text { Flow Material }\end{array}$ & - & - & $\begin{array}{c}\text { Volcanic flows that have } \\
\text { embayed topographic }\end{array}$ & - & $\begin{array}{c}\text { Dewi-Ratih } \\
\text { Chasma }\end{array}$ \\
\hline
\end{tabular}




\begin{tabular}{|c|c|c|c|c|c|c|}
\hline & & & & $\begin{array}{l}\text { lows in Dewi-Ratih } \\
\text { Chasma. }\end{array}$ & & \\
\hline fDR1 & Unit 1 & $\begin{array}{l}0.3^{\circ} \mathrm{E} \\
7.5^{\circ} \mathrm{S}\end{array}$ & $\begin{array}{l}\text { Moderately bright } \\
\text { radar backscatter. }\end{array}$ & $*$ & $\begin{array}{l}\text { Embays GFL1. Cross-cut by } \\
\text { WRL1. }\end{array}$ & $\begin{array}{l}\text { Dewi-Ratih } \\
\text { Chasma }\end{array}$ \\
\hline fDR2 & Unit 2 & $\begin{array}{l}2.7^{\circ} \mathrm{E} \\
9.5^{\circ} \mathrm{S}\end{array}$ & $\begin{array}{l}\text { Dark radar } \\
\text { backscatter. }\end{array}$ & $*$ & $\begin{array}{l}\text { Embays or partially embays } \\
\text { GFL1. Cross-cut by WRL1. }\end{array}$ & $\begin{array}{l}\text { Dewi-Ratih } \\
\text { Chasma }\end{array}$ \\
\hline fDM & $\begin{array}{c}\text { Dzalarhons Mons } \\
\text { Flow Material }\end{array}$ & $\begin{array}{c}29.9^{\circ} \mathrm{E} \\
0.2^{\circ} \mathrm{S}\end{array}$ & $\begin{array}{l}\text { Intermediate to } \\
\text { moderately bright } \\
\text { radar backscatter. }\end{array}$ & $\begin{array}{l}\text { Lobate volcanic flow with } \\
\text { a mottled appearance, } \\
\text { interpreted to have } \\
\text { originated at Dzalarhons } \\
\text { Mons (Mead (V-21) } \\
\text { quadrangle). }\end{array}$ & $\begin{array}{l}\text { Overlies WRL1. Cross-cut } \\
\text { by some wrinkle ridges in } \\
\text { WRC1. }\end{array}$ & $\begin{array}{l}\text { Dzalarhons } \\
\text { Mons (V-21 } \\
\text { quadrangle) }\end{array}$ \\
\hline fBF & $\begin{array}{l}\text { Brynhild Fossae } \\
\text { Flow Material }\end{array}$ & - & - & $\begin{array}{l}\text { Lobate volcanic flows, } \\
\text { interpreted to have } \\
\text { erupted from fissures in } \\
\text { GFR4. }\end{array}$ & Cross-cut by WRL2. & $\begin{array}{l}\text { GFR4; Fatua } \\
\text { Corona }\end{array}$ \\
\hline fBF1 & Unit 1 & $\begin{array}{l}23.1^{\circ} \mathrm{E}, \\
24.7^{\circ} \mathrm{S}\end{array}$ & $\begin{array}{l}\text { Dark radar } \\
\text { backscatter. }\end{array}$ & $*$ & $*$ & - \\
\hline fBF2 & Unit 2 & $\begin{array}{l}22.7^{\circ} \mathrm{E}, \\
24.7^{\circ} \mathrm{S}\end{array}$ & $\begin{array}{l}\text { Bright radar } \\
\text { backscatter. }\end{array}$ & $*$ & $*$ & - \\
\hline fd & $\begin{array}{l}\text { Digitate Flow } \\
\text { Material }\end{array}$ & - & - & $\begin{array}{c}\text { Overlapping digitate } \\
\text { volcanic flows with lobate } \\
\text { margins. The outlines of } \\
\text { individual flows have } \\
\text { been mapped, where } \\
\text { possible. }\end{array}$ & - & - \\
\hline $\mathrm{fd} 1$ & Unit 1 & $\begin{array}{l}0.5^{\circ} \mathrm{E} \\
16.6^{\circ} \mathrm{S} \\
\end{array}$ & $\begin{array}{l}\text { Bright radar } \\
\text { backscatter. }\end{array}$ & - & $\begin{array}{c}\text { Overlies all observable } \\
\text { structures. }\end{array}$ & - \\
\hline $\mathrm{fd} 2$ & Unit 2 & $\begin{array}{l}4.7^{\circ} \mathrm{E} \\
15.1^{\circ} \mathrm{S}\end{array}$ & $\begin{array}{c}\text { Intermediate radar } \\
\text { backscatter. }\end{array}$ & - & $\begin{array}{l}\text { Partially embays GFL1 in } \\
\text { some areas. Cross-cut by } \\
\text { WRL1. }\end{array}$ & - \\
\hline $\mathrm{fd} 3$ & Unit 3 & $\begin{array}{l}6.5^{\circ} \mathrm{E} \\
17.6^{\circ} \mathrm{S}\end{array}$ & $\begin{array}{l}\text { Dark radar } \\
\text { backscatter. }\end{array}$ & - & $\begin{array}{c}\text { Overlies all observable } \\
\text { structures. }\end{array}$ & - \\
\hline
\end{tabular}




\begin{tabular}{|c|c|c|c|c|c|c|}
\hline $\mathrm{fd} 4$ & Unit 4 & $\begin{array}{l}8.5^{\circ} \mathrm{E} \\
15.8^{\circ} \mathrm{S}\end{array}$ & $\begin{array}{l}\text { Varies; intermediate } \\
\text { to moderately dark } \\
\text { radar backscatter. }\end{array}$ & - & $\begin{array}{l}\text { Varies; partially embays } \\
\text { GFL1 in some areas. Cross- } \\
\text { cut by WRL1. }\end{array}$ & - \\
\hline fu & $\begin{array}{l}\text { Unsourced Flow } \\
\text { Material }\end{array}$ & - & - & $\begin{array}{l}\text { Discrete volcanic flows } \\
\text { that could not be } \\
\text { attributed to a source. }\end{array}$ & - & - \\
\hline ful & Unit 1 & $\begin{array}{l}12.4^{\circ} \mathrm{E} \\
21.2^{\circ} \mathrm{S}\end{array}$ & $\begin{array}{l}\text { Intermediate radar } \\
\text { backscatter with dark } \\
\text { and moderately } \\
\text { bright patches. }\end{array}$ & $\begin{array}{l}\text { Lobate volcanic sheet } \\
\text { flow with bright margins. }\end{array}$ & $\begin{array}{c}\text { Embays unnamed } \\
\text { extensional structures } \\
\text { (NNW-SSE). Cross-cut by } \\
\text { WRL1. }\end{array}$ & - \\
\hline fu2 & Unit 2 & $\begin{array}{l}15.0^{\circ} \mathrm{E} \\
20.6^{\circ} \mathrm{S}\end{array}$ & $\begin{array}{l}\text { Moderately bright } \\
\text { radar backscatter. }\end{array}$ & $\begin{array}{l}\text { Lobate volcanic sheet } \\
\text { flow, flow direction } \\
\text { inferred to be SW. }\end{array}$ & $\begin{array}{c}\text { Embays, but is also cross-cut } \\
\text { by some structures in } \\
\text { GFC5b. Cross-cut by } \\
\text { WRL1 and ungrouped } \\
\text { extensional structures } \\
\text { (NNW-SSE). }\end{array}$ & - \\
\hline fu3 & Unit 3 & $\begin{array}{l}14.3^{\circ} \mathrm{E} \\
15.4^{\circ} \mathrm{S}\end{array}$ & $\begin{array}{l}\text { Moderately bright } \\
\text { radar backscatter. }\end{array}$ & $\begin{array}{l}\text { Lobate volcanic sheet } \\
\text { flow, flow direction } \\
\text { inferred to be NNE. } \\
\text { Possibly related to fd. }\end{array}$ & $\begin{array}{c}\text { Embays GFR4 and GFC5b. } \\
\text { Cross-cut by WRL1. } \\
\text { Uncertain relationship with } \\
\text { GFL9. }\end{array}$ & - \\
\hline fu4 & Unit 4 & $\begin{array}{c}14.2^{\circ} \mathrm{E} \\
2.0^{\circ} \mathrm{S}\end{array}$ & $\begin{array}{l}\text { Moderately bright } \\
\text { radar backscatter. }\end{array}$ & $\begin{array}{l}\text { Volcanic flow with rubbly } \\
\text { to lobate margins. }\end{array}$ & Cross-cut by WRL1. & - \\
\hline fu5 & Unit 5 & $\begin{array}{l}19.6^{\circ} \mathrm{E} \\
12.1^{\circ} \mathrm{S}\end{array}$ & $\begin{array}{l}\text { Moderately dark to } \\
\text { dark radar } \\
\text { backscatter. }\end{array}$ & $*$ & $\begin{array}{l}\text { Embays GFL7. Embays or } \\
\text { partially embays GFL8. } \\
\text { Cross-cut by WRL1. }\end{array}$ & - \\
\hline fu6 & Unit 6 & $\begin{array}{l}29.0^{\circ} \mathrm{E} \\
18.0^{\circ} \mathrm{S}\end{array}$ & $\begin{array}{l}\text { Moderately bright } \\
\text { radar backscatter. }\end{array}$ & $\begin{array}{l}\text { Lobate volcanic flow, } \\
\text { possibly related to nearby } \\
\text { shield volcanoes. }\end{array}$ & $\begin{array}{l}\text { Cross-cut by some small } \\
\text { wrinkle ridges and fractures } \\
\text { of unknown association. }\end{array}$ & $\begin{array}{c}\text { Shield } \\
\text { volcanoes? }\end{array}$ \\
\hline fu7 & Unit 7 & $\begin{array}{l}9.8^{\circ} \mathrm{E} \\
6.5^{\circ} \mathrm{S}\end{array}$ & $\begin{array}{l}\text { Bright radar } \\
\text { backscatter. }\end{array}$ & Lobate volcanic flow. & $\begin{array}{l}\text { Overlies all observable } \\
\text { structures. }\end{array}$ & $\begin{array}{l}\text { GFC3; } \\
\text { Atargatis } \\
\text { Corona? }\end{array}$ \\
\hline fu8 & Unit 8 & $\begin{array}{c}17.4^{\circ} \mathrm{E} \\
8.5^{\circ} \mathrm{S}\end{array}$ & $\begin{array}{l}\text { Moderately bright } \\
\text { radar backscatter. }\end{array}$ & Lobate volcanic flow. & Cross-cut by WRL1. & $\begin{array}{l}\text { GFC6; Cybele } \\
\text { Corona? }\end{array}$ \\
\hline
\end{tabular}


CORONA MATERIAL

\begin{tabular}{|c|c|c|c|c|c|c|}
\hline cmH & $\begin{array}{l}\text { Heng-O Corona } \\
\text { Flow Material }\end{array}$ & $\begin{array}{l}0.2^{\circ} \mathrm{E} \\
2.5^{\circ} \mathrm{S}\end{array}$ & $\begin{array}{l}\text { Intermediate radar } \\
\text { backscatter. }\end{array}$ & $\begin{array}{l}\text { Volcanic flow material; } \\
\text { extends into neighbouring } \\
\text { quadrangles. Interpreted } \\
\text { to originate at Heng-o } \\
\text { Corona. }\end{array}$ & $\begin{array}{l}\text { Embays GFL1. Overlies } \\
\text { ps2. Cross-cut by WRL1 } \\
\text { and some structures in } \\
\text { GFR1. }\end{array}$ & Heng-o Corona \\
\hline ciA & $\begin{array}{l}\text { Atargatis Corona } \\
\text { Interior Material }\end{array}$ & $\begin{array}{l}9.9^{\circ} \mathrm{E} \\
9.0^{\circ} \mathrm{S}\end{array}$ & $\begin{array}{l}\text { Dark radar } \\
\text { backscatter. }\end{array}$ & $\begin{array}{l}\text { Volcanic material inferred } \\
\text { to be associated with the } \\
\text { formation of Atargatis } \\
\text { Corona. }\end{array}$ & $\begin{array}{l}\text { Embays GFR3. Overlies } \\
\text { ps1. }\end{array}$ & $\begin{array}{l}\text { Atargatis } \\
\text { Corona }\end{array}$ \\
\hline cfA & $\begin{array}{l}\text { Atargatis Corona } \\
\text { Fractured Material }\end{array}$ & $\begin{array}{l}8.4^{\circ} \mathrm{E} \\
8.6^{\circ} \mathrm{S}\end{array}$ & $\begin{array}{l}\text { Intermediate to } \\
\text { moderately dark } \\
\text { radar backscatter. }\end{array}$ & $\begin{array}{c}\text { Material heavily } \\
\text { deformed by extensional } \\
\text { structures, interpreted to } \\
\text { be related to the formation } \\
\text { of Atargatis Corona. }\end{array}$ & $\begin{array}{l}\text { Contains/defined by } \\
\text { structures in GFC3 and } \\
\text { GFR3. Structures in GFC3 } \\
\text { and GFR3 are embayed by } \\
\text { ciA, and ps1. Cross-cut by } \\
\text { WRL1. }\end{array}$ & $\begin{array}{l}\text { Atargatis } \\
\text { Corona }\end{array}$ \\
\hline cmK & $\begin{array}{l}\text { Kuan-Yin Corona } \\
\text { Flow Material }\end{array}$ & - & 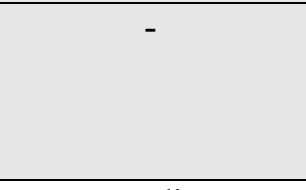 & $\begin{array}{l}\text { Volcanic flows } \\
\text { interpreted to be related to } \\
\text { the formation of Kuan- } \\
\text { Yin Corona. }\end{array}$ & - & $\begin{array}{l}\text { Kuan-Yin } \\
\text { Corona }\end{array}$ \\
\hline cmK1 & Unit 1 & $\begin{array}{l}10.3^{\circ} \mathrm{E} \\
2.4^{\circ} \mathrm{S}\end{array}$ & $\begin{array}{l}\text { Intermediate to } \\
\text { moderately bright } \\
\text { radar backscatter. }\end{array}$ & $\begin{array}{l}\text { Lobate volcanic flow, } \\
\text { possibly originates from } \\
\text { extensional structures in } \\
\text { GFC2. }\end{array}$ & $\begin{array}{c}\text { Embays or partially embays } \\
\text { GFL2 and GFC2. Overlies } \\
\text { cmK2. }\end{array}$ & $\begin{array}{l}\text { Kuan-Yin } \\
\text { Corona }\end{array}$ \\
\hline $\mathrm{cmK} 2$ & Unit 2 & $\begin{array}{c}10.9^{\circ} \mathrm{E} \\
2.0^{\circ} \mathrm{S}\end{array}$ & $\begin{array}{l}\text { Intermediate to } \\
\text { moderately dark } \\
\text { radar backscatter. }\end{array}$ & $*$ & $\begin{array}{l}\text { Embays or partially embays } \\
\text { GFC2. Overlies pr3. } \\
\text { Overlain by cmK2. Cross- } \\
\text { cut by GFL2 and WRL1. }\end{array}$ & $\begin{array}{l}\text { Kuan-Yin } \\
\text { Corona }\end{array}$ \\
\hline ciK & $\begin{array}{l}\text { Kuan-Yin Corona } \\
\text { Interior Material }\end{array}$ & $\begin{array}{l}10.5^{\circ} \mathrm{E} \\
4.0^{\circ} \mathrm{S}\end{array}$ & $\begin{array}{l}\text { Moderately dark } \\
\text { radar backscatter. }\end{array}$ & $\begin{array}{l}\text { Volcanic material inferred } \\
\text { to be associated with the }\end{array}$ & $\begin{array}{l}\text { Embays GFR2 and cfK. } \\
\text { Overlies pr3. Cross-cut by } \\
\text { WRL1. }\end{array}$ & $\begin{array}{l}\text { Kuan-Yin } \\
\text { Corona }\end{array}$ \\
\hline
\end{tabular}




\begin{tabular}{|c|c|c|c|c|c|c|}
\hline & & & & $\begin{array}{l}\text { formation of Kuan-Yin } \\
\text { Corona. }\end{array}$ & & \\
\hline cfK & $\begin{array}{l}\text { Kuan-Yin Corona } \\
\text { Fractured Material }\end{array}$ & $\begin{array}{l}8.8^{\circ} \mathrm{E} \\
3.6^{\circ} \mathrm{S}\end{array}$ & $\begin{array}{l}\text { Intermediate radar } \\
\text { backscatter. }\end{array}$ & $\begin{array}{c}\text { Material heavily } \\
\text { deformed by extensional } \\
\text { structures, interpreted to } \\
\text { be related to the formation } \\
\text { of Kuan-Yin Corona. }\end{array}$ & $\begin{array}{c}\text { Contains/defined by } \\
\text { structures in GFC2 and } \\
\text { GFR2. Structures in GFC2 } \\
\text { and GFR2 are embayed by } \\
\text { cmK1, cmK2, ciK, pr3, and } \\
\text { ps1. GFC2 is cross-cut by } \\
\text { GFR2 and GFL2. All } \\
\text { structures are cross-cut by } \\
\text { WRL1. }\end{array}$ & $\begin{array}{c}\text { Kuan-Yin } \\
\text { Corona }\end{array}$ \\
\hline cfT & $\begin{array}{c}\text { Thouris Corona } \\
\text { Fractured Material }\end{array}$ & $\begin{array}{l}12.7^{\circ} \mathrm{E} \\
6.2^{\circ} \mathrm{S}\end{array}$ & $\begin{array}{l}\text { Intermediate radar } \\
\text { backscatter. }\end{array}$ & $\begin{array}{c}\text { Material heavily } \\
\text { deformed by extensional } \\
\text { structures, interpreted to } \\
\text { be related to the formation } \\
\text { of Thouris Corona. }\end{array}$ & $\begin{array}{l}\text { Contains/defined by } \\
\text { structures in GFC4. } \\
\text { Structures in GFC4 are } \\
\text { embayed by ps1. }\end{array}$ & $\begin{array}{l}\text { Thouris } \\
\text { Corona }\end{array}$ \\
\hline cmF & $\begin{array}{c}\text { Fatua Corona Flow } \\
\text { Material }\end{array}$ & - & - & $\begin{array}{c}\text { Volcanic flows } \\
\text { interpreted to be related to } \\
\text { the formation of Fatua } \\
\text { Corona. }\end{array}$ & - & Fatua Corona \\
\hline cmF1 & Unit 1 & $\begin{array}{l}20.0^{\circ} \mathrm{E} \\
20.0^{\circ} \mathrm{S}\end{array}$ & $\begin{array}{c}\text { Intermediate radar } \\
\text { backscatter with } \\
\text { moderately bright } \\
\text { patches. }\end{array}$ & $\begin{array}{l}\text { Lobate volcanic flow, } \\
\text { flow direction inferred to } \\
\text { be SE. Possibly originates } \\
\text { from extensional } \\
\text { structures in GFC5b. }\end{array}$ & $\begin{array}{l}\text { Cross-cut by WRL1 and } \\
\text { WRL2, and by some } \\
\text { structures in GFC5 and } \\
\text { GFR4. Uncertain } \\
\text { relationship with pi1 and } \\
\text { pm1. }\end{array}$ & Fatua Corona \\
\hline $\mathrm{cmF} 2$ & Unit 2 & $\begin{array}{l}18.2^{\circ} \mathrm{E} \\
13.8^{\circ} \mathrm{S}\end{array}$ & $\begin{array}{l}\text { Moderately bright to } \\
\text { intermediate radar } \\
\text { backscatter. }\end{array}$ & $\begin{array}{l}\text { Lobate volcanic flow. } \\
\text { Possibly originates from } \\
\text { extensional structures in } \\
\text { GFC5b. }\end{array}$ & $\begin{array}{l}\text { Embays or partially embays } \\
\text { GFL8. Overlies pi1. } \\
\text { Overlain by cmF3. }\end{array}$ & Fatua Corona \\
\hline $\mathrm{cmF} 3$ & Unit 3 & $\begin{array}{l}19.6^{\circ} \mathrm{E}, \\
13.8^{\circ} \mathrm{S}\end{array}$ & $\begin{array}{l}\text { Bright radar } \\
\text { backscatter. }\end{array}$ & $\begin{array}{l}\text { Lobate volcanic flow. } \\
\text { Possibly originates from }\end{array}$ & $\begin{array}{l}\text { Embays GFC5. Embays or } \\
\text { partially embays GFL8. } \\
\text { Overlies } \mathbf{c m F 2} \text {. Cross-cut by }\end{array}$ & Fatua Corona \\
\hline
\end{tabular}




\begin{tabular}{|c|c|c|c|c|c|c|}
\hline & & & & $\begin{array}{l}\text { extensional structures in } \\
\text { GFC5b. }\end{array}$ & $\begin{array}{c}\text { GFL7 and WRL1. Overlain } \\
\text { by fu5. }\end{array}$ & \\
\hline ciF & $\begin{array}{l}\text { Fatua Corona } \\
\text { Interior Material }\end{array}$ & - & - & $\begin{array}{l}\text { Volcanic material inferred } \\
\text { to be associated with the } \\
\text { formation of Fatua } \\
\text { Corona; contains } \\
\text { hundreds of shield } \\
\text { volcanoes. }\end{array}$ & - & Fatua Corona \\
\hline ciF1 & Unit 1 & $\begin{array}{l}17.7^{\circ} \mathrm{E} \\
16.2^{\circ} \mathrm{S}\end{array}$ & $\begin{array}{l}\text { Intermediate to } \\
\text { moderately bright } \\
\text { radar backscatter. }\end{array}$ & $\begin{array}{l}\text { Margins are lobate in } \\
\text { some areas. }\end{array}$ & $\begin{array}{l}\text { Cross-cut by GFR4. } \\
\text { Uncertain relationship with } \\
\text { ciF2 and pi1. }\end{array}$ & Fatua Corona \\
\hline $\operatorname{ciF} 2$ & Unit 2 & $\begin{array}{l}17.9^{\circ} \mathrm{E} \\
15.4^{\circ} \mathrm{S}\end{array}$ & $\begin{array}{c}\text { Intermediate radar } \\
\text { backscatter. }\end{array}$ & $*$ & $\begin{array}{c}\text { Cross-cut by GFC5a. } \\
\text { Uncertain relationship with } \\
\text { ciF1 and pi1. }\end{array}$ & Fatua Corona \\
\hline cfF & $\begin{array}{c}\text { Fatua Corona } \\
\text { Fractured Material }\end{array}$ & $\begin{array}{l}16.9^{\circ} \mathrm{E} \\
17.4^{\circ} \mathrm{S}\end{array}$ & $\begin{array}{l}\text { Intermediate to } \\
\text { moderately bright } \\
\text { radar backscatter. }\end{array}$ & $\begin{array}{c}\text { Material heavily } \\
\text { deformed by extensional } \\
\text { structures, interpreted to } \\
\text { be related to the formation } \\
\text { of Fatua Corona. }\end{array}$ & $\begin{array}{c}\text { Contains/defined by } \\
\text { structures in GFC5 and } \\
\text { GFR4. Structures in GFC5 } \\
\text { and GFR4 cross-cut pi1. } \\
\text { GFR4 cross-cuts cmF1. } \\
\text { GFC5 is embayed or } \\
\text { partially embayed by vf2a } \\
\text { and vf2b. }\end{array}$ & Fatua Corona \\
\hline ciC & $\begin{array}{l}\text { Cybele Corona } \\
\text { Interior Material }\end{array}$ & $\begin{array}{l}20.8^{\circ} \mathrm{E} \\
8.0^{\circ} \mathrm{S}\end{array}$ & $\begin{array}{c}\text { Intermediate radar } \\
\text { backscatter with } \\
\text { moderately dark } \\
\text { patches. }\end{array}$ & $\begin{array}{l}\text { Volcanic material inferred } \\
\text { to be associated with the } \\
\text { formation of Cybele } \\
\text { Corona; contains tens of } \\
\text { shield volcanoes. }\end{array}$ & $\begin{array}{l}\text { Embays or partially embays } \\
\text { GFC6 and GFR5. Overlies } \\
\text { pi7, pr4 and ps1. Uncertain } \\
\text { relationship with WRL1. }\end{array}$ & Cybele Corona \\
\hline cfC & $\begin{array}{c}\text { Cybele Corona } \\
\text { Fractured Material }\end{array}$ & $\begin{array}{l}22.7^{\circ} \mathrm{E} \\
8.3^{\circ} \mathrm{S}\end{array}$ & $\begin{array}{c}\text { Intermediate radar } \\
\text { backscatter. }\end{array}$ & $\begin{array}{c}\text { Material heavily } \\
\text { deformed by extensional } \\
\text { structures, interpreted to } \\
\text { be related to the formation } \\
\text { of Cybele Corona. }\end{array}$ & $\begin{array}{c}\text { Contains/defined by } \\
\text { structures in GFC6 and } \\
\text { GFR5. Structures in GFC6 } \\
\text { and GFR5 are embayed or } \\
\text { partially embayed by ciC, }\end{array}$ & Cybele Corona \\
\hline
\end{tabular}




\begin{tabular}{|c|c|c|c|c|c|c|}
\hline & & & & & $\begin{array}{l}\text { pi9, pi6, and ps1, and are } \\
\text { cross-cut by WRL1. }\end{array}$ & \\
\hline cl & $\begin{array}{c}\text { Corona-Like } \\
\text { Feature Material }\end{array}$ & $\begin{array}{l}18.3^{\circ} \mathrm{E} \\
3.8^{\circ} \mathrm{S}\end{array}$ & $\begin{array}{l}\text { Moderately bright } \\
\text { radar backscatter. }\end{array}$ & $\begin{array}{l}\text { Material containing } \\
\text { extensional structures and } \\
\text { volcanic flows inferred to } \\
\text { be associated with the } \\
\text { formation of a corona-like } \\
\text { feature }\left(18.6^{\circ} \mathrm{E}, 15.2^{\circ} \mathrm{S}\right) \text {. }\end{array}$ & $\begin{array}{l}\text { Uncertain relationships with } \\
\text { surrounding features. } \\
\text { Structures are embayed by } \\
\text { ps1, but flow lobes overly } \\
\text { ps1 and pr3. }\end{array}$ & $\begin{array}{c}\text { Corona-Like } \\
\text { Feature }\left(18.6^{\circ}\right. \\
\left.\mathrm{E}, 15.2^{\circ} \mathrm{S}\right)\end{array}$ \\
\hline
\end{tabular}

\section{PLAINS MATERIAL}

\begin{tabular}{|c|c|c|c|c|c|c|}
\hline ps & $\begin{array}{c}\text { Smooth Plains } \\
\text { Material }\end{array}$ & & & $\begin{array}{c}\text { Smooth plains material of } \\
\text { unknown origin. }\end{array}$ & - & - \\
\hline ps 1 & Unit 1 & $\begin{array}{l}17.4^{\circ} \mathrm{E} \\
6.2^{\circ} \mathrm{S}\end{array}$ & $\begin{array}{l}\text { Moderately dark } \\
\text { radar backscatter } \\
\text { with dark patches. }\end{array}$ & $*$ & $\begin{array}{c}\text { Embays or partially embays } \\
\text { GFL1/bf1, GFC2, GFC3, } \\
\text { GFR3, GFC4, GFL4/bf3, } \\
\text { GFC6a, GFL5, GFL7. } \\
\text { Overlies pr3, pr4, pf1, pf3, } \\
\text { and pi7. Cross-cut by GFR4 } \\
\text { and WRL1. Overlain by pi3, } \\
\text { vf1, cmK2, fu7, fd (all), } \\
\text { fDR2. Uncertain relationship } \\
\text { with pi1. }\end{array}$ & - \\
\hline ps2 & Unit 2 & $\begin{array}{l}1.1^{\circ} \mathrm{E} \\
3.0^{\circ} \mathrm{S}\end{array}$ & $\begin{array}{l}\text { Moderately dark } \\
\text { radar backscatter. }\end{array}$ & $*$ & $\begin{array}{c}\text { Partially embays GFL1/bf1. } \\
\text { Cross-cut by WRL1. } \\
\text { Overlain by } \mathbf{c m H} \text {. }\end{array}$ & - \\
\hline ps3 & Unit 3 & $\begin{array}{l}1.3^{\circ} \mathrm{E} \\
12.7^{\circ} \mathrm{S}\end{array}$ & $\begin{array}{l}\text { Dark radar } \\
\text { backscatter. }\end{array}$ & $*$ & $\begin{array}{l}\text { Embays or partially embays } \\
\text { GFL1/bf1. Uncertain } \\
\text { relationship with pi5. }\end{array}$ & - \\
\hline ps4 & Unit 4 & $\begin{array}{l}14.9^{\circ} \mathrm{E} \\
2.0^{\circ} \mathrm{S}\end{array}$ & $\begin{array}{c}\text { Dark radar } \\
\text { backscatter with } \\
\text { intermediate patches. }\end{array}$ & $\begin{array}{l}\text { Possibly associated with a } \\
\text { volcanic edifice } \sim 30 \mathrm{~km} \\
\text { in diameter }\left(15.6^{\circ} \mathrm{E}, 1.9^{\circ}\right. \\
\mathrm{S}) .\end{array}$ & $\begin{array}{l}\text { Overlies pr3. Cross-cut by } \\
\text { WRL1. Overlain by fu4. }\end{array}$ & $\begin{array}{c}\text { Volcanic } \\
\text { Edifice }\left(15.6^{\circ}\right. \\
\left.\text { E, } 1.9^{\circ} \mathrm{S}\right) ?\end{array}$ \\
\hline
\end{tabular}




\begin{tabular}{|c|c|c|c|c|c|c|}
\hline ps5 & Unit 5 & $\begin{array}{l}0.1^{\circ} \mathrm{E} \\
1.5^{\circ} \mathrm{S}\end{array}$ & $\begin{array}{l}\text { Dark radar } \\
\text { backscatter. }\end{array}$ & * & $\begin{array}{l}\text { Embays GFL1. Overlies } \\
\text { cmH and ps2. Cross-cut by } \\
\text { WRL1. }\end{array}$ & - \\
\hline ps6 & Unit 6 & $\begin{array}{l}12.6^{\circ} \mathrm{E} \\
24.2^{\circ} \mathrm{S}\end{array}$ & $\begin{array}{l}\text { Moderately dark to } \\
\text { dark radar } \\
\text { backscatter. }\end{array}$ & $*$ & $\begin{array}{l}\text { Cross-cut by GFR4 and } \\
\text { WRL2. Overlain by fu1. } \\
\text { Uncertain relationship with } \\
\text { pi1. }\end{array}$ & - \\
\hline ps 7 & Unit 7 & $\begin{array}{c}29.2^{\circ} \mathrm{E} \\
6.4^{\circ} \mathrm{S}\end{array}$ & $\begin{array}{l}\text { Moderately dark to } \\
\text { dark radar } \\
\text { backscatter. }\end{array}$ & $*$ & $\begin{array}{l}\text { Cross-cut by GFC8, GFR6, } \\
\text { WRC1, WRR1, and WRL1. } \\
\text { Overlain by pr4 and pr10. }\end{array}$ & - \\
\hline pi & $\begin{array}{c}\text { Intermediate Plains } \\
\text { Material }\end{array}$ & - & - & $\begin{array}{c}\text { Plains material of } \\
\text { unknown origin; mostly } \\
\text { of intermediate } \\
\text { backscatter. }\end{array}$ & 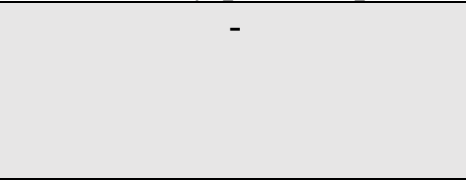 & - \\
\hline pil & Unit 1 & $\begin{array}{l}15.5^{\circ} \mathrm{E} \\
22.3^{\circ} \mathrm{S}\end{array}$ & $\begin{array}{l}\text { Intermediate radar } \\
\text { backscatter with } \\
\text { moderately dark to } \\
\text { dark patches. }\end{array}$ & $\begin{array}{c}\text { East of } 20^{\circ} \mathrm{E} \text { it contains } \\
\text { hundreds of shield } \\
\text { volcanoes. }\end{array}$ & $\begin{array}{l}\text { Embays or partially embays } \\
\text { GFL1, GFL8/bf4, } \\
\text { GFL9/bf3, GFL11/bf5. } \\
\text { Cross-cut by GFR4, WRL1 } \\
\text { and WRL2, and by some } \\
\text { structures in GFC5b. } \\
\text { Overlain by fd (all), fu1, } \\
\text { fu2, fu3, fu5, fu6, pm1, vf1, } \\
\text { vf2a, vf2b, vf3, fBF1, fBF2, } \\
\text { cmF1, and cmF2. Uncertain } \\
\text { relationship with ps1, ps6, } \\
\text { and pm2. }\end{array}$ & - \\
\hline pi2 & Unit 2 & $\begin{array}{l}5.2^{\circ} \mathrm{E} \\
2.8^{\circ} \mathrm{S}\end{array}$ & $\begin{array}{l}\text { Intermediate radar } \\
\text { backscatter with } \\
\text { moderately dark } \\
\text { patches. }\end{array}$ & $\begin{array}{c}\text { Contains some shield } \\
\text { volcanoes. }\end{array}$ & $\begin{array}{l}\text { Embays or partially embays } \\
\text { GFL1/bf1 and GFL2/bf2. } \\
\text { Cross-cut by WRL1. } \\
\text { Uncertain relationship with } \\
\text { pr1, pr2, and pf1. }\end{array}$ & - \\
\hline
\end{tabular}




\begin{tabular}{|c|c|c|c|c|c|c|}
\hline pi3 & Unit 3 & $\begin{array}{l}4.8^{\circ} \mathrm{E} \\
10.7^{\circ} \mathrm{S}\end{array}$ & $\begin{array}{l}\text { Intermediate radar } \\
\text { backscatter. }\end{array}$ & $*$ & $\begin{array}{l}\text { Embays GFL1/bf1. Overlies } \\
\text { WRL1, pi4, ps1. Overlain } \\
\text { by fDR2. }\end{array}$ & - \\
\hline pi4 & Unit 4 & $\begin{array}{l}1.2^{\circ} \mathrm{E} \\
6.7^{\circ} \mathrm{S}\end{array}$ & $\begin{array}{l}\text { Intermediate radar } \\
\text { backscatter. }\end{array}$ & * & $\begin{array}{l}\text { Embays or partially embays } \\
\text { GFL1/bf1. Cross-cut by } \\
\text { WRL1. Uncertain } \\
\text { relationship with ps1 and } \\
\text { pi3. }\end{array}$ & - \\
\hline pi5 & Unit 5 & $\begin{array}{l}0.3^{\circ} \mathrm{E} \\
12.3^{\circ} \mathrm{S}\end{array}$ & $\begin{array}{l}\text { Intermediate radar } \\
\text { backscatter. }\end{array}$ & $*$ & $\begin{array}{l}\text { Embays or partially embays } \\
\text { GFL1/bf1. Uncertain } \\
\text { relationship with ps3. }\end{array}$ & - \\
\hline pi6 & Unit 6 & $\begin{array}{l}20.6^{\circ} \mathrm{E} \\
10.4^{\circ} \mathrm{S}\end{array}$ & $\begin{array}{l}\text { Moderately bright } \\
\text { radar backscatter. }\end{array}$ & $*$ & $\begin{array}{l}\text { Partially embays GFL7 and } \\
\text { NW-SE extensional } \\
\text { structures of unknown } \\
\text { association (possibly GFL6). } \\
\text { Cross-cut by WRL1. } \\
\text { Overlain by fu5, ps1, and } \\
\text { vf1. Unknown relationship } \\
\text { with cmF3, pi7, and pi9. }\end{array}$ & - \\
\hline pi7 & Unit 7 & $\begin{array}{c}18.6^{\circ} \mathrm{E} \\
8.3^{\circ} \mathrm{S}\end{array}$ & $\begin{array}{l}\text { Intermediate to } \\
\text { moderately bright } \\
\text { radar backscatter. }\end{array}$ & $*$ & $\begin{array}{l}\text { Partially embays structures } \\
\text { in GFL4. Cross-cut by } \\
\text { WRL1, WRC2, and by } \\
\text { some structures in GFC6a. } \\
\text { Overlain by ps1 and ciC. } \\
\text { Uncertain relationship with } \\
\text { cfC, pi6 and pr4. }\end{array}$ & - \\
\hline pi8 & Unit 8 & $\begin{array}{l}24.1^{\circ} \mathrm{E} \\
8.3^{\circ} \mathrm{S}\end{array}$ & $\begin{array}{l}\text { Moderately bright } \\
\text { radar backscatter. }\end{array}$ & $*$ & $\begin{array}{l}\text { Cross-cut by GFL7, WRR1 } \\
\text { and some structures in } \\
\text { GFR5. Overlain by pi9 and } \\
\text { pr4. Uncertain relationship } \\
\text { with ps7. }\end{array}$ & - \\
\hline
\end{tabular}




\begin{tabular}{|c|c|c|c|c|c|c|}
\hline pi9 & Unit 9 & $\begin{array}{l}24.4^{\circ} \mathrm{E} \\
10.6^{\circ} \mathrm{S}\end{array}$ & $\begin{array}{c}\text { Uniformly } \\
\text { intermediate radar } \\
\text { backscatter. }\end{array}$ & $*$ & $\begin{array}{l}\text { Embays or partially embays } \\
\text { GFR5. Overlies pi8. Cross- } \\
\text { cut by WRL1 (possibly } \\
\text { WRR1) and some structures } \\
\text { in GFL7. Uncertain } \\
\text { relationship with pr4, pi1, } \\
\text { vf2b, and cmF3. }\end{array}$ & - \\
\hline pil0 & Unit 10 & $\begin{array}{c}28.4^{\circ} \mathrm{E} \\
8.7^{\circ} \mathrm{S}\end{array}$ & $\begin{array}{l}\text { Moderately bright } \\
\text { radar backscatter. }\end{array}$ & $*$ & $\begin{array}{c}\text { Embays or partially embays } \\
\text { GFL10 and GFC8. Overlies } \\
\text { ps7. Cross-cut by WRR1 } \\
\text { and WRC1, but obscures } \\
\text { some structures in WRR1. } \\
\text { Uncertain relationship with } \\
\text { pr4. }\end{array}$ & - \\
\hline pm & $\begin{array}{l}\text { Mottled Plains } \\
\text { Material }\end{array}$ & - & - & $\begin{array}{c}\text { Plains material of } \\
\text { unknown origin; } \\
\text { characterized by a mottled } \\
\text { texture, related to } \\
\text { abundant small, } \\
\text { overlapping volcanic } \\
\text { flows. }\end{array}$ & 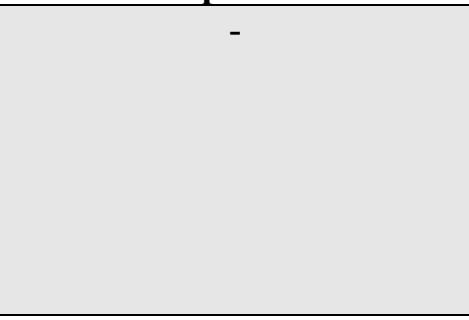 & - \\
\hline pm1 & Unit 1 & $\begin{array}{l}29.3^{\circ} \mathrm{E} \\
23.1^{\circ} \mathrm{S}\end{array}$ & $\begin{array}{l}\text { Intermediate radar } \\
\text { backscatter with } \\
\text { moderately bright to } \\
\text { moderately dark } \\
\text { patches. }\end{array}$ & $*$ & $\begin{array}{l}\text { Cross-cut by GFR4 and } \\
\text { WRL2. Uncertain } \\
\text { relationship with pi1 and } \\
\text { cmF1. }\end{array}$ & - \\
\hline $\mathrm{pm} 2$ & Unit 2 & $\begin{array}{l}19.0^{\circ} \mathrm{E} \\
23.0^{\circ} \mathrm{S}\end{array}$ & $\begin{array}{l}\text { Intermediate radar } \\
\text { backscatter with } \\
\text { moderately bright to } \\
\text { moderately dark } \\
\text { patches. }\end{array}$ & $*$ & $\begin{array}{l}\text { Embays or partially embays } \\
\text { GFL11/bf6. Cross-cut by } \\
\text { WRL2. Uncertain } \\
\text { relationship with pi1. }\end{array}$ & - \\
\hline pf & $\begin{array}{c}\text { Densely Fractured } \\
\text { Plains Material }\end{array}$ & - & - & $\begin{array}{c}\text { Plains material of } \\
\text { unknown origin; heavily }\end{array}$ & - & - \\
\hline
\end{tabular}




\begin{tabular}{|c|c|c|c|c|c|c|}
\hline & & & & $\begin{array}{c}\text { deformed by extensional } \\
\text { structures. }\end{array}$ & & \\
\hline pf1 & Unit 1 & $\begin{array}{l}11.3^{\circ} \mathrm{E} \\
0.8^{\circ} \mathrm{S}\end{array}$ & $\begin{array}{l}\text { Intermediate radar } \\
\text { backscatter. }\end{array}$ & $*$ & $\begin{array}{l}\text { Embays some structures, but } \\
\text { is also cross-cut by some } \\
\text { structures in GFL2. Cross- } \\
\text { cut by WRL1. Overlain by } \\
\text { pi2, cmK1 and cmK2. } \\
\text { Uncertain relationship with } \\
\text { pr1 and pr3. }\end{array}$ & - \\
\hline pf2 & Unit 2 & $\begin{array}{l}9.0^{\circ} \mathrm{E} \\
0.5^{\circ} \mathrm{S}\end{array}$ & $\begin{array}{l}\text { Moderately dark to } \\
\text { dark radar } \\
\text { backscatter. }\end{array}$ & $*$ & $\begin{array}{l}\text { Embays some structures, but } \\
\text { is also cross-cut by some } \\
\text { structures in GFL2. Cross- } \\
\text { cut by WRL1. }\end{array}$ & - \\
\hline pf3 & Unit 3 & $\begin{array}{l}16.6^{\circ} \mathrm{E}, \\
13.3^{\circ} \mathrm{S}\end{array}$ & $\begin{array}{c}\text { Intermediate radar } \\
\text { backscatter. }\end{array}$ & - & $\begin{array}{c}\text { Embays or partially embays } \\
\text { GFL4/bf3. Cross-cut by } \\
\text { WRL1. Overlain by vf1 and } \\
\text { ps1. }\end{array}$ & \\
\hline pr & $\begin{array}{l}\text { Ridged Plains } \\
\text { Material }\end{array}$ & - & - & $\begin{array}{c}\text { Plains material of } \\
\text { unknown origin; heavily } \\
\text { deformed by wrinkle } \\
\text { ridges. }\end{array}$ & - & - \\
\hline pr1 & Unit 1 & $\begin{array}{l}2.2^{\circ} \mathrm{E} \\
4.4^{\circ} \mathrm{S}\end{array}$ & $\begin{array}{l}\text { Intermediate radar } \\
\text { backscatter with } \\
\text { moderately dark to } \\
\text { dark patches. }\end{array}$ & $*$ & $\begin{array}{l}\text { Contains/defined by } \\
\text { structures in WRL1. } \\
\text { Embays.or partially embays } \\
\text { GFL1/bf1. Uncertain } \\
\text { relationship with pi2, pf1, } \\
\text { pf2, ps1 and ps2. }\end{array}$ & - \\
\hline pr2 & Unit 2 & $\begin{array}{l}5.6^{\circ} \mathrm{E} \\
4.5^{\circ} \mathrm{S}\end{array}$ & $\begin{array}{l}\text { Bright radar } \\
\text { backscatter. }\end{array}$ & $*$ & $\begin{array}{l}\text { Contains/defined by } \\
\text { structures in WRL1. } \\
\text { Overlain by ps1.Uncertain } \\
\text { relationship with pi2 and } \\
\text { pr3. }\end{array}$ & - \\
\hline
\end{tabular}




\begin{tabular}{|c|c|c|c|c|c|c|}
\hline pr3 & Unit 3 & $\begin{array}{c}14.7^{\circ} \mathrm{E} \\
0.9^{\circ} \mathrm{S}\end{array}$ & $\begin{array}{l}\text { Intermediate to } \\
\text { moderately bright } \\
\text { radar backscatter. }\end{array}$ & $*$ & $\begin{array}{c}\text { Contains/defined by } \\
\text { structures in WRL1. Embays } \\
\text { or partially embays GFL2, } \\
\text { GFC2/cfK and GFR2/cfK. } \\
\text { Overlain by ps1, ps4, cmK1, } \\
\text { cmK2, and cl. Uncertain } \\
\text { relationship with pf1 and } \\
\text { ciK. }\end{array}$ & - \\
\hline pr4 & Unit 4 & $\begin{array}{c}28.6^{\circ} \mathrm{E} \\
2.5^{\circ} \mathrm{S}\end{array}$ & $\begin{array}{l}\text { Intermediate radar } \\
\text { backscatter with } \\
\text { moderately dark } \\
\text { patches. }\end{array}$ & $*$ & $\begin{array}{c}\text { Contains/defined by } \\
\text { structures in WRL1. Embays } \\
\text { structures in GFC6a, GFR5 } \\
\text { and GFL10/bf6. Overlies } \\
\text { pi7 and pi8. Cross-cut by } \\
\text { GFL7, WRC1, and WRR1, } \\
\text { and some structures in GFC8 } \\
\text { and GFR6. Overlain by ps1, } \\
\text { vf2b and ciC. Uncertain } \\
\text { relationship with ps7 and } \\
\text { pi10. }\end{array}$ & - \\
\hline pt & $\begin{array}{c}\text { Intratessera Plains } \\
\text { Material }\end{array}$ & $\begin{array}{l}4.1^{\circ} \mathrm{E} \\
20.6^{\circ} \mathrm{S}\end{array}$ & $\begin{array}{l}\text { Intermediate to } \\
\text { moderately dark } \\
\text { radar backscatter. }\end{array}$ & $\begin{array}{c}\text { Plains material of } \\
\text { unknown origin; located } \\
\text { within topographic lows } \\
\text { of tessera terrain }(\mathbf{t t}) \text {. }\end{array}$ & $\begin{array}{c}\text { Embays tt and associated } \\
\text { structures. }\end{array}$ & $\begin{array}{c}\text { Tessera } \\
\text { Terrain }(\mathbf{t t})\end{array}$ \\
\hline
\end{tabular}

\section{STRUCTURAL TERRAINS}

\begin{tabular}{|l|c|c|c|c|c|}
\hline bf & Fracture Belts & - & - & $\begin{array}{c}\text { Material of unknown } \\
\text { origin; intensely deformed } \\
\text { by extensional structures } \\
\text { of similar orientation. } \\
\text { Preserved in regions of } \\
\text { elevated topography. }\end{array}$ & - \\
\hline
\end{tabular}




\begin{tabular}{|c|c|c|c|c|c|c|}
\hline bf1 & Unit 1 & $\begin{array}{l}0.9^{\circ} \mathrm{E} \\
9.8^{\circ} \mathrm{S}\end{array}$ & $\begin{array}{l}\text { Intermediate radar } \\
\text { backscatter. }\end{array}$ & $\begin{array}{c}\text { Defined by/associated } \\
\text { with GFL1. }\end{array}$ & $\begin{array}{l}\text { Structures in GFL1 are } \\
\text { mostly embayed or partially } \\
\text { embayed by surrounding } \\
\text { units, except for tt. Overlain } \\
\text { by surrounding units, except } \\
\text { for tt. }\end{array}$ & $\begin{array}{l}\text { GFL1, Dewi- } \\
\text { Ratih Chasma }\end{array}$ \\
\hline bf2 & Unit 2 & $\begin{array}{l}7.8^{\circ} \mathrm{E} \\
2.2^{\circ} \mathrm{S}\end{array}$ & $\begin{array}{l}\text { Intermediate radar } \\
\text { backscatter. }\end{array}$ & $\begin{array}{c}\text { Defined by/associated } \\
\text { with GFL2. }\end{array}$ & $\begin{array}{l}\text { Structures in GFL2 are } \\
\text { embayed or partially } \\
\text { embayed by cmK1, pi2, and } \\
\text { pr3. Structures are embayed } \\
\text { by, but also cross-cut, pf1 } \\
\text { and pf } 2 \text {. Structures cross-cut } \\
\text { cmK2 and GFC2. }\end{array}$ & GFL2 \\
\hline bf3 & Unit 3 & $\begin{array}{l}14.8^{\circ} \mathrm{E} \\
9.8^{\circ} \mathrm{S}\end{array}$ & $\begin{array}{l}\text { Intermediate radar } \\
\text { backscatter. }\end{array}$ & $\begin{array}{c}\text { Defined by/associated } \\
\text { with GFL4. }\end{array}$ & $\begin{array}{l}\text { Structures in GFL4 are } \\
\text { embayed or partially } \\
\text { embayed by vf1, ps1, pi7, } \\
\text { and pf3. Structures cross-cut } \\
\text { GFC4 (in cfT). }\end{array}$ & GFL4 \\
\hline bf4 & Unit 4 & $\begin{array}{l}20.8^{\circ} \mathrm{E} \\
13.4^{\circ} \mathrm{S}\end{array}$ & $\begin{array}{l}\text { Intermediate radar } \\
\text { backscatter. }\end{array}$ & $\begin{array}{c}\text { Defined by/associated } \\
\text { with GFL8. }\end{array}$ & $\begin{array}{l}\text { Structures in GFL8 are } \\
\text { embayed by vf2a, cmF2, } \\
\text { cmF3, and pi1. }\end{array}$ & GFL8 \\
\hline bf5 & Unit 5 & $\begin{array}{l}27.7^{\circ} \mathrm{E} \\
22.6^{\circ} \mathrm{S}\end{array}$ & $\begin{array}{l}\text { Intermediate radar } \\
\text { backscatter. }\end{array}$ & $\begin{array}{c}\text { Defined by/associated } \\
\text { with GFL11. }\end{array}$ & $\begin{array}{l}\text { Structures in GFL11 are } \\
\text { embayed by pi1 and pm2. }\end{array}$ & GFL11 \\
\hline bf6 & Unit 6 & $\begin{array}{l}29.5^{\circ} \mathrm{E} \\
11.0^{\circ} \mathrm{S}\end{array}$ & $\begin{array}{l}\text { Intermediate radar } \\
\text { backscatter. }\end{array}$ & $\begin{array}{c}\text { Defined by/associated } \\
\text { with GFL10. }\end{array}$ & $\begin{array}{l}\text { Structures in GFL10 are } \\
\text { embayed by vf3, pi10, pr4. }\end{array}$ & GFL10 \\
\hline
\end{tabular}

TESSERA TERRAIN

\begin{tabular}{|c|c|c|c|c|c|c|}
\hline $\mathbf{t m}$ & $\begin{array}{c}\text { Tessera Margin } \\
\text { Material }\end{array}$ & $\begin{array}{c}7.7^{\circ} \mathrm{E}, \\
14.7^{\circ} \mathrm{S}\end{array}$ & $\begin{array}{c}\text { Intermediate to } \\
\text { bright radar } \\
\text { backscatter. }\end{array}$ & $\begin{array}{c}\text { Concentrated along the } \\
\text { margins of tt. Contains } \\
\text { structures that extend into }\end{array}$ & $\begin{array}{c}\text { Structures are embayed by } \\
\text { surrounding units. }\end{array}$ & $\begin{array}{c}\text { Tessera } \\
\text { Terrain }(\mathbf{t t})\end{array}$ \\
\hline
\end{tabular}




\begin{tabular}{|l|c|c|c|c|c|}
\hline & & & $\begin{array}{c}\text { tt. Interpreted to represent } \\
\text { the margins of tt that have } \\
\text { been embayed or overlain } \\
\text { by younger units. }\end{array}$ & \\
\hline tt & Tessera Terrain & $1.5^{\circ} \mathrm{E}$, & $\begin{array}{c}\text { Exteremely bright } \\
\text { radar backscatter. }\end{array}$ & $\begin{array}{c}\text { Highly deformed material } \\
\text { containing abundant } \\
\text { extensional and } \\
\text { compressional structures } \\
\text { of various orientations. } \\
\text { Typically only prevalent } \\
\text { in regions of elevated } \\
\text { topography. Interpreted to } \\
\text { represent intensely } \\
\text { deformed, regional } \\
\text { basement material. }\end{array}$ & $\begin{array}{c}\text { Embayed and cross-cut by all } \\
\text { surrounding units and } \\
\text { structures. }\end{array}$ \\
\hline
\end{tabular}

\section{IMPACT MATERIAL}

\begin{tabular}{|c|c|c|c|c|c|c|}
\hline im & $\begin{array}{l}\text { Impact Crater } \\
\text { Material }\end{array}$ & $\begin{array}{l}16.3^{\circ} \mathrm{E} \\
4.3^{\circ} \mathrm{S}\end{array}$ & $\begin{array}{c}\text { Extremely bright to } \\
\text { dark radar } \\
\text { backscatter. }\end{array}$ & $\begin{array}{l}\text { Ejecta and impact melt } \\
\text { flows with lobate } \\
\text { margins. Crater floors } \\
\text { vary in brightness, and } \\
\text { may be bright or dark. } \\
\text { The rims, walls, and } \\
\text { central peaks of craters } \\
\text { have a rubbly appearance. } \\
\text { Materials that are } \\
\text { interpreted to form as a } \\
\text { result of meteorite } \\
\text { impacts. }\end{array}$ & $\begin{array}{l}\text { Varies, typically overlies } \\
\text { adjacent units and structures. }\end{array}$ & Impact Craters \\
\hline ih & Impact Crater Halo & $\begin{array}{l}15.2^{\circ} \mathrm{E} \\
14.4^{\circ} \mathrm{S}\end{array}$ & $\begin{array}{l}\text { Dark radar } \\
\text { backscatter. }\end{array}$ & $\begin{array}{c}\text { Typically have a } \\
\text { parabolic or "butterfly" } \\
\text { shape. Interpreted to form }\end{array}$ & $\begin{array}{l}\text { Uncertain, thought to overly } \\
\text { adjacent units and structures. }\end{array}$ & Impact Craters \\
\hline
\end{tabular}




\begin{tabular}{|l|l|l|l|l|l|}
\hline & & & $\begin{array}{c}\text { from thin deposits of fine- } \\
\text { grained ejecta airfall. }\end{array}$ & \\
\hline
\end{tabular}

Footnotes:

* denotes a sub-unit that has the same characteristics as the description for the major unit. 


\subsection{Figures}

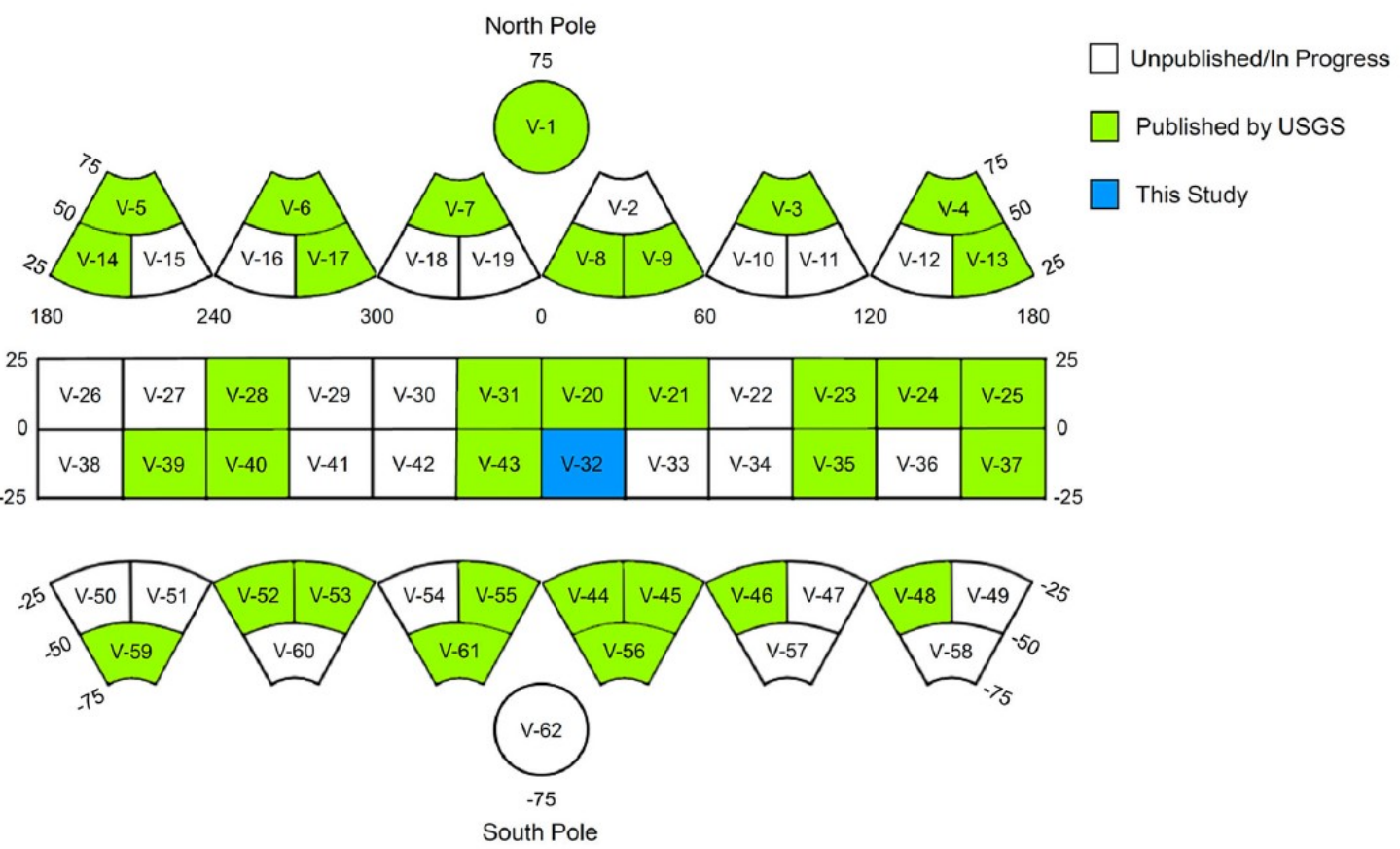

Figure 2.1: Geological mapping status of 1:5 million scale Venus quadrangles (as of March 2021). Modified after schematic from the International Astronomical Union (IAU)/USGS/NASA. 

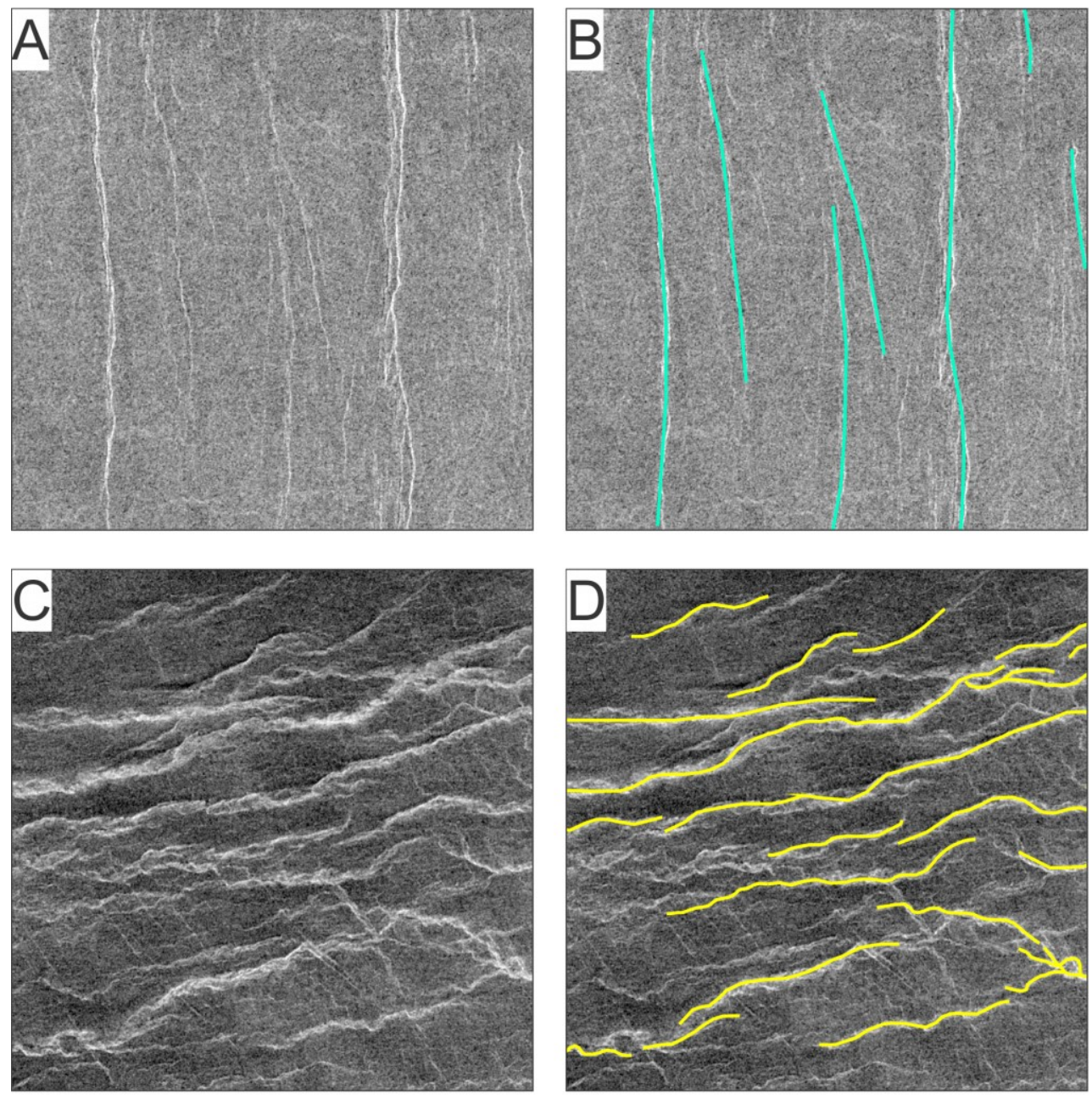

\section{$10 \mathrm{~km}$}

Figure 2.2: Examples of SAR images (left) and superimposed mapping (right) of the two main types of linear features, extensional structures $(A, B$; image centred on $\left.19.1^{\circ} \mathrm{E}, 20.4^{\circ} \mathrm{S}\right)$ and wrinkle ridges (C,D; image centred on $16.0^{\circ} \mathrm{E}, 2.0^{\circ} \mathrm{S}$ ). 
A.i)

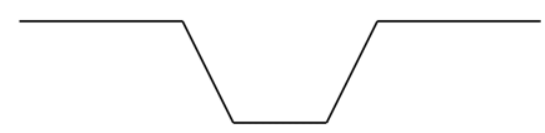

Graben

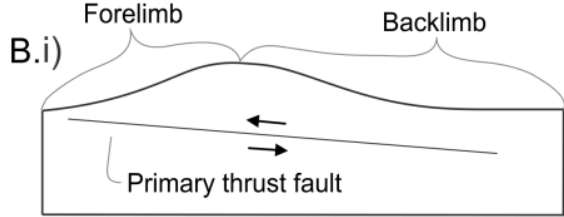

Primary fold ii)

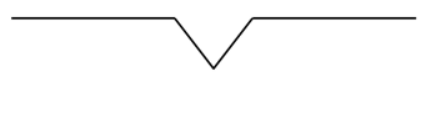

Fissure

Fracture

iii)

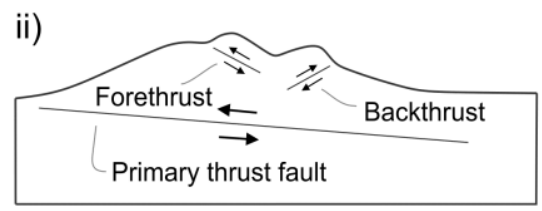

Primary and secondary folds

Figure 2.3: Schematic cross-sections of the interpreted geometries of structures mapped in this study. A) Geometries of extensional structures, modified after Grosfils and Head (1994b): i) graben, ii) fissure, and iii) fracture. B) Hypothetical geometries of wrinkle ridges interpreted to represent anticlines and thrust faults, modified after Okubo and Schultz (2004): i) primary thrust, and ii) secondary forethrusts and backthrusts. 


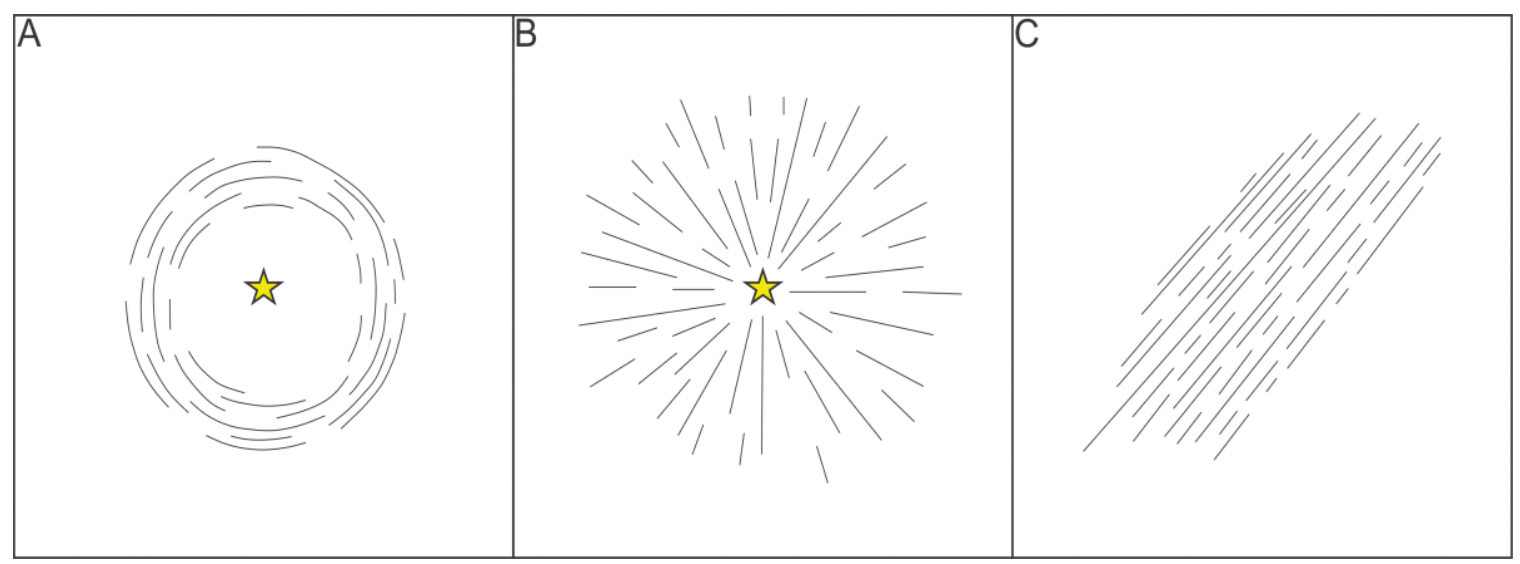

Figure 2.4: Examples of the three geometry classes for structural systems: A) circumferential about a focal point (yellow star), B) radiating from a focal point (yellow star), and C) linear. 


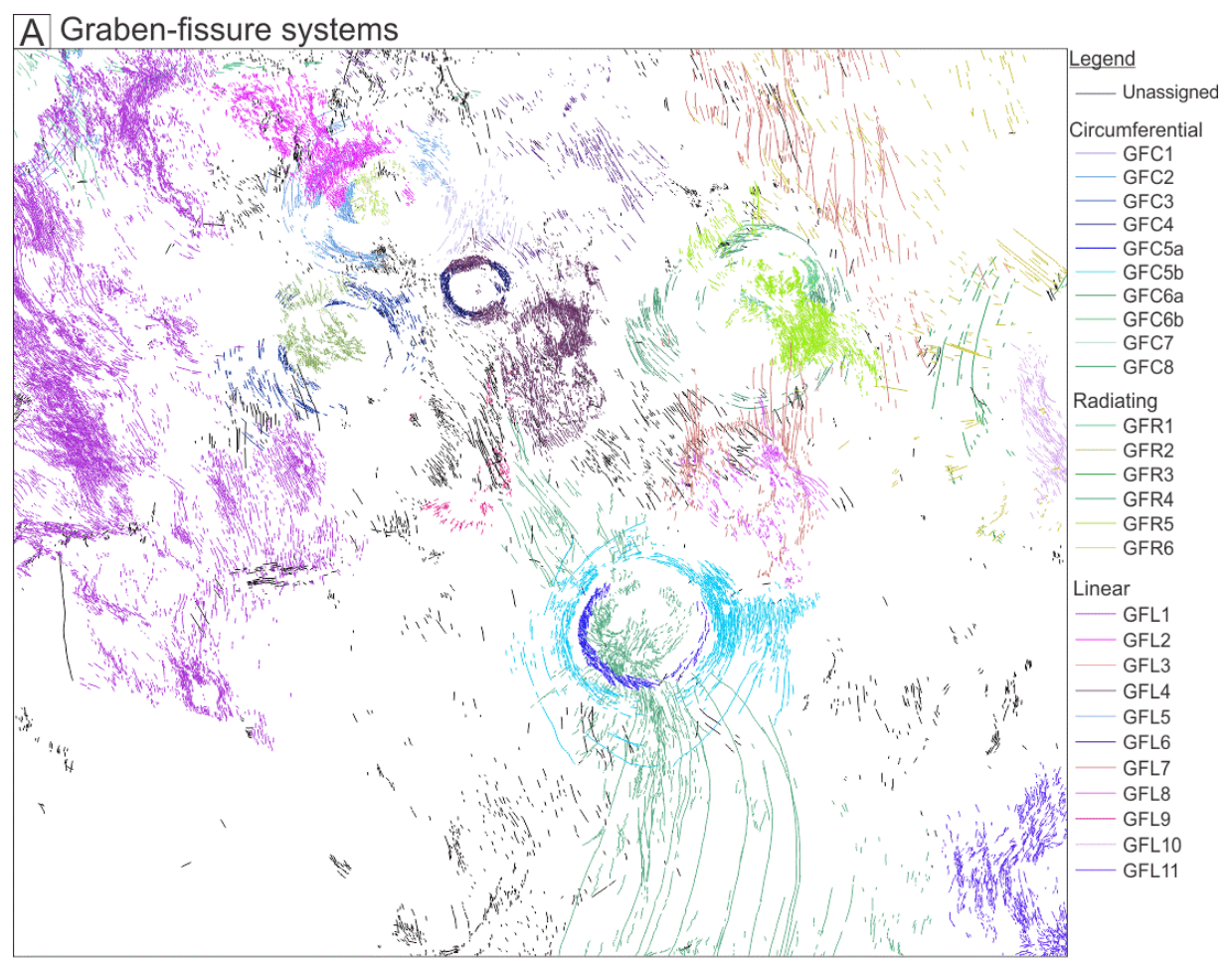

$500 \mathrm{~km}$

B Wrinkle ridge systems

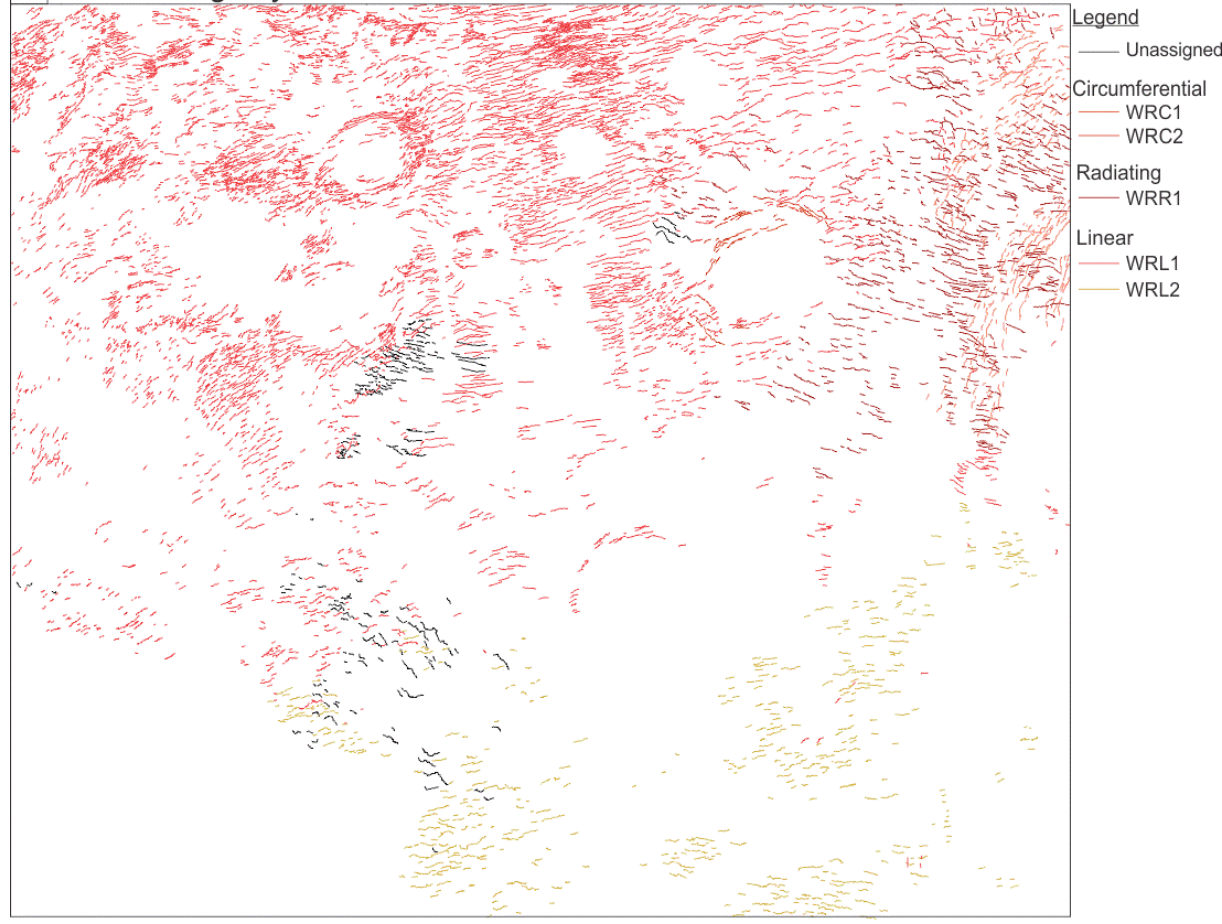

$500 \mathrm{~km}$

Figure 2.5: Map showing each structural system (represented by different colours) in the V-32 quadrangle: A) graben-fissure systems, and B) wrinkle ridges. 

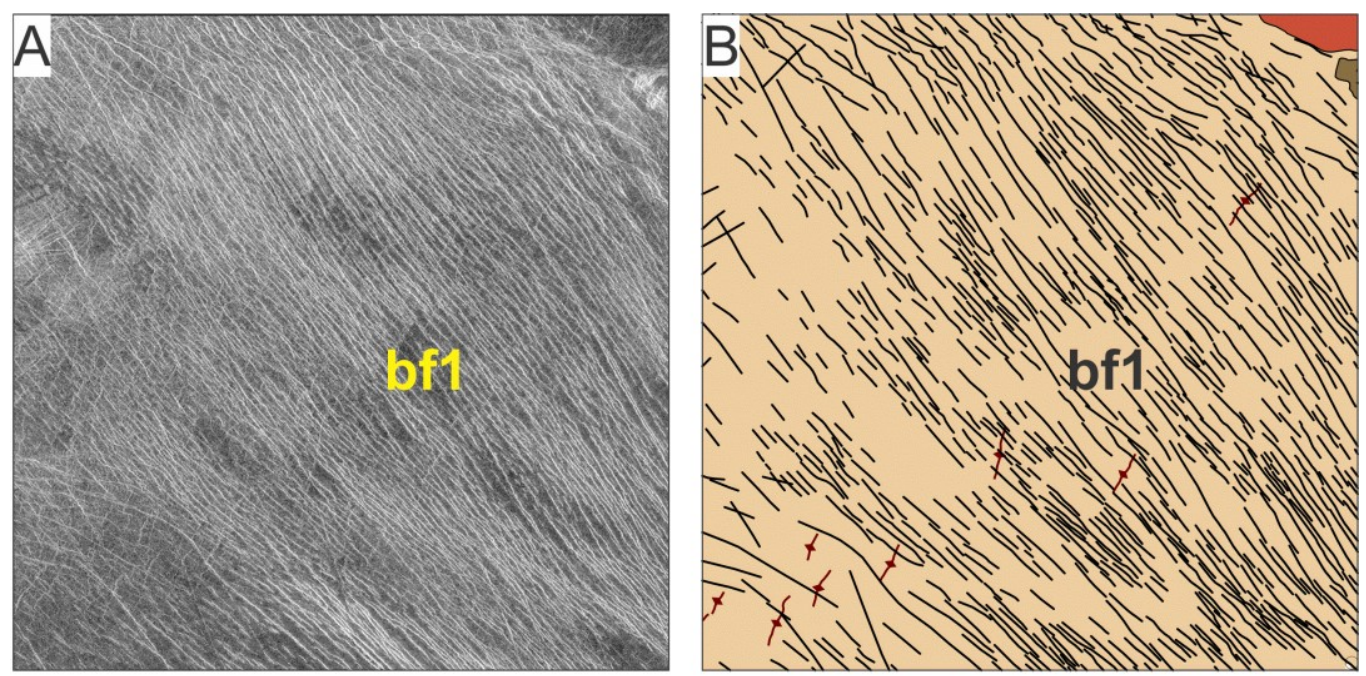

$50 \mathrm{~km}$
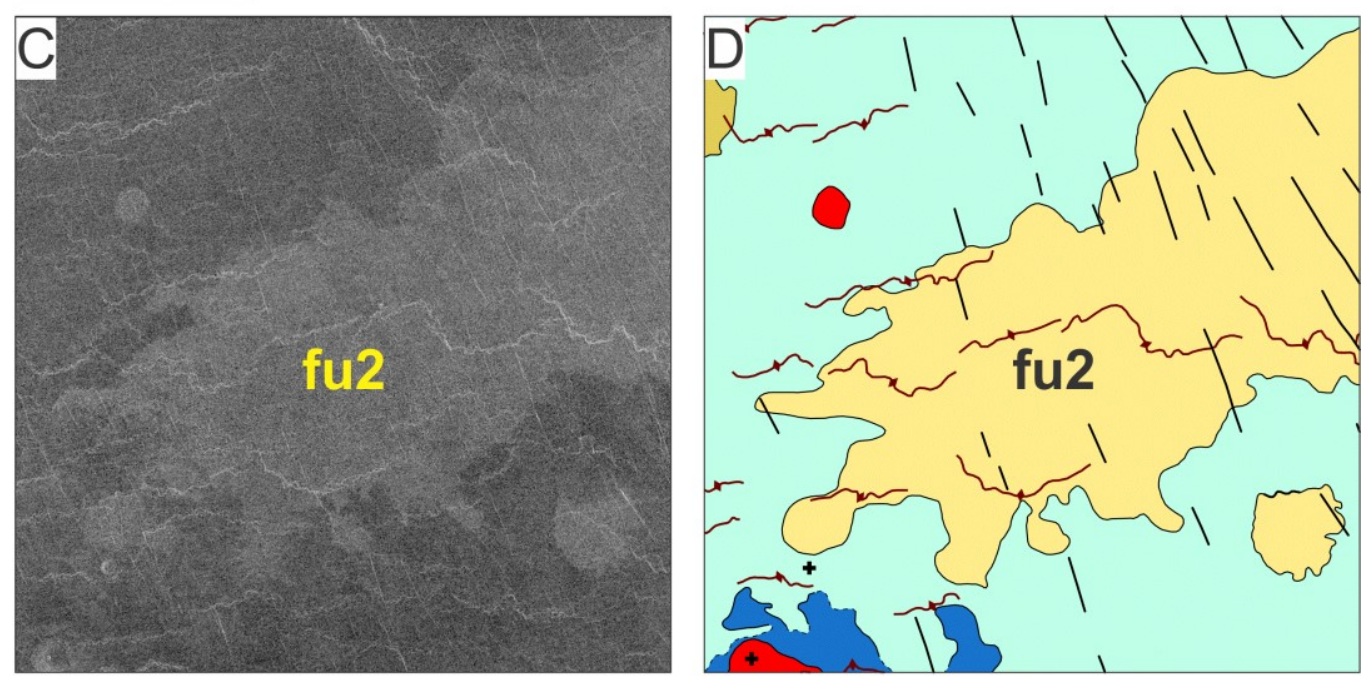

$50 \mathrm{~km}$
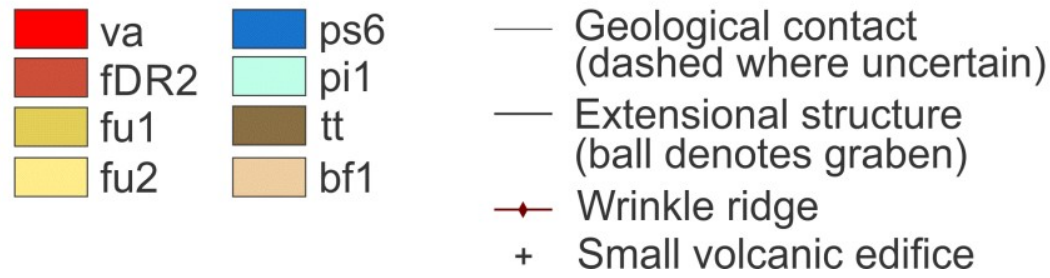

Figure 2.6: Left-looking SAR images and corresponding geological maps of examples of the types of geological units: lithodemic $(A, B)$ and material $(C, D)$. A) Fracture Belt Unit 1 (bf1; centred at $10.2^{\circ} \mathrm{S}, 1.2^{\circ} \mathrm{E}$ ), a lithodemic unit; B) geological map corresponding to A; C) Unsourced Flow Material Unit 2 (fu2; centred at $21.6^{\circ} \mathrm{S}, 13.6^{\circ} \mathrm{E}$ ), a material unit; and D) geological map corresponding to $\mathrm{C}$. 


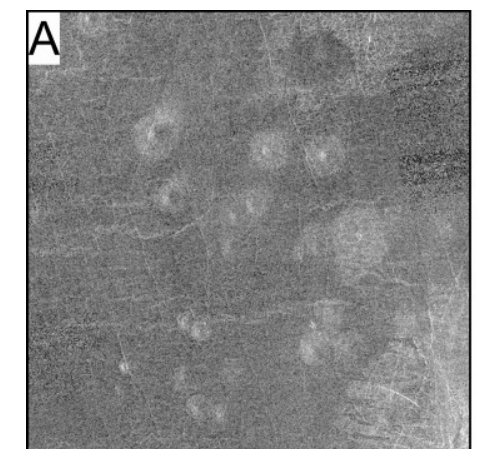

$10 \mathrm{~km}$

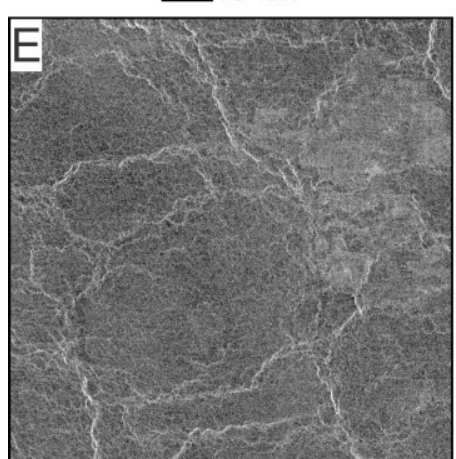

10 km

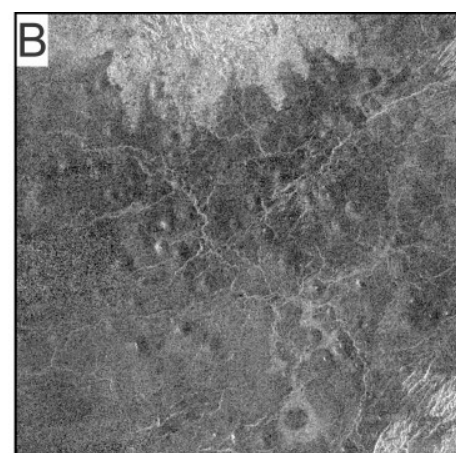

$\square 10 \mathrm{~km}$

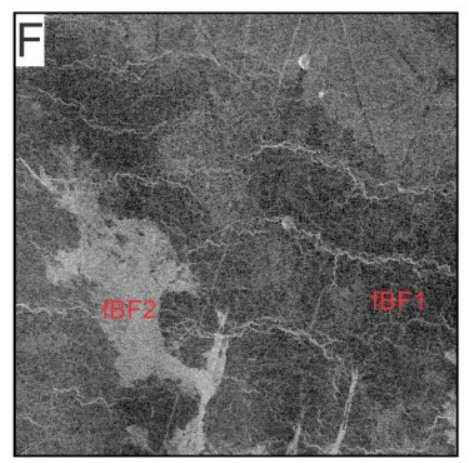

$10 \mathrm{~km}$

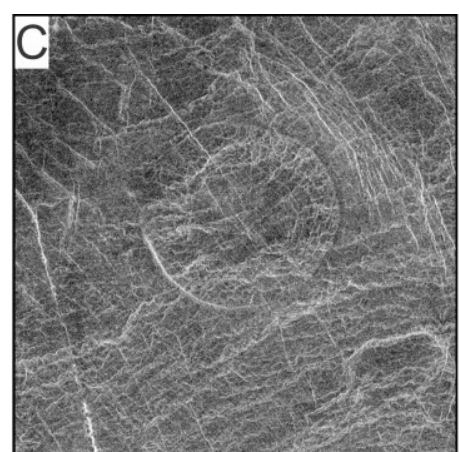

10 km

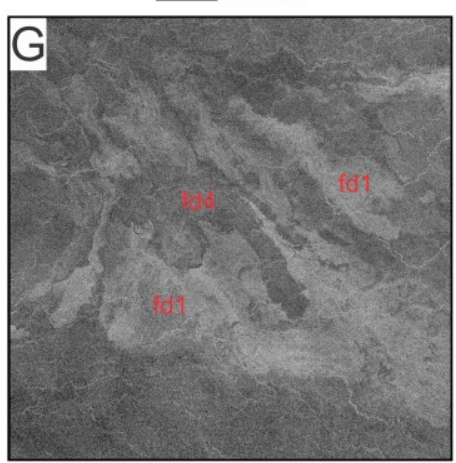

$25 \mathrm{~km}$

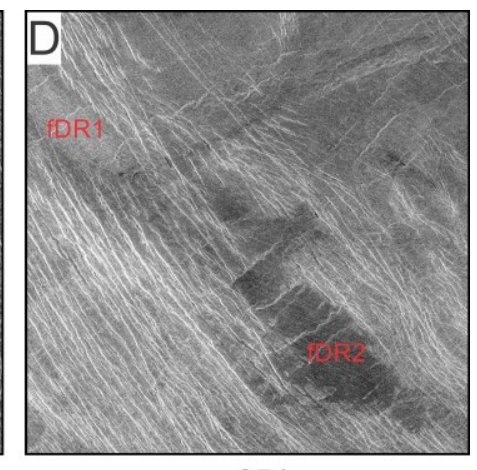

$25 \mathrm{~km}$

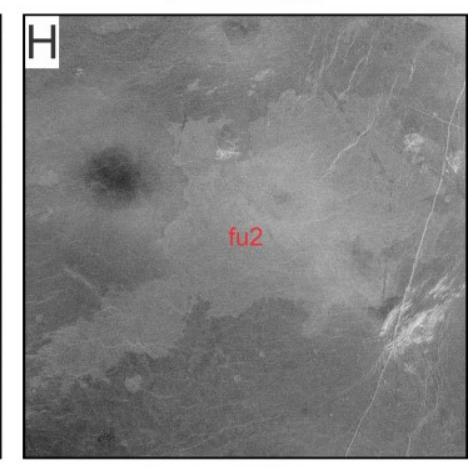

100 km

Figure 2.7: Left-looking SAR images of examples of the major geological units within the category 'Volcanic Edifice and Flow Materials'. A) Shield Volcano Apron Material (va; image centred on $25.7^{\circ} \mathrm{E}, 19.0^{\circ} \mathrm{S}$ ); B) Shield Volcano Field (vf; image centred on $29.7^{\circ} \mathrm{E}, 15.2^{\circ} \mathrm{S}$ ); C) Steep-Sided Dome Material (sd; image centred on 9.8 $\mathrm{E}, 0.9^{\circ} \mathrm{S}$ ); D) Dewi-Ratih Chasma Material (fDR; image centred on $0.9^{\circ} \mathrm{E}, 7.8^{\circ} \mathrm{S}$ ); E) Dzalarhons Mons Flow Material (fDM; image centred on $29.6^{\circ}$ $\mathrm{E}, 0.3^{\circ} \mathrm{S}$ ); F) Brynhild Fossae Flow Material (fBF; image centred on $22.9^{\circ} \mathrm{E}, 24.7^{\circ} \mathrm{S}$ ); G) Digitate Flow Material (fd; image centred on $9.4^{\circ} \mathrm{E}, 17.5^{\circ} \mathrm{S}$ ); and $\mathrm{H}$ ) Unsourced Flow Material (fu; image centred on $15.0^{\circ} \mathrm{E}, 20.6^{\circ} \mathrm{S}$ ). 


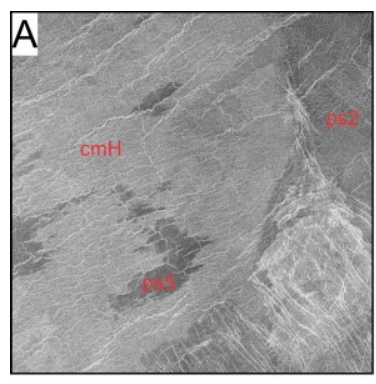

$20 \mathrm{~km}$

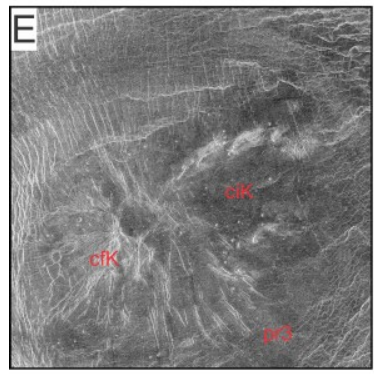

$25 \mathrm{~km}$

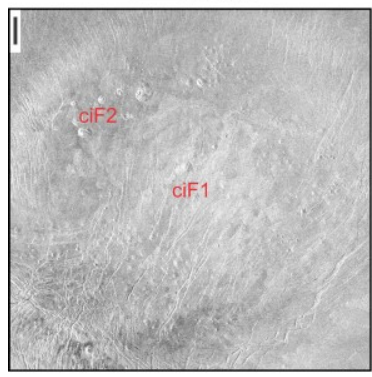

30 km

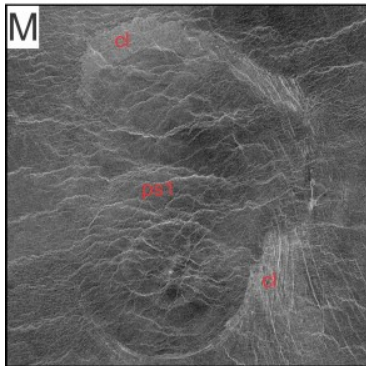

$30 \mathrm{~km}$

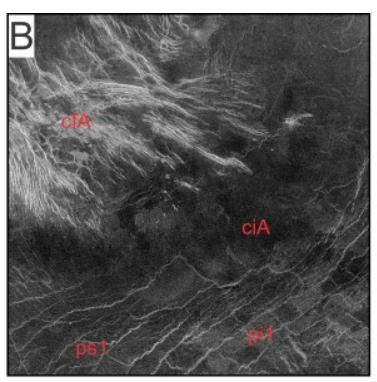

$30 \mathrm{~km}$

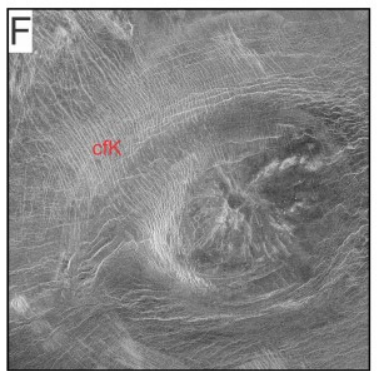

50 km

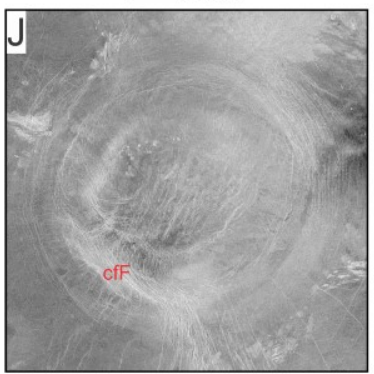

90 km

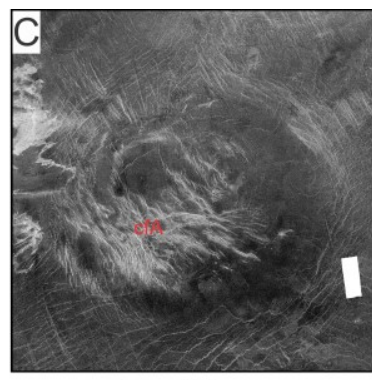

$70 \mathrm{~km}$

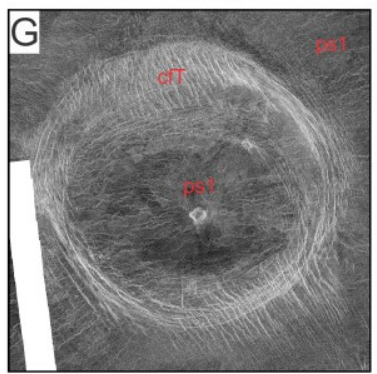

30 km

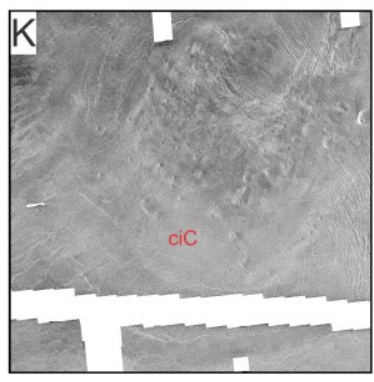

50 km

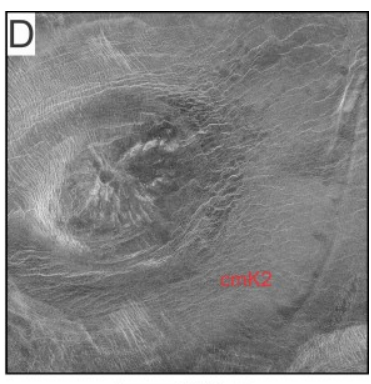

$70 \mathrm{~km}$

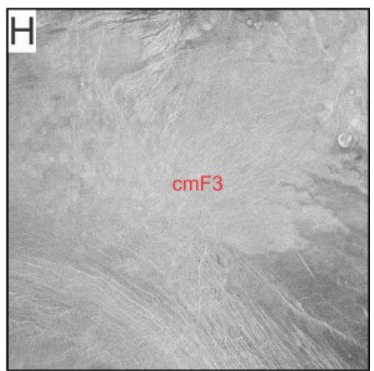

$30 \mathrm{~km}$

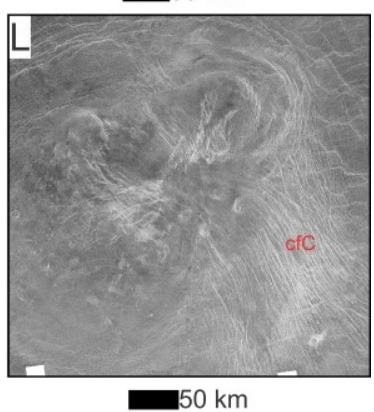

Figure 2.8: Left-looking SAR images of examples of the major geological units within the category 'Corona Material'. A) Heng-O Corona Flow Material $(\mathrm{cmH}$; image centred on $0.6^{\circ} \mathrm{E}, 1.1^{\circ} \mathrm{S}$ ); B) Atargatis Corona Interior Material (ciA; image centred on $9.5^{\circ} \mathrm{E}, 8.8^{\circ} \mathrm{S}$ ); C) Atargatis Corona Fractured Material (cfA; image centred on $\left.9.2^{\circ} \mathrm{E}, 8.1^{\circ} \mathrm{S}\right)$; D) Kuan-Yin Corona Flow Material (cmK; image centred on $11.2^{\circ} \mathrm{E}, 4.4^{\circ} \mathrm{S}$ ); E) Kuan-Yin Corona Interior Material (ciK; image centred on $10.3^{\circ} \mathrm{E}, 4.1^{\circ} \mathrm{S}$ ); F) Kuan-Yin Corona Fractured Material (cfK; image centred on $9.8^{\circ} \mathrm{E}, 4.1^{\circ} \mathrm{S}$ ); G) Thouris Corona Fractured Material (cfT; image centred on $\left.\left.13.0^{\circ} \mathrm{E}, 6.7^{\circ} \mathrm{S}\right) ; \mathrm{H}\right)$ Fatua Corona Flow Material (cmF; image centred on $19.5^{\circ} \mathrm{E}, 14.0^{\circ} \mathrm{S}$ ); I) Fatua Corona Interior Material (ciF; image centred on $17.8^{\circ} \mathrm{E}, 16.3^{\circ} \mathrm{S}$ ); J) Fatua Corona Fractured Material (cfF; image 
centred on $18.0^{\circ} \mathrm{E}, 16.3^{\circ} \mathrm{S}$ ); K) Cybele Corona Interior Material (ciC; image centred on $20.6^{\circ} \mathrm{E}, 8.0^{\circ} \mathrm{S}$ ); L) Cybele Corona Fractured Material (cfC; image centred on $21.3^{\circ} \mathrm{E}, 7.1^{\circ} \mathrm{S}$ ); and M) Corona-Like Feature Material (ci; image centred on $18.6^{\circ} \mathrm{E}, 4.6^{\circ} \mathrm{S}$ ). 


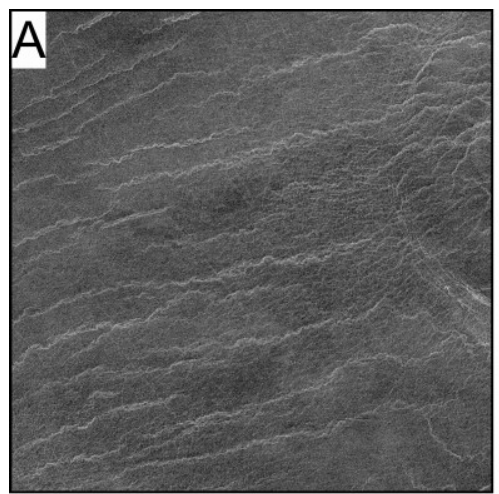

25 km

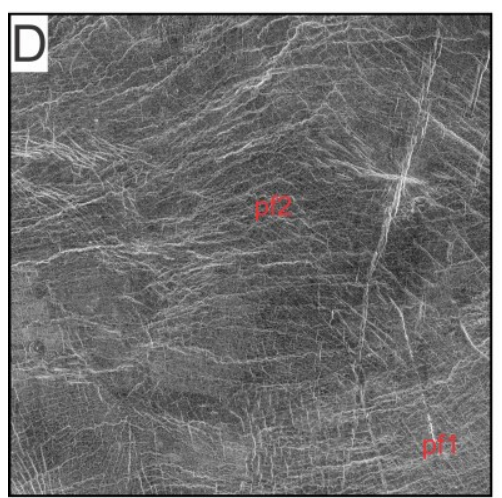

$20 \mathrm{~km}$

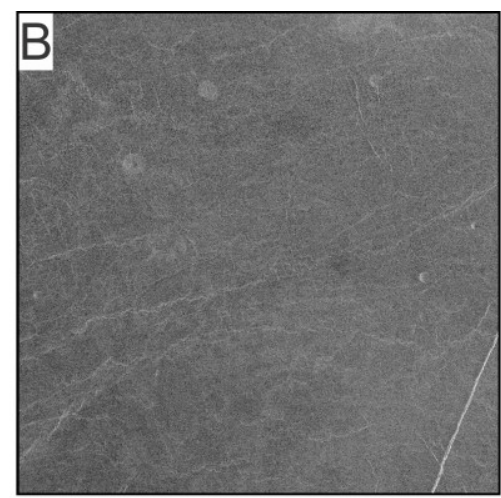

$25 \mathrm{~km}$

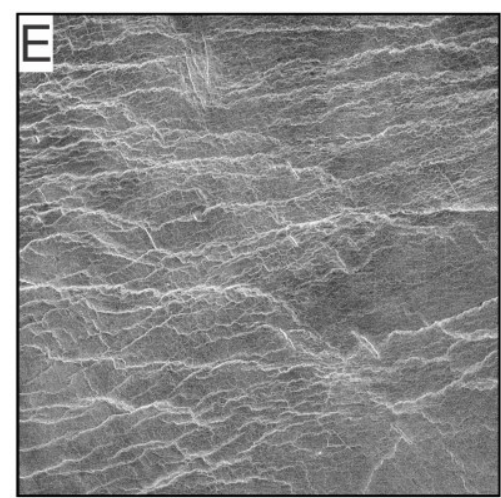

$20 \mathrm{~km}$

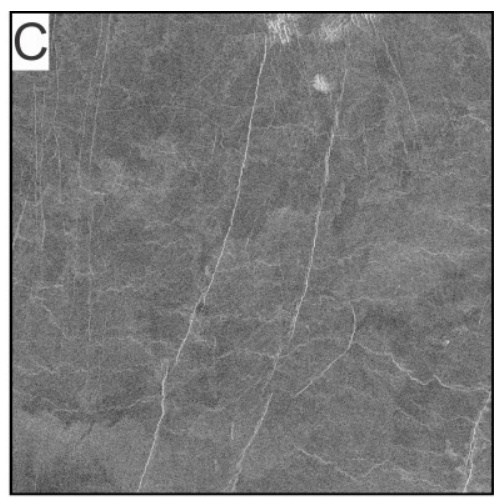

20 km

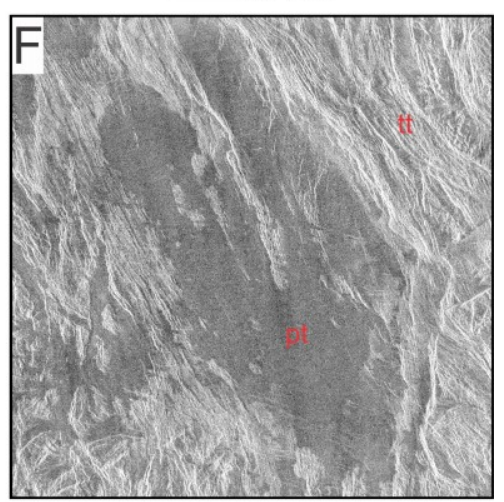

$20 \mathrm{~km}$

Figure 2.9: Left-looking SAR images of examples of the major geological units within the category 'Plains Material'. A) Smooth Plains Material (ps; image centred on $17.6^{\circ} \mathrm{E}, 5.5^{\circ} \mathrm{S}$ ); B) Intermediate Plains Material (pi; image centred on $\left.15.7^{\circ} \mathrm{E}, 22.2^{\circ} \mathrm{S}\right)$; C) Mottled Plains Material (pm; image centred on $18.5^{\circ} \mathrm{E}$, 23. $2^{\circ} \mathrm{S}$ ); D) Densely Fractured Plains Material (pf; image centred on $9.0^{\circ} \mathrm{E}, 0.6^{\circ}$ $\mathrm{S})$; E) Ridged Plains Material (pr; image centred on $17.1^{\circ} \mathrm{S}, 1.4^{\circ} \mathrm{S}$ ); and F) Intratessera Plains Material (pt; image centred on $3.9^{\circ} \mathrm{E}, 20.3^{\circ} \mathrm{S}$ ). 


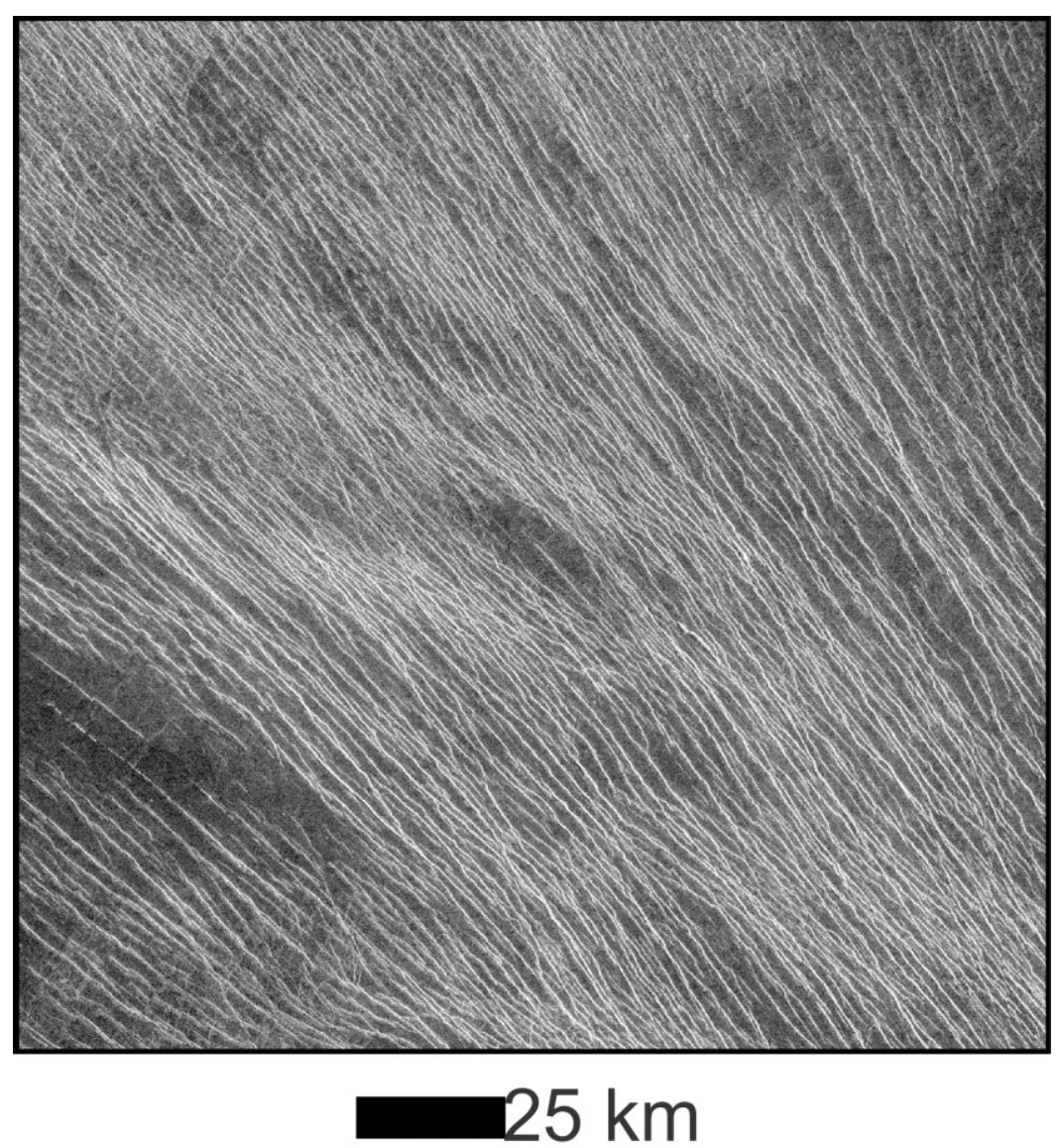

Figure 2.10: Left-looking SAR images of examples of the major geological unit (Fracture Belts) within the category 'Structural Terrains' (image centred on $1.8^{\circ}$ $\left.\mathrm{E}, 10.9^{\circ} \mathrm{S}\right)$. 


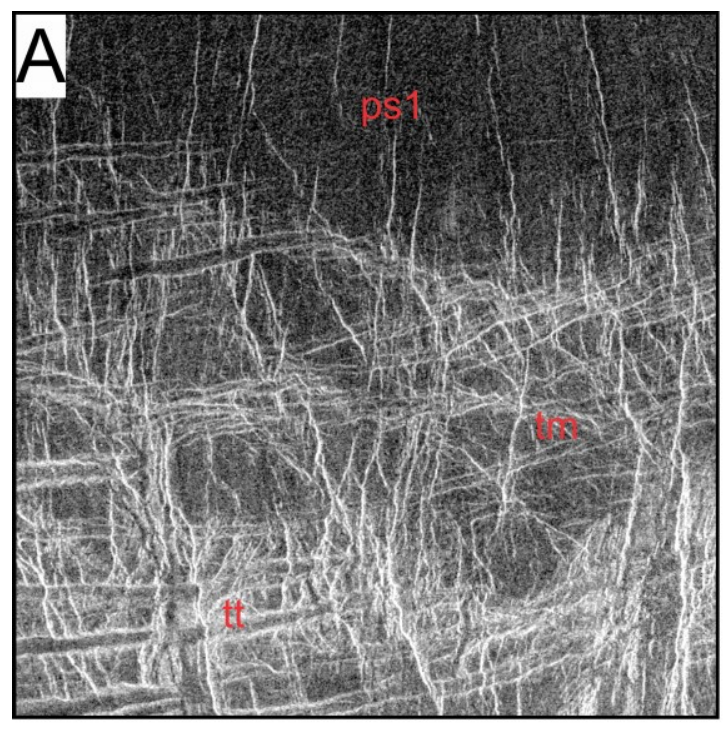

$10 \mathrm{~km}$

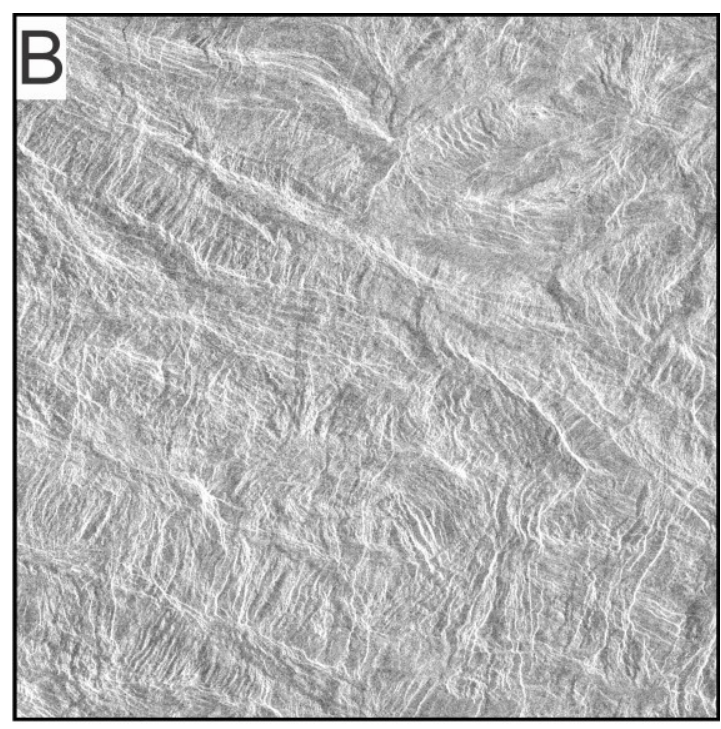

$25 \mathrm{~km}$

Figure 2.11: Left-looking SAR images of examples of the major geological units within the category 'Tessera Material'. A) Tessera Margin Material (tm; image centred on $7.6^{\circ} \mathrm{E}, 14.7^{\circ} \mathrm{S}$ ); and B) Tessera Terrain (tt; image centred on $1.9^{\circ} \mathrm{E}$, $\left.24.2^{\circ} \mathrm{S}\right)$. 


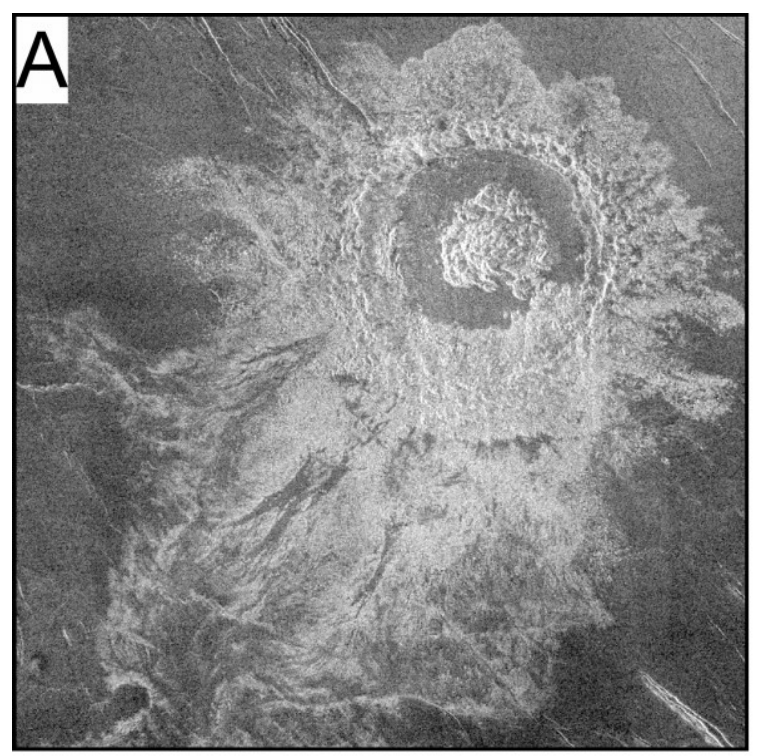

$10 \mathrm{~km}$

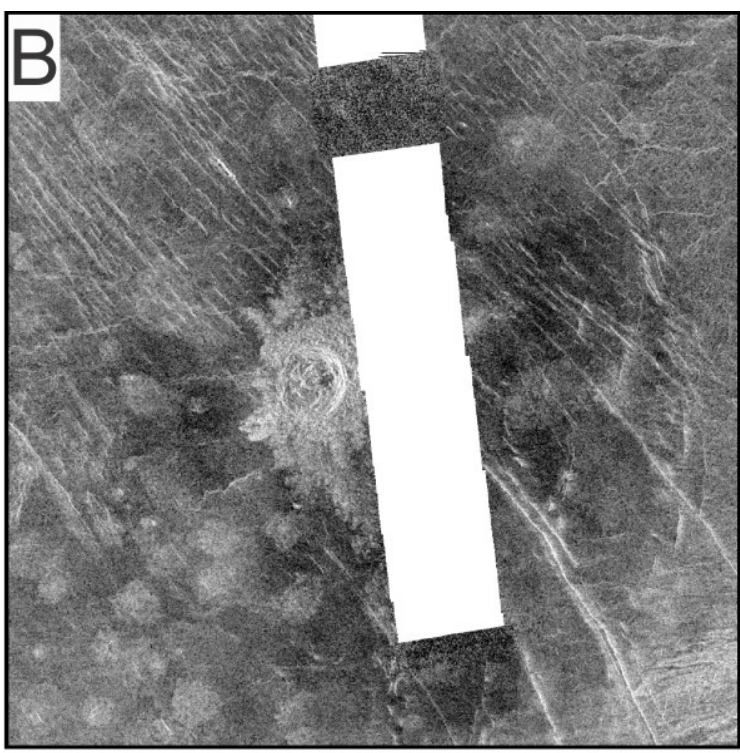

$10 \mathrm{~km}$

Figure 2.12: Left-looking SAR images of examples of the major geological units within the category 'Impact Material'. A) Impact Crater Material (im; image centred on $11.8^{\circ} \mathrm{E}, 11.0^{\circ} \mathrm{S}$ ); and $\mathrm{B}$ ) Impact Crater Halo (ih; image centred on $\left.17.8^{\circ} \mathrm{E}, 12.4^{\circ} \mathrm{S}\right)$. 

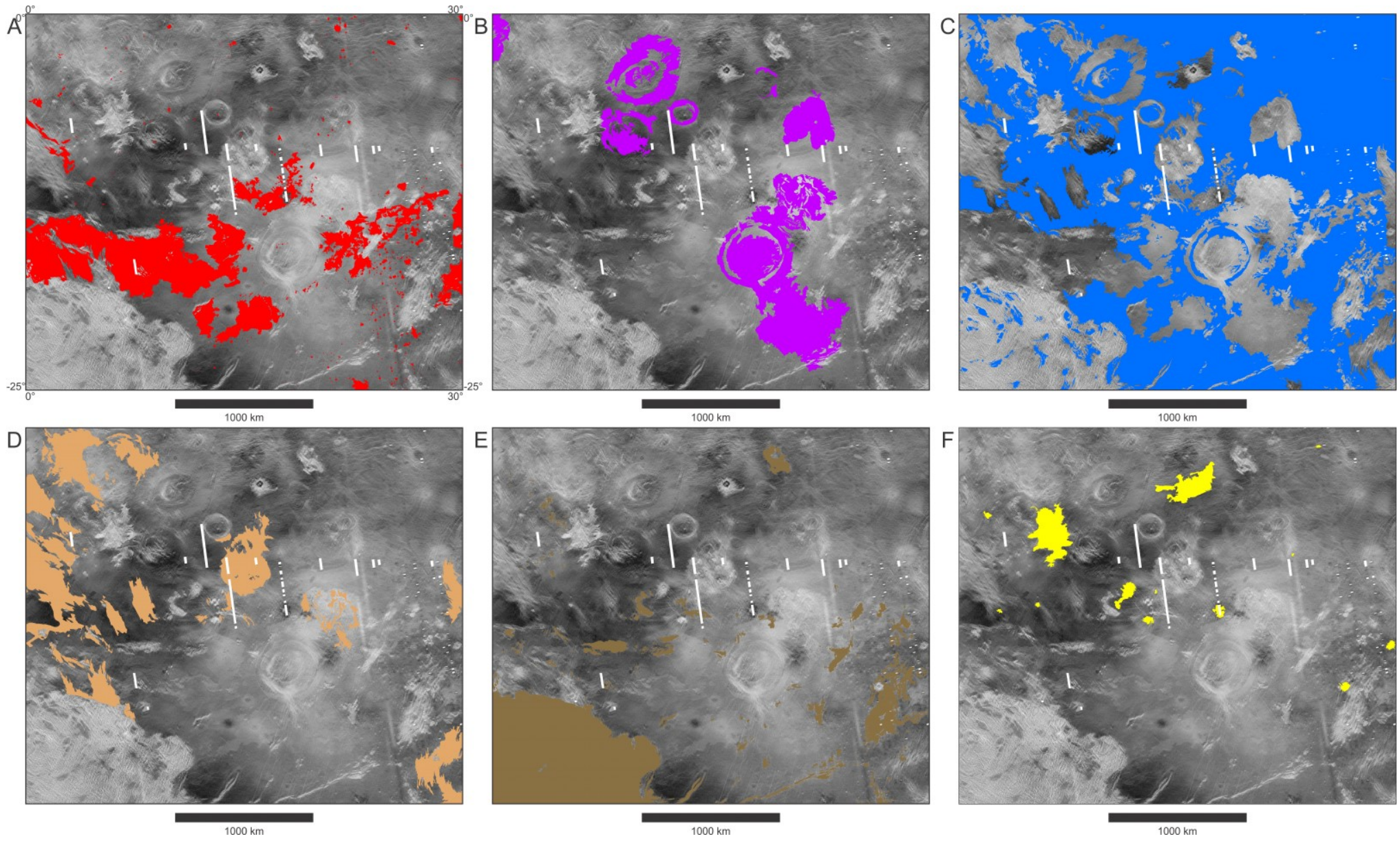

Figure 2.13: Thematic maps showing the distribution of the categories of geological units superimposed on a left-looking SAR basemap. A) Volcanic edifice and flow material; B) corona material; C) plains material; D) structural terrains; E) tessera material; and F) impact material. 

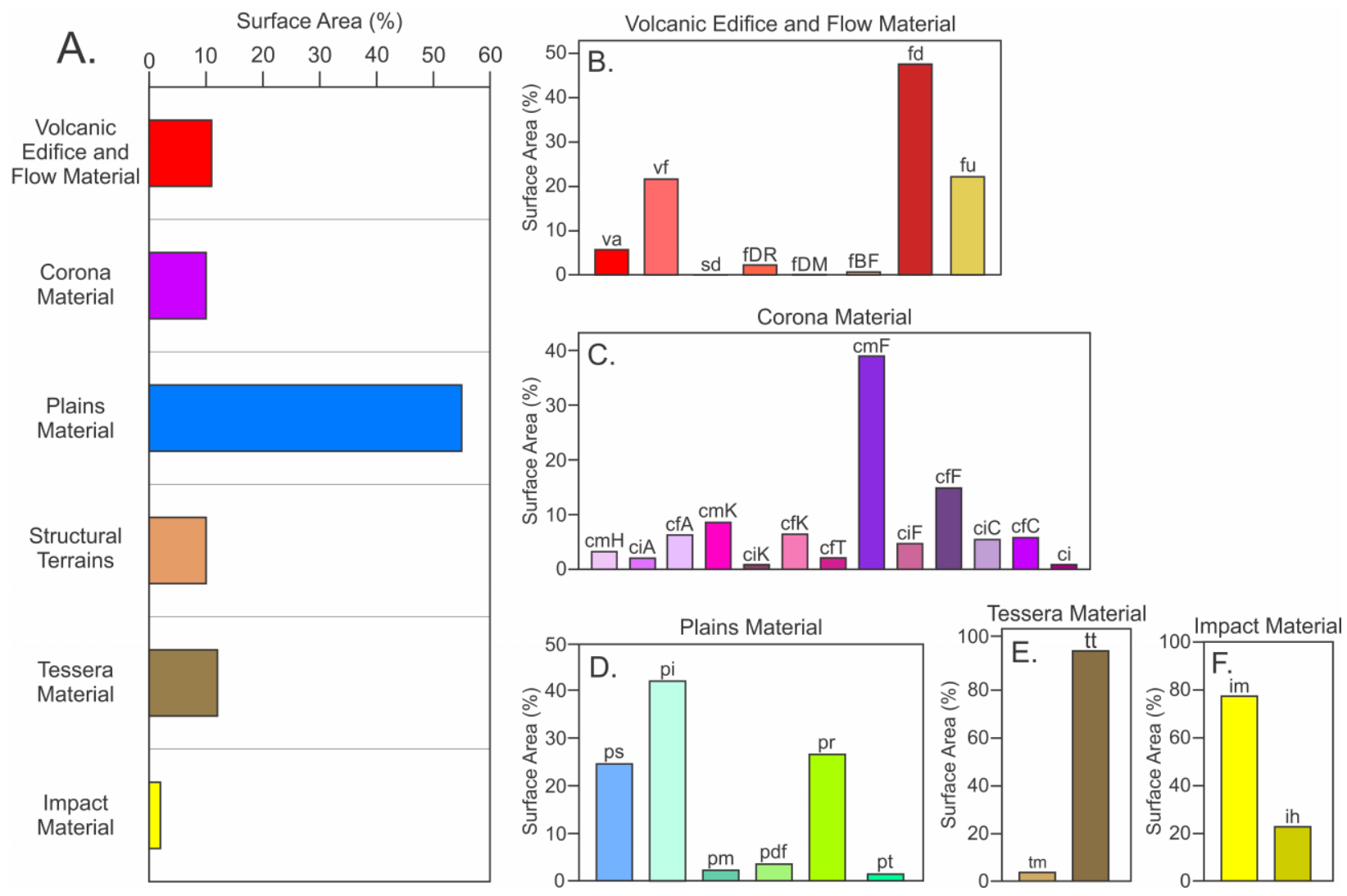

Figure 2.14: Relative proportions, by percentage of surface area covered, of geological units in the V-32 quadrangle, arranged by: A) each unit category; B) units within the volcanic edifice and flow material category; C) major units within the corona material category; D) major units within the plains material category; E) major units within the tessera material category; and F) major units within the impact material category. 


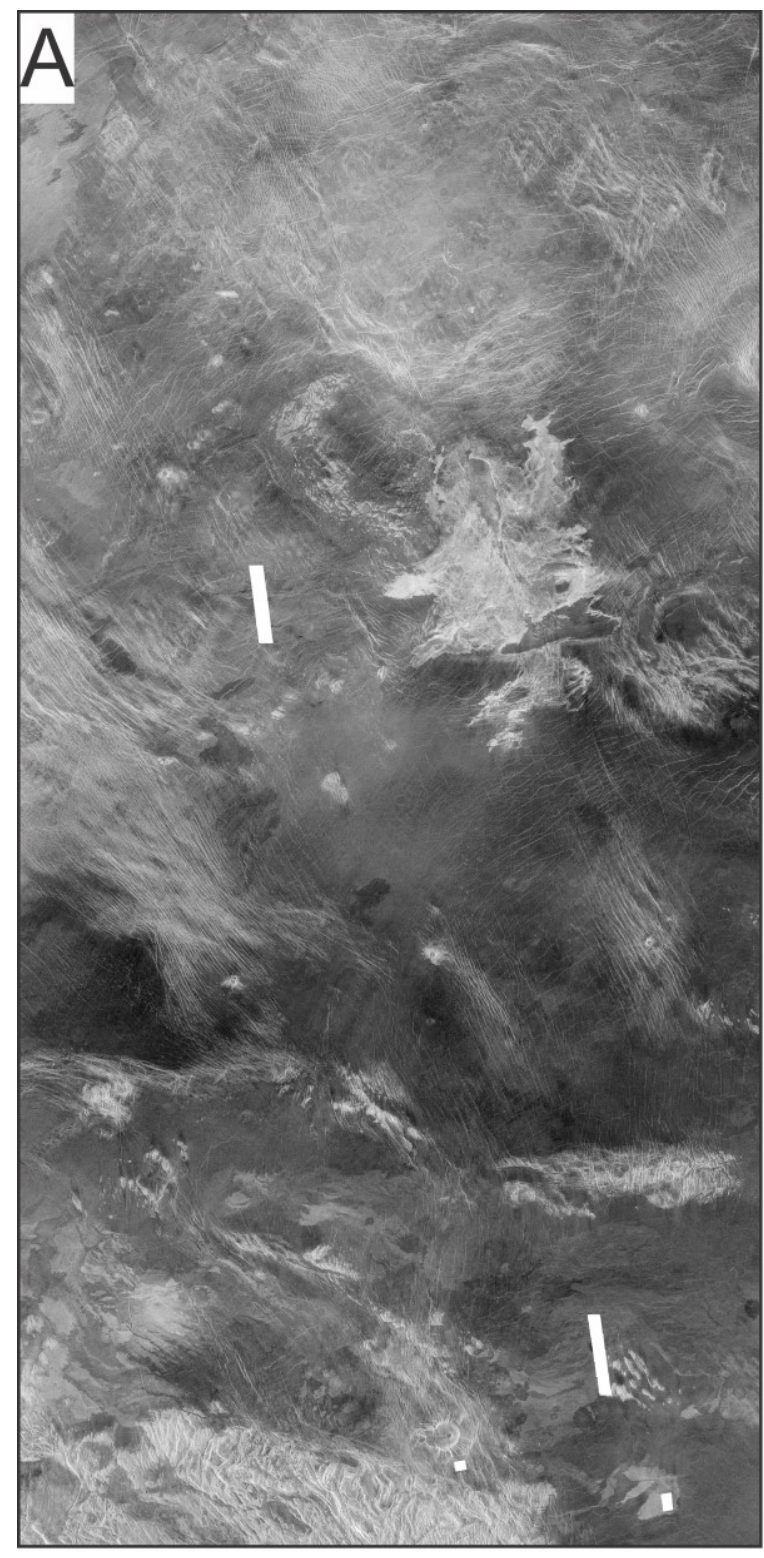

$250 \mathrm{~km}$

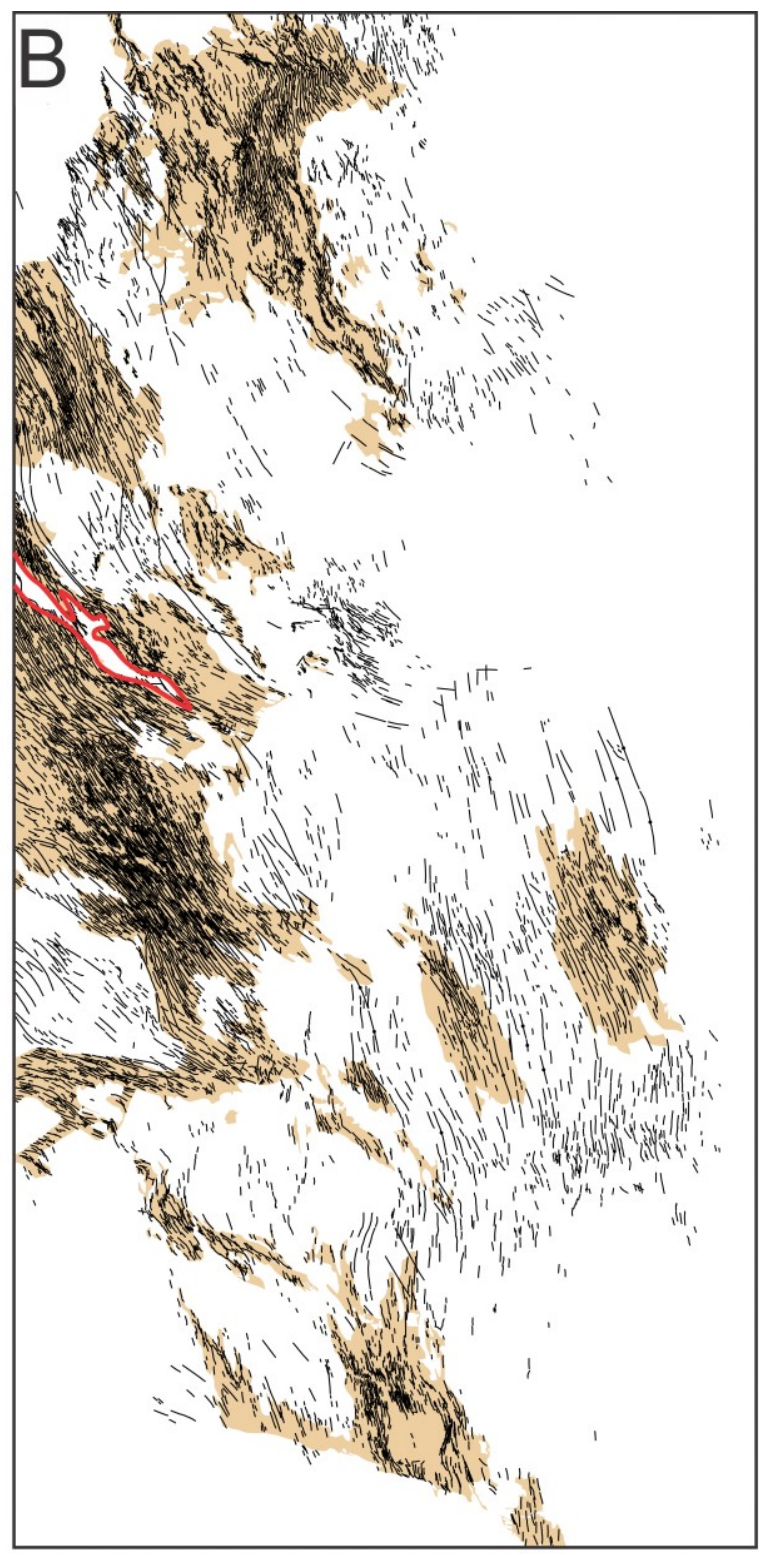

bf1 _ Extensional structure (ball denotes graben) Outline of Dewi-Ratih Chasma

Figure 2.15: Fracture Belt Unit 1 (bf1), associated with Dewi-Ratih Chasma $\left(0^{\circ}-20^{\circ} \mathrm{S}\right.$, $\left.0^{\circ}-9^{\circ} \mathrm{E}\right)$. A) Left-looking SAR image; and B) extent of the mapped bf1 unit and associated structures. See accompanying geological map for other mapped units and structures. 


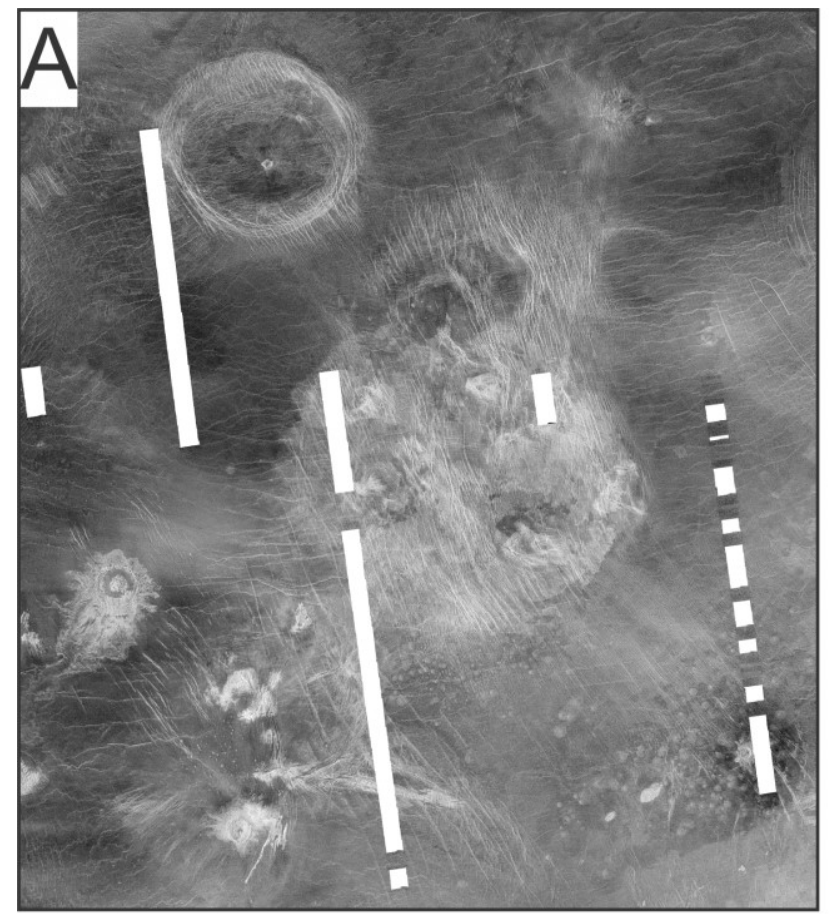

$250 \mathrm{~km}$

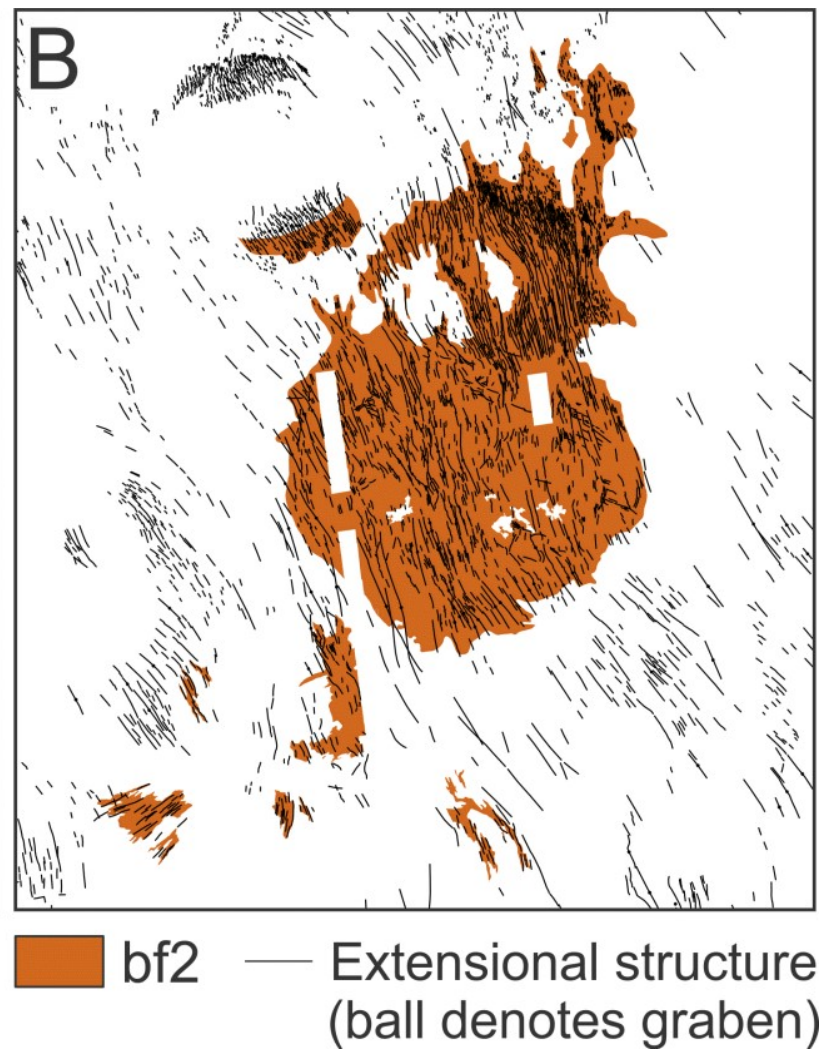

Figure 2.16: Fracture Belt Unit 3 (bf3) $\left(6^{\circ}-14^{\circ} \mathrm{S}, 11^{\circ}-19^{\circ} \mathrm{E}\right)$. A) Left-looking SAR basemap; and B) extent of the mapped bf 3 unit and associated structures. See accompanying geological map for other mapped units and structures. 

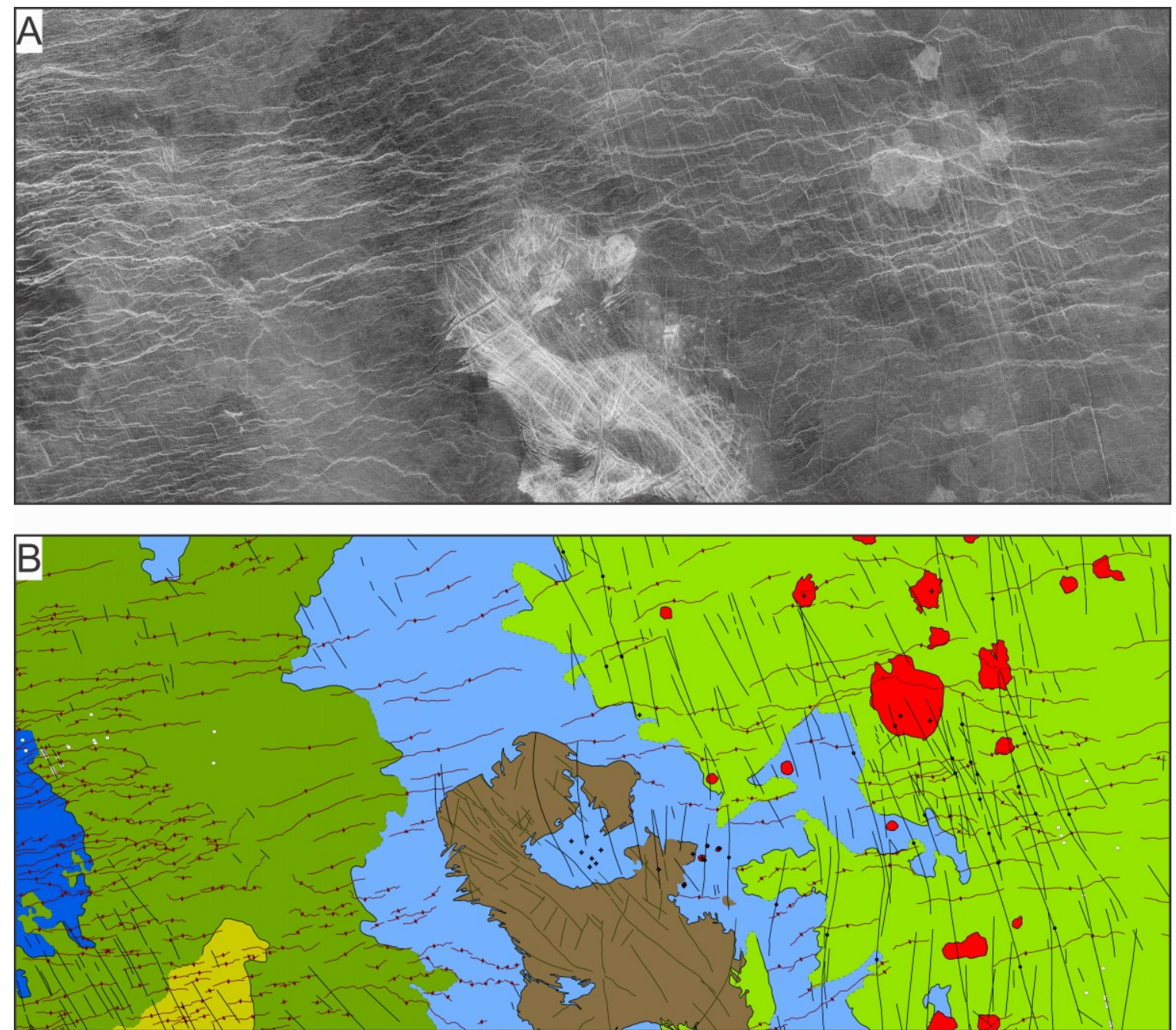

$100 \mathrm{~km}$

Smooth Plains Material Unit 1 (ps1)

Ridged Plains Material Unit 3 (ps3)

Ridged Plains Material Unit 4 (ps4)

Figure 2.17: Example of mapping of plains units and the use of cross-cutting relationships of structures (NNW trending extensional structures) to define separate units (images centred on $19.1^{\circ} \mathrm{E}, 1.4^{\circ} \mathrm{S}$ ). A) Left-looking SAR basemap; and B) geological map. 


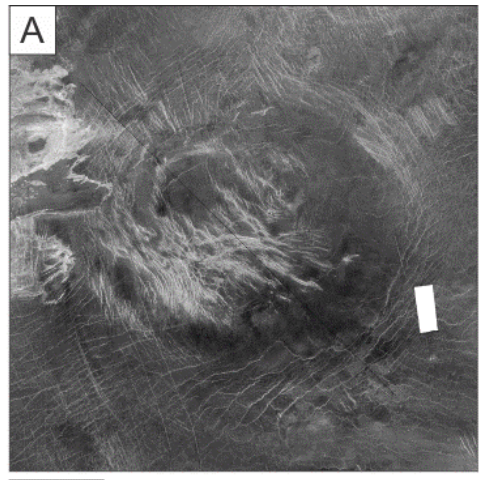

$100 \mathrm{~km}$

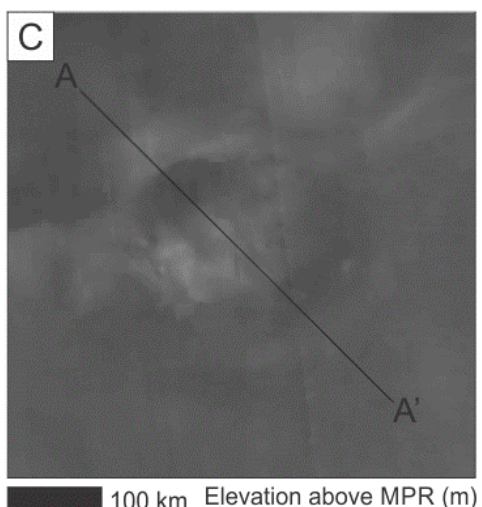

100 km Elevation above MPR (m)

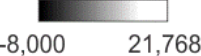

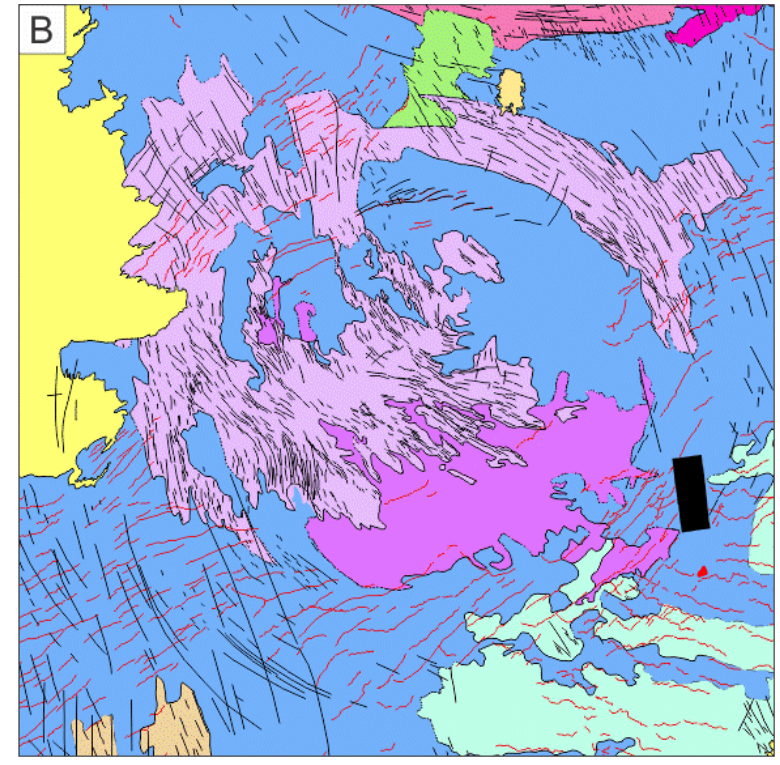

$100 \mathrm{~km}$

Atargatis Corona Units

Atargatis Corona

Fractured Material (cfA)

Atargatis Corona

Interior Material (ciA)

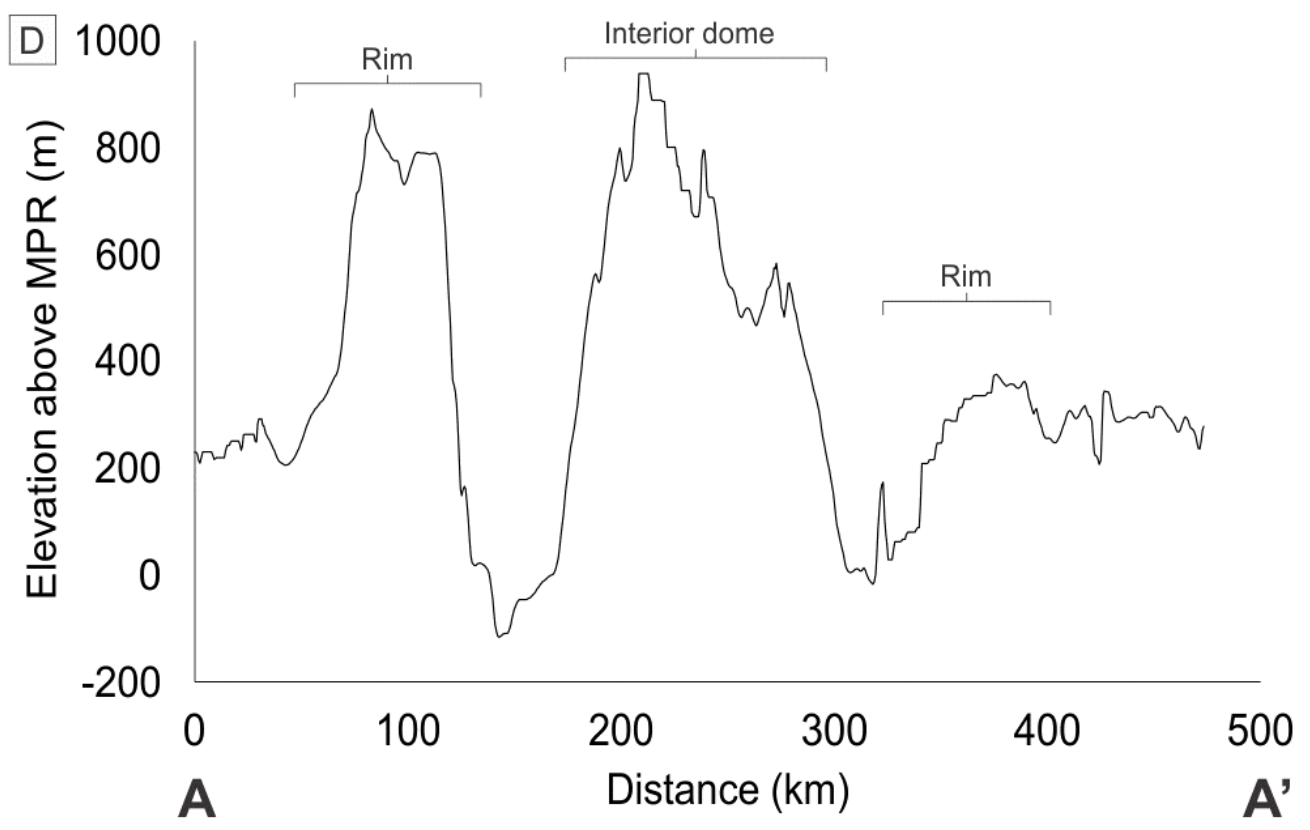

Figure 2.18: Atargatis Corona: A) Left-looking SAR image; B) geological map; C) stereo-derived topography showing location of profile line for $D$; and $D$ ) stereo-derived topographic profile (MPR = Mean Planetary Radius). 


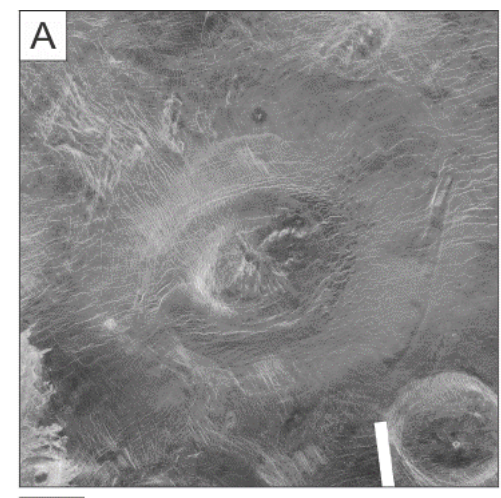

$100 \mathrm{~km}$

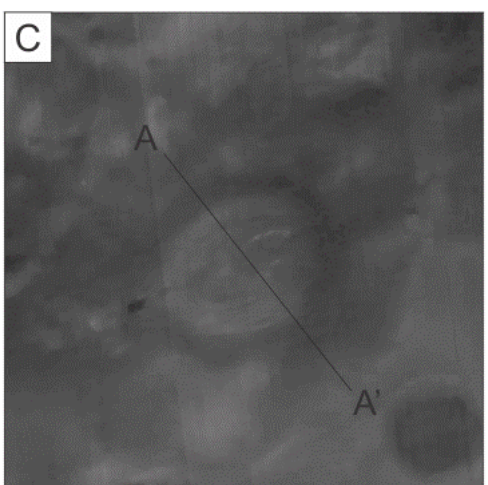

$100 \mathrm{~km}$

Elevation above MPR $(\mathrm{m})$

$-8,000 \quad 21,768$

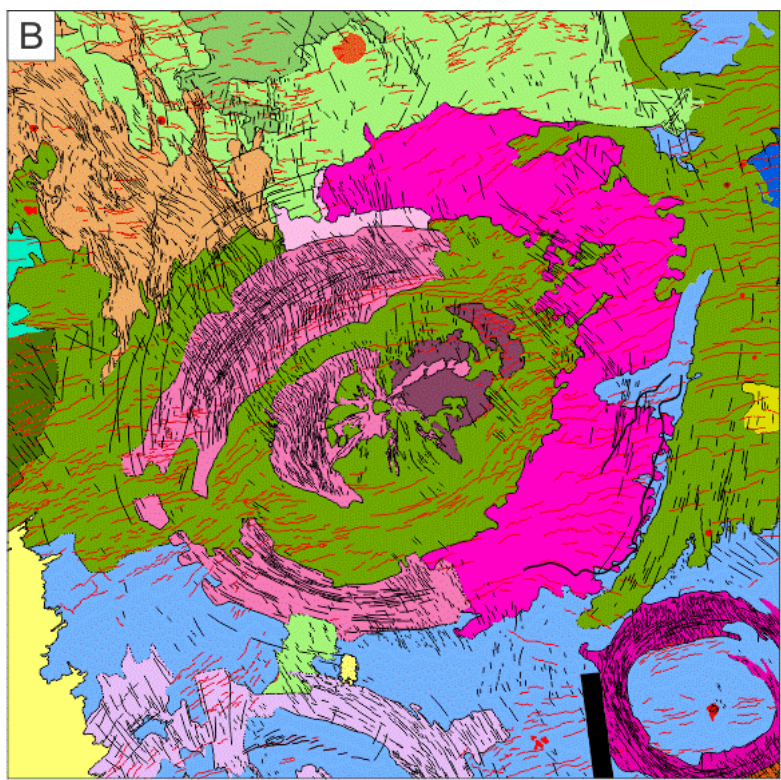

$100 \mathrm{~km}$

Kuan-Yin Corona Units

Kuan-Yin Corona

Fractured Material (cfK)

Kuan-Yin Corona

Interior Material (ciK)

Kuan-Yin Corona

Flow Material Unit 1 (cmK1)

Kuan-Yin Corona

Flow Material Unit 2 (cmK2)

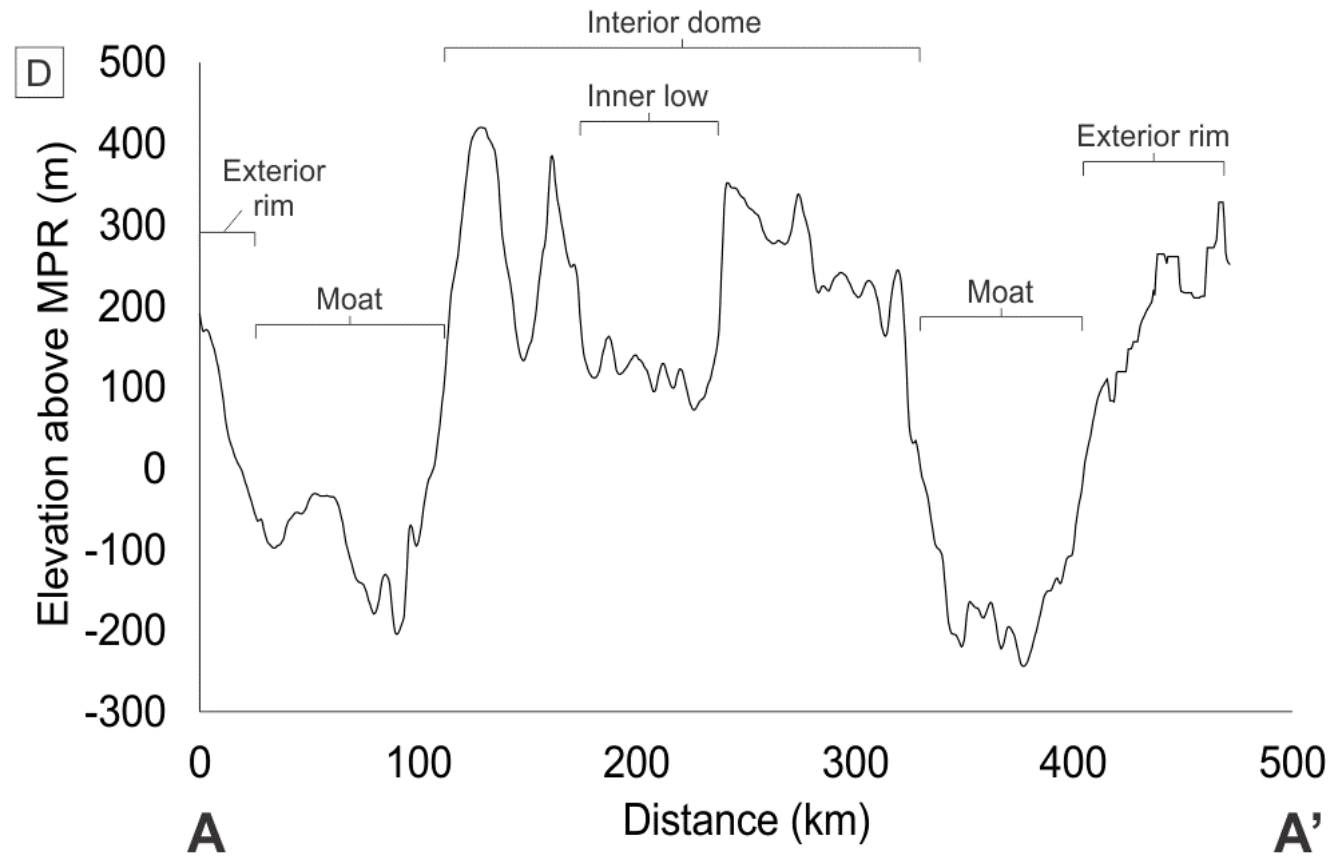

Figure 2.19: Kuan-Yin Corona: A) Left-looking SAR image; B) geological map; C) stereo-derived topography showing location of profile line for $D$; and $D$ ) stereo-derived topographic profile (MPR = Mean Planetary Radius). 


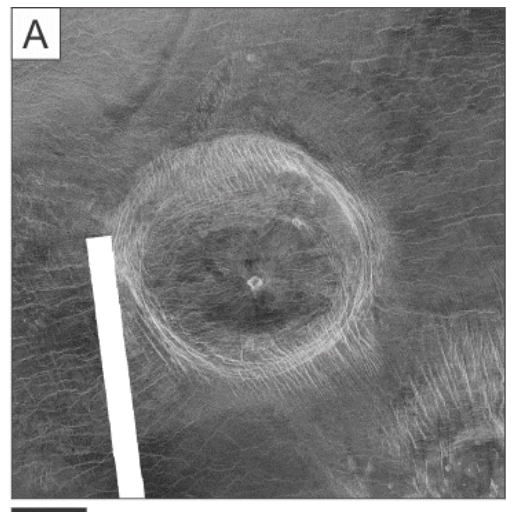

$50 \mathrm{~km}$

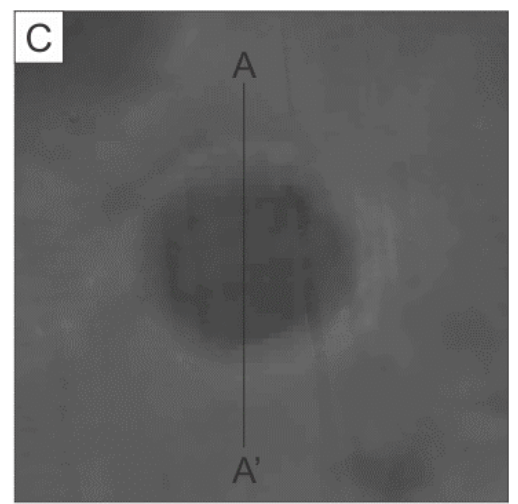

$50 \mathrm{~km}$

Elevation above MPR (m)

$-8,000 \quad 21,768$

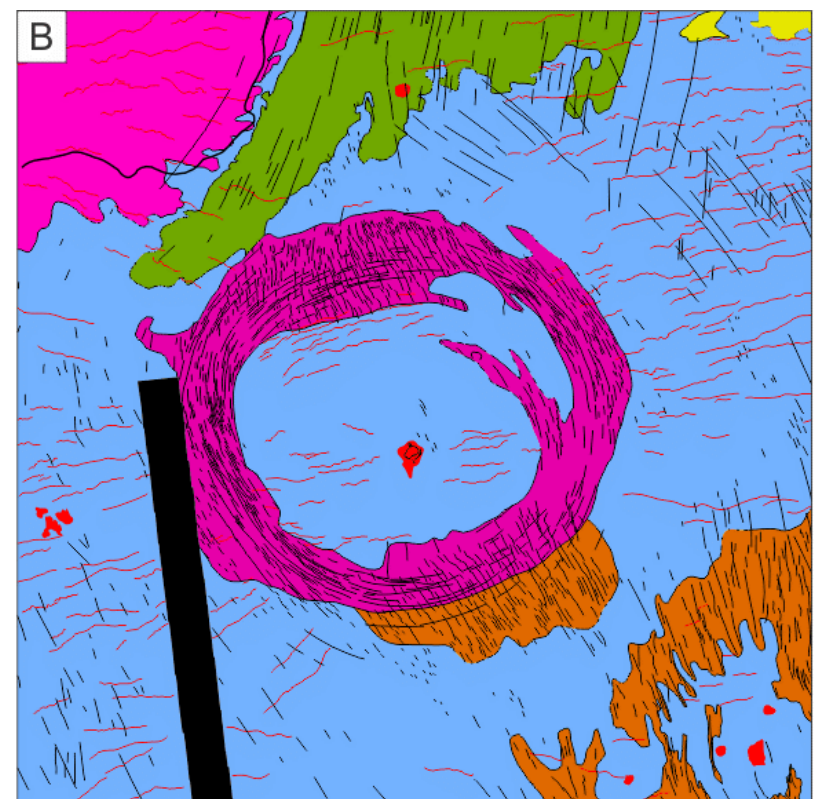

Thouris Corona Units

Thouris Corona

Fractured Material (cfT)

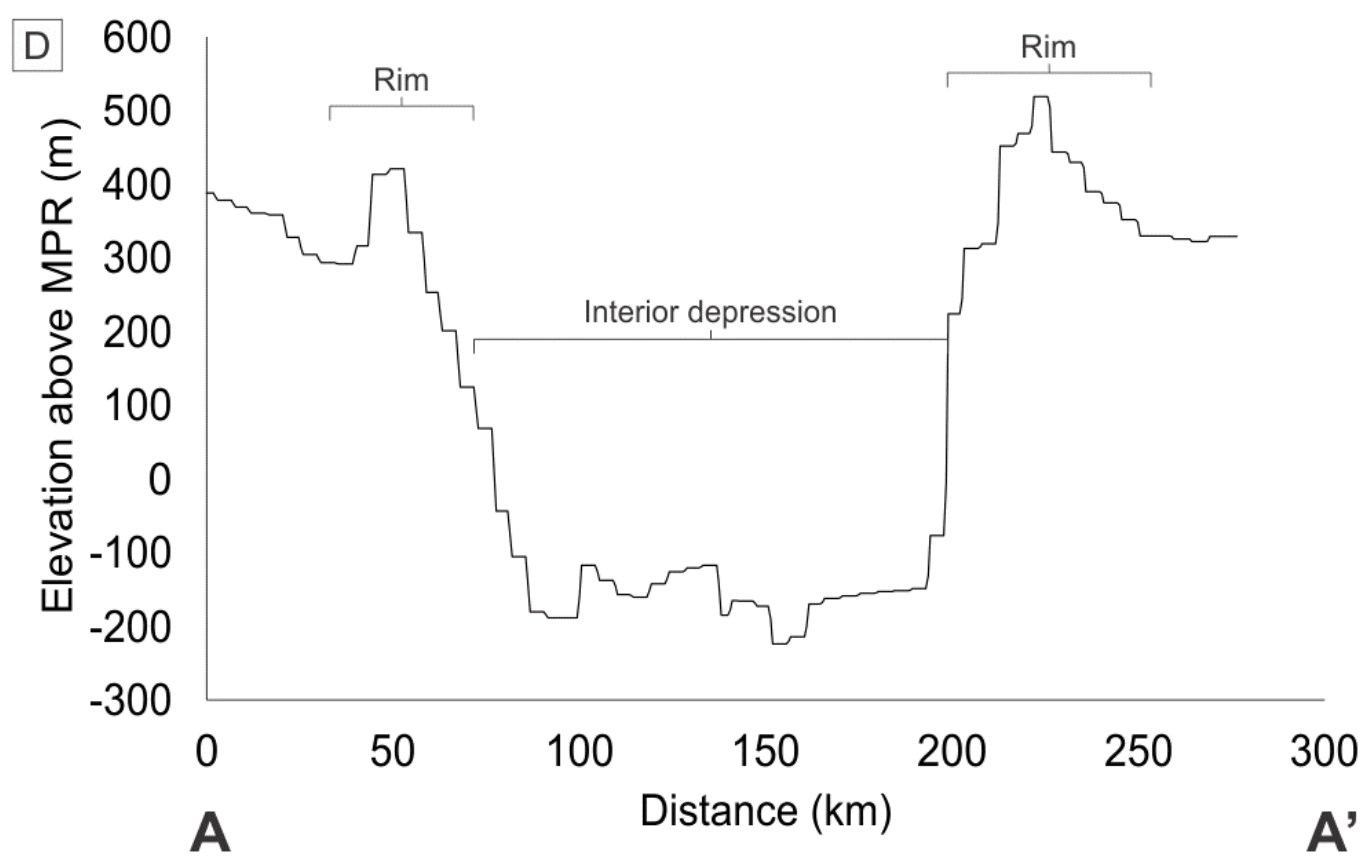

Figure 2.20: Thouris Corona: A) Left-looking SAR image; B) geological map; C) stereoderived topography showing location of profile line for $D$; and $D$ ) stereo-derived topographic profile (MPR = Mean Planetary Radius). 


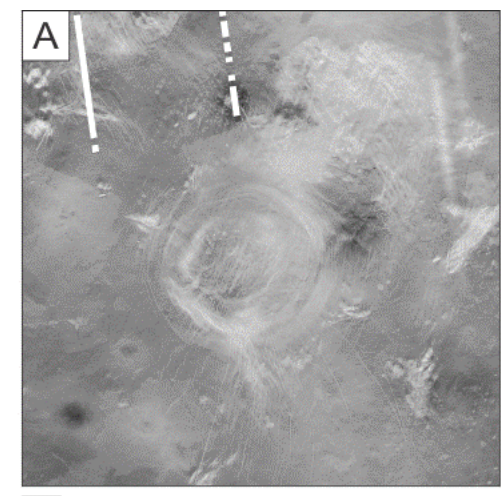

$100 \mathrm{~km}$

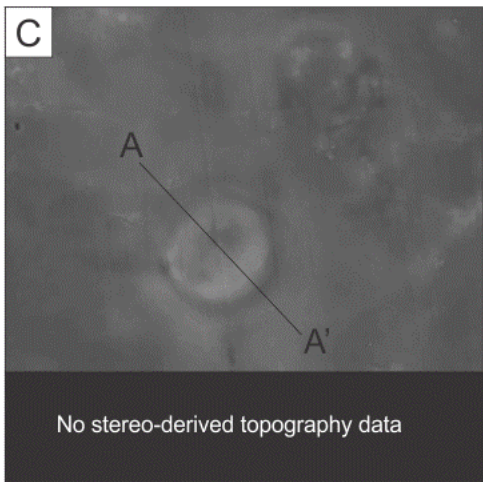

$100 \mathrm{~km}$

Elevation above MPR (m)

$-8,000$

21,768

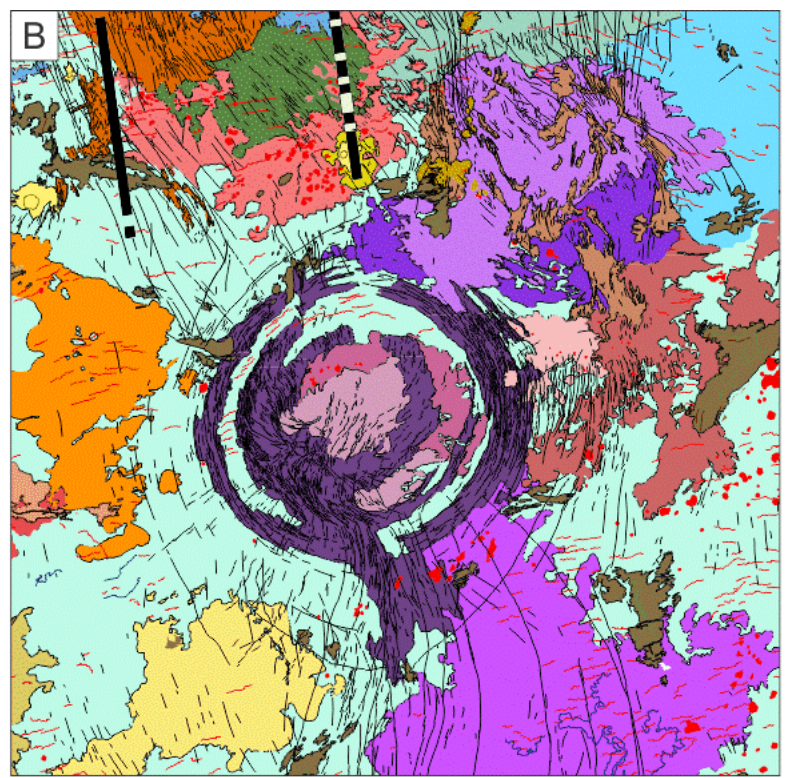

$100 \mathrm{~km}$

Fatua Corona Units

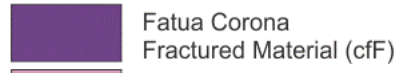

Fractured Mat

Fatua Corona

Interior Material Unit 1 (ciF1)

Fatua Corona

Interior Material Unit 2 (ciF2)

Fatua Corona

Flow Material Unit 1 (cmF1)

Fatua Corona

Flow Material Unit 2 (cmF2)

Fatua Corona

Flow Material Unit 3 (cmF3)

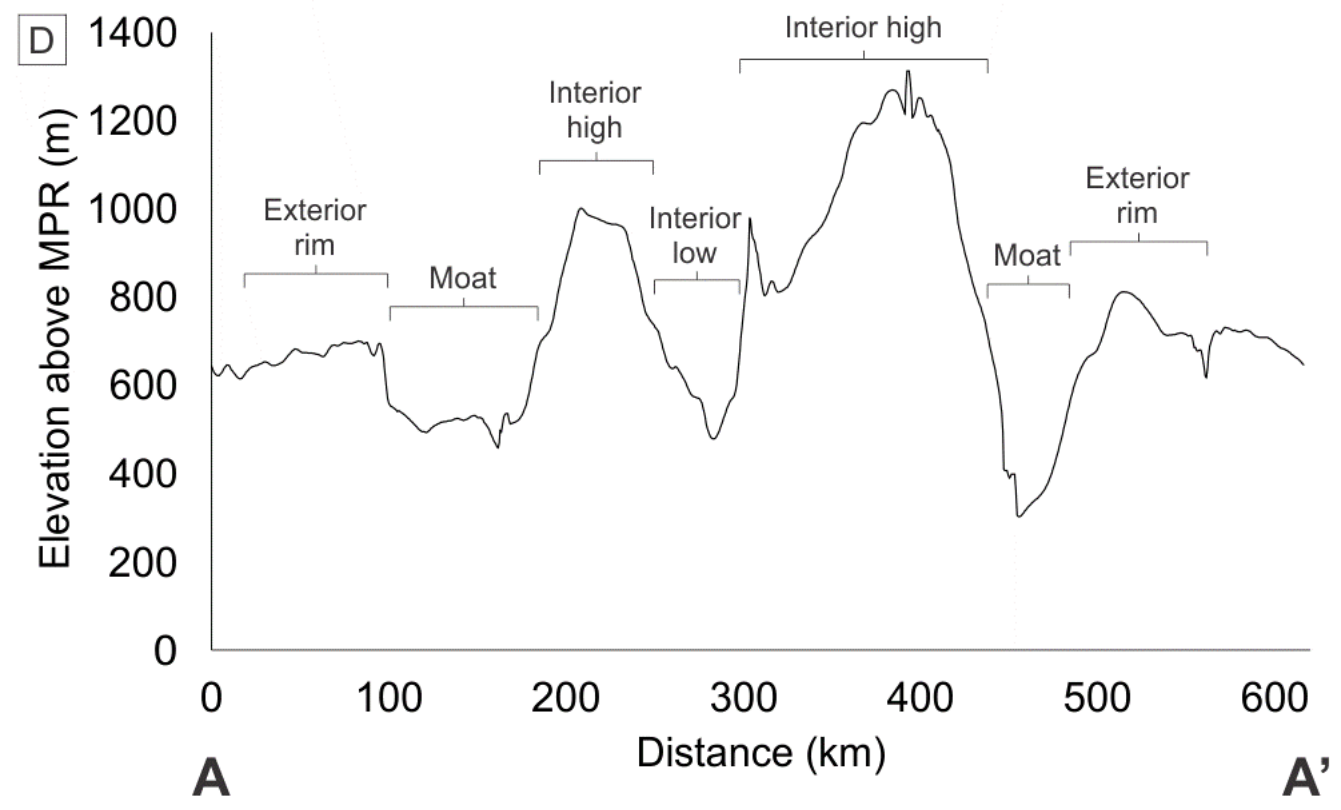

Figure 2.21: Fatua Corona: A) Left-looking SAR image; B) geological map; C) stereoderived topography showing location of profile line for $D$; and $D$ ) stereo-derived topographic profile (MPR = Mean Planetary Radius). 


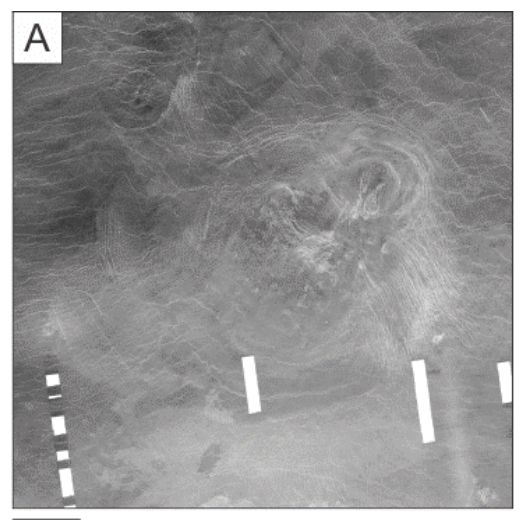

$100 \mathrm{~km}$

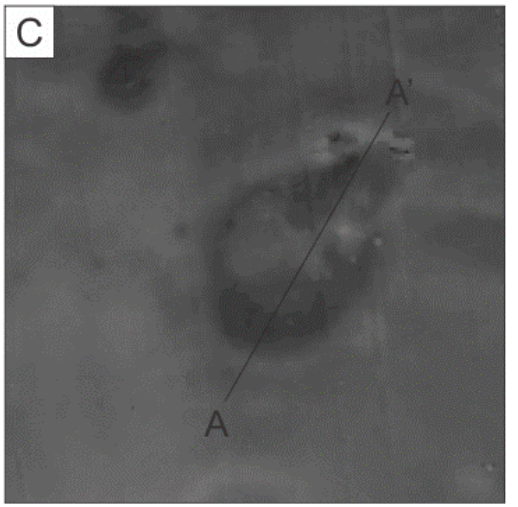

$100 \mathrm{~km} \quad$ Elevation above MPR (m)

$-8,000 \quad 21,768$

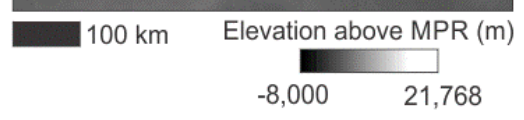

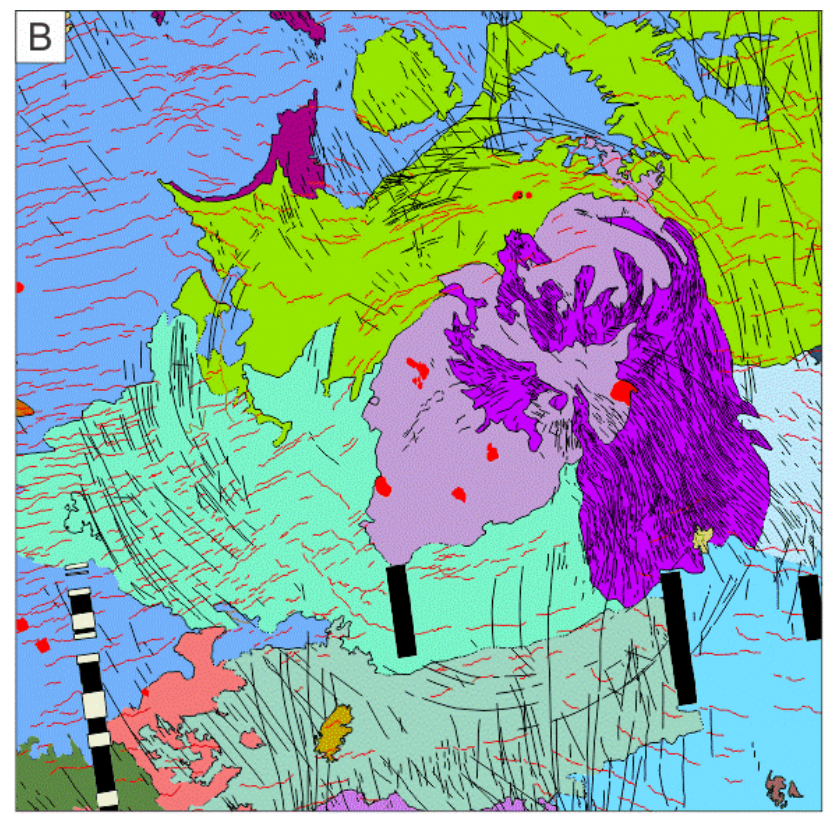

$100 \mathrm{~km}$

Cybele Corona Units

Cybele Corona

Fractured Material (cfC)

Cybele Corona

Interior Material (ciC)

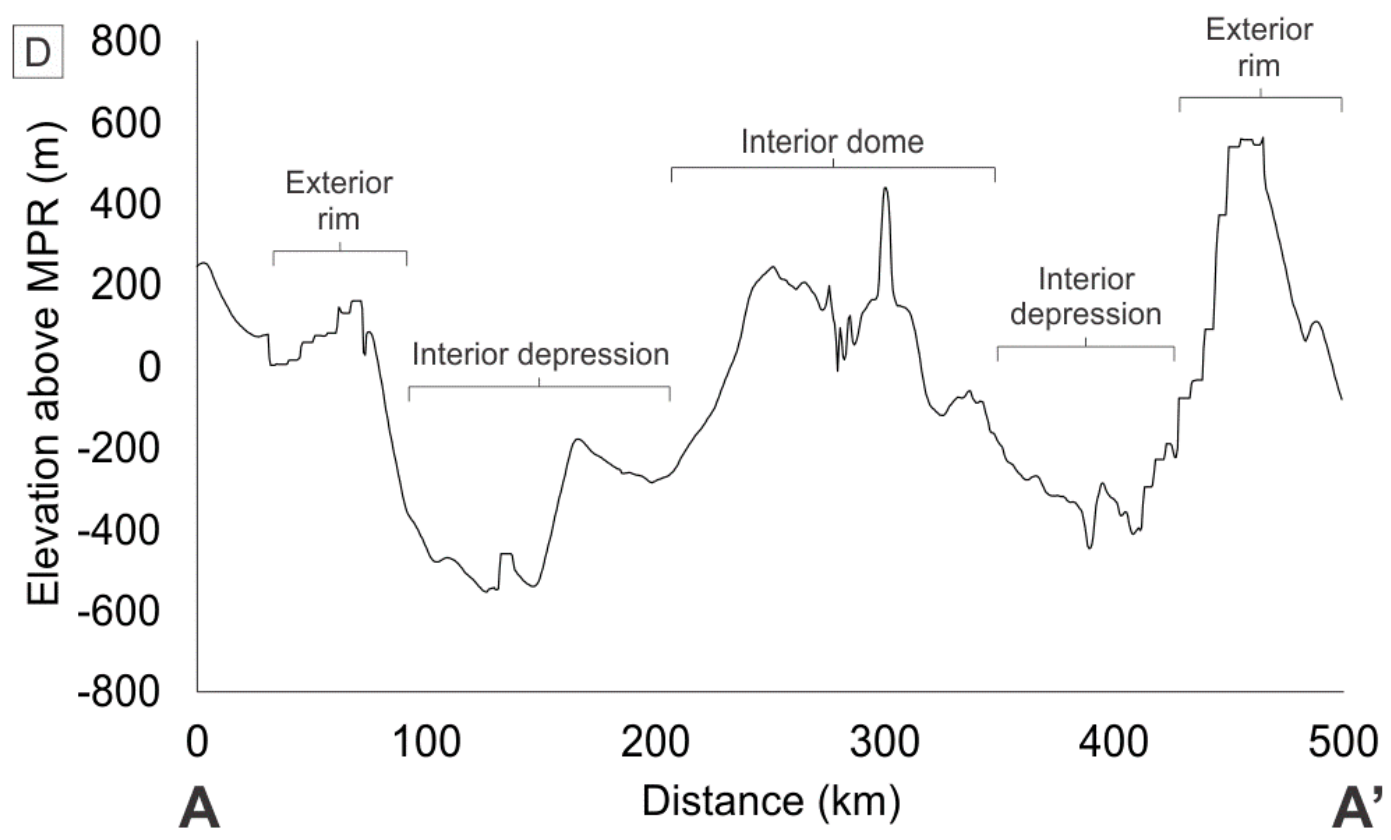

Figure 2.22: Cybele Corona: A) Left-looking SAR image; B) geological map; C) stereoderived topography showing location of profile line for $D$; and $D$ ) stereo-derived topographic profile (MPR = Mean Planetary Radius). 


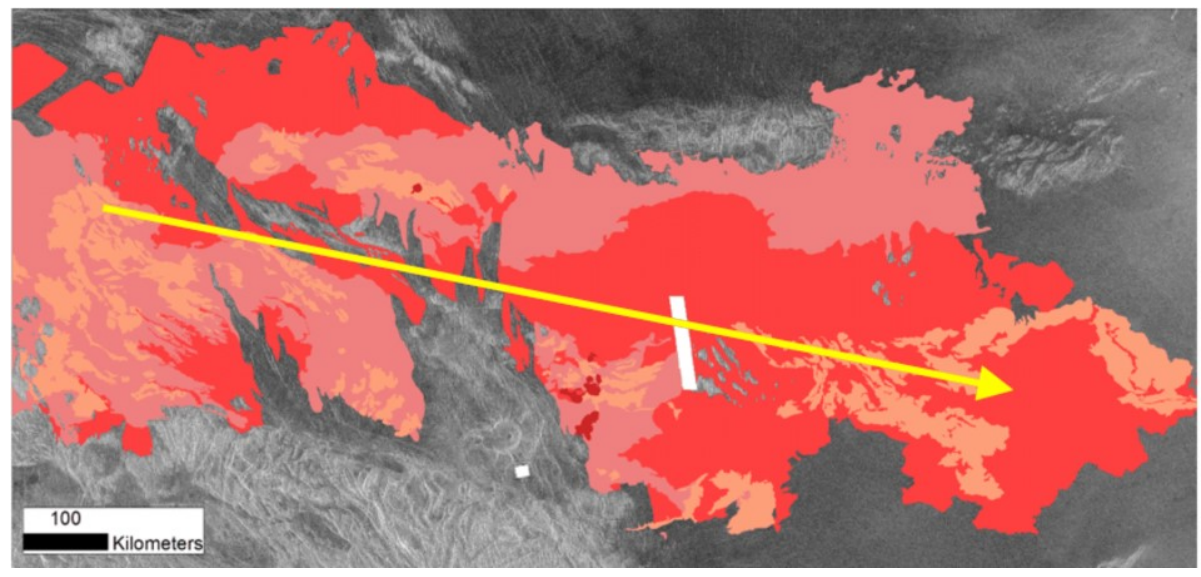

Digitate Flow Material Units

Digitate Flow Material Unit 1 (fd1)

Digitate Flow Material Unit 2 (fd2)

Digitate Flow Material Unit 3 (fd3)

Digitate Flow Material Unit 4 (fd4)

Figure 2.23: Map of Digitate Flow Material Units superimposed on left-looking SAR image (centred on $6.2^{\circ} \mathrm{E}, 16.6^{\circ} \mathrm{S}$ ). The inferred flow direction of these volcanic flows is represented by the yellow arrow. 


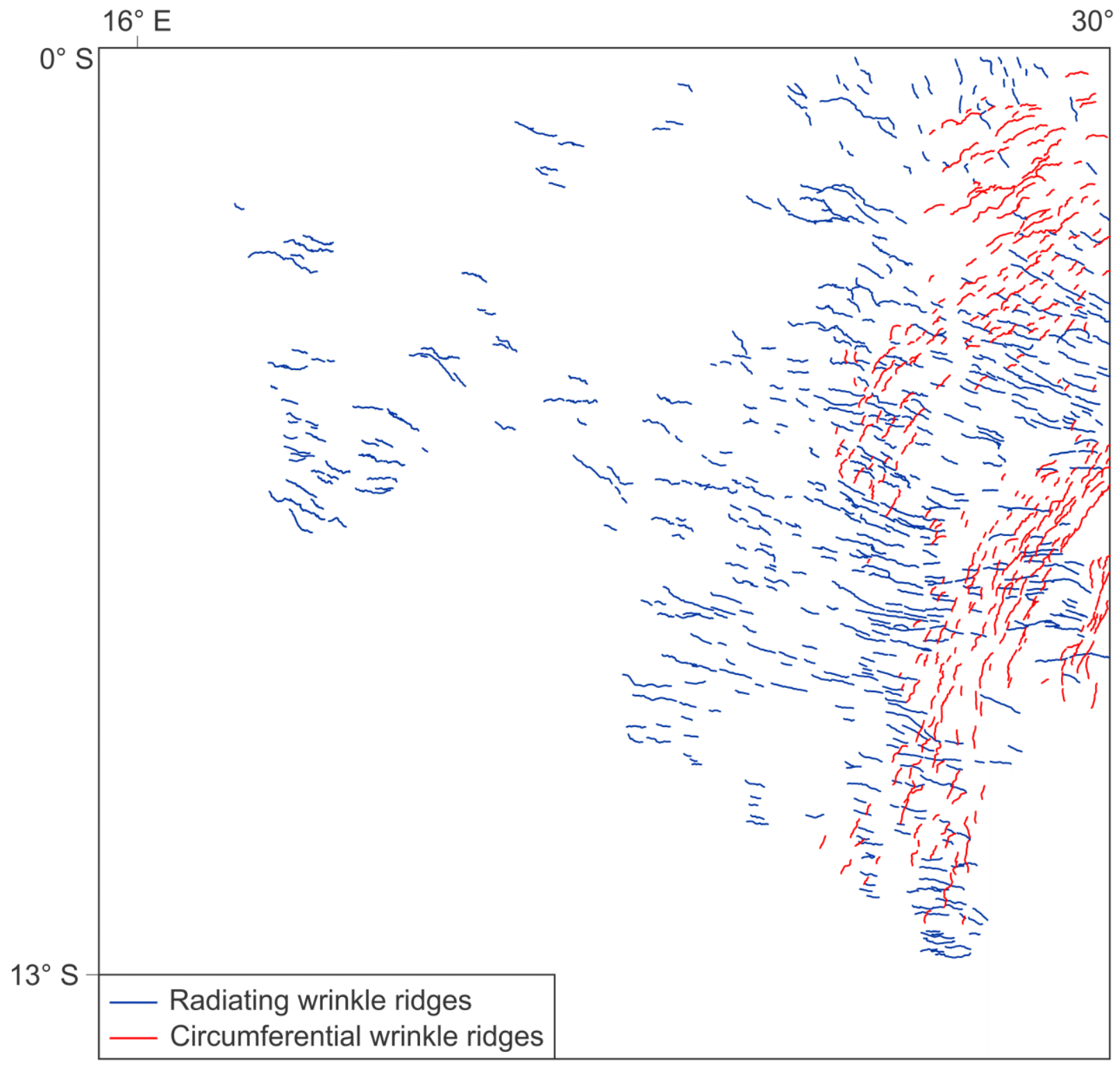

$500 \mathrm{~km}$

Figure 2.24: Map of the two wrinkle ridge systems of radiating (blue) and circumferential (red) geometry identified in association with Thermuthis Corona (to the east). 


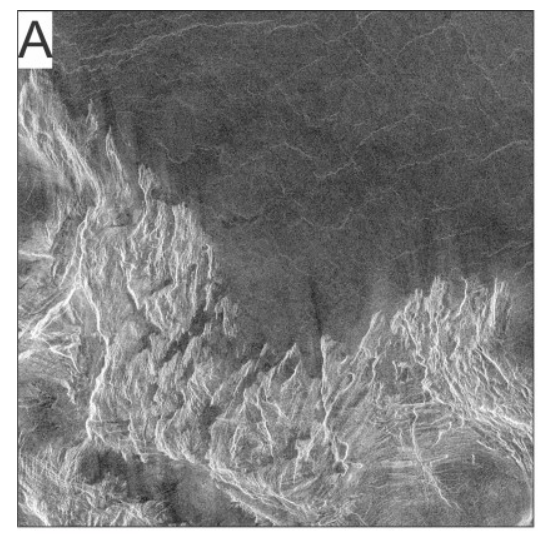

$50 \mathrm{~km}$

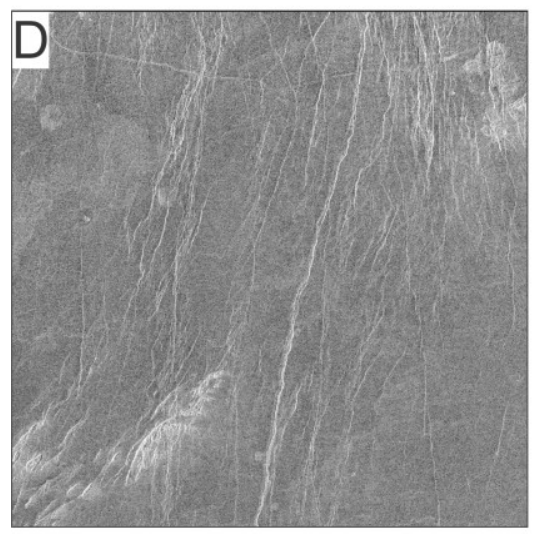

$50 \mathrm{~km}$

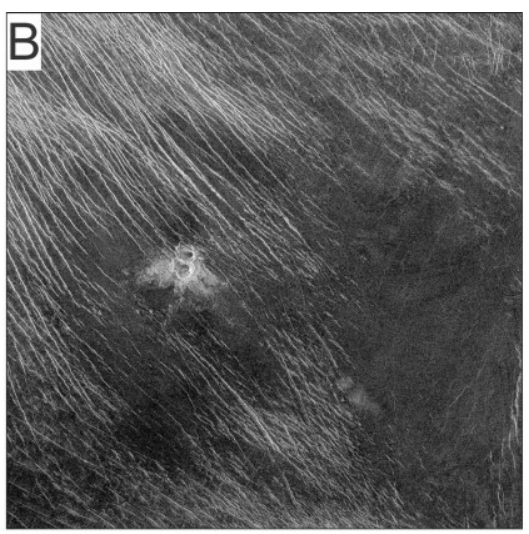

$50 \mathrm{~km}$

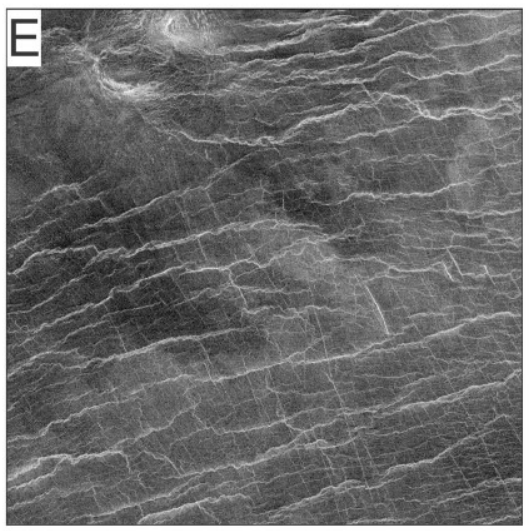

$50 \mathrm{~km}$

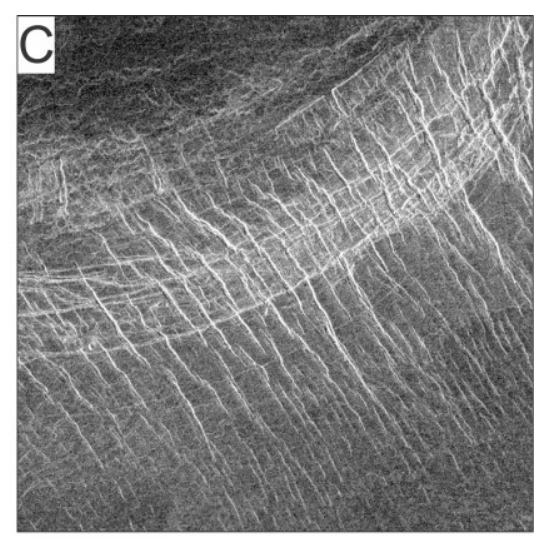

$25 \mathrm{~km}$

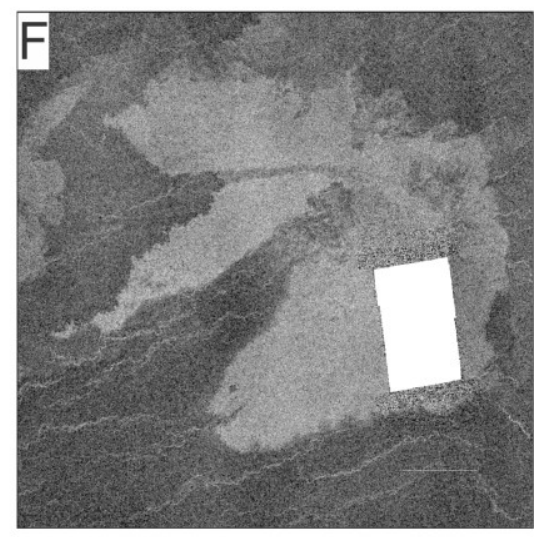

$25 \mathrm{~km}$

Figure 2.25: SAR images displaying examples of the major cross-cutting relationships in the $\mathrm{V}$-32 quadrangle. A) Embayment of tessera terrain (tt; below, radar-bright) by plains material (pi1; above, radar-dark) (image centred on $8.4^{\circ} \mathrm{E}, 20.4^{\circ} \mathrm{S}$ ); B) embayment of NNW-SSE trending extensional structures within a fracture belt (bf1) by plains material (ps1) (image centred on $3.1^{\circ} \mathrm{E}, 12.5^{\circ} \mathrm{S}$ ); C) NNW-SSE trending extensional structures within a fracture belt (bf3) cross-cutting circumferential extensional structures associated with Thouris Corona (image centred on $13.5^{\circ} \mathrm{E}, 7.6^{\circ} \mathrm{S}$ ); D) radiating extensional structures associated with Fatua Corona cross-cutting plains material (pi1) (image centred on $18.1^{\circ} \mathrm{E}, 20.5^{\circ} \mathrm{S}$ ); E) Smooth Plains Material Unit 4 (ps4; above, relatively radar-dark) truncating NNW-SSE trending extensional structures in the adjacent relatively radar-bright Ridged Plains Material Unit 3 (pr3; below, relatively radar-bright), indicating different relative ages for plains material (image centred on $15.9^{\circ} \mathrm{E}, 2.5^{\circ} \mathrm{S}$ ); and $\mathrm{F}$ ) relatively recent volcanic flow material (fd4) overlying NE-SW trending regional wrinkle ridges (image centred on $8.2^{\circ} \mathrm{E}, 18.8^{\circ} \mathrm{S}$ ). 


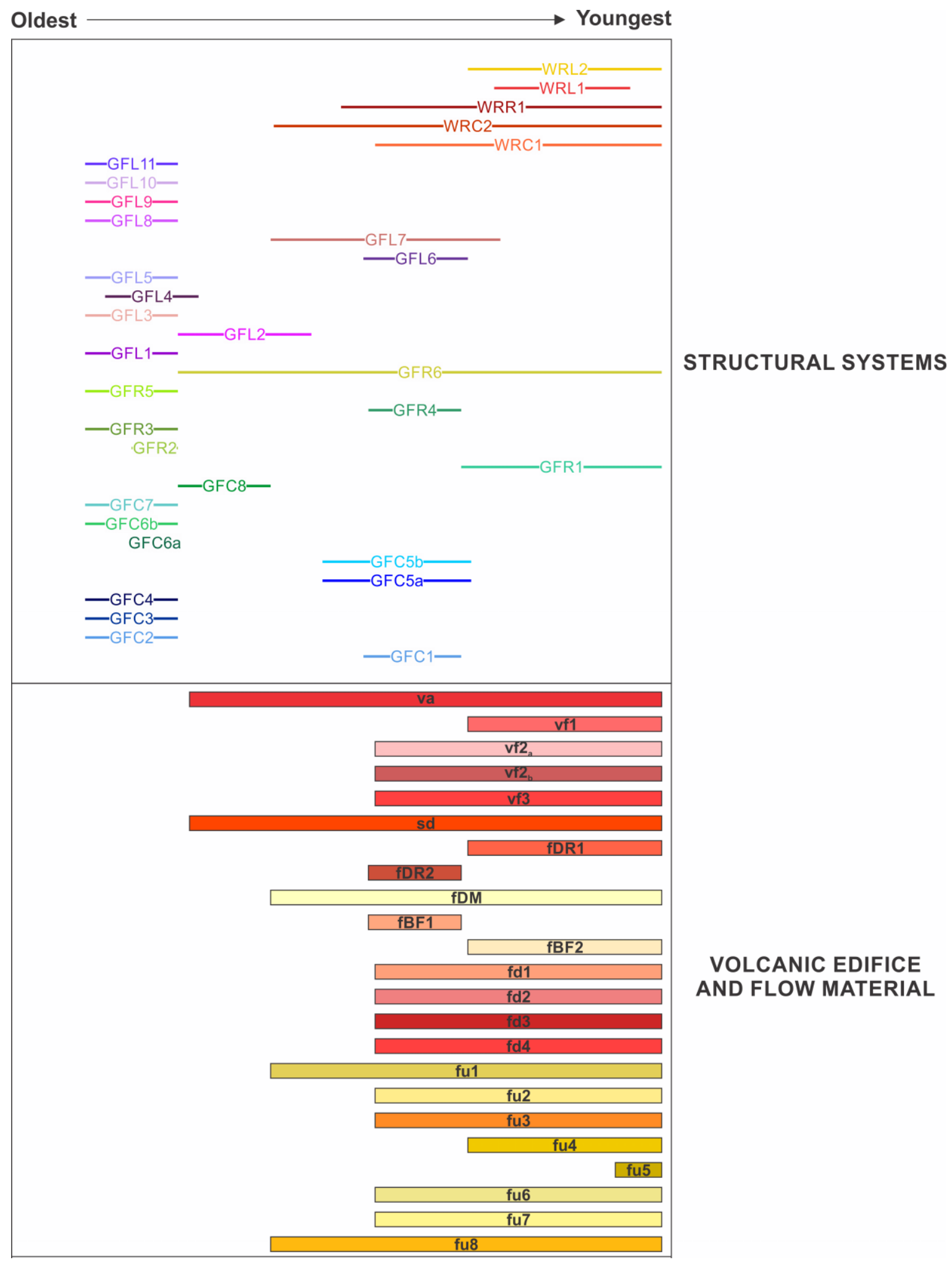

Figure 2.26 (part 1): Full stratigraphic column showing relative ages of all geological units and structural systems. 


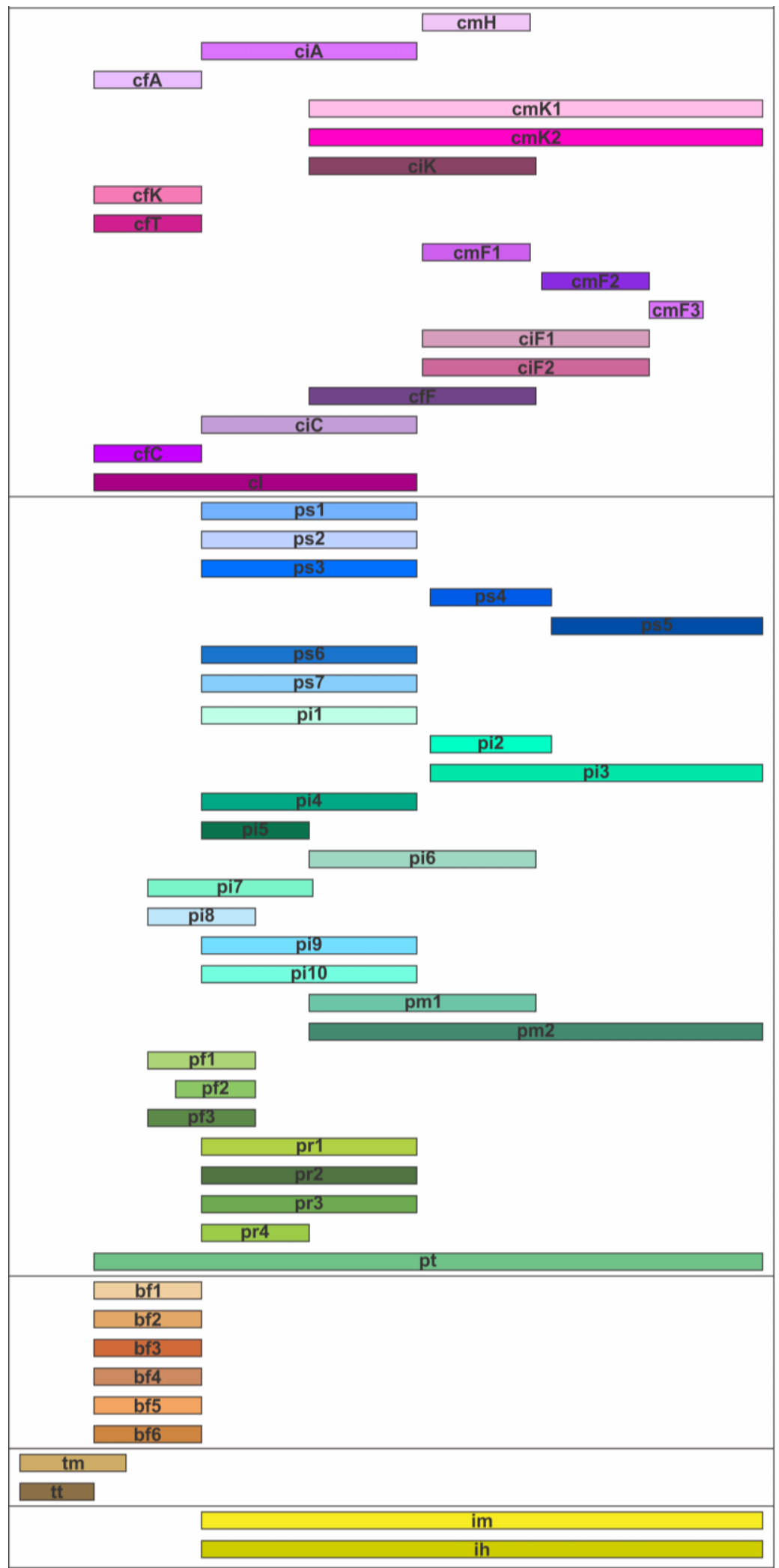

CORONA MATERIAL

PLAINS MATERIAL

STRUCTURAL

TERRAINS

TESSERA MATERIAL

IMPACT MATERIAL

Figure 2.26 (part 2): Full stratigraphic column showing relative ages of all geological units and structural systems. 


\section{CHAPTER 3: GRABEN-FISSURE SYSTEMS ASSOCIATED WITH FATUA CORONA}

\subsection{Introduction}

Fatua Corona is located in the Alpha Regio (V-32) quadrangle and is centred at approximately $17.6^{\circ} \mathrm{E}, 16.1^{\circ} \mathrm{S}$ (Figures $\left.3.1,3.2 \mathrm{~A}\right)$. The annulus has an arc length of $360^{\circ}$ around the centre. Fatua Corona has been described as having a maximum diameter of $310 \mathrm{~km}$ and a maximum annulus width of $85 \mathrm{~km}$ (Stofan et al., 1992). However, detailed structural mapping in the surrounding region using full resolution ( $\sim 75$ $\mathrm{m} / \mathrm{pixel)}$ Magellan SAR images has revealed the maximum diameter and maximum width of the annulus to be $915 \mathrm{~km}$ and $316 \mathrm{~km}$, respectively (Figure 3.2A). Fatua Corona is also associated with a radiating graben-fissure system that extends for approximately $1700 \mathrm{~km}$, and includes the Brynhild Fossae that extend southward into the Kaiwan Fluctus (V-44) quadrangle (Figures 3.1, 3.2A; McKenzie et al., 1992; Bridges and McGill, 2002). The Brynhild Fossae terminate at the northeast margin of the Alpha-Lada extensional belt, which intersects with the Derceto-Quetzalpetlatl extensional belt at Astkhik Planum (Figure 3.1; Bridges and McGill, 2002). Approximately $450 \mathrm{~km}$ south of the centre of Fatua Corona, the radiating graben-fissure system gradually changes trend to become a subparallel linear swarm oriented NE-SW. A full description of Fatua Corona is given in Section 2.3.4.5.

\subsection{Associated Dyke Swarms}

The extent of the radiating graben-fissure system associated with Fatua Corona suggests a link with an underlying giant dyke swarm. This interpretation is supported by the observation of numerous volcanic flows (e.g., the Brynhild Fossae Flow Material Units 1 and 2 (fBF1 and fBF2); refer to Section 2.3.5) and shield volcanoes clustered 
along the radiating graben. Numerous researchers argue that many radiating grabenfissure systems associated with magmatic centres on Venus are likely underlain by dyke swarms (e.g., Grosfils and Head, 1994a,b; Ernst et al., 1995; Grindrod et al., 2005; Studd et al., 2011; refer to Section 4.1.2).

The circumferential graben-fissure system around Fatua Corona may also be associated with an underlying dyke swarm, although this interpretation is more speculative (e.g., Bethell et al., 2016; Buchan and Ernst, 2016; Buchan and Ernst, 2019). There is evidence for magma transport that has occurred along these circumferential structures; some volcanic flow units associated with Fatua Corona (Fatua Corona Flow Material Units 2 and 3 (cmF2 and cmF3); refer to Section 2.3.4.5) are sourced from these structures. It Is unclear if these circumferential dykes are the result of direct emplacement of magma driven by local stresses associated with corona formation (as is thought to be the case for radiating dyke swarms (e.g., McKenzie et al., 1992)), or if pre-existing extensional structures have simply facilitated later magma transport to the surface. It should be noted that the stress field orientation favouring the formation of circumferential extensional structures would favour the same orientation of dyke emplacement.

\subsection{Estimates of Magma Volume}

The total volume of magma emplaced in a dyke swarm can be estimated if the cumulative length, average width, and vertical extent of the dykes within the crust can be approximated (Fahrig, 1987). 
Located in northern Canada, the Mackenzie swarm is the largest currently recognized radiating dyke swarm on Earth (Figure 3.3A). It was first compared to Fatua Corona by McKenzie et al. (1992). It resembles the radiating system associated with Fatua Corona both in size (the Mackenzie and Fatua Corona swarms extend approximately $2500 \mathrm{~km}$ and $1700 \mathrm{~km}$ from their centres, respectively) and in the gradual change in dyke trend from a proximal radial to a distal subparallel linear arrangement. Assuming an average dyke thickness of $30 \mathrm{~m}$, and an average vertical dyke depth of 50 $\mathrm{km}$, Fahrig (1987) estimated that the Mackenzie swarm has approximately $80,000 \mathrm{~km}^{3}$ of magma emplaced in its dykes. A similar estimate can be generated for the radiating swarm associated with Fatua Corona, assuming similar geometric dyke parameters. This estimate yields a value of approximately $57,000 \mathrm{~km}^{3}$ or $71 \%$ of the estimate for the Mackenzie swarm.

Fatua Corona is also associated with three volcanic flow units (Fatua Corona Flow Material Units 1, 2, and $3(\mathrm{cmF} 1, \mathrm{cmF} 2$, and $\mathrm{cmF} 3$; refer to Section 2.3.4.5), corresponding to a combined surface area of $327,512 \mathrm{~km}^{2}$. These volcanic flow units extend well beyond the rim of the corona; unit cmF1 extends to a distance of approximately $600 \mathrm{~km}$ from the southeastern edge of the corona rim. Assuming a volcanic flow thickness of $10 \mathrm{~m}$ (Roberts et al., 1992), the corresponding volume of these flow units is $3,275 \mathrm{~km}^{3}$. Combining the estimated volume of these flow units with the estimate on the upper limit of the intrusive volume of radiating dykes associated with Fatua Corona (approximately $57,000 \mathrm{~km}^{3}$ ) leads to a total igneous volume estimate of $60,275 \mathrm{~km}^{3}$. However, this estimate does not take into account additional igneous material which may be associated with volcanic constructs in the corona's interior, or 
with circumferential dykes and/or other intrusive bodies, such as layered intrusions. The assumption of a $10 \mathrm{~m}$ flow thickness may also be an underestimation of the true flow thickness, which is not ascertainable with the available data. With the consideration of these potential additional sources of igneous material, Fatua Corona may meet the volume criteria $\left(100,000 \mathrm{~km}^{3}\right)$ to be considered a large igneous province (LIP) (Coffin and Eldholm, 1994; Bryan and Ernst, 2008; Ernst, 2014). Additionally, Fatua Corona has been classified in the global corona catalogue of Venus by Stofan et al. (1992) as volcanic category 2 (moderate associated volcanism). The recognition of its three associated volcanic flow units may warrant its re-classification to volcanic category 3 (extensive associated volcanism).

\subsection{Regional Stress Field}

Dyke swarms are useful indicators of the paleostress field at the time of their formation, as long as they have not experienced significant subsequent deformation (e.g., Odé, 1957; Grosfils and Head, 1994a,b; Marinoni and Gudmundsson, 2000; Hou et al., 2006; Hou et al., 2010). Dykes propagate parallel to the maximum compressive principal stress $\left(\sigma_{1}\right)$ and perpendicular to the least compressive principal stress $\left(\sigma_{3}\right)$ (Delaney et al., 1986; Pollard, 1987; Gudmundsson, 1995; Rivalta et al., 2015; Townsend et al., 2017).

The extensive nature of the Fatua Corona radiating graben-fissure system provides a unique opportunity to study the stress field across a large area. The change in geometry of the system from a radiating geometry into a subparallel linear geometry reflects a change in the stress field southward from the corona's centre (Figure 3.2B). At 
the time of radial dyke emplacement, proximal to the magmatic centre of Fatua Corona, the regional stress field was perturbed by the corona's locally induced stress field; $\sigma_{3}$ was the hoop stress and the formation of radially oriented dykes is preferred. At distances greater than approximately $450 \mathrm{~km}$, the dykes propagated along the orientation of the regional stress field. In this case, the regional stress field is inferred from the dyke geometry to have had the maximum compressive stress $\left(\sigma_{1}\right)$ oriented NESW (Figure 3.2B). The structures overlying the dykes terminate approximately $150 \mathrm{~km}$ northeast of the outer margins of the Alpha-Lada extensional belt. The geometry of the circumferential system also appears to be influenced by the regional stress field. The innermost annulus structures are near-circular, whereas the outermost graben of the annulus form an ovoid geometry that is elongated to the south. These outermost graben extend to approximately the same distance that the radiating dykes begin to swing in trend (approximately $450 \mathrm{~km}$ from the centre of the corona) (Figure 3.2A). Similar deflections of circumferential structures associated with coronae were observed by Baer et al. (1994) for some of the coronae contained within the Alpha-Lada and DercetoQuetzalpetlatl extensional belts, and were attributed to the superposition of local (corona) and regional (extension) stresses. The influence of the regional stress field on the orientations of both the radiating and circumferential structures associated with Fatua Corona implies that the stress field remained relatively constant throughout the duration of the corona's formation.

The Alpha-Lada extensional belt trends NW-SE, with a total length of approximately $6000 \mathrm{~km}$ and a maximum width of approximately $200 \mathrm{~km}$ (Figure 3.1; Baer et al., 1994). The Alpha-Lada extensional belt intersects with the Derceto- 
Quetzalpetlatl extensional belt at Astkhik Planum (Bridges and McGill, 2002). The Derceto-Quetzalpetlatl extensional belt trends NNE-SSW, extends for approximately $2000 \mathrm{~km}$, and reaches widths of approximately $300 \mathrm{~km}$ in some areas (Figure 3.1; Baer et al., 1994). Both extensional belts are associated with abundant coronae and volcanism. Cross-cutting relationships demonstrate that extension in the DercetoQuetzalpetlatl belt initiated before the Alpha-Lada belt, but extension in the two belts more or less overlapped in time (Baer et al., 1994). Along the area of intersection between the two belts, the Alpha-Lada belt is continuous and cuts structures and depressions associated with the Derceto-Quetzalpetlatl belt (Baer et al., 1994). Bridges and McGill (2002) determined that the formation of the Alpha-Lada extensional belt was likely broadly contemporaneous with the formation of the Fatua Corona radiating graben-fissure system.

Radiating graben-fissure systems (likely underlain by dyke swarms) are commonly associated with coronae contained within the Alpha-Lada and DercetoQuetzalpetlatl extensional belts, and in most cases, swing in trend to align with the main trend of the belts (Baer et al., 1994; Bridges and McGill, 2002). The overall trend and the geometry of the extensional structures suggest that extension (along $\sigma_{3}$ ) was in the NE-SW and WNW-ESE directions for the Alpha-Lada and Derceto-Quetzalpetlatl belts, respectively. Therefore, the orientation of the $\sigma_{1}$ within the Alpha-Lada and DercetoQuetzalpetlal extensional belts was likely NW-SE and NNE-SSW, respectively. This is consistent with observations of the geometries of giant dyke swarms in the Beta-AtlaThemis (BAT) region on Venus (Grosfils and Head, 1994a). However, the southernmost portion of the radiating system extending from Fatua Corona trends orthogonally to the 
main orientation of the Alpha-Lada extensional belt; radiating graben are truncated near the northeastern margin of the belt by younger regional flood basalt plains (Bridges and McGill, 2002). The geometry of the Fatua Corona radiating system suggests that $\sigma_{1}$ close to the Alpha-Lada extensional belt was oriented NE-SW.

Although the geometry of Fatua's radiating dykes was first studied by McKenzie et al. (1992), a discrete tectonic mechanism for the regional stress field pattern was not detailed. Two endmember hypotheses are proposed to explain the orientation of the regional stress field at the time of emplacement of the Fatua Corona radiating dyke swarm.

The first hypothesis is that extension in the Derceto-Quetzalpetlatl extensional belt was the dominant cause for the NE-SW orientation of $\sigma_{1}$. This hypothesis requires that the dykes were emplaced when extension was active along the DercetoQuetzalpetlatl belt, but prior to the onset of extension in the Alpha-Lada belt. It also necessitates that extensional stresses from the Derceto-Quetzalpetlatl belt were continuous for nearly $3000 \mathrm{~km}$ beyond the northernmost extent of the belt, where it intersects with Astkhik Planum. Bridges and McGill (2002) found that in the vicinity of Astkhik Planum, lineaments in the Derceto-Quetzalpetlatl belt are deflected parallel to the trend of the Alpha-Lada belt. This observation indicates that the stress field of the Alpha-Lada belt may have already been active when the Derceto-Quetzalpetlatl belt was forming. Extension in the Alpha-Lada belt appears to have been dominant both spatially and temporally relative to the Derceto-Quetzalpetlatl belt; the Alpha-Lada belt is more regionally continuous and its structures cross-cut those of the Derceto- 
Quetzalpetlatl belt. For these reasons, the second hypothesis (discussed in the following paragraph) is favoured.

The second hypothesis is that extension in the Alpha-Lada belt was the driving force for the regional stress field orientation recorded by the dykes. This hypothesis requires that the orientation of $\sigma_{1}$ changed from rift-parallel within the zone of extension, to rift-orthogonal at its margins. A similar scenario has been proposed to explain the orientation of the Mackenzie dyke swarm on Earth. The Mackenzie dykes swing in trend from a N-S trend in the focal area to a NW-SE trend further south (Figure 3.3A; Ernst and Buchan, 2001). The terminations of the Mackenzie dykes are oriented orthogonally to the trend of the Grenville Ocean. Modeling of the paleostress field suggests that the NW-SE orientation of $\sigma_{1}$ was a result of ridge push forces produced by Grenville Ocean spreading (Figure 3.3B; Hou et al., 2010). This type of stress field configuration is also observed within intraplate settings away from divergent plate boundaries on Earth, where $\sigma_{1}$ is oriented orthogonally to the main rifting trend (Zoback, 1992). Through analogy with these examples on Earth, extension in the Alpha-Lada belt may be inducing a ridge push force in the surrounding lithosphere, and may therefore represent a more Earth-like, insipient divergent boundary than the styles of rifting observed elsewhere on Venus (such as in the BAT region).

To provide further support for either hypothesis, future work should be focused on mapping additional stress indicators (e.g., wrinkle ridges) in the vicinity of the AlphaLada and Derceto-Quetzalpetlatl extensional belts in order to better constrain the orientation of the regional stress field throughout their development. Further detailed analysis of the cross-cutting relationships between geological units and structures at the 
intersection between the two extensional belts and at the southern terminus of Fatua's radial graben may also help constrain the age relationships between these three features.

\subsection{Summary}

Mapping of graben-fissure systems associated with Fatua Corona reveal a circumferential graben-fissure system with a maximum diameter of $915 \mathrm{~km}$ and a radiating graben-fissure system that extends for $1700 \mathrm{~km}$ southward from the corona's centre. Association of these graben-fissure systems with volcanic flows and shield volcanoes, and analogy with other giant radiating systems on Venus and Earth, suggests links with underlying giant dyke swarms. The estimate of the volume of magma emplaced in radiating dykes associated with Fatua Corona is approximately $57,000 \mathrm{~km}^{3}$, which is comparable to the Mackenzie swarm (the largest dyke swarm on Earth), and is approaching the volume requirement for a LIP $\left(100,000 \mathrm{~km}^{3}\right)$. In addition to dyke magmatism, Fatua Corona is also associated with three volcanic flow units that are estimated to represent an additional volume component of $3,275 \mathrm{~km}^{3}$. These volume estimates do not account for circumferential dykes or other magmatic intrusions.

Fatua Corona's radiating dykes exhibit a change in geometry southward from the corona's centre into a subparallel linear geometry trending NNE-SSW. Since dyke orientations can be used as stress indicators, the maximum compressive stress is inferred to be NNE-SSW. The southward termination of these dykes is spatially associated with the margins of the Alpha-Lada extensional belt. Comparison of these stress orientations with similar observations of tectonic stress field interactions on Earth 
(e.g., the Mackenzie dyke swarm and the Grenville Ocean, and the Atlantic and Pacific Ocean spreading centres) suggests that the Alpha-Lada extensional belt may represent an example of an insipient Earth-like divergent plate boundary. 


\subsection{Figures}

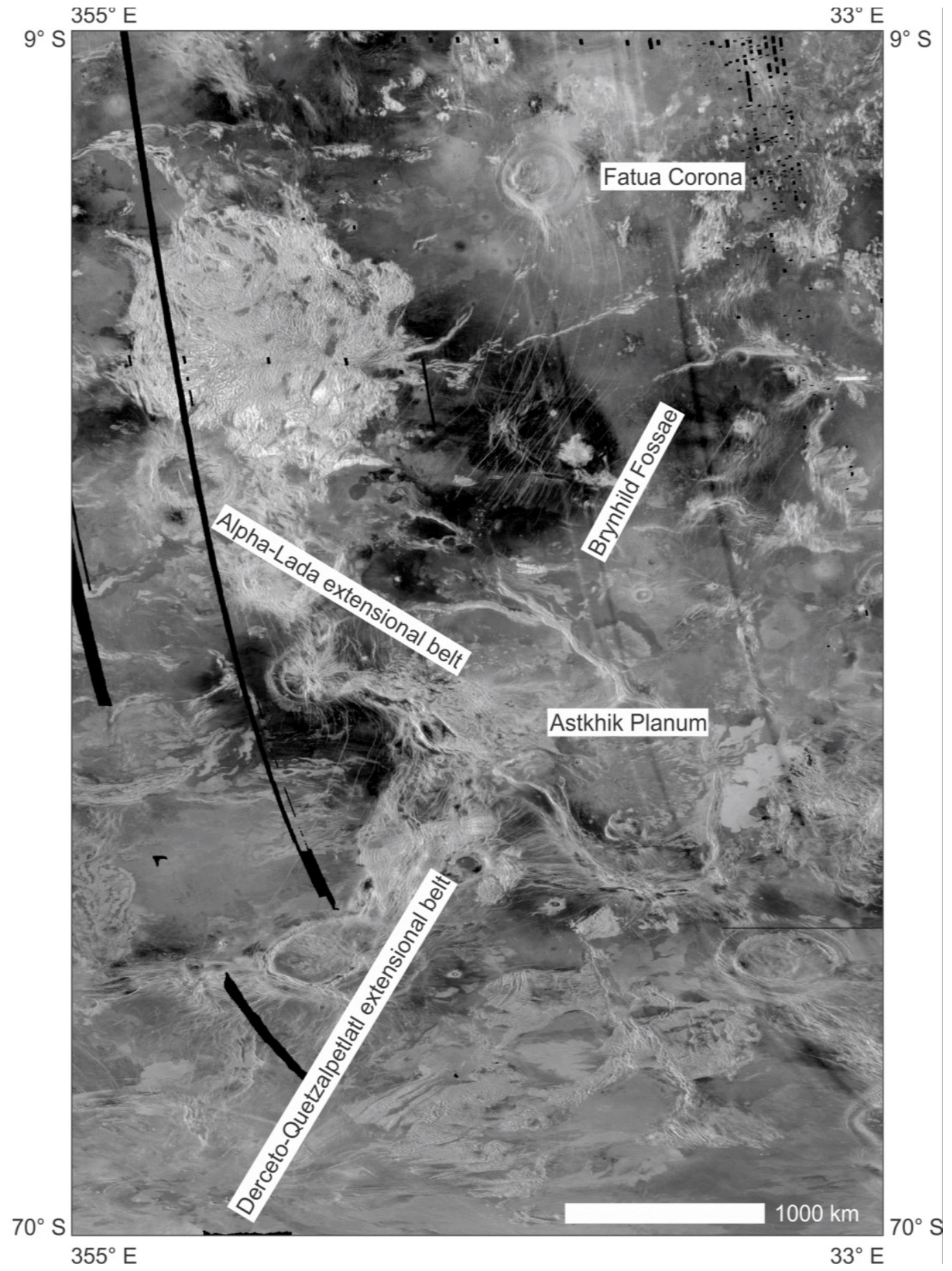

Figure 3.1: Regional map showing the location of the Alpha-Lada and DercetoQuetzalpetlatl extensional belts, their intersection (at Astkhik Planum), Fatua Corona, and the Brynhild Fossae (radiating graben associated with Fatua Corona). 


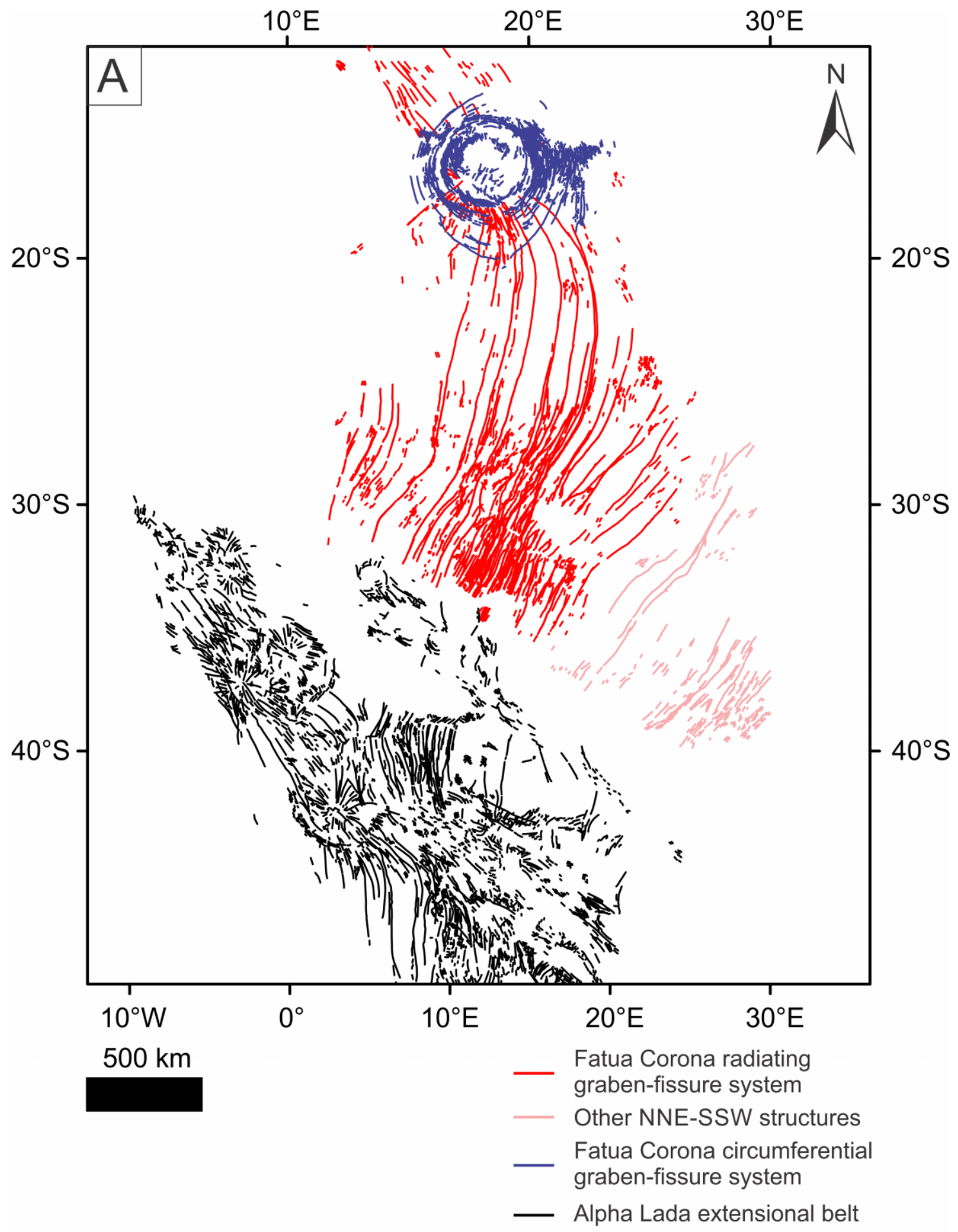




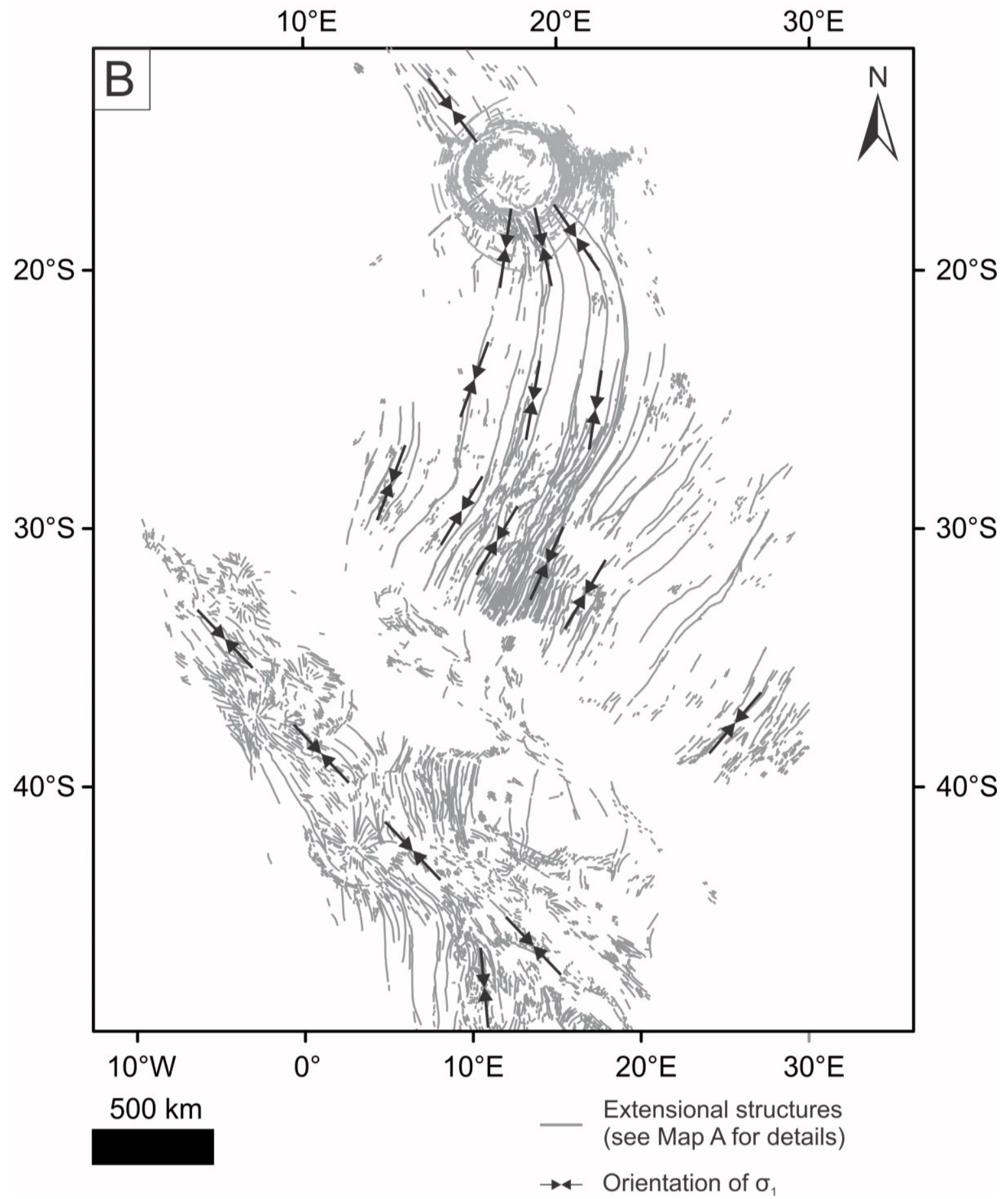

Figure 3.2: Map of structures associated with Fatua Corona and the Alpha-Lada extensional belt: A) structural map depicting the relationships between graben-fissure systems associated with Fatua Corona (radiating (red) and circumferential (blue)) and extensional structures within the Alpha-Lada extensional belt (black); B) map depicting the structures in map A (grey) and superimposed orientations of the maximum compressive stress (black arrows). 


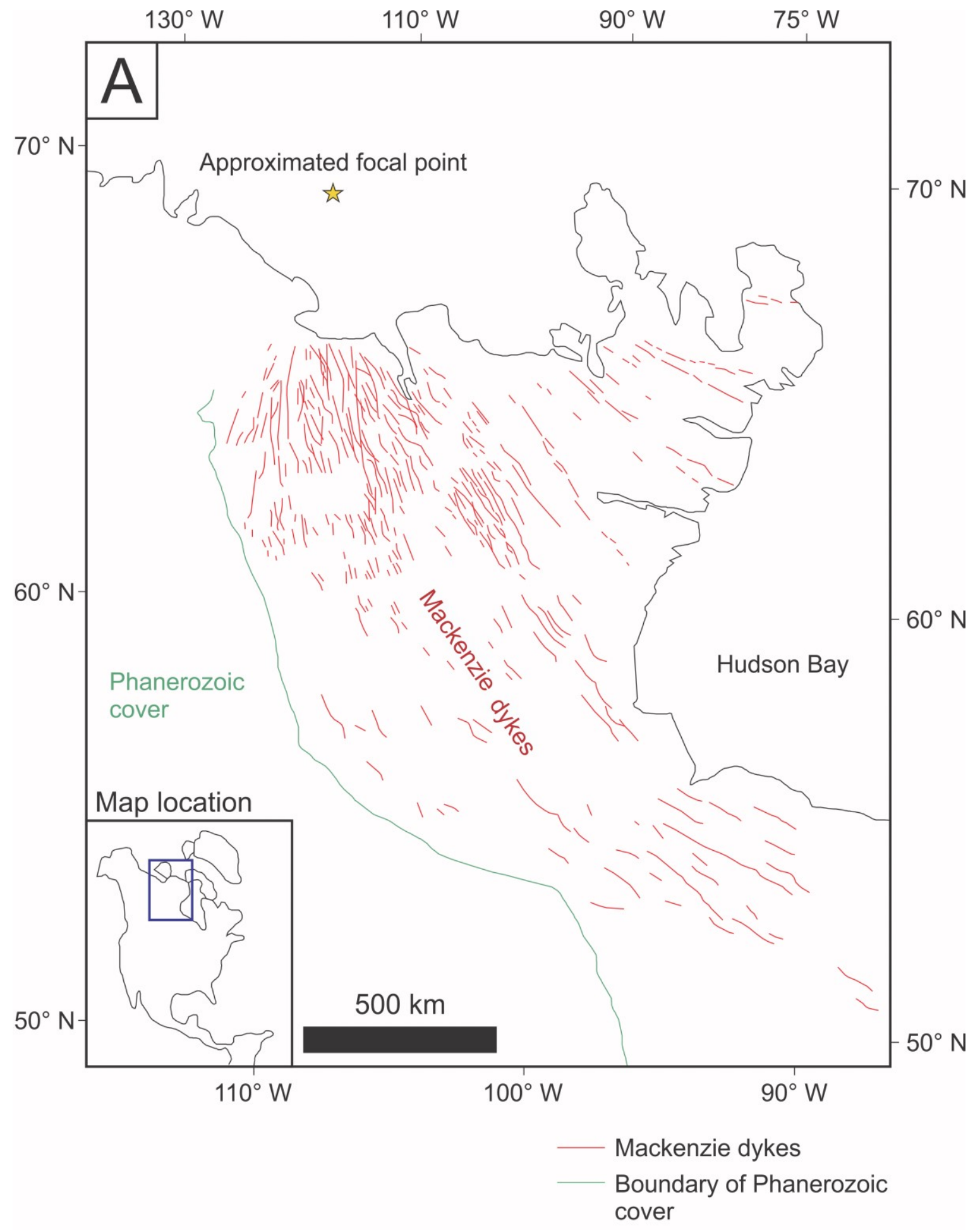




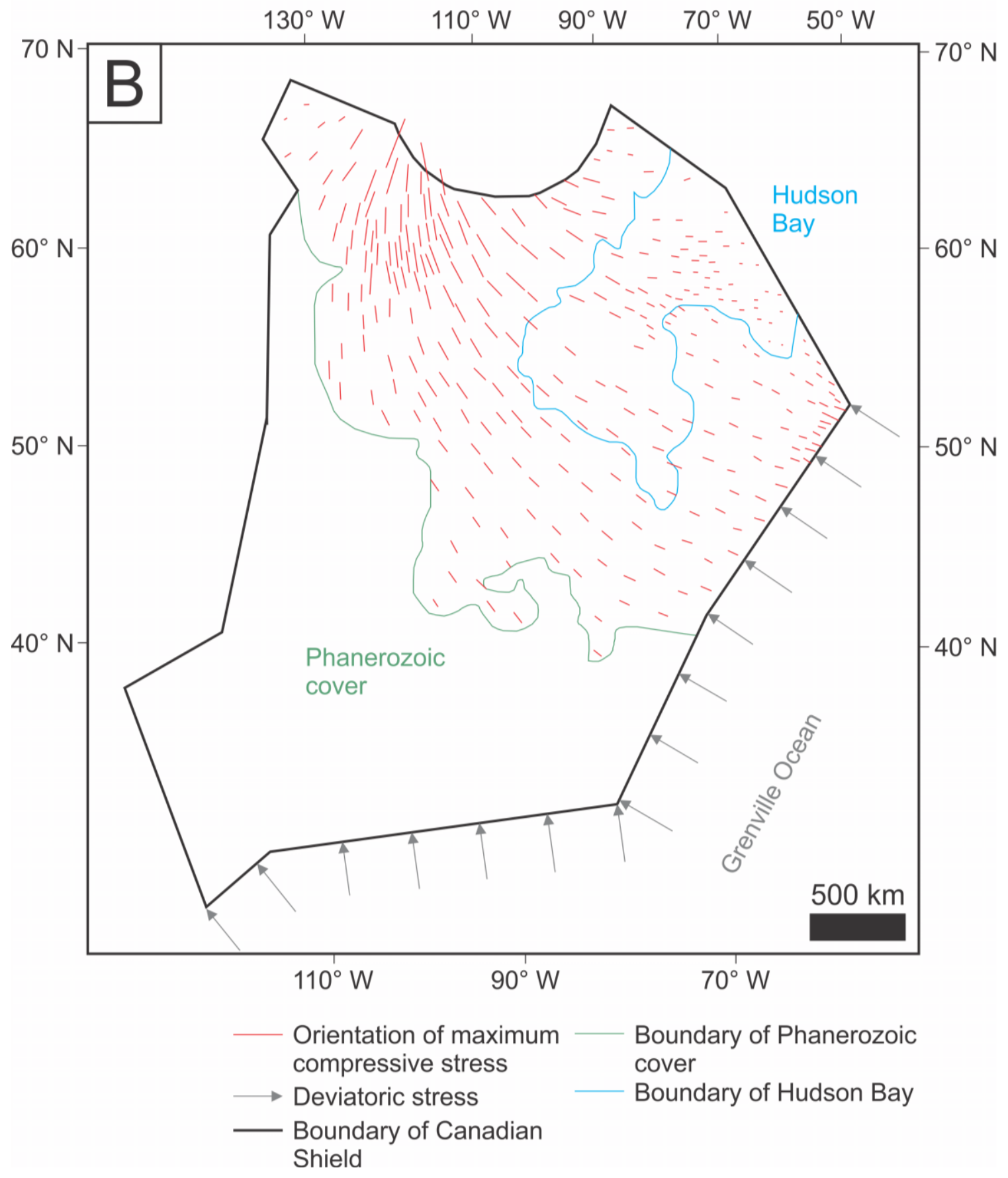

Figure 3.3: The Mackenzie radiating dyke swarm: A) map of the generalized distribution of Mackenzie radiating dykes (after Day et al., 2008); B) map of modeled maximum compressive stress orientations along the trajectory of the Mackenzie dykes (after Hou et al., 2010). 


\section{CHAPTER 4: INSIGHTS ON CORONAE FROM GEOLOGICAL MAPPING}

\subsection{Coronae on Venus as Analogues to Large Igneous Provinces (LIPs) on Earth 4.1.1 Coronae: Unique to Venus?}

From initial observations returned from the Venera 15/16 and Magellan missions, coronae were thought to be unique to Venus (Barsukov et al., 1984; Barsukov et al., 1986; Basilevsky et al., 1986; Stofan and Head, 1990; Pronin and Stofan, 1990; Stofan et al., 1991; Grindrod and Hoogenboom, 2006). However, some analogues have been proposed on Earth, Mars, and Miranda (e.g., Anguita and Chiccaro, 1991; Burba and Shashkina, 1992; Watters and Janes, 1995; Lopéz et al., 1999; Williams and Moore, 2003; Bethell et al., 2016; Buchan and Ernst, 2016). It has been proposed that the lack of corona formation processes on Earth may be due to the presence of horizontal plate motion (i.e., plate tectonics). While plate tectonics may restrict the formation and preservation of terrestrial coronae, it does not necessarily exclude them (Lopéz et al., 1999). Some discrete features on Earth have been compared to Venusian coronae, including volcanic constructs associated with the East African Rift System (Lopéz et al., 1999), oceanic plateaus (e.g., Ontong-Java; Lopéz et al., 1999), and the Transylvanian Ring Structure (Burba and Shashkina, 1992).

Large igneous provinces (LIPs) are massive emplacements of mainly mafic igneous rocks, including volcanic and intrusive components, occurring over relatively short timescales (Coffin and Eldholm, 1994; Bryan and Ernst, 2008; Ernst, 2014). Bryan and Ernst (2008) define LIPs as follows: "Large igneous provinces are magmatic provinces with areal extents $>0.1 \mathrm{Mkm}^{2}$, igneous volumes $>0.1 \mathrm{Mkm}^{3}$ and maximum lifespans of $\sim 50$ Myr that have intraplate tectonic settings or geochemical affinities, and 
are characterized by igneous pulse(s) of short duration ( 1-5 Myr), during which a large proportion ( $>75 \%)$ of the total igneous volume has been emplaced". The major mafic components of LIP magmatism include flood basalts, giant dyke swarms (of radiating, linear, and circumferential geometries), sill provinces, magmatic underplating, and mafic-ultramafic intrusions (Figure 4.1; Ernst et al., 2019). Many LIPs are inferred to originate from mantle plumes (e.g., Richards et al., 1989; Campbell and Griffiths, 1990; Campbell, 2005; Dobretsov, 2008; Campbell, 2007).

Venus' coronae are associated with many of the characteristics that define terrestrial LIPs. Many coronae are the source of major volcanic flow units analogous to flood basalts (e.g., Fatua Corona is associated with over $300,000 \mathrm{~km}^{2}$ of volcanic flows; refer to Section 3.3). Giant dyke swarms that have been recognized on Venus are frequently found in associated with coronae (see discussion in the following Section 4.1.2). The presence of sill provinces, magmatic underplating and mafic-ultramafic intrusions associated with coronae are more speculative as these features are not as directly observable at the surface (Figure 4.1). A limiting factor in the designation of coronae on Venus as LIPs is the lack of constraints on the timing of these features. On Earth, the timing of LIPs can be constrained in detail due to the availability of high precision radioisotope dating of LIP-related rocks (e.g., Jourdan et al., 2007; Svensen et al., 2012; Shellnutt et al., 2012; Burgess et al., 2015; Kasbohm et al., 2021). The lack of such absolute ages and the absence of a significant impact cratering record on Venus means that only relative ages can be obtained for coronae and their associated features. 


\subsubsection{Dyke Swarms on Venus}

On Earth, many dyke swarms are recognized at the surface as they have been exposed by erosion of the overlying rock. On other planets, namely Mars and Venus, global rates of erosion have not been significant enough to expose dykes at the surface to the extent observed on Earth. In some areas of Mars, dykes have been locally exposed by erosion (e.g., Early Amazonian dykes in the Elysium Rise/Utopia Basin Region; Pedersen et al., 2010), yet to date, no exposed dykes have been recognized on Venus. However, unexposed subsurface dyke swarms should still be recognizable from the resultant surface deformation. The giant radiating graben-fissure systems observed around many volcanic centres on Venus have been compared to giant radiating dyke swarms on Earth in terms of both their scale, geometry, and associations with other features (Grosfils and Head, 1991; Head et al., 1991; McKenzie et al., 1992). Further analysis through global cataloguing of these radiating graben-fissure systems on Venus, and supplemented with modeling, suggests that many radiating graben-fissure systems on Venus are likely underlain by dyke swarms, and not solely produced by tectonic uplift (Parfitt and Head, 1993; Grosfils and Head, 1994a,b; Ernst et al., 1995; Ernst et al., 2001; Grindrod et al., 2005). The surface deformation associated with dyke emplacement is thought to occur when extensional stresses above propagating dykes produce normal faulting that can result in the formation of a graben at the surface above the dyke (Pollard et al., 1983; Rubin, 1992; Grosfils and Head, 1994a; Ernst et al., 2003). Grosfils and Head (1994b) observed that many of these radiating graben-fissure systems display systematic transitions from graben to fractures to fissures with increasing distance from their origin at their respective volcanic centre, which is 
consistent with the formation of these structures from underlying, laterally propagating dykes. Detailed mapping of radiating graben-fissure systems on Venus shows that they are commonly associated with lobate volcanic flows, clusters of shield volcanoes, and pit craters (Grosfils and Head, 1994b). Many radiating graben-fissure systems emanate from volcanic centres such as large volcanoes and coronae (Head et al., 1992; Grosfils and Head, 1994a,b; Ernst et al., 1995; Ernst et al., 2003; Studd et al., 2011; Graff et al., 2018). On Mars, radiating graben-fissure systems are also observed in association with volcanic centres, notably with the Tharsis rise, where they are also interpreted to overly dyke swarms (Ernst et al., 2001; Wilson and Head, 2002).

\subsubsection{Giant Circumferential Dyke Swarms}

Since circumferential graben-fissure systems around magmatic centres also possess the aforementioned associations with volcanic features, it is hypothesized they also are underlain by dyke swarms (Bethell et al., 2015; Bethell et al., 2016; Buchan and Ernst, 2016, 2018, 2019).

Recently, at least fifteen giant circumferential dyke swarms have been recognized on Earth (Buchan and Ernst, 2019). These comprise a new class of dyke swarms associated with LIPs; they are quasi-circular, span $50^{\circ}-180^{\circ}$ in arc, are sometimes associated with coeval radiating dyke swarms, and have diameters from hundreds of kilometres, potentially up to thousands of kilometres (Ernst and Buchan, 1998; Buchan and Ernst, 2016, 2018, 2019). They are of a much larger scale, than smaller circumferential dyke swarms and fissure systems, such as those observed at the volcanoes of the Galapagos Islands (Chadwick and Dieterich, 1995). The most 
notable example of a giant circumferential dyke swarm discovered to date is the 1385 Ma Lake Victoria dyke swarm that is related to the Kunene-Kibaran LIP in East Africa (Figure 4.2). It has a diameter of approximately $650 \mathrm{~km}$ and an arc length of $180^{\circ}$, although it may extend much further, into neighbouring areas that have not been studied (Mäkitie et al., 2014; Buchan and Ernst, 2016, 2019).

\subsubsection{Characteristics of Circumferential Graben-Fissure Systems Associated with Coronae}

To provide further comparison between coronae on Venus and LIPs on Earth, specifically between the circumferential graben-fissure systems associated with coronae on Venus and the giant circumferential dyke swarms associated with some LIPs on Earth, a detailed global analysis of the characteristics of coronae should be conducted that builds upon previous global cataloguing efforts (e.g., Stofan et al., 1992, 2001; Crumpler and Aubele, 2000). This section of the thesis includes a summary of the characteristics of circumferential graben-fissure systems associated with coronae in the V-32 quadrangle and considers implications (e.g., magma source location) if the graben-fissure systems are underlain by dyke swarms. Observations for the coronae in the V-32 quadrangle are summarized in Table 4.1, and a schematic drawing demonstrating the various measurements is given in Figure 4.3.

Comparative planetology is a powerful tool that enables us to learn more about processes occurring on different planets. A greater understanding of LIPs and their various components on Earth will inform the study of coronae on Venus, and vice versa. This summary will be a predictive guide for the expanded identification of giant circumferential dyke swarms on Earth and Venus 


\subsubsection{Arc Length}

Arc length is used here to refer to the central angle that corresponds to the proportion of the circumference about a magmatic centre that a circumferential system of structures extends. Stofan et al. (1992) defined a condition wherein a corona-like feature must have an annulus arc length of at least $180^{\circ}$ to be classified as a corona. This definition was later revised by Stofan et al. (2001) to include corona-like features that have a topographic expression but lack significant development of circumferential structures, leading to the creation of two sub-divisions of coronae: a) type 1 coronae, which have arc lengths of $180^{\circ}$ or greater ( 409 or $79 \%$ of coronae), and b) type 2 coronae, which have arc lengths of less than $180^{\circ}$ or completely lack an annulus (106 or $21 \%$ of coronae).

Arc lengths less than $360^{\circ}$ may be the result of primary processes of corona formation (such as asymmetry of the underlying diapir or magma chamber), but in many cases are explained by partial volcanic flooding of the annulus. For example, circumferential structures associated with Atargatis Corona are older than the surrounding volcanic plains unit (Smooth Plains Material Unit 1 (ps1)) and have been obscured by this unit in topographically low-lying areas, leading to a diminished arc length of $270^{\circ}$ (refer to Section 2.3.4.2). The currently recognized giant circumferential dyke swarms on Earth possess arc lengths ranging from $70^{\circ}$ to $220^{\circ}$ (Buchan and Ernst, 2019). On Earth, the reason for arc lengths less than $360^{\circ}$ is more difficult to explain. Differential levels of erosion or covering by sediments could lead to diminished arc lengths. In addition, it is hypothesized that circumferential dykes can be narrower and therefore more difficult to recognize than radiating dykes (Buchan and Ernst, 2019). 


\subsubsection{Minimum and Maximum Diameter}

The diameters of coronae on Venus have been estimated in global cataloguing efforts, such as those of Stofan et al. (1992) and Crumpler and Aubele (2000). However, these estimates are based on global reconnaissance-level surveys of coronae and other volcanic features. Detailed mapping of the structures associated with each corona at the full resolution of the Magellan SAR data is needed to accurately determine the maximum diameters of these features. As discussed in the following paragraphs, detailed mapping studies have shown that some coronae have multiple generations of annulus structures (e.g., Copp et al., 1998) and this information should also be recorded. A discussion on estimations of coronae size and the importance to comparisons with terrestrial analogues is included in Section 4.2 below.

In addition to characterizing the maximum diameter of corona-related structures, a catalogue of the minimum diameters is also important as the morphology of coronae and their associated circumferential graben-fissure systems are often asymmetric. Cybele Corona is asymmetric; its annulus has been divided into two rings that overlap each other and possess different relative ages (Figure 2.22; refer to Section 2.3.4.6). This asymmetry may reflect the size and shape of an underlying magma chamber/magmatic underplate. One of the models proposed to explain the formation of the Lake Victoria Dyke Swarm on Earth by Mäkitie et al. (2014) conceptualizes the dykes as cone sheets propagating from the edges of an approximately $400 \mathrm{~km}$ wide ellipsoidal magma chamber above a mantle plume. However, more research is needed to understand the possible existence of such a large magma chamber at the base of an approximately $40 \mathrm{~km}$ thick crust. Alternative explanations may involve one or more 
smaller feeder magma chambers peripheral to the centre of the mantle plume (Mäkitie et al., 2014). This model may be supported by the interpretation of large intrusions along the circumference of mantle plume centres from gravity and magnetic data for some LIPs, such as the Mackenzie LIP (Blanchard et al., 2017). Dombard et al. (2007) proposed a model for corona formation on Venus wherein coronae form as a response to magmatic loading of the crust over a magmatic underplate. The magmatic underplating model of Dombard et al. (2007) is able to account for the wide ranges in diameters observed for coronae, which are not well explained by previous upwelling models. By analogy with Earth, magmatic underplates could account for even the largest coronae on Venus. For example, the High Arctic LIP is associated with an ellipsoidal, approximately $1000 \mathrm{~km}$ long deep crustal magnetic anomaly that has been interpreted to represent magmatic underplating (Oakey and Saltus, 2016). It has also been proposed that giant circumferential dyke swarms may be produced at the margins of a flattening plume head and directly reflect the size of the mantle plume (Buchan and Ernst, 2019, and references therein). In any of the models discussed above, the configuration of the feeder magma chamber(s)/magmatic underplate above the plume is a primary control on the resulting geometry of a circumferential dyke swarm and associated graben-fissure system at the surface.

Other detailed mapping studies on Venus have documented evidence for multiple episodes of annulus formation at coronae (Copp et al., 1998). Multiple generations of annulus structures, as observed here with Cybele Corona (Figure 2.22, refer to Section 2.3.4.6), may also reflect different pulses of plume-induced magmatism, as is frequently observed for LIPs on Earth (Ernst, 2014). 


\subsubsection{Minimum and Maximum Annulus Width}

The width of circumferential graben-fissure systems often varies along the annulus of coronae. For coronae in the $\mathrm{V}-32$ quadrangle, annulus widths vary by as much as $270 \mathrm{~km}$ around the structure (Table 4.1). If underlain by dykes, variations in the width of a circumferential graben-fissure system may represent variations in the width of the feeding zone off the magma chamber(s)/magmatic underplate. However, the apparent variations in width may also be the result of partial flooding of the structures by later volcanism. Circumferential structures associated with Atargatis Corona are partially flooded by later plains volcanism (corresponding to Smooth Plains Material Unit 1 (ps1)) in various locations along the annulus (Figure 2.18). On Earth, similar secondary modifications, such as differential erosion or levels of sedimentary cover, may also affect the observed width of circumferential dyke swarms. Terrestrial giant circumferential dyke swarms have been described as possessing a broad range in widths along the swarm (Buchan and Ernst, 2019). A generally positive relationship between annulus width and corona size has been suggested (Stofan et al., 1992), and may also be true for circumferential dyke swarms on Earth (Buchan and Ernst, 2019).

\subsubsection{Distribution with Respect to Corona Topography}

While circumferential graben-fissure systems (i.e., the "fracture annulus") are often concentrated in the uplifted rim of coronae, researchers have noted that they do not always coincide with the topographic rim (Stofan et al., 1992; Smrekar and Stofan, 1997; Copp et al., 1998). In some cases, circumferential graben-fissure systems can extend significantly beyond the uplifted rim. All of the coronae in the V-32 quadrangle 
possess circumferential structures that extend beyond the outermost extent of the topographic rim (Table 4.1). In the case of Fatua Corona, circumferential graben are observed as far as $170 \mathrm{~km}$ beyond the topographic rim of the corona (Figure 2.21, refer to Section 2.3.4.5). This suggests the generation of circumferential graben-fissure systems might not be entirely controlled by the same mechanisms that generate corona topography. In addition, Copp et al. (1998) noticed several instances of temporal offsets between the formation of circumferential graben-fissures and that of the rim topography. Smrekar and Stofan (1997) argue in their model of corona formation by coupled upwelling and delamination that the spatial discrepancy between the annulus of grabenfissures and the topography can be explained by the complex topographic evolutions predicted by the models. These models, however, do not explicitly describe the detailed relationship between the annulus and topography. One explanation could be that if some of these circumferential graben-fissures are underlain by dykes, they may be fed by magma propagating outward from the plume centre via sills or dykes. These sills or dykes may feed peripheral "staging chambers" that can act as sources for circumferential dyke swarms, or the intrusions may change geometry and ascend to the surface, as suggested for plumbing system models for LIPs on Earth (Ernst et al., 2019). In these scenarios involving lateral and/or vertical propagation of magma away from the plume centre, the distribution of circumferential dykes is not necessarily confined to the region of topographic influence from an impinging mantle plume.

On Earth, the relationship between the geometry of giant circumferential dyke swarms and any primary associated topography is harder to constrain due to erosion (Buchan and Ernst, 1998; Bethell et al., 2015; Buchan and Ernst, 2019). Domal uplifts 
above mantle plume centres have been inferred from the sedimentary record for many LIPs (Ernst, 2014, and references therein). The High Arctic LIP, which is associated with a circumferential dyke swarm approximately $1600 \mathrm{~km}$ in diameter, has been suggested to possess a domal uplift or circumferential rim (Maher, 2001; Buchan and Ernst, 2019).

\subsubsection{Relationship with Radiating Graben-Fissure Systems}

According to the models of corona formation involving mantle upwelling and/or diapiric uplift, radiating systems are thought to be generated during the uplift and magmatic construction phase (Stofan and Head, 1990; Stofan et al., 1992; Squyres et al., 1992). Circumferential systems are thought to be generated during gravitational relaxation of the diapir (Squyres et al., 1992). This suggests that the circumferential systems are mostly younger than the radiating systems. When radiating and circumferential systems occur together, their respective foci are commonly offset, which further indicates a time lapse between their formation. In some cases, mutual crosscutting relationships suggest broadly contemporaneous formation (Stofan et al., 1992). Some coronae in the V-32 quadrangle have contradictory, or ambiguous cross-cutting relationships in consideration of this model. Kuan-Yin Corona's radiating graben-fissure system cross-cuts its circumferential graben-fissure system (Table 4.1; refer to Section

2.3.4.3). Cybele Corona possesses two rings of differing ages in its annuli; its associated radiating system cross-cuts the older of these rings, but is cross-cut by the younger ring (Table 4.1; refer to Section 2.3.4.6). Similar observations between the timing of radiating graben-fissure systems and corona annuli were made by Copp et al. (1998) in their detailed mapping of Benten Corona; its annulus is cross-cut by late-stage 
radial graben and the authors interpreted this as evidence for a secondary phase of uplift. These observations again suggest that coronae may experience multiple pulses of activity as is frequently observed with LIPs on Earth (Ernst, 2014).

Not all coronae are associated with a radiating graben-fissure system; for example, Thouris Corona (Figure 2.20, refer to Section 2.3.4.4). This is also true for giant circumferential dyke swarms on Earth. The most notable example, the Lake Victoria Dyke Swarm, does not appear to be associated with a radiating swarm (Mäkitie et al., 2014; Buchan and Ernst, 2019).

\subsubsection{Association with Magmatic Features}

The annuli of coronae are frequently host to a variety of features of magmatic origin (Figure 4.4). Volcanic flows are observed to originate from circumferential structures associated with coronae (Figure 4.4A). In the V-32 quadrangle, volcanic flow units cfK1, cfK2, cmF1, cmF2, and cmF3 are sourced from structures in the annuli of coronae (refer to Section 2.3.4). Some annuli of coronae also contain numerous shield volcanoes and other smaller volcanic constructs (Figure 4.4B). The annulus of Fatua Corona contains a field of hundreds of shield volcanoes and their associated deposits, which has been mapped as the units vf2a and vf2b. Some channelized volcanic features (i.e., sinuous rilles or canali-like features) have been observed to originate from circumferential graben-fissures; notably, circumferential structures associated with Cybele Corona in the V-32 quadrangle are the source of a few channelized features (Figure 4.4C). Although not observed in association with any of the coronae in the V-32 quadrangle, some coronae have also been observed to have steep-sided domes in their 
annuli (Figure 4.4B). Lang and Lopéz (2013) observed that tholi are spatially associated with circumferential graben-fissures around several coronae and they interpret these to be sourced from the circumferential structures. Circumferential graben-fissure systems are also commonly associated with pit crater chains, which have been linked by some researchers to underlying dyke injection (Figure 4.4D; Davey et al., 2013; Patterson et al., 2016). However, purely extensional modes of origin have been proposed for pit crater chains on other terrestrial bodies (Wyrick et al., 2004).

The observations described above demonstrate that the annuli of coronae are an important pathway for magmatic activity and circumferential dyke swarms may provide a mechanism for magma transport to the surface.

\subsubsection{Conclusions}

The recognition that giant circumferential dyke swarms occur on Earth and are of similar scale to the annuli of Venusian coronae suggests these features may be analogous (Ernst and Buchan, 1998; Ernst et al., 2014; Bethell et al., 2016; Buchan and Ernst, 2016, 2018, 2019). If so, circumferential graben-fissure systems on Venus would be underlain by dykes and their distribution would be linked with one or more underlying magma chamber(s) and/or magmatic underplate(s). The dip of the dykes would depend, in part, on the depth and size of the magma source (within the crust, or at the base of the crust as a magmatic underplate). Improving the characterization of circumferential graben-fissure systems on Venus will be a predictive guide for the expanded identification of proposed terrestrial analogues of coronae. Furthermore, the continued 
study of terrestrial analogues will provide a more detailed understanding of Venusian coronae and their magmatic plumbing systems.

\subsection{Corona Size}

\subsubsection{Evaluating Corona Size}

There have been several efforts to characterize the global corona record on Venus (e.g., Pronin and Stofan, 1990; Stofan et al., 1992, 2001; Smrekar and Stofan, 1997; Crumpler and Aubele, 2000; Glaze et al., 2002). These surveys have focused on characterizing their size, shape, associated topography and geological setting. Coronae are typically classified based on the shape of their topographic signature and associated circumferential graben-fissures (i.e., annulus).

Corona size can be estimated using either of the two defining components: 1) the maximum width of the topographic signature (used by Stofan et al., 2001 for "type 2" coronae), or 2) the maximum width of circumferential structures associated with the corona (used by Stofan et al., 1992, 2001 and Crumpler and Aubele, 2000, for "type 1" coronae). A re-evaluation of the size of coronae and corona-like features based on these criteria and the implications for comparisons with terrestrial analogues is explored in the following sections.

The method used to estimate size is of importance when comparing Venusian coronae to analogues on other planets. In particular, the maximum width of structures associated with coronae should be taken into account to facilitate comparisons with potential terrestrial analogues. In general, the primary topography associated with terrestrial corona analogues (i.e., LIPs) cannot be evaluated in detail as it has been 
removed by erosion. With LIPs on Earth, dyke swarms are observed where the surface has been eroded and the subsurface is exposed, and the diameter of circumferential dyke swarms is what is recorded. The extent of these dyke swarms is more comparable to the extent of structures associated with Venusian coronae, rather than their topographic expression. Researchers have previously noted that the circumferential swarms recognized on Earth have diameters ranging from approximately $450-2500 \mathrm{~km}$ (Figure 4.5B; Buchan and Ernst, 2019), whereas coronae on Venus include a much wider range of diameters, ranging from approximately 60 to over $2000 \mathrm{~km}$ (Stofan et al., 1992, 2001; Crumpler and Aubele, 2000).

Diameters of both the structural elements and topographic expressions associated with coronae in the V-32 quadrangle were catalogued from detailed mapping and compared with previous estimates by Stofan et al. (1992) and Crumpler and Aubele (2000). As discussed in Section 4.1.3.4, mapping of the full extent of circumferential structures demonstrates that in most cases, circumferential structures extend well beyond the outermost topography of the corona. Stofan et al. (1992) used the maximum distance between the outermost fractures of the annuli, or the furthest extent of associated fracturing for features with no annulus, to derive corona size. In their catalogue of volcanic features on Venus, Crumpler and Aubele (2000) documented corona size using "the mean diameter of the most prominent concentric ring". While these catalogues have been crucial in studying these structures, they are based on global reconnaissance-level surveys, and detailed mapping at the full resolution of the Magellan SAR data will provide more precise constraints. Estimates of maximum corona diameter using the structural method for the coronae mapped in the V-32 
quadrangle are compared with the estimates of Stofan et al. (1992) and Crumpler and Aubele (2000) in Table 4.2 and Figure 4.5A. Thermuthis Corona is also included in these comparisons; while its focus is contained within the V-33 (Scarpellini) quadrangle, numerous structures associated with the corona extend into the V-32 quadrangle (discussed in more detail in the following Section 4.2.2). The size measurements presented herein are generally larger than previously documented (by up to $1000 \mathrm{~km}$ ) and have average percentage difference values of $30.4 \%$ and $28.1 \%$, respectively, when compared with the maximum diameters recorded by Stofan et al. (1992) and Crumpler and Aubele (2000).

If the structural method to estimating size were applied to other coronae on Venus, it may also lead to larger size estimates than have previously been described. Systematically larger size estimates derived from the maximum diameters of annulus structures of coronae, which are more comparable to the circumferential dykes associated with LIPs on Earth, may solve the apparent size discrepancies observed between corona-like features on Venus and Earth (Buchan and Ernst, 2019). It Is also possible that some of the smaller features on Venus that have been designated as coronae are more analogous to large caldera complexes (e.g., Thouris Corona (refer to Section 2.3.4.3); Squyres et al., 1992) or may be volcano-corona hybrids (e.g., Grindrod et al., 2006).

\subsubsection{Re-Evaluating the Structure of Thermuthis Corona: The Second Largest Corona on Venus?}

While the centre of Thermuthis Corona $\left(33^{\circ} \mathrm{E}, 8^{\circ} \mathrm{S}\right)$ is not contained within the V-32 quadrangle, structures were mapped within the quadrangle that were interpreted 
to be associated with the corona (GFC8, GFR6, WRC1, and WRR1; refer to Section 2.3 and Table 2.1). In order to map all of the structures associated with Thermuthis, and gain a comprehensive understanding of the full extent of these structures, a subset $\left(30^{\circ}-40^{\circ} \mathrm{E}, 0^{\circ}-17^{\circ} \mathrm{S}\right)$ of the adjacent Scarpellini (V-33) quadrangle was also mapped (Figure 4.6A).

\subsubsection{Topography}

Thermuthis Corona (Figure 4.6) is listed in the global corona catalogue of Stofan et al. (1992) as a concentric corona of category 2 (moderate associated volcanic features), with a maximum diameter of $330 \mathrm{~km}$ and a maximum annulus width of $60 \mathrm{~km}$. The topographic signature of Thermuthis Corona was described as an interior rim approximately 260 by $330 \mathrm{~km}$ in diameter that surrounds an interior depression.

As with many coronae, the topographic signature associated with Thermuthis Corona is complex. There is an interior rim that defines the outer boundary according to Stofan et al. (1992). The interior contains several regions of high and low elevation. In addition, a much larger exterior rim has been recognized herein, with a maximum diameter of approximately $970 \mathrm{~km}$ (Figure 4.6B, C). With the consideration of this newly recognized exterior rim, Thermuthis Corona best fits within group 6 (outer rise, trough, rim, inner low; comprising $1 \%$ of coronae) in the topographic classification scheme for coronae defined by Smrekar and Stofan (1997).

\subsubsection{Structural Trends}

Five significant structural trends were identified in the mapping of this study (GFC8, GFR6, WRL1, WRC1, and WRR1; refer to Table 2.1). Four of these structural 
trends ( 2 comprised of extensional structures and 2 comprised of contractional structures) have been interpreted to be related to Thermuthis Corona (Figure 4.6A) and are described below. The remaining trend is a regional linear ENE-WSW trending system of wrinkle ridges (WRL1) that is the focus of Chapter 5 and is not shown on Figure 4.6A.

A circumferential (GFC8) and a radiating (GFR6) extensional system were identified and interpreted to be associated with Thermuthis Corona (Figure 4.6A). Extensional structures in GFC8 extend for approximately $270^{\circ}$ around the centre of the corona and are mostly concentrated on the western and eastern edges. They generally coincide with relatively high regions along the exterior and interior rims. Structures associated with GFR6 are also mostly preserved close to the central region, and especially within the exterior rim. However, a portion of GFR6 extends for more than $1300 \mathrm{~km}$ away from the centre. Both GFR6 and GFC8 have been flooded by a later volcanic plains unit (Ridged Plains Material Unit 4 (pr4)). Cross-cutting relationships between these two extensional systems are ambiguous, thus their relative ages are uncertain. Based on the relationships of these systems with surrounding geological units, it appears that some structures in GFR6 may be younger than the youngest observable structures in GFC8.

Two contractional structural trends, expressed as wrinkle ridges, are present that are spatially associated with Thermuthis Corona (Figure 4.6A). These include a circumferential system (WRC1) and a radiating system (WRR1). The focus of both WRC1 and WRR1 appears to be approximately centred on Thermuthis Corona. WRC1 is concentrated along the exterior rim of the corona; some structures in WRC1 extend 
approximately $800 \mathrm{~km}$ from the centre. WRC1 clearly cross-cuts some ridges in WRL1 and WRR1. Wrinkle ridges in WRR1 extend approximately $1200 \mathrm{~km}$ from the centre. WRR1 does not clearly cross-cut WRL1. However, the structures in WRR1 often transition into the trend observed in WRL1 away from the centre of Thermuthis Corona. WRR1 is also often observed to follow the trends of graben in GFR6. WRR1 may therefore represent the same generation of structures as WRL1, which: 1) changed trend locally around Thermuthis Corona, reflecting potential changes in the stress field, and/or 2) represent re-activated pre-existing faults in GFR6.

\subsubsection{Evidence for an Increased Maximum Diameter}

As discussed above (refer to Section 4.2.1), corona size can be estimated using either the topographic signature or the structures associated with the corona. The former approach yields the estimate of $330 \mathrm{~km}$ cited by Stofan et al. (1992), which is the maximum diameter of the interior rim. However, the detailed structural mapping presented herein identifies a secondary exterior rim located approximately $200 \mathrm{~km}$ outside of the interior rim. The extensional structural system GFC8 has also been identified, which extends beyond the secondary exterior rim and has a maximum diameter of $1250 \mathrm{~km}$.

The outermost extent of GFC8 (i.e., the annulus of the corona) has been chosen herein to define the maximum diameter of the corona. A revised maximum diameter of $1250 \mathrm{~km}$ would make Thermuthis Corona the second largest currently recognized corona on Venus, larger than Heng-O Corona (1060 km) (Stofan et al., 1992) and smaller than Artemis Corona (2400-2600 km) (Stofan et al., 1992; Hansen and Olive, 
2010); although the Artemis structure is not always classified as a corona (Hansen and Olive, 2010).

\subsection{Conclusions}

Coronae on Venus bear many similarities to LIPs on Earth. Many coronae are associated with extensive magmatic activity, including surficial volcanic flows and constructs as well as intrusive activity in the form of radiating dyke swarms which are represented by graben-fissure systems at the surface. Through analogy with LIP plumbing systems on Earth, other intrusive components such as sill provinces, magmatic underplating, mafic-ultramafic intrusions, and circumferential dyke swarms are speculated to be present. In particular, recently described circumferential dyke swarms on Earth (such as the Lake Victoria Dyke Swarm) share many similarities with the circumferential graben-fissure systems associated with coronae on Venus. Thorough geological testing is needed to confirm the analogy between these features and cataloguing of the following characteristics through detailed geological mapping are suggested to contribute to this undertaking: 1) arc length, 2) minimum and maximum diameter, 3) minimum and maximum annulus width, 4) distribution with respect to corona topography, 5) relationship with radiating graben-fissure systems, and 6) association with magmatic features.

The diameter of coronae can be estimated using either the maximum extent of the topographic signature or associated circumferential structures. Documenting the extent of circumferential structures is of particular importance when comparing the sizes of coronae and giant circumferential dyke swarms on Earth. Detailed mapping of the 
structures associated with coronae in the V-32 quadrangle has led to significant increases in the size estimates of these features, particularly with Thermuthis Corona, which is partially contained in the $\mathrm{V}-33$ quadrangle. The results of this mapping suggest that circumferential graben-fissures extend for a maximum distance of $1250 \mathrm{~km}$ away from the corona's centre, along with the recognition of a secondary exterior rim with a maximum diameter of $970 \mathrm{~km}$. This would make Thermuthis Corona the second largest on Venus, after the Artemis structure. 


\subsection{Tables}

Table 4.1: Characteristics of circumferential graben-fissure systems associated with coronae in the V-32 quadrangle.

\begin{tabular}{|c|c|c|c|c|c|c|c|}
\hline Corona & $\begin{array}{c}\text { Arc } \\
\text { length }\end{array}$ & $\begin{array}{l}\text { Min and max } \\
\text { diameter of } \\
\text { C-GFS }{ }^{1}\end{array}$ & $\begin{array}{l}\text { Min and max } \\
\text { annulus width }\end{array}$ & $\begin{array}{l}\text { Max diameter of } \\
\text { topographic } \\
\text { signature }\end{array}$ & $\begin{array}{l}\text { Max extent of } \\
\text { C-GFS }{ }^{1} \text { beyond } \\
\text { topographic } \\
\text { signature }\end{array}$ & $\begin{array}{l}\text { Relationship with } \\
\text { R-GFS }\end{array}$ & $\begin{array}{c}\text { Magmatic features } \\
\text { associated with } \\
\text { C-GFS }{ }^{1}\end{array}$ \\
\hline Atargatis & $270^{\circ}$ & 380 to $540 \mathrm{~km}$ & 20 to $90 \mathrm{~km}$ & $350 \mathrm{~km}$ & $190 \mathrm{~km}$ & $\begin{array}{l}\text { R-GFS } \\
\text { concentrated in the } \\
\text { interior dome, offset } \\
\text { to the west from } \\
\text { centre of C-GFS }\end{array}$ & $\begin{array}{l}\text { A few small, } \\
\text { localized radar- } \\
\text { bright flows } \\
\text { originate from C- } \\
\text { GFS }\end{array}$ \\
\hline Kuan-Yin & $300^{\circ}$ & 380 to $530 \mathrm{~km}$ & $\begin{array}{l}\text { Divided into an } \\
\text { inner ( } 12 \text { to } 50 \\
\mathrm{~km}) \text { and outer } \\
\text { ring ( } 40 \text { to } 160 \\
\mathrm{~km})\end{array}$ & $400 \mathrm{~km}$ & $70 \mathrm{~km}$ & $\begin{array}{l}\text { R-GFS } \\
\text { concentrated in the } \\
\text { interior dome, } \\
\text { extends up to } 460 \\
\text { km from the centre; } \\
\text { R-GFS cross-cuts } \\
\text { C-GFS }\end{array}$ & $\begin{array}{l}\text { Two separate } \\
\text { volcanic flow units }\end{array}$ \\
\hline Thouris & $360^{\circ}$ & To $235 \mathrm{~km}$ & To $60 \mathrm{~km}$ & $220 \mathrm{~km}$ & $40 \mathrm{~km}$ & None & None \\
\hline Fatua & $360^{\circ}$ & $\begin{array}{l}\text { Divided into an } \\
\text { inner }(350 \text { to } \\
370 \mathrm{~km}) \text { and } \\
\text { outer }(460 \text { to } \\
870 \mathrm{~km}) \text { ring }\end{array}$ & $\begin{array}{l}\text { Divided into an } \\
\text { inner ( } 20 \text { to } 40 \\
\mathrm{~km}) \text { and outer } \\
(25 \text { to } 295 \mathrm{~km}) \\
\text { ring }\end{array}$ & $420 \mathrm{~km}$ & $170 \mathrm{~km}$ & $\begin{array}{l}\text { R-GFS originates at } \\
\text { the southern outer } \\
\text { edge of C-GFS, } \\
\text { extends up to } 1700 \\
\mathrm{~km} \text { from the centre }\end{array}$ & $\begin{array}{l}\text { Hundreds of shield } \\
\text { volcanoes, three } \\
\text { separate volcanic } \\
\text { flow units }\end{array}$ \\
\hline Cybele & $300^{\circ}$ & $\begin{array}{l}\text { Divided into } \\
\text { two rings: } A \\
(510 \text { to } 670 \\
\mathrm{km}) \text { and } B \\
(200 \text { to } 290 \\
\mathrm{km}) .\end{array}$ & $\begin{array}{l}\text { Divided into two } \\
\text { rings: } A \text { ( } 55 \text { to } \\
155 \mathrm{~km}) \text { and } B \\
(15 \text { to } 45 \mathrm{~km}) \text {. }\end{array}$ & $450 \mathrm{~km}$ & $75 \mathrm{~km}$ & $\begin{array}{l}\text { R-GFS } \\
\text { concentrated in the } \\
\text { interior dome in the } \\
\text { eastern half of the } \\
\text { corona; extends up } \\
\text { to } 450 \mathrm{~km} \text { from the } \\
\text { centre; younger } \\
\text { than and } \\
\text { significantly offset } \\
\text { from the focal point } \\
\text { of C-GFS A }\end{array}$ & $\begin{array}{l}\text { Tens of shield } \\
\text { volcanoes, a few } \\
\text { canali or sinuous } \\
\text { rille-like features }\end{array}$ \\
\hline
\end{tabular}

GFS: Circumferential graben-fissure system. 
Table 4.2: Maximum diameters for coronae in the V-32 quadrangle and Thermuthis Corona (located partially in the neighbouring V-33 quadrangle). The percentage difference between the estimates of this study and others are also included.

\begin{tabular}{l|c|cc|cc}
\hline \multirow{2}{*}{ Corona } & This study & \multicolumn{2}{|c|}{ Stofan et al. (1992) } & \multicolumn{2}{c}{ Crumpler and Aubele (2000) } \\
\cline { 2 - 6 } & Diameter $(\mathrm{km})$ & Diameter $(\mathrm{km})$ & \% Difference & Diameter (km) & \% Difference \\
\hline Thermuthis & 1250 & 330 & 58.2 & 250 & 66.7 \\
Fatua & 870 & 310 & 47.5 & 500 & 27.0 \\
Cybele & 670 & 480 & 16.5 & 250 & 45.7 \\
Atargatis & 540 & 410 & 13.7 & 400 & 14.9 \\
Kuan-Yin & 530 & 250 & 35.9 & 600 & -6.2 \\
Thouris & 235 & 290 & -10.5 & 200 & 28.1
\end{tabular}




\subsection{Figures}

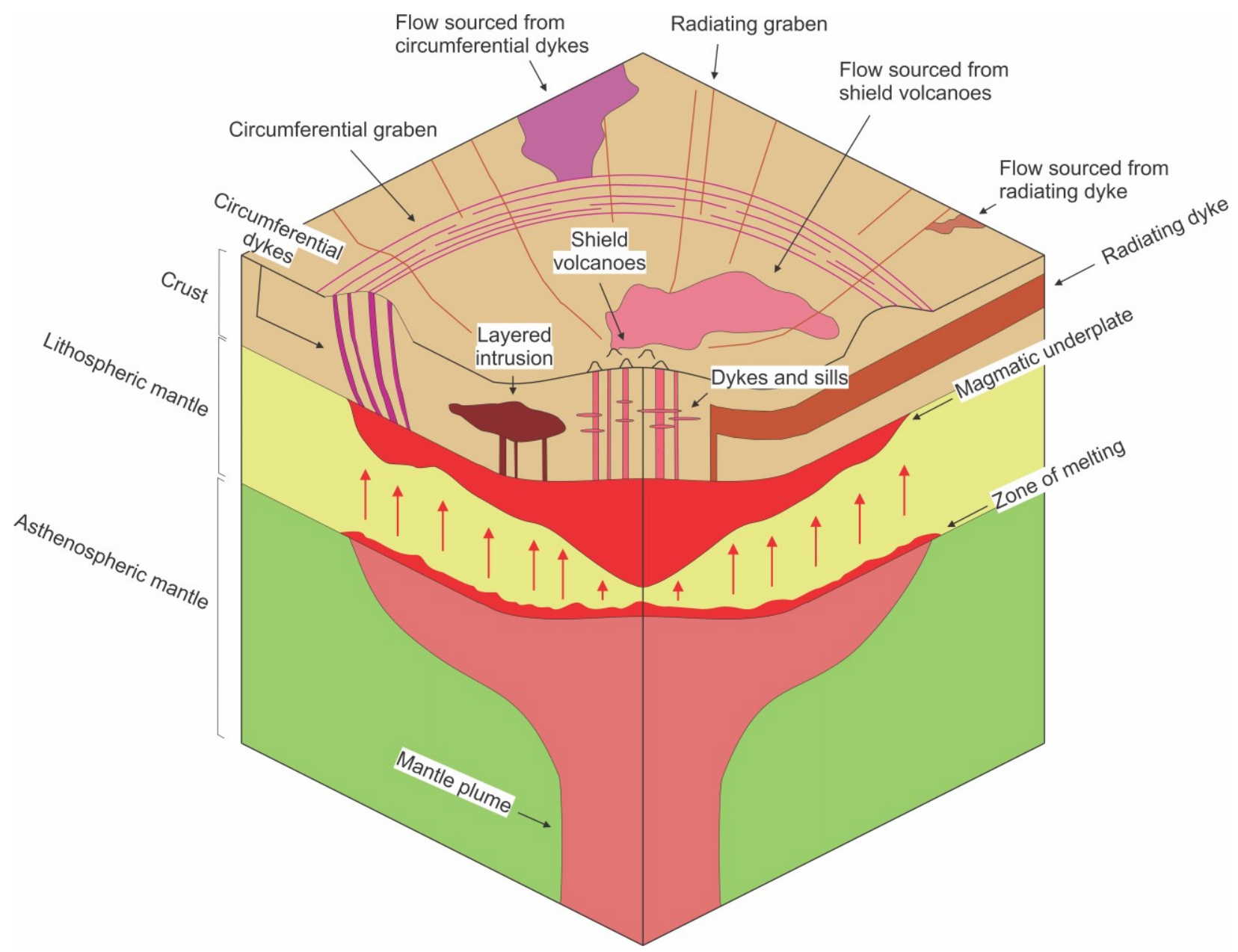

Figure 4.1: Hypothetical cross section of a corona through analogy with large igneous provinces (LIPs) on Earth. The corona topography represented in the model is of topographic subtype $3 \mathrm{~b}$ (rim surrounding interior dome) from the classification scheme of Smrekar and Stofan (1997). Modified after the model for terrestrial LIPs by Ernst et al. (2019). The circumferential dykes in this model are represented as cone sheets; the actual dip of possible circumferential dykes, and whether they are more likely to be cone sheets or vertical dykes, is unknown. The magmatic underplate is depicted as the same size of the plume head; in reality, it may not extend across the entire plume head or there may be several regions of magmatic underplating (Ernst et al., 2019). 


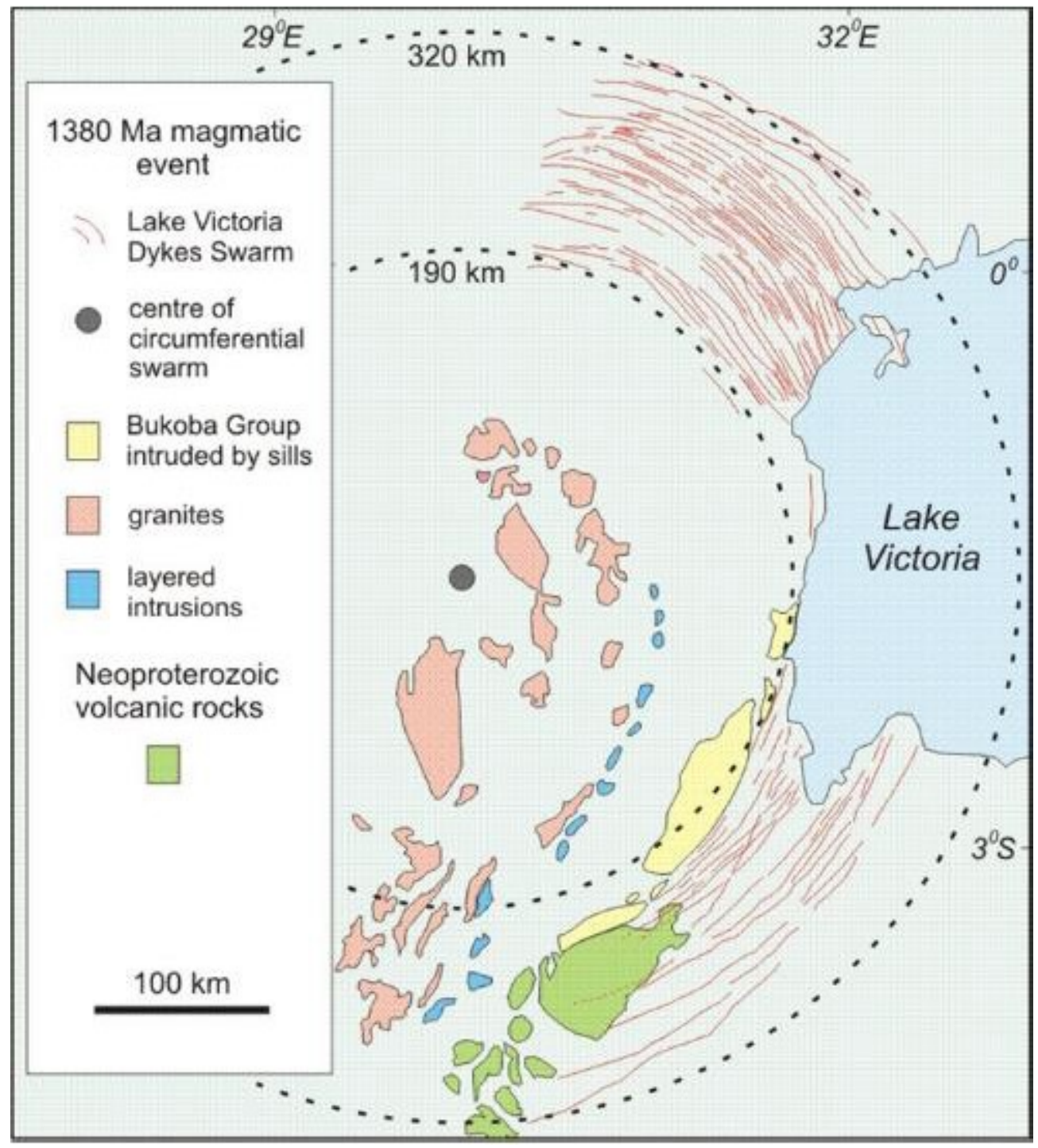

Figure 4.2: The $1385 \mathrm{Ma}$ Lake Victoria giant circumferential dyke swarm, associated with the Kunene-Kibaran LIP, in East Africa on Earth. After Mäkitie et al. (2014) and Buchan and Ernst (2016). 


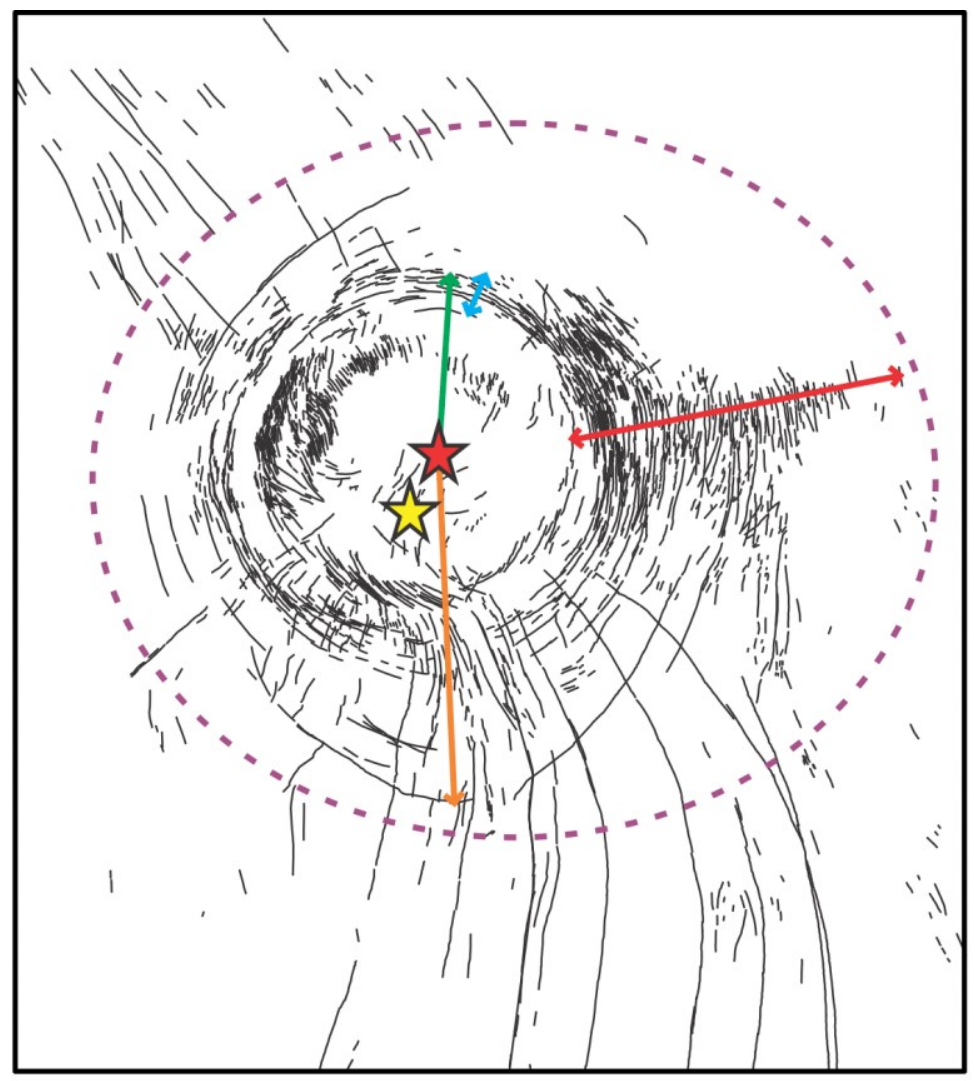

Centre of circumferential graben-fissure system

负 Centre of radiating graben-fissure system

- Minimum radius from centre

- Maximum radius from centre

- Minimum annulus width

- Maximum annulus width

--- Arc length

Figure 4.3: Schematic drawing of the characteristics of circumferential graben-fissure systems and dyke swarms. Fatua Corona (centre coordinates $17.7^{\circ} \mathrm{E}, 16.3^{\circ} \mathrm{S}$ ) is shown as an example. 


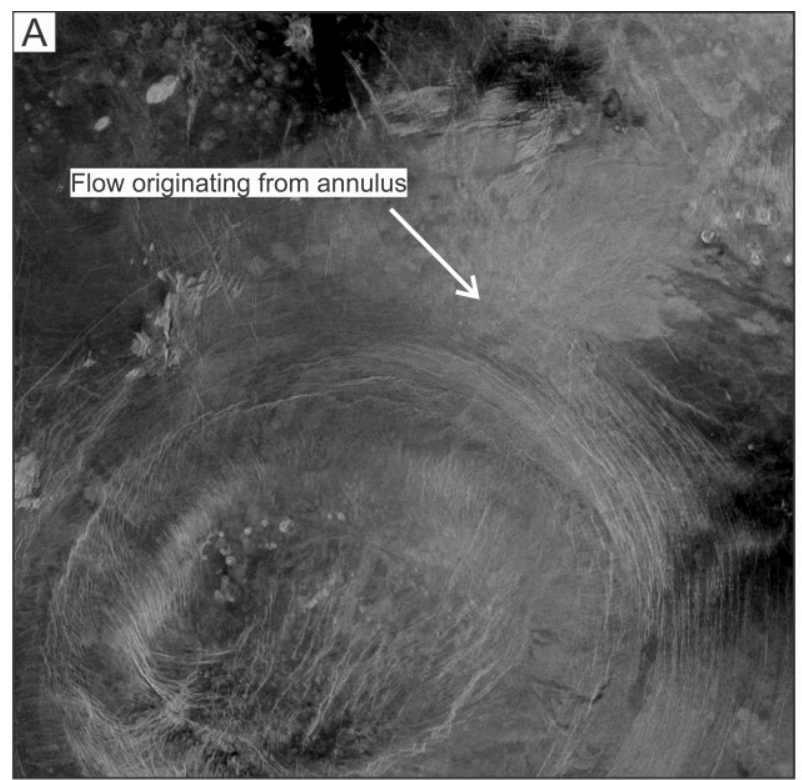

$100 \mathrm{~km}$

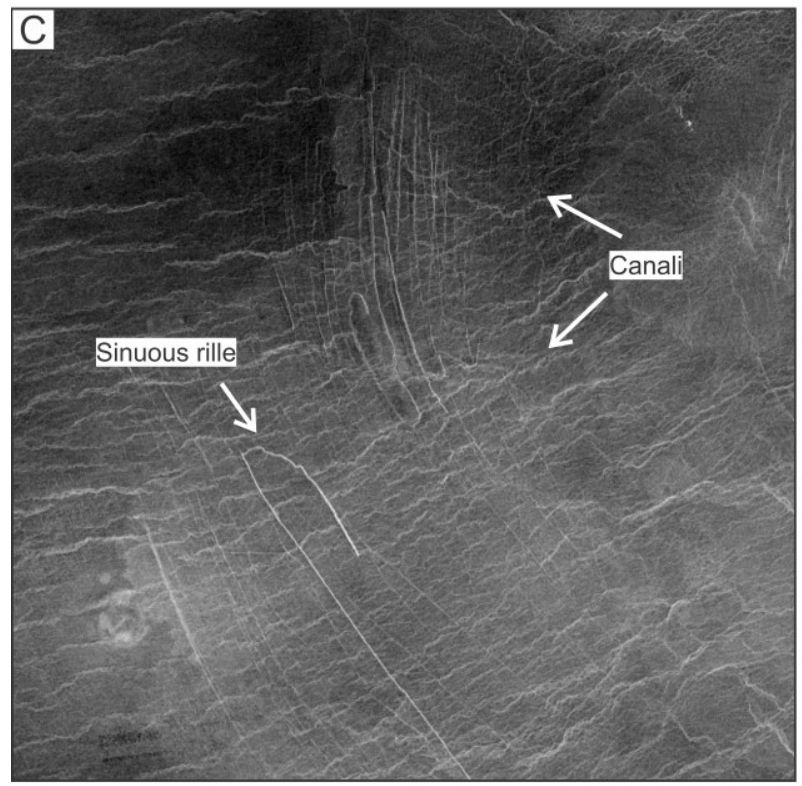

$50 \mathrm{~km}$

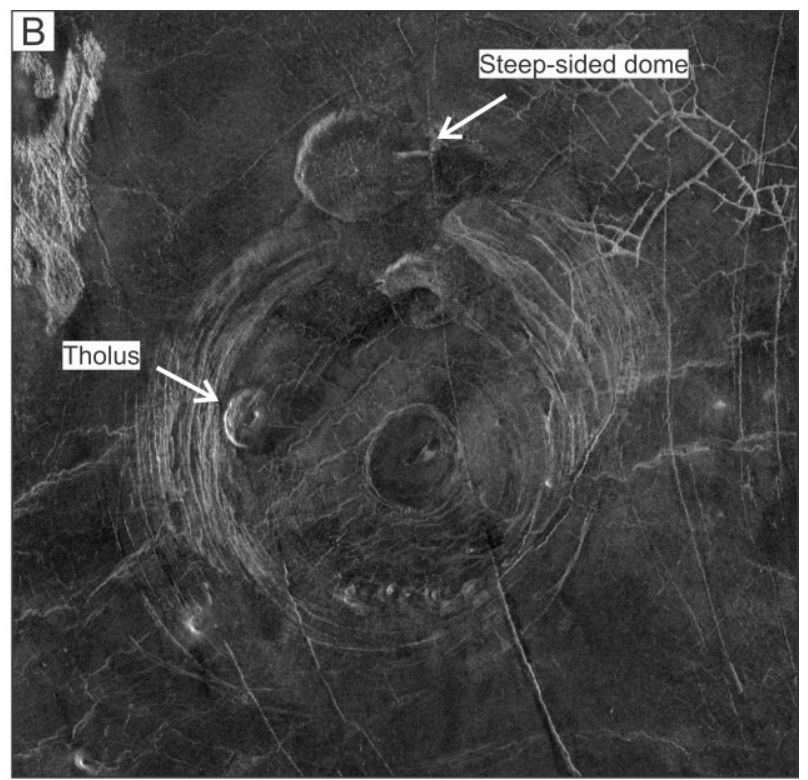

$50 \mathrm{~km}$

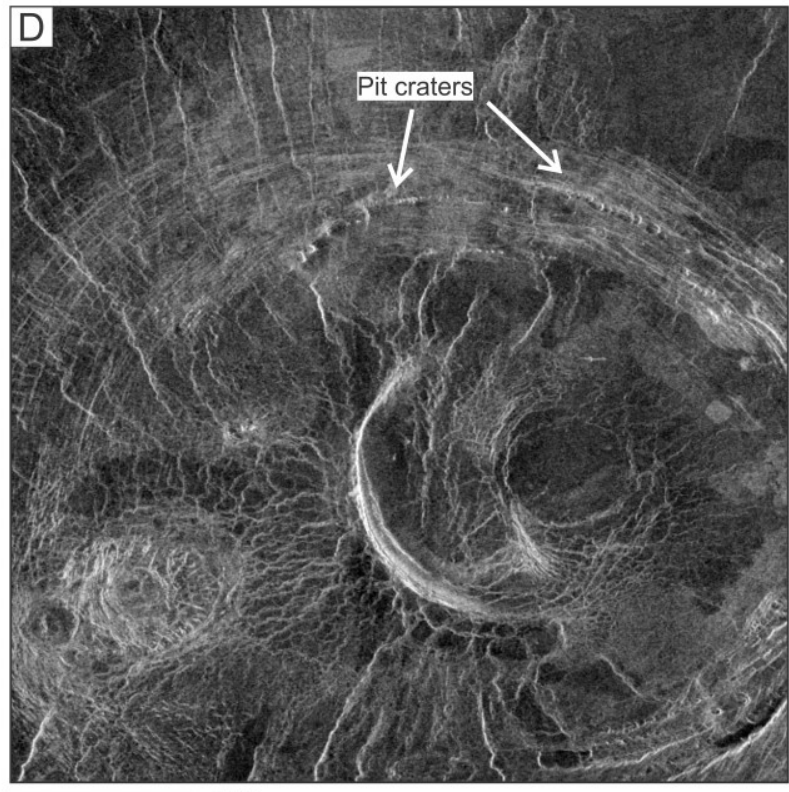

$25 \mathrm{~km}$

Figure 4.4: Examples of magmatic features associated with circumferential grabenfissure systems of coronae: A) volcanic flows origination from circumferential graben associated with Fatua Corona (centre coordinates $17.7^{\circ} \mathrm{E}, 16.3^{\circ} \mathrm{S}$ ); B) steep-sided dome and a tholus in the annulus of Fotla Corona (centre coordinates $163.5^{\circ} \mathrm{E}, 58.5^{\circ}$ $\mathrm{S})$, as well as a chain of shield volcanoes along the southern margin; C) channelized features emanate from circumferential graben associated with Cybele Corona (centre coordinates $20.7^{\circ} \mathrm{E}, 7.5^{\circ} \mathrm{S}$ ); and D) pit crater chains associated with the circumferential graben-fissure system around Qakma Corona (centre coordinates $207.1^{\circ} \mathrm{E}, 35.5^{\circ} \mathrm{N}$ ). 

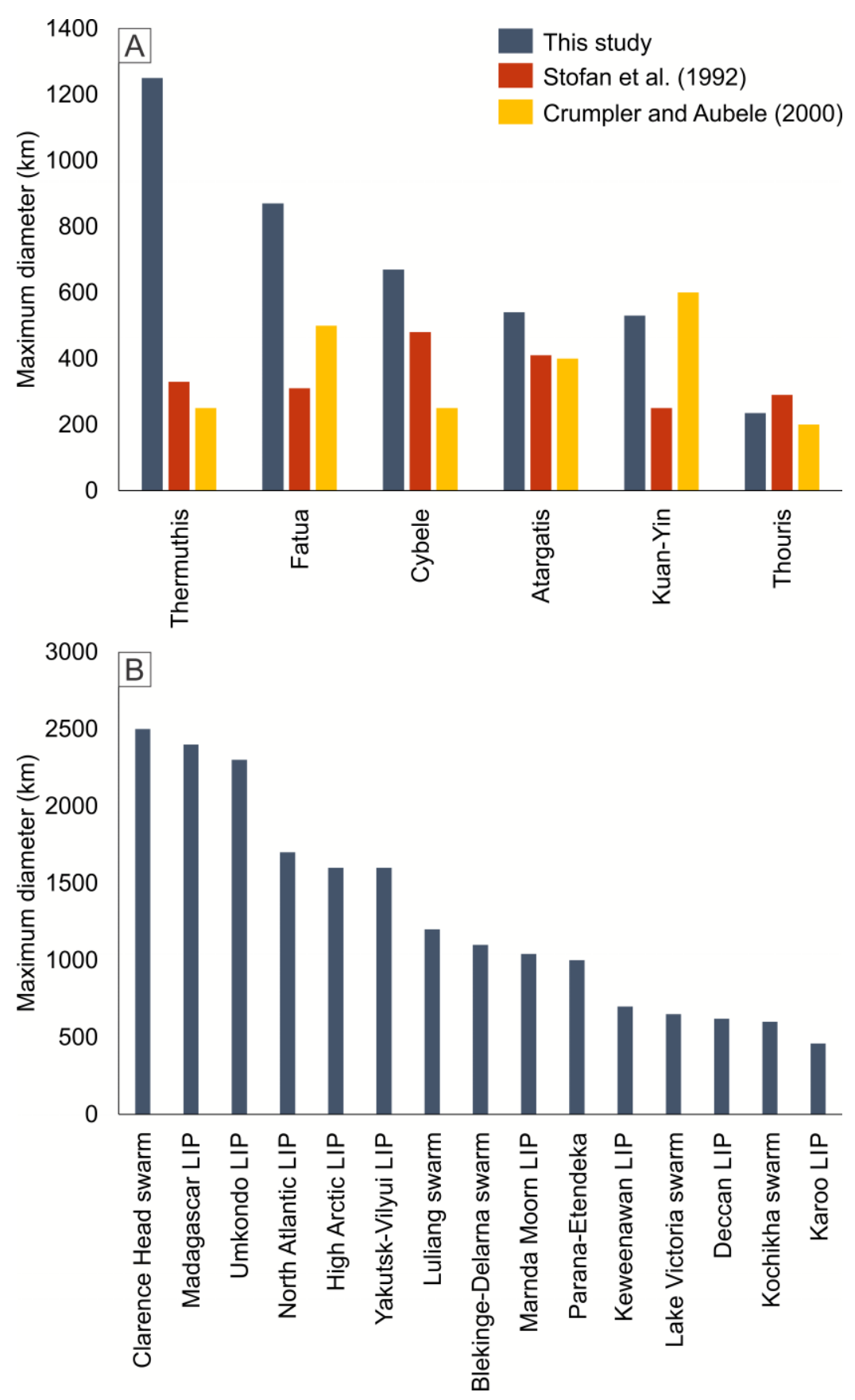

Figure 4.5: Graphical comparisons between maximum size estimates for corona-like features on Venus and Earth: A) comparison of estimates from this study, Stofan et al. (1992), and Crumpler and Aubele (2000) for coronae in the V-32 quadrangle and Thermuthis Corona (located partially in the neighbouring V-33 quadrangle); B) maximum diameters of giant circumferential dyke swarms on Earth as presented by Buchan and Ernst (2019). Labels refer to either the name of the dyke swarm or its associated LIP. 

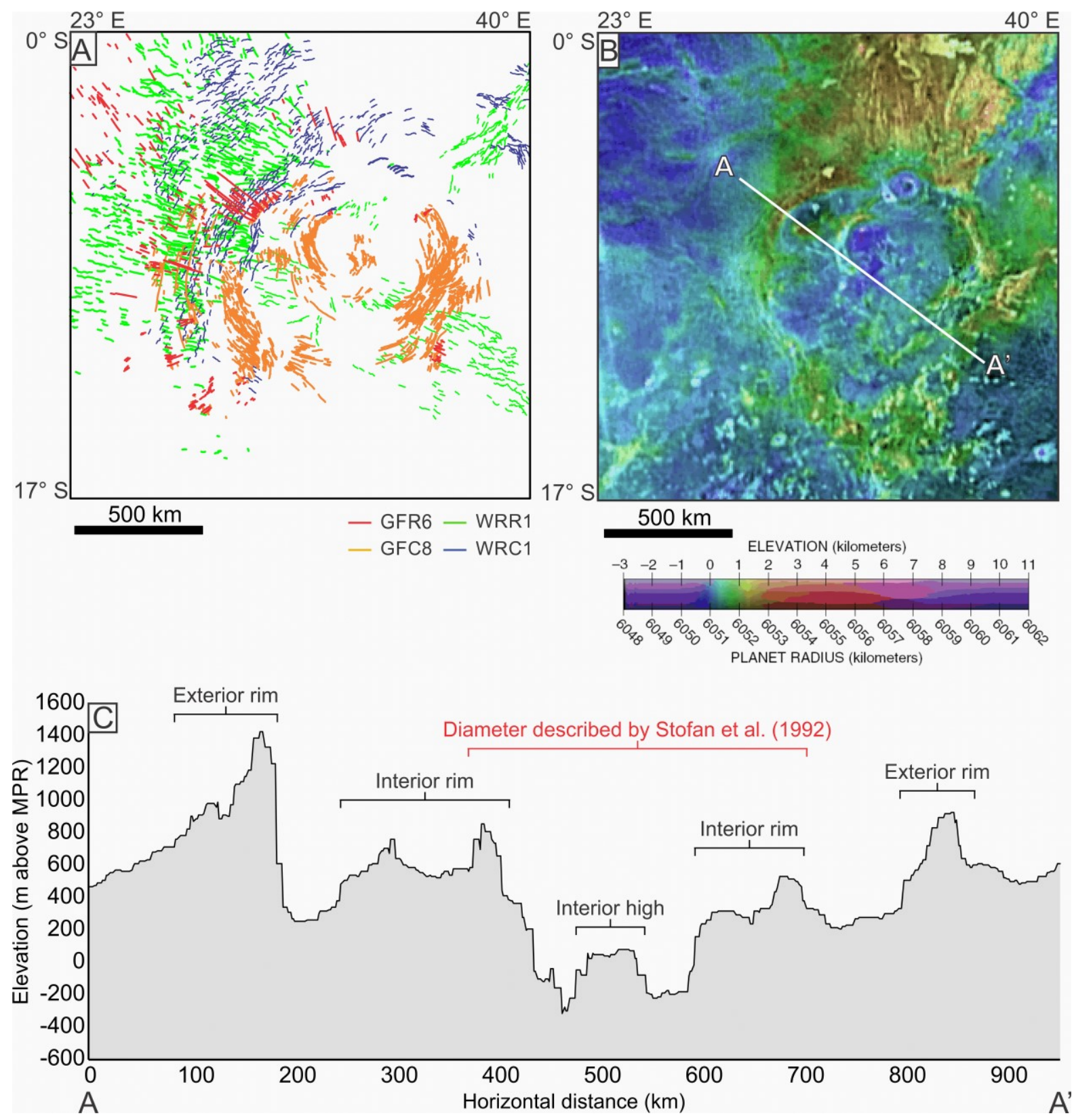

Figure 4.6: Maps and topographic profiles of the extended map area around Thermuthis Corona. A) Map of structures interpreted to be associated with Thermuthis Corona. WRL1 and other structures which have been mapped but are not associated with the corona have been omitted from the map; B) Composite image of colourized Magellan altimetry data superimposed over a Magellan SAR (C3-MIDR) basemap. The line extending from $A$ to $A^{\prime}$ corresponds to the topographic profile in $C$. The accompanying legend was obtained courtesy of the USGS Astrogeology Science Center; C) Topographic profile of Thermuthis Corona along the A to A' line shown in B. The elevations on the vertical axis are relative to Mean Planetary Radius (MPR), which is approximately $6051 \mathrm{~km}$. 


\section{CHAPTER 5: ANALYSIS OF VENUSIAN WRINKLE RIDGE MORPHOMETRY USING STEREO-DERIVED TOPOGRAPHY: A CASE STUDY FROM SOUTHERN EISTLA REGIO}

\subsection{Introduction}

Wrinkle ridges are common surface features on several terrestrial bodies and moons of our solar system (Figure 5.1). They are sinuous along their strike, have positive topography, and are widely interpreted to be contractional in origin. Wrinkle ridges are described as a broad arch (ridge) with a superimposed crenulation (wrinkle) (e.g., Sharpton and Head, 1988; Watters, 1988; Watters, 1993). An anticline (i.e., fold) and/or thrust fault mechanism for the formation of wrinkle ridges has commonly been proposed (e.g., Plescia and Golombek, 1986; Watters, 1988; Suppe and Narr, 1989; Golombek et al., 1991).

Some aspects of the two-dimensional morphometry of wrinkle ridges on Venus have been studied using synthetic aperture radar (SAR) images of the surface obtained during NASA's Magellan mission (Bilotti, 1997; Kreslavsky and Basilevsky, 1998). The Magellan SAR data included three cycles of mapping: 1 (left-looking, at incidence angles varying between $45-16^{\circ}$ ), 2 (right-looking, at a near-constant incidence angle of approximately $25^{\circ}$ ), and 3 (left-looking, at incidence angles smaller than those of Cycles 1 and 2) (Ford et al., 1993).

Wrinkle ridges are not apparent in Magellan altimetry data as they are relatively small features (a few kilometres wide) compared to the footprint size of the dataset (approximately $10-20 \mathrm{~km}$ ). However, a topography dataset with increased resolution has recently been developed, using left- and stereo-looking SAR images (Cycles 1 and 3, respectively), that has a horizontal resolution of approximately $1-2 \mathrm{~km}$ and a vertical 
resolution of approximately 50-100 m (Herrick et al., 2012). Some wrinkle ridges are resolvable in this stereo-derived topography dataset.

In this chapter, the three-dimensional morphometry of Venusian wrinkle ridges is characterized, including inter-ridge spacing, width, height, and shape, through the analysis of stereo-derived topography data. The wrinkle ridges selected for study lie in the vicinity of Tinatin Planitia and Southern Eistla Regio (Figure 5.2). The shortening and strain accommodated by these ridges is also calculated. Furthermore, statistical analyses are provided to test for potential correlations between the wrinkle ridge parameters. Finally, the implications of these results for models of wrinkle ridge morphometry and formation are discussed, results are compared to analogous studies on Earth, Mars, the Moon, and Mercury, and the results are considered in the context of the regional tectonic setting and lithospheric structure of the study area.

\subsection{Background}

\subsubsection{Models for Planetary Wrinkle Ridge Formation}

Most studies of wrinkle ridge structure have focused on Lunar and Martian wrinkle ridges (e.g., Watters, 1991; Golombek et al., 1991; Watters and Robinson, 1997; Tate et al., 2001; Schultz, 2000; Golombek et al., 2001; Okubo and Schultz, 2002; Montesi and Zuber, 2003; Watters, 2004). Early models of planetary wrinkle ridge formation included a range of processes, from purely volcanic models invoking intrusive and/or extrusive volcanism (e.g., Whitaker, 1966), to models involving a mixture of volcanism and tectonism (e.g., Colton et al., 1972), and purely tectonic models (e.g. Lucchitta, 1976) (Plescia and Golombek, 1986). 
Most recent models explain the formation of planetary wrinkle ridges using contractional tectonics (i.e., folding and thrust faulting). The lack of subsurface information for planetary wrinkle ridges implies that these models are based on surface morphology revealed in topographic cross-sections. They disagree on the morphometry and number of associated thrust faults, as well as the relative importance of thrust faulting versus folding (e.g., Schultz, 2000; Okubo and Schultz, 2004; Watters, 1991; Watters, 2004). Models range from treating wrinkle ridges as low-amplitude buckle folds, to shallowly dipping thrust faults (Schultz, 2000). The majority of models combine both faulting and folding processes, either in the form of fault-bend folding, where folding occurs in response to flexure above an irregular fault surface (such as those with ramp and flat geometries), or fault-propagation folding, where displacement transfers from slip along the fault surface to folding in the overlying rocks (Schultz, 2000).

Further debate is focused on the nature of wrinkle ridge-forming deformation and whether it represents a thick-skinned deformation style (e.g., Zuber, 1995; Golombek et al., 1991; 2001; Montési and Zuber, 2003; Byrne et al., 2015), penetrating through most of the lithosphere, or a thin-skinned deformation style (e.g., Watters, 1988; Suppe and Narr, 1989; Allemand and Thomas, 1992; Mangold et al., 1998; Watters, 2004), penetrating only to shallow depths in the lithosphere. Models of thick-skinned deformation typically require relatively steep dip angles for underlying thrust faults, as opposed to the shallow dip angles typically invoked in thin-skinned deformation models. Some research supports the idea that wrinkle ridge thrusts propagate upward from shallow décollements (Mangold et al., 1998; Watters, 2004). Researchers have also disagreed on whether most of the faults beneath wrinkle ridges have breached the 
surface (e.g., Golombek et al., 1991) or remain blind (e.g., Schultz, 2000). Recent analysis of a wrinkle ridge exposed by erosion along the wall of Melas Chasma, Mars, led to the interpretation that an underlying, shallowly dipping blind fault was present (Cole and Andrews-Hanna, 2017). Secondary faults are also observed in the form of backthrusts and have been included in some models of wrinkle ridge morphology (e.g., Schultz, 2000; Okubo and Schultz, 2004; Andrews-Hanna, 2020).

Some workers have looked for possible terrestrial analogues to inform models of planetary wrinkle ridge formation. The most commonly cited terrestrial example is the Yakima fold belt of the Columbia Plateau, proposed by some authors to circumscribe the mantle plume centre associated with the Columbia River large igneous province (LIP) (Plescia and Golombek, 1986; Mège and Ernst, 2001; Mège and Reidel, 2001). Seismic data has indicated that the faults underlying the Yakima folds are relatively shallowly dipping and most likely represent thin-skinned deformation (Lutter et al., 1994). Other studies that have measured dips in surface exposures or through the construction of balanced cross-sections argue for steeper fault dips, ranging from $30^{\circ}$ 70 (Reidel et al., 2013; Casale and Pratt, 2015; Crane and Klimczak, 2019).

\subsubsection{Wrinkle Ridges on Venus}

Numerous efforts, mostly at global scales, have attempted to characterize the nature, distribution, and timing of wrinkle ridge formation on Venus. Venusian wrinkle ridges have been interpreted as contractional structures, mostly from analogy with wrinkle ridges on Mars, the Moon, and Mercury (e.g., Solomon et al., 1992; Watters, 1992; McGill, 1993; Kreslavsky and Basilevsky, 1998). McGill (1993) strengthened this 
hypothesis by illustrating the interactions of wrinkle ridges with pre-existing geological features, noting that wrinkle ridges diverge around topographic highs and converge into topographic lows. McGill (1993) noted that these observations are consistent with the expected orientations of contractional structures that would result from the compressive stress trajectories predicted by the theory of elasticity.

There have been few attempts to characterize Venusian wrinkle ridge morphometry due to the limitations of the Magellan altimetry dataset. Using Magellan SAR data, Kreslavsky and Basilevsky (1998) measured the spacing, width, and height of wrinkle ridges at 30 different sites on Venus. Widths were measured using the breaks in slope on either side of the ridge, or, where slope breaks were not readily apparent, using the characteristic width of the sinuosity of ridge crests. To measure ridge height, they used two methods: 1) stereo analysis (using both left-looking SAR datasets from Cycles 1 and 3 of the Magellan data), and 2) the difference between the apparent lengthening and shortening of wrinkle ridge slopes in different illumination geometries (using left- and right-looking SAR data from Cycles 1 and 2 of the Magellan data). Ridge height was successfully measured at 3 points along only one wrinkle ridge, yielding estimates of 40-90 m, 140-260 m, and 50-170 m. For the 30 sites studied, Kreslavsky and Basilevsky (1998) reported a mean spacing of $12.9 \mathrm{~km}(\mathrm{SD} \pm 5.8 \mathrm{~km})$, and a mean width of $1.25 \mathrm{~km}(S D \pm 0.66 \mathrm{~km})$, leading them to conclude that wrinkle ridges on Venus have systematically smaller spacing and width than on other planets.

Estimates of shortening and strain accommodated by wrinkle ridges on Venus have also been conducted, although again, these studies were limited by the low resolution of the Magellan data. By measuring limb dips along wrinkle ridges and 
assuming a fault-bend-folding formation mechanism, Bilotti (1997) estimated that wrinkle ridges accommodate about $2-5 \%$ regional strain. Kreslavsky and Basilevsky (1998) used their measurements of Venusian wrinkle ridge morphometry to constrain the limits of shortening using pure folding and faulting mechanisms; they obtained an average regional strain of approximately $0.3 \%$ and global strain of approximately 0.1 $0.3 \%$. While these shortening calculations provide order-of-magnitude estimations, they should be interpreted with caution, due to the following factors: 1) morphometric measurements were obtained indirectly using SAR imagery, not from topography data, and 2) the shortening calculations assume a formation mechanism.

Many researchers have proposed directional models to explain Venus' geological history (e.g., Basilevsky and Head, 1995, 1998, 2000; Head and Basilevsky,1998; Phillips and Hansen, 1997) that suggest that most geological units and deformational events are globally correlated and occurred once in Venus' geological history. They used relative age relationships deduced from geological mapping to estimate the timing of these events. Some of them have defined a geological unit "pwr" referred to as "plains with wrinkle ridges" or "ridged plains", which is a lithodemic unit that represents volcanic plains material later deformed by wrinkle ridges (e.g., Basilevsky et al., 1997; Basilevsky and Head, 1998; Kreslavsky and Head, 1999; Basilevsky and Head, 2000; Basilevsky and Head, 2002). Following a directional model, the volcanic material comprising unit pwr and the wrinkle ridges that characteristically deform it should have formed over a specific time interval in Venus' stratigraphic sequence (McGill, 2004). However, in many locations on Venus, there are multiple intersecting generations of wrinkle ridges with different relative ages (McGill, 1993; McGill, 2004). There is also 
evidence for progressive wrinkle ridge formation, with wrinkle ridges of the same orientation deforming material units that have different relative stratigraphic ages, providing support for a nondirectional geological model (Guest and Stofan, 1999; McGill, 2004).

Wrinkle ridges are not uniformly distributed across the surface of Venus. The pwr unit covers approximately $50-60 \%$ of the planet's surface (Basilevsky and Head, 2000). Global mapping of lineaments interpreted to be wrinkle ridges has indicated that wrinkle ridge deformation is preferentially located within topographic and geoid lows (Bilotti and Suppe, 1999). Some geoid highs, including Western Aphrodite, Themis Regio, Lada Terra, Bell Regio, and three within Eistla Regio, are ringed by wrinkle ridge deformation (Bilotti and Suppe, 1999). These observations are consistent with the modeling of the global strain field by Sandwell et al. (1997), who presented that the swell-push body force, coupled with lithospheric thickness, is proportional to the gradient of the geoid height. The model of Sandwell et al. (1997) predicts overall states of extension within geoid highs, and compression within geoid lows. There are a few exceptions to the predictions of Sandwell et al. (1997), such as Bereghinya Planitia, Aphrodite Terra, and the vicinity of Eistla Regio, where several generations of contractional wrinkle ridge deformation are present in geoid highs (Bilotti and Suppe, 1999).

\subsection{Study Area}

The study area, bounded by $0^{\circ} \mathrm{E}-30^{\circ} \mathrm{E}, 8.5^{\circ} \mathrm{N}-25^{\circ} \mathrm{S}$, is located in the vicinity of Tinatin Planitia and to the south of the Eistla Regio volcanic rise (Figure 5.2). It is contained within the Alpha Regio (V-32; to the south) and Sappho Patera (V-20; to the 
north) quadrangles. This area contains a high density of relatively large wrinkle ridges (greater than $30 \mathrm{~km}$ long and several kilometres wide) that are prominent radar-bright features in both left- and stereo-looking SAR images. The area also has pervasive coverage (approximately $50 \%$ of the surface area) by the stereo-looking SAR and stereo-derived topography datasets, which have limited global extent (approximately $20 \%$ global coverage) (Herrick et al., 2012). This work builds upon mapping of structural features in a recently produced 1:2.5 million scale geological map of the $\mathrm{V}-32$ quadrangle (Figure 5.3; refer to Section 2; Bethell et al., 2019b).

The majority of wrinkle ridges in the study area possess a general ENE-WSW trend. Two smaller, more localized wrinkle ridge trends of circumferential and radiating orientation are also present and have been attributed to Thermuthis Corona (Figure 5.3; Bethell et al. 2019a,b). This study is focused on the regional ENE-WSW system of ridges. In their global mapping of wrinkle ridges on Venus, Bilotti and Suppe (1999) interpreted the geometry of the ENE-WSW system of wrinkle ridges as circumferential to Eistla Regio. Eistla Regio is a region of elevated terrain (standing approximately $1 \mathrm{~km}$ above the surrounding plains) that is elongated roughly E-W and is approximately 7,500 $\mathrm{km}$ long (McGill, 2000). Eistla Regio is associated with numerous volcanic centres and has been interpreted to be the surface expression of one or more mantle plumes (McGill, 2000; Phillips and Malin, 1983; Stofan and Saunders, 1990; Kiefer and Hager, 1991; Senske et al., 1992; Grimm and Phillips, 1992; Solomon et al., 1992). 


\subsection{Morphometry}

\subsubsection{Datasets and Construction of Topographic Profiles}

A total of 13,457 wrinkle ridges were mapped in the study area, corresponding to a cumulative length of $275,162 \mathrm{~km}$ (Figure 5.3). Mapping of wrinkle ridges was conducted primarily using left-looking SAR images and supplemented with stereolooking SAR images where available. The longest individual mapped wrinkle ridge is $195 \mathrm{~km}$. The average length of individual wrinkle ridges is $20.4 \mathrm{~km} \pm 15.1 \mathrm{~km}$, though this is likely lower than the actual average length of the structures, due to the mapping of en echelon sections as separate segments. From the 13,457 mapped wrinkle ridges, 40 wrinkle ridges imaged at the maximum resolution of the stereo-derived topography dataset were selected for topographic analysis (Figure 5.4). In addition to considerations of data resolution, wrinkle ridges were selected to sample as much of the study area as possible, and to reflect a range in along-strike lengths. A total of 552 topographic profiles were constructed across these 40 wrinkle ridges.

Several profiles were created for each studied wrinkle ridge, with each profile constructed perpendicular to the local strike and with an approximate lateral spacing between profiles of $5 \mathrm{~km}$ (Figure 5.5). Profiles within a given ridge that showed anomalous shapes possibly representing data errors, or whose shapes were influenced by features other than wrinkle ridges, were rejected. A total of 49 profiles were rejected based on these criteria, leaving 503 viable profiles. For each wrinkle ridge, profiles were then combined and shifted horizontally to align peak amplitudes. Data for each 
topographic profile, including start and end coordinates, width, height, and skewness are given in Appendix B.

The overall topography of the study area is dominated by the Eistla Regio rise to the north, which transitions into a lower elevation region of volcanic plains (Tinatin Planitia) to the south. Elevation decreases from just over $1 \mathrm{~km}$ above Mean Planetary Radius (MPR) at the northernmost portion of the study area ( $14^{\circ} \mathrm{N}$ latitude), to a minimum elevation of approximately $800 \mathrm{~m}$ below MPR at $0^{\circ}$ latitude, then gradually increases to an average elevation of approximately $400 \mathrm{~m}$ above MPR at the southernmost edge of the study area ( $25^{\circ} \mathrm{S}$ latitude; Figure 5.6). In addition to this regional topographic gradient, there are numerous local topographic gradients whose wavelengths exceed the length of the wrinkle ridges.

In order to analyze wrinkle ridge morphometry, topographic changes resulting from wrinkle ridge formation at a local scale must be separated from changes resulting from regional scale processes. Previous workers have attempted to isolate the effects of regional topography from geological features by de-trending topographic data (e.g., Ivanov and Head, 2006; Kreslavsky et al., 2017; Andrews-Hanna, 2019, 2020). However, the complex regional topography in the study area is too complex for automatic de-trending.

To circumvent this problem, regional gradients were assumed to be linear and subtracted from the elevation data for each profile on an individual basis. The results of this process are individually de-trended profiles along which measurements of wrinkle ridge morphometry can be made without being affected by regional topography. $\mathrm{A}$ 
caveat of this approach is that any potential elevation differences related to the formation of the wrinkle ridge itself that overprint the regional topography will also be removed. Many wrinkle ridges have elevation offsets across the structure; that is, one side of the ridge is at a higher elevation than the other side (Golombek et al., 1991;

Okubo and Schultz, 2001; Golombek et al., 2001). The occurrence of these elevation offsets is cited by some researchers as evidence supporting the presence of thrust faults underlying wrinkle ridges, with the upthrown side representing the hanging wall and the downthrown side representing the footwall. Other researchers have not observed elevation offsets in association with wrinkle ridges (e.g., Watters and Robinson, 1997), or argue that these offsets are artefacts related to the regional topographic slope (Watters, 2004). In order to investigate the presence and magnitude of potential elevation offsets, a subset of 30 profiles were selected along ridges that are located in areas with little to no background topographic gradients. Among these profiles, the minimum measured elevation offset is $14.1 \mathrm{~m}$, the maximum is $202.6 \mathrm{~m}$, and the average value is $71.8 \mathrm{~m}(\mathrm{SD} \pm 43.8 \mathrm{~m})$. The elevation offsets measured in this subset are assumed to be representative of the entire population, though it is recognized that they represent only a small fraction $(6 \%)$ of the studied profiles. The significance of the recorded elevation offsets is discussed further in Section 5.6.2.5.

\subsubsection{Inter-Ridge spacing}

Inter-ridge spacing was measured as the distance between intersection points along the line depicted in Figure 5.3. A total of 91 wrinkle ridges intersect with this line, leading to an average spacing of $36.3 \mathrm{~km} \pm 72.8 \mathrm{~km}$. Along the entire transect, the minimum spacing measured is $3.4 \mathrm{~km}$, and the maximum spacing is $496.9 \mathrm{~km}$. On a 
plot of wrinkle ridge spacing versus latitude (Figure 5.7A), it is evident that wrinkle ridge spacing is not constant across the study area. Wrinkle ridge spacing is much lower from $6^{\circ} \mathrm{N}$ latitude to $7^{\circ} \mathrm{S}$ latitude, with an average spacing of $17.4 \mathrm{~km} \pm 11.3 \mathrm{~km}$. The average wrinkle ridge spacing is therefore heavily skewed by the larger spacing measurements from the southern half of the study area, where wrinkle ridges are nearly absent.

As in previous studies of regional wrinkle ridge distribution on Venus (Kreslavsky and Basilevsky, 1998), a systematically smaller inter-ridge spacing is observed than is documented on other planetary bodies. A histogram of wrinkle ridge spacing shows that the spacing values are heavily skewed towards low values; $63 \%$ of the measurements are below $23.4 \mathrm{~km}$ (Figure 5.7B). In comparison, average spacing values for wrinkle ridges in the Tharsis ridge system on Mars range between 30 and $88 \mathrm{~km}$, with the majority between 20-60 km (Watters, 1991).

To gain a comprehensive view of the spatial distribution of wrinkle ridges in the study area, a map of wrinkle ridge density, which displays the line (along-strike) length of wrinkle ridges per square kilometre $\left(\mathrm{km} / \mathrm{km}^{2}\right)$, was also computed (Figure $\left.5.8 \mathrm{~A}\right)$. Note that the calculation of wrinkle ridge density is a direct result of the coverage of wrinkle ridge mapping, which in turn is influenced by the coverage of the SAR data. Some areas of low wrinkle ridge density can be attributed to gaps or areas of low resolution in the SAR data (particularly a NNW-SSE trending swath extending from $20.5^{\circ}$ to $23.5^{\circ} \mathrm{E}$, $4.5^{\circ}$ to $-14.0^{\circ} \mathrm{N}$ ), as opposed to geological parameters. 
Wrinkle ridge density increases towards the north of the study area whereas wrinkle ridge spacing decreases. There are a few exceptions to this pattern, which can be explained by the influence of geological and topographic features, and data coverage (Figure 5.8C). Some regions of low wrinkle ridge density coincide with the centres of coronae (e.g., Cybele, Kuan-Yin), where previous workers have identified wrinkle ridges diverging around the topographic rims (McGill, 1993). In some areas, such as in the vicinity of Carreno Crater, wrinkle ridges have been obscured by later impact craters and their associated deposits. Wrinkle ridges have not been observed in tessera terrain, and as a result, areas of tessera terrain coincide with low wrinkle ridge density.

The majority of the wrinkle ridges selected for topographic analysis are contained within a corridor of high wrinkle ridge density between $9.5^{\circ} \mathrm{N}$ and $1.5^{\circ} \mathrm{S}$ latitude (referred to as "Location 1" in Figures 5.6 and 5.8). In this area, wrinkle ridges are more prominent on SAR images and in the stereo-derived topography data, appearing more radar-bright and wider than other features to the north and south, suggesting that they might be larger in width and height. This part of the study area also has the lowest elevation (reaching more than $800 \mathrm{~m}$ below Mean Planetary Radius) and is correlated with a positive Bouguer anomaly of up to $152 \mathrm{mGal}$ (Figures $5.6,5.8$ ).

A statistical correlation between wrinkle ridge density and the Bouguer gravity anomaly across the entire study area was computed and resulted in a high positive correlation with a coefficient of 0.98 (Figure 5.8B). 


\subsubsection{Width}

The distinct morphological components of a broad arch and superimposed crenulation were not observed for the wrinkle ridges studied. This may be an effect of the low resolution of the topography data, in which crenulations with widths of a kilometre or less are not resolvable. Width measurements were thus performed on the 'broad arch' component.

Wrinkle ridge widths were estimated by measuring the distance between the slope breaks on the backslope and the foreslope of the ridge. In other words, the measured wrinkle ridge widths encompass the part of the structure that is elevated with respect to the background topography. Some of the studied wrinkle ridges have more than one peak contained within the slope breaks (so-called "double" ridges, see Section 5.4.5 below); in these cases, both peaks were included in the width measurement. Individual profiles have measured widths ranging from 4.01 to $20.90 \mathrm{~km}$. Average values for individual wrinkle ridges range from a minimum value of $7.01(S D \pm 1.16) \mathrm{km}$ to a maximum value of 17.85 ( $S D \pm 2.52) \mathrm{km}$. The average height across all wrinkle ridges is $9.60(S D \pm 0.71) \mathrm{km}$ (Figure 5.9A).

The measurements of wrinkle ridge width presented here are consistent with those from wrinkle ridges on the Moon, Mars, and Mercury (Figure 5.10; Watters, 1988). Across the 30 sites studied by Kreslavsky and Basilevsky (1998), however, the mean wrinkle ridge width is $1.25 \mathrm{~km}(\mathrm{SD} \pm 0.66 \mathrm{~km})$, nearly an order of magnitude smaller than the average measurement herein. It is hypothesized herein that the primary reason for this difference is the fact that the brightness observed across wrinkle ridges in SAR 
data is mainly a function of changes in slope, and subtle changes in slope along a ridge are not easily detectable. This is especially true along on the backslope of a ridge, where the topographic profiles demonstrate that slopes may be very gradual (often $1^{\circ}$ or less; see Table 5.1). Kreslavsky and Basilevsky (1998) may have been measuring only the portions of the ridge where the slope change is most dramatic, near the ridge crest and foreslope.

\subsubsection{Height}

Wrinkle ridge heights were estimated using the de-trended profiles and taken as the maximum height along the ridge crest. Individual profiles have measured heights ranging from 7.0 to $251.3 \mathrm{~m}$. Average values for individual wrinkle ridges range from a minimum value of $38.9(S D \pm 19.6) \mathrm{m}$ to a maximum value of $178.4(S D \pm 62.6) \mathrm{m}$. The average height across all wrinkle ridges is $87.5(\mathrm{SD} \pm 30.1) \mathrm{m}$ (Figure $5.9 \mathrm{~B})$.

Prior to the development of the stereo-derived topography dataset, various methods were used to attempt to measure wrinkle ridge height on Venus using SAR data. These attempts were largely unsuccessful due to the low resolution of the SAR data, but a few estimates of wrinkle ridge height were nevertheless obtained. Bilotti (1997) was unable to directly measure wrinkle ridge heights, but estimated surface "limb" dip angles, finding that the limb dips are less than $15^{\circ}$, and probably closer to $5^{\circ}$. At one site, Kreslavsky and Basilevsky (1998) used stereo analysis of the three different SAR viewing geometries to provide a height estimate between $40-90 \mathrm{~m}$ for a point along one wrinkle ridge. Using another method, where height estimation was taken from the difference in lengthening and shortening of slopes between different SAR viewing 
geometries, Kreslavsky and Basilevsky (1998) measured the heights at two other points along the same ridge, yielding estimates of 140-260 m and 50-170 m, respectively. These height estimates, although based upon indirect methods with large uncertainties, fall within the range of the measured values of this study (Figure 5.10).

\subsubsection{Shape}

Wrinkle ridge symmetry and shape were evaluated through a combination of qualitative (visual inspection) and quantitative (skewness) methods. Calculation of skewness along topographic profiles provides information on wrinkle ridge symmetry. It can be applied to evaluate wrinkle ridges with singular peaks, as they approximate the shape of a normal distribution. A perfectly symmetric ridge would have a skewness value of zero, an asymmetric ridge with vergence toward the left or the right of the profile would have a positive or negative skewness value, respectively. Due to the fact that all profiles were constructed from northwest to the southeast (perpendicular to strike), asymmetric ridges with positive skewness values represent ridges with vergence to the northwest, whereas negative skewness values represent ridges with vergence to the southeast. The actual skewness value reflects both the degree to which the ridge is "leaning", as well as the length of the respective scarps (foreslope and backslope).

To evaluate the skewness of a given profile, the background topographic slope (i.e., a slope in the profile not related to the individual ridge) was first removed as discussed in Section 5.4.1. The skewness was then calculated using:

$$
S=\frac{n}{(n-1)(n-2)} \sum\left(\frac{x_{i}-\bar{x}}{s}\right)^{3}
$$


where $n$ is the number of data points, $x_{i}$ is the data point of interest, $\bar{x}$ is the sample mean, and $s$ is the sample standard deviation.

In addition to skewness, average slope values for the fore- and backslopes were calculated for a representative subset of 20 de-trended wrinkle ridges (Table 5.1). This subset was chosen to sample wrinkle ridges across the entire study area.

For the 424 ENE-WSW trending single peak wrinkle ridge profiles studied, the average skewness is -0.1 (Figure 5.9D). Individual wrinkle ridges have skewness values ranging from -1.2 to 0.8 . A total of $63.8 \%$ have negative skewness and $36.2 \%$ have positive skewness. Furthermore, $52.3 \%$ of the wrinkle ridges are SE-verging asymmetric (S <-0.09), 25.0\% are NW-verging asymmetric $(\mathrm{S}>-0.09)$ and $22.7 \%$ are symmetric $(-0.09 \leq \mathrm{S} \leq 0.09)$.

Based on the skewness analysis above, wrinkle ridges were grouped into three general categories, following those used by Andrews-Hanna $(2019,2020)$ for wrinkle ridges on Mars: 1) symmetric, comprising $22.7 \%$ of the population, 2 ) asymmetric ("ramp" in Andrews-Hanna (2019), "arch-style ridges" in Andrews-Hanna (2020)), comprising $77.3 \%$ of the population, and 3 ) double, a subcategory of asymmetric ridges with multiple peaks, comprising $15.7 \%$ of the population (Figure 5.11 ).

Out of the population of 715 wrinkle ridges in the western hemisphere of Mars studied by Andrews-Hanna (2019), $50 \%$ of the population were classified as "symmetric", $24 \%$ as "ramp", and $26 \%$ as "double". When the results of this study from 424 profiles across 40 Venusian wrinkle ridges are compared to the results of AndrewsHanna (2019), a lower fraction of "double" (15.7\%) and symmetric $(22.7 \%)$ ridges is 
found. If the Martian wrinkle ridges of classes "double" and "ramp" are grouped into a more general category of asymmetric, they comprise slightly more than $50 \%$ of the population. A higher occurrence of asymmetric ridges is observed, with asymmetric and symmetric ridges comprising $77 \%$ and $23 \%$ of the population, respectively. The topographic dataset used by Andrews-Hanna (2019) for Mars (MOLA topography) has a much higher resolution ( $\sim 63 \mathrm{~m} / \mathrm{pixel}$ ) than the stereo-derived topography data for Venus $(1-2 \mathrm{~km} / \mathrm{pixel})$. It is possible that if higher resolution topographic data were available for Venus, the relative proportions of wrinkle ridges in these classes would be shifted.

Andrews-Hanna $(2019,2020)$ proposed two nearly symmetrical antithetic thrust faults forming a "pop-up structure" to explain the formation of symmetric wrinkle ridges. The symmetric wrinkle ridges observed here may be the result of such pop-up structures but could also form above more deeply buried thrust faults (see Section 5.6.2.4)

\subsection{Modeling Fault Geometry}

\subsubsection{Model Construction}

To gain insight on the morphometry of thrust faults and associated folds potentially underlying wrinkle ridges, forward modeling of fault morphometry was conducted using COULOMB 3.3 (Toda et al., 2011). The COULOMB software allows for calculations of static stress and strain induced by slip along a fault, using elastic dislocation theory. Models are set up in a uniform, isotropic, elastic half-space and fault parameters including length, depth, dip, and amount of slip are iteratively varied until a 
good fit between the calculated and observed surface deformation (as expressed by the topography) is achieved.

Some potentially important wrinkle ridge-forming processes and parameters are ignored in the modeling. Because the model is constructed in an isotropic medium, the effect of mechanical contrasts between stratigraphic layers in the crust cannot be investigated. The model also only considers a single main thrust fault and does not explicitly consider the role of antithetic backthrust faults, synthetic splay faults, or folds branching off the main fault.

The calculated surface deformation was compared to the average topographic profile of a wrinkle ridge created from the 503 profiles considered in this study. An average profile has been chosen to compare with the model results so that the derived estimates of the fault parameters would reflect the generalized fault morphometry of wrinkle ridges in the study area.

This elastic dislocation modeling provides a first attempt at a quantitative study of subsurface wrinkle ridge morphometry on Venus. For the half-space, a homogeneous basaltic crust was assumed with a Young's modulus of $80 \mathrm{GPa}$, a Poisson's ratio of 0.25 , and a coefficient of friction of 0.8 . These elastic parameters are within the range of those determined experimentally for basalt (Schultz, 1993). For all models, an alongstrike fault length of $20 \mathrm{~km}$ was used, equivalent to the average length of mapped wrinkle ridge segments (Section 5.4.1). The depth to the lower fault tip was varied between 5 and $20 \mathrm{~km}$ (close to the average estimated crustal thickness in the study area), chosen to reflect the range in observed wrinkle ridge widths from approximately 7 
to $18 \mathrm{~km}$. Following previous similar studies (e.g., Okubo and Schultz, 2006; EgeaGonzález et al., 2012; Williams et al., 2013), the amount of along-strike and along-dip fault slip was tapered to reach zero at the edges of the fault, in 5 increments of $100 \mathrm{~m}$. Fault slips ranging from 100 to $250 \mathrm{~m}$ were studied. Both planar and listric fault geometries were modeled. Planar fault dips were modeled with dips ranging between $10^{\circ}$ and $45^{\circ}$. Listric faults were approximated using four linear segments of decreasing dip with increasing depth; these fault segments had dips of $30^{\circ}, 10^{\circ}, 5^{\circ}$, and $0.01^{\circ}$. Both blind and surface-breaching faults were modeled; blind faults were modeled to a maximum depth of $3 \mathrm{~km}$ beneath the surface to the upper fault tip. For surfacebreaching faults, the upper fault tip was placed at the boundary of the model with the free surface. Schematic diagrams illustrating the range of fault geometries modeled are shown in Figure 5.12.

\subsubsection{Modeling Results}

The comparisons between the calculated and observed wrinkle ridge morphometries focus predominantly on ridge heights, widths, and surface fore- (ahead or above the upper fault tip) and backslope (behind the upper fault tip) morphologies.

As the fault dip decreases, the resulting ridge width increases (Figure 5.13A). The syncline behind the fault (the 'trailing syncline') increases in depth and width, whereas the syncline ahead of the fault (the 'leading syncline') decreases in depth and width. For the same amount of fault slip, shallower fault dips also produce lower maximum relief. Fault dips of approximately $30^{\circ}-40^{\circ}$ provide the best fit when compared to the average wrinkle ridge profile. 
Varying the modeled depth to the lower fault tip also changes the width of the resulting ridge (Figure 5.13B). The ridge increases in width as the depth to the lower fault tip is increased. When compared with the average wrinkle ridge profile, the bestfitting lower fault tip depth is $5 \mathrm{~km}$ or less. Faults that extend to depths greater than 10 $\mathrm{km}$ produce ridges that are too wide to be compatible with the observations. The trailing syncline increases in size with decreasing depth to the lower fault tip; the reverse relationship is observed with the leading syncline.

Blind faults, rather than surface-breaching faults, produce a better match with the average wrinkle ridge profile (Figure 5.13C). The best fit was achieved with an upper fault tip depth of $2 \mathrm{~km}$. Increasing depth to the upper fault tip shifts the position of the resulting ridge ahead of the fault plane. As the depth to the upper fault tip increases, the crest of the ridge and base of the fault scarp become progressively rounder, thereby trending towards a more symmetrical geometry. At shallow dips $\left(<30^{\circ}\right)$, blind faults begin to develop a narrow crenulation at the crest of the ridge, above the upper fault tip. These crenulations were not observed on any of the surface-breaching fault models. For surface-breaching faults, leading synclines present as sharply angled fault offsets beginning at the base of the fault scarp. As the depth to the upper fault tip increases, the offset becomes more rounded and fold-like.

Planar faults better match the average wrinkle ridge profile than listric faults (Figure 5.13D). When compared to a $30^{\circ}$-dipping planar fault with the same faulting parameters, a listric fault produces a ridge with a secondary crest on the backslope and a deeper trailing syncline. Listric faults produced the most dramatic trailing synclines, with maximum amplitudes of nearly $60 \mathrm{~m}$ for a surface-breaching fault penetrating to a 
depth of $5 \mathrm{~km}$. For planar faults, the trailing syncline is located approximately above the lower end of the fault plane, whereas for listric faults, the trailing syncline is located slightly ahead of the lower fault tip. Neither secondary ridge crests (i.e., the "double" category, refer to Section 5.4.5) nor trailing synclines were commonly observed among the topographic profiles, and thus are not apparent in the average wrinkle ridge profile.

For a $30^{\circ}$ dipping planar fault with an upper depth of $2 \mathrm{~km}$ and a lower depth of 5 $\mathrm{km}$, a slip of approximately $230 \mathrm{~m}$ is required to produce a ridge relief of approximately $97 \mathrm{~m}$ and a ridge width of approximately $10 \mathrm{~km}$ (Figure 5.14). Slightly more slip on the fault is required to produce a similar relief for faults with shallower lower depths.

\subsection{Discussion}

\subsubsection{Comparison with Ridge Belts}

Ridge belts are a type of contractional feature found on Venus that are distinct from wrinkle ridges (Figure 5.15). They are bundles of individual ridges that can be 30$400 \mathrm{~km}$ wide and $200-2000 \mathrm{~km}$ long. Some ridge belts are spatially associated with tessera terrain (Frank and Head, 1990). Recent analysis of the morphometry of twelve ridge belts, using the stereo-derived topography dataset of Herrick et al. (2012), has shown that these structures have an average relief and width of nearly $600 \mathrm{~m}$ and 80 $\mathrm{km}$, respectively (Williams et al., 2019, 2020). Across the individual faults within the ridge belts, asymmetric profiles displaying fore- and backslope morphology were observed (Williams et al., 2020).

Both ridge belts and wrinkle ridges are inferred to have contractional origins but may represent different styles of deformation. The key difference between them is that 
ridge belts are comprised of linear clusters of ridges, representing more localized expressions of strain, whereas wrinkle ridges are individual structures, representing more distributed expressions of strain. Ridge belts also have significantly higher average relief than wrinkle ridges.

Tectonic modeling shows that the faults within ridge belts on Venus penetrate to depths of $10-20 \mathrm{~km}$, have dips of $25-30^{\circ}$, and have accommodated $1-2 \mathrm{~km}$ of offset (Moruzzi and Kiefer, 2019, 2020). In comparison with the modeling results for wrinkle ridges, ridge belt formation appears to represent a more thick-skinned style of deformation. Although the modeled lower depths of the faults underlying ridge belts are lower than what is typically discussed for a thick-skinned deformation style (e.g., Golombek et al., 2001), the majority of Venus' crust is likely to be $20-25 \mathrm{~km}$ thick or less (Jiménez-Díaz et al., 2015); thus, ridge belt deformation may frequently involve most or all of the elastic lithosphere. The differences in regional distribution, morphology and faulting parameters suggest that wrinkle ridges represent a more distributed, thinskinned deformation style, whereas ridge belts represent a more localized, thickskinned deformation style.

\subsubsection{Thrust Fault Geometry}

The modeling results indicate that potential thrust faults underlying wrinkle ridges in the study area have moderately shallow planar dips of around $30^{\circ}$, are shallow-rooted with lower penetrating depths of $5 \mathrm{~km}$ or less, are blind and buried to depths of $2 \mathrm{~km}$ or greater, and have accommodated on average approximately $200 \mathrm{~m}$ of dip-slip. 


\subsubsection{Thick- vs. Thin-Skinned Deformation}

Various studies have disagreed on the maximum depth of wrinkle ridge thrust faults. Some studies have inferred a thin-skinned deformation style, with the faults extending to only the upper few kilometres of the lithosphere and having shallow dips, remaining either planar or with a listric geometry flattening into a décollement (e.g., Watters, 1988; Suppe and Narr, 1989; Allemand and Thomas, 1992; Mangold et al., 1998; Watters, 2004). Other studies have argued for a thick-skinned deformation style, with the faults possessing steeper dips and extending to greater depths within the lithosphere (e.g., Zuber, 1995; Golombek et al., 1991; 2001; Montési and Zuber, 2003; Byrne et al., 2015). The results herein support a thin-skinned deformation style, with the faults dipping $30^{\circ}$ and penetrating to depths of $5 \mathrm{~km}$ or less. Faults that extend deeper into the crust are incompatible with the observations.

Recent complex mechanical models investigating the role of multiple faults (including a primary fault and one or more backthrust(s)), variations in fault dip with depth, horizontal slip surfaces, and décollements have been able to match the topography of the main morphometric groups of wrinkle ridges on Mars (symmetric, asymmetric (also called "ramp" or "arch-style"), and double) (Andrews-Hanna, 2020). The average wrinkle ridge profile determined here would be best described as an "archstyle" ridge, which is suggested from the modeling results of Andrews-Hanna (2020) to be dominated by a single, planar blind thrust fault with a dip between $20^{\circ}-40^{\circ}$. These results align well with the models presented here, except for the predicted depths of faulting for the Martian ridges (18-37 km), which are much greater (Andrews-Hanna, 2020). 


\subsubsection{Comparison with an Exposed Wrinkle Ridge in Melas Chasma, Mars}

Almost all studies of wrinkle ridge fault geometry have been based on observations of surface deformation, mechanical modeling, or comparison with analogous structures on other planets. One study (Cole and Andrews-Hanna, 2017) was able to obtain direct observations using High Resolution Stereo Camera topography (HRSC; vertical resolution of $10 \mathrm{~m}$ ) on the structure of a wrinkle ridge exposed in the wall of Melas Chasma, Mars. Cole and Andrews-Hanna (2017) found that the wrinkle ridge was shallowly dipping, with a dip between $21^{\circ}$ and $6^{\circ}$ and blind, with a depth to the upper fault tip between 1 and $3.5 \mathrm{~km}$. Cole and Andrews-Hanna (2017) also found no evidence for a listric fault geometry. The observations of Cole and Andrews-Hanna (2017) are consistent with the interpretations from this study of fault geometry from modeling, although the predicted fault dip (approximately $30^{\circ}$ ) is slightly steeper.

\subsubsection{Associated Synclines}

In many of the models, leading and trailing synclines were observed proximal to the ridges. Trailing synclines were most prominent in models with shallow dips, shallow depths to the lower fault tip, and listric faults. Leading synclines were not as prominent as trailing synclines for any of the models and display reverse behaviour; leading synclines increase in size with increasing dip and depth to the lower fault tip. Previous studies modeling planetary thrust faults have made similar observations regarding the behaviour of their associated synclines (e.g., Schultz and Watters, 2001; Watters and Schultz, 2002). Schultz and Watters (2001) and Watters and Schultz (2002) found in 
their modeling of lobate scarps on Mars and Mercury that the trailing synclines

produced in listric fault models had much greater amplitudes than were observed in any of the topographic data.

\subsubsection{Secondary Peaks and Crenulations}

Some of the wrinkle ridges observed contain multiple peaks along the backslope of the ridge. These multiple peak structures have been observed in association with wrinkle ridges on other planetary bodies and are frequently interpreted as backthrusts (e.g., Schultz, 2000; Okubo and Schultz, 2004; Andrews-Hanna, 2020). The modeling results presented here and of other similar studies (Watters, 2004) suggest that listric faults may also be capable of generating wrinkle ridges with multiple peaks along the backslope. However, the incompatibility between the observations and the calculated surface deformation of listric fault models leads us to infer the majority of the wrinkle ridges with multiple peaks are associated with backthrust faults.

Although the separate broad arch and crenulation components were not observed in the wrinkle ridges studied, the modeling presented here may provide some insight into the formation of these components. Shallowly dipping $\left(<30^{\circ}\right)$, blind thrust fault models produce wrinkle ridges with a main, broad ridge and superposed, sharp crenulation just before the fault scarp.

\subsubsection{Elevation Offsets}

Elevation offsets were observed in association with all of the wrinkle ridges in the subset of 30 topographic profiles located in areas with no background topographic gradient, ranging in magnitude from tens to hundreds of metres (Section 5.4.1). The 
identification of these offsets in areas without a regional slope suggests that they are real, and not simply artefacts of the background topography (e.g., Watters, 2004). However, the absolute value of the offsets recorded here should be interpreted with caution, due to the small sample size of the subset studied and the low resolution of the stereo-derived topography data.

\subsubsection{Regional Strain}

Following the methodology of Golombek et al. (1991), a regional strain estimate is calculated for the study area by summing the shortening accommodated by the wrinkle ridges along the transect used to measure inter-ridge spacing (Figure 5.7) and dividing it by the length of the transect. The model-derived slip value of $230 \mathrm{~m}$ is assumed to be a good approximation of the shortening value of the average wrinkle ridge in the study area. This method leads to a regional strain estimate of $0.69 \%$.

A regional strain of $0.69 \%$ is higher than regional strain values that have been determined for other planetary bodies. Golombek et al. (1991) determined the regional strain represented by wrinkle ridges in the Humorum basin on the Moon to be $0.22 \%$. Golombek et al. (1991) also estimated the strain across Lunae Planum, Mars, and found it to be approximately $0.2-0.5 \%$. Given that wrinkle ridges are more common and closely spaced on Venus than on Mars or the Moon, it is not surprising to find higher degrees of regional shortening on Venus.

\subsubsection{Regional Tectonic Setting}

Some studies have attempted to use Bouguer gravity data to compute global crustal thickness estimates for Venus (e.g., Jiménez-Díaz et al., 2015; Anderson and 
Smrekar, 1999). With the assumption of constant crust and mantle densities (2900 and $3300 \mathrm{~kg} / \mathrm{m}^{3}$, respectively), these studies have found that the low-lying volcanic plains are typically correlated with thinner crust, on the order of $10-20 \mathrm{~km}$, whereas the highlands are correlated with thicker crust, approaching $100 \mathrm{~km}$. Jiménez-Díaz et al. (2015) used the relationship between global topography and gravity data to create global maps of crustal thickness, effective elastic thickness (a measure of the rigidity of the lithosphere), and internal load fraction for the planet, and found that most of the crust is $20-25 \mathrm{~km}$ thick, with effective elastic thicknesses ranging from $14 \mathrm{~km}$ to $94 \mathrm{~km}$, with the majority of the planet trending toward low to moderate elastic thickness values. Their models predict that the present study area (excluding Alpha Regio, of which the northeastern part is included in the study area) is located in a region of thin crust, with crustal thicknesses ranging between approximately $16-25 \mathrm{~km}$, and effective elastic thicknesses ranging between approximately $18-60 \mathrm{~km}$ (Figure 5.6). The area containing the wrinkle ridges selected for topographic analysis (Figure 5.4 , bounded by $0^{\circ}-30^{\circ} \mathrm{E}$, $9.5^{\circ} \mathrm{N}-1.5^{\circ} \mathrm{S}$; referred to as "Location 1" in Figures 5.6 and 5.8) is correlated with particularly low crustal thickness, averaging less than $20 \mathrm{~km}$. The correlation coefficient between wrinkle ridge density and crustal thickness is -0.38 , implying a moderate negative correlation between crustal thickness and wrinkle ridge density. The effective elastic thickness shows less of a correlation with wrinkle ridge density; the two parameters share a correlation coefficient of -0.29 .

The correlation between wrinkle ridge density, Bouguer anomaly, and the crustal thickness map of Jimenez-Diaz et al. (2015) at a regional scale demonstrates the importance of lithospheric properties on wrinkle ridge formation. Wrinkle ridge spacing 
in the study area appears to be mostly controlled by the magnitude of strain which, in turn, is related to the relationship between mantle dynamics and crustal thickness.

Overall, the observations presented here align reasonably well with previous modeling of Venus' global stress state from the geoid and topography by Sandwell et al. (1997), and its relationship to global wrinkle ridge distribution (Bilotti and Suppe, 1999). As was observed in these previous works, a correlation between wrinkle ridge distribution and areas of low geoid, gravity, and topography is observed, and these correlations are related regionally to mantle plume activity in Eistla Regio. Additionally, this study is able to verify the predicted negative correlation between wrinkle ridge density and crustal thickness; the magnitude of the strain resulting from the swell-push body force in the model of Sandwell et al. (1997) is directly related to lithospheric thickness.

Montési and Zuber (2003) explained variations in wrinkle ridge spacing on Mars as a result of a localization instability. They observed smaller values of wrinkle ridge spacing in highland ridged plains areas, where the lithosphere is $50-60 \mathrm{~km}$ thick, and higher values of wrinkle ridge spacing in the northern lowlands, where the crust is $30 \mathrm{~km}$ thick. In their model, wrinkle ridge spacing is directly a function of the depth to the brittle-ductile transition (BDT). They suggest the depth to the BDT is greater in the northern lowlands because the BDT is located within and controlled by mantle rocks with different rheological properties than crustal rocks.

The relationship between lithospheric properties and wrinkle ridge spacing for the study area does not support the hypothesis that the depth to the BDT is the dominant control on wrinkle ridge spacing. Because a strong correlation between wrinkle ridge density and the effective elastic thickness of the lithosphere modeled by Jiménez-Díaz 
et al. (2015) (which essentially tracks the depth to the BDT) was not found, the depth to the BDT may influence wrinkle ridge spacing but is not the dominant factor. In this study, the areas of greatest wrinkle ridge density are correlated with the thinnest crust, which is contrary to the observations of Montési and Zuber (2003) for Martian wrinkle ridge spacing.

Dragoni and Plombo (2003) modeled wrinkle ridges on Venus as dip-slip shear dislocations on reverse faults resulting from compressive stress. Based on the suggestions of Solomon et al. (1999), they hypothesized that these compressive stresses were largely a result of thermal stresses related to the greenhouse warming of Venus' atmosphere. The model of Solomon et al. (1999) dictates that most wrinkle ridges formed after a period of global warming resulting from the rapid emplacement of widespread volcanic plains. They also determined that the density of wrinkle ridges is controlled by lithospheric elastic and thermal properties, thermal stress, the contrast between tectonic stress and the rock strength, and fault slip, where wrinkle ridge density decreases with increasing strength and slip.

While thermal stresses resulting from atmospheric warming may certainly be a factor in wrinkle ridge formation (Anderson and Smrekar, 1999; Solomon et al., 1999; Dragoni and Plombo, 2003), the contribution from tectonic stress is also likely significant, and the relative importance of these stress mechanisms is probably variable at a global scale. Additionally, wrinkle ridge deformation has been observed to be progressive and not confined to the specific time interval of post-atmospheric heating (Guest and Stofan, 1999; McGill, 1993, 2004). In particular, the wrinkle ridges studied here vary in trend at a regional scale, circumscribing geoid highs within Eistla Regio 
(Bilotti and Suppe, 1999). Previous works have suggested that the western and central portions of Eistla Regio are sites of mantle upwelling and dynamic compensation in the form of mantle plumes (Grimm and Phillips, 1992; Stofan et al., 1995; Sandwell et al., 1997; McGill, 1998). The central Eistla mantle plume is inferred to be more mature than its western counterpart (Grimm and Phillips, 1992; McGill, 1998). The wrinkle ridges surrounding western Eistla formed after the main topographic uplift, but before the formation of Sif and Gula Montes (Grimm and Phillips, 1992; Stofan et al., 1995). The present study area is located in the plains south of central Eistla Regio. Grimm and Phillips (1992) suggested mantle downwelling to be occurring in these southern plains (Tinatin Planitia). Stress trajectories from their modeling align well with the orientations of the wrinkle ridges studied here. Mantle downwelling along the peripheries of the mantle plume(s) beneath Eistla Regio thus provides an explanation for the driving tectonic forces responsible for the intense contractional deformation observed in the study area.

Similar wrinkle ridge systems circumscribing potential mantle plume centres are observed on Mars (Syria Planum, in association with the Tharsis province), Earth (e.g., the Yakima folds of the Columbia Plateau, which some have interpreted to be in association with the Columbia River large igneous province), and elsewhere on Venus (e.g., the circum-Themis wrinkle ridge trend) (Mège and Masson, 1996; Bilotti and Suppe, 1999; Mège and Ernst, 2001). Mechanisms of generating compression involving plume tectonic models include surface loading by lavas, thermal subsidence, and subsidence resulting from surface loading by lavas and underplating. Mège and Ernst (2001) indicate that intensive wrinkle ridge formation from load-induced subsidence at a 
mantle plume site appears to necessitate thin crust. Mège and Ernst (2001) point out that the Yakima ridges formed only on a part of the Columbia Plateau, termed the 'western terrane', that is associated with thinned crust. They also speculate that the reason no wrinkle ridges are associated with post-Syria Planum activity at the Tharsis Montes on Mars may be due to crustal thickening during Syria Planum magmatic activity. Although the mechanism for generating compressive stresses may be different, these examples support the observations of this study wherein thin crust is associated with greater wrinkle ridge density.

\subsection{Conclusions}

Morphometric analysis of a subset of wrinkle ridges in the plains in Southern Eistla Regio show that they have average widths and heights on the order of $10 \mathrm{~km}$ and $100 \mathrm{~m}$, respectively. Most morphometric indicators are consistent with those of wrinkle ridges on Mars, the Moon, and Mercury, except width measurements which are nearly an order of magnitude larger than previous estimates for Venus derived using SAR data (Kreslavsky and Basilevsky, 1998). It is hypothesized that this difference is a function of the low slopes along the backslope of wrinkle ridges, which are not detectable in SAR images. Similar shape categories as those described in studies of Martian wrinkle ridges (Andrews-Hanna, 2019) are observed, although a higher fraction of asymmetric wrinkle ridges is found. These asymmetric wrinkle ridges possess a predominant vergence towards the southeast. Modeling of thrust fault geometry suggests that faults associated with wrinkle ridges are relatively shallow with moderate dips and do not breach the surface. The models presented here provide the foundation for further modeling of more complex faulting mechanisms and geometries. Wrinkle ridges likely 
represent thin-skinned deformation, whereas another class of contractional features on Venus, ridge belts, may represent more thick-skinned deformation. These results warrant further validation from similar analyses in other areas of Venus.

Wrinkle ridge density in the study area is correlated positively with the Bouguer gravity anomaly and negatively with crustal thickness. The strain represented by the wrinkle ridges is explained as a result of mantle downwelling along the peripheries of a central Eistla mantle plume; the strain is magnified by the relatively thin crust in the plains directly south of central Eistla. 


\subsection{Tables}

Table 5.1: Calculations of average slope (in degrees) along fore- and back-slopes for a representative subset of 20 de-trended wrinkle ridge profiles.

\begin{tabular}{llll} 
Wrinkle ridge & Profile & NW slope $( \pm$ SD $)$ & SE slope $( \pm$ SD $)$ \\
\hline 2 & c & $1.02 \pm 0.67$ & $1.70 \pm 1.02$ \\
3 & j & $0.93 \pm 0.43$ & $1.28 \pm 0.58$ \\
4 & d & $1.52 \pm 0.88$ & $1.49 \pm 0.85$ \\
6 & d & $1.19 \pm 0.63$ & $1.64 \pm 0.67$ \\
7 & f & $1.10 \pm 0.36$ & $1.07 \pm 0.36$ \\
8 & l & $0.96 \pm 0.57$ & $1.73 \pm 0.67$ \\
11 & g & $0.94 \pm 0.37$ & $1.36 \pm 0.49$ \\
13 & d & $1.12 \pm 0.52$ & $0.91 \pm 0.35$ \\
14 & g & $0.77 \pm 0.34$ & $0.99 \pm 0.40$ \\
17 & b & $1.10 \pm 0.55$ & $1.84 \pm 0.56$ \\
18 & s & $1.58 \pm 0.81$ & $1.18 \pm 0.54$ \\
20 & d & $2.04 \pm 1.42$ & $1.18 \pm 0.96$ \\
25 & j & $1.08 \pm 0.75$ & $0.71 \pm 0.25$ \\
27 & $\mathrm{c}$ & $1.62 \pm 1.33$ & $1.35 \pm 0.65$ \\
28 & $\mathrm{e}$ & $1.56 \pm 0.98$ & $1.32 \pm 0.56$ \\
30 & $\mathrm{n}$ & $1.54 \pm 0.85$ & $0.98 \pm 0.41$ \\
32 & $\mathrm{w}$ & $1.29 \pm 0.46$ & $0.94 \pm 0.38$ \\
35 & $\mathrm{~m}$ & $1.39 \pm 0.67$ & $1.27 \pm 0.72$ \\
39 & $\mathrm{~b}$ & $0.73 \pm 0.48$ & $1.37 \pm 0.62$ \\
40 & $\mathrm{~g}$ & $1.44 \pm 0.92$ & $1.34 \pm 0.97$
\end{tabular}




\subsection{Figures}

\section{A. Venus}

Northern Eistla Regio

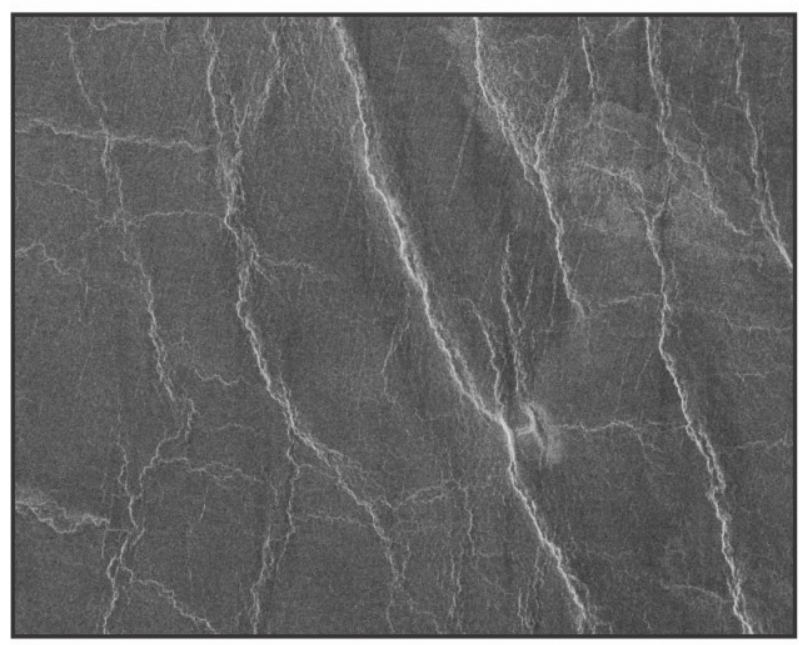

Magellan Left-Look SAR

$50 \mathrm{~km}$

\section{Moon}

Northeast of Nicollet Crater

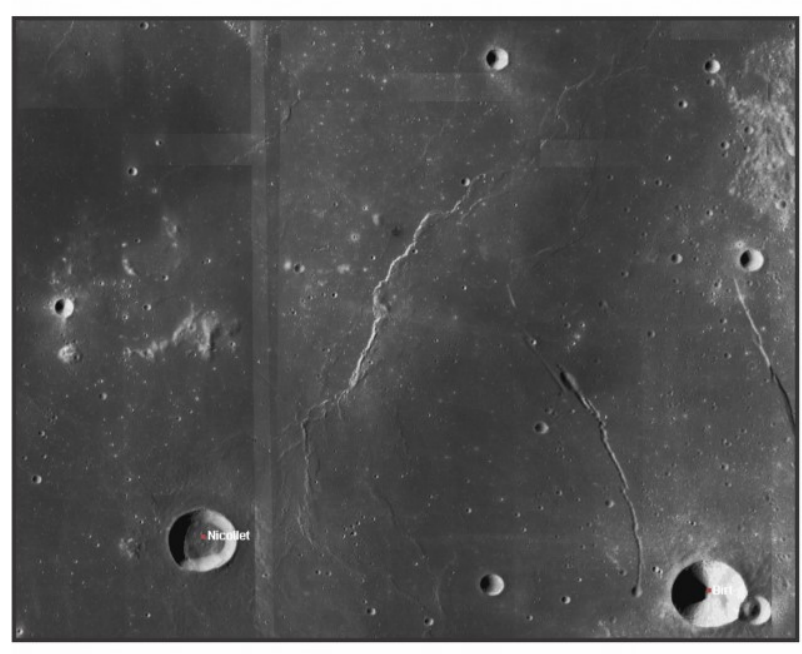

$50 \mathrm{~km}$

\section{B. Mars}

Northern Lunae Planum

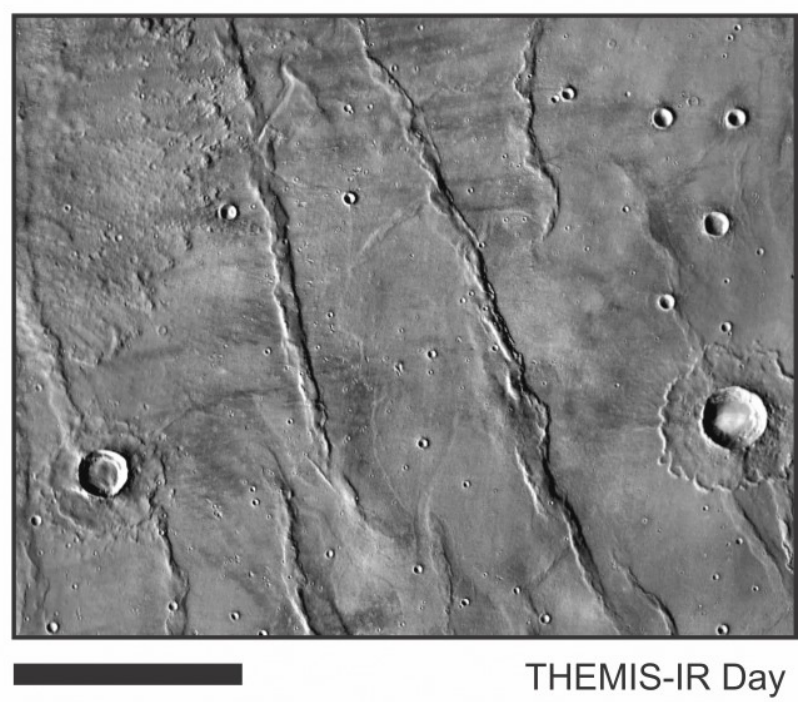

$50 \mathrm{~km}$
Southeast of Gaudi Crater

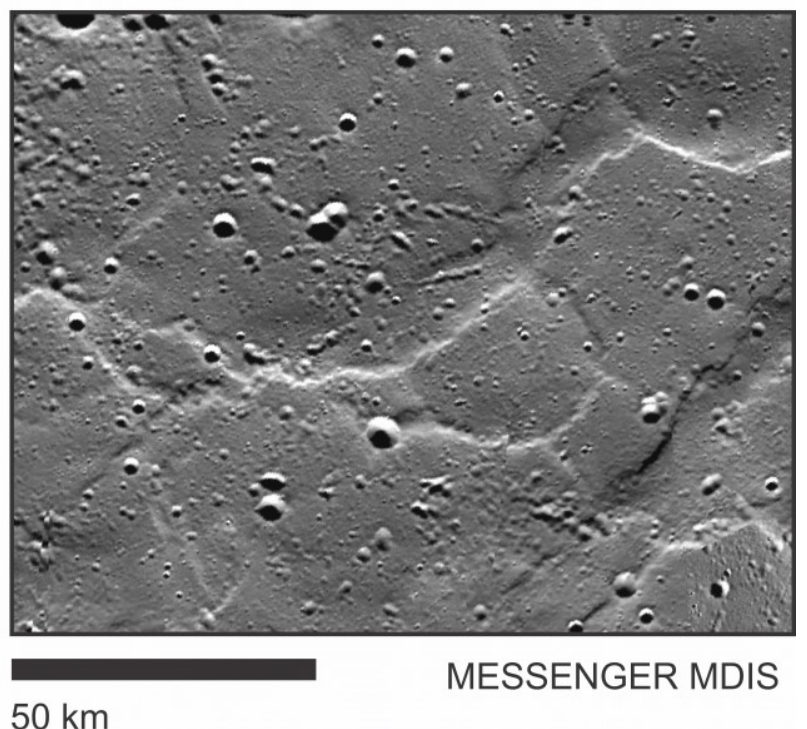

Figure 5.1: Examples of wrinkle ridges set to similar scales: A) NNW-SSE trending wrinkle ridges in the volcanic plains of northern Eistla Regio, Venus; B) NNW-SSE trending wrinkle ridges in northern Lunae Planum, Mars; C) NNE-SSW trending wrinkle ridges northeast of Nicollet Crater, the Moon; D) E-W trending wrinkle ridges southeast of Gaudi Crater, Mercury. 


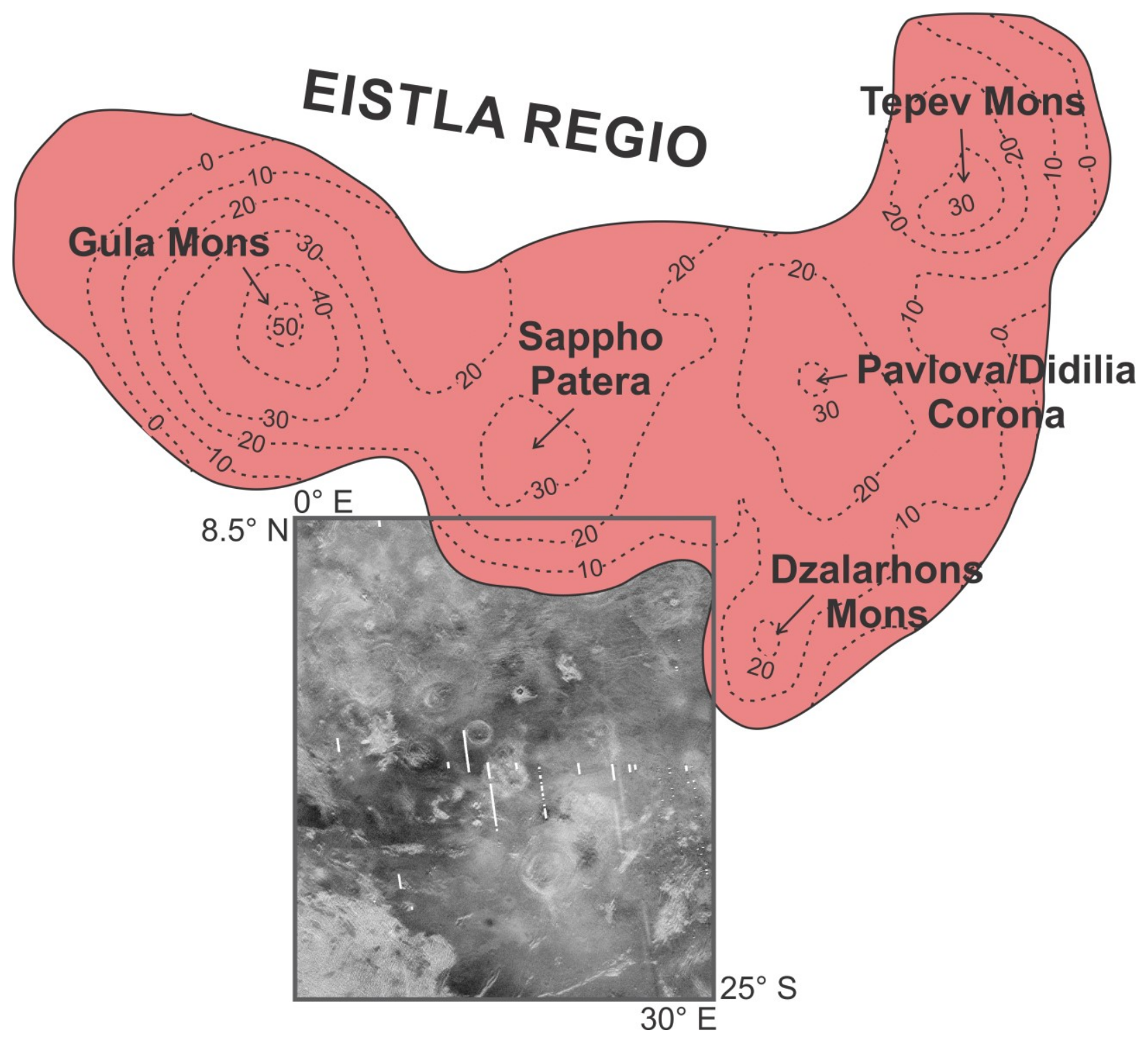

Figure 5.2: Location of the study area (left-looking SAR image) in relation to Eistla Regio. Dashed lines within Eistla Regio are contours of the geoid anomaly, with a contour interval of $10 \mathrm{mGal}$. Volcanic centres corresponding with major geoid highs within Eistla Regio are labelled. A scalebar for the study area is given in Figure 5.3. 


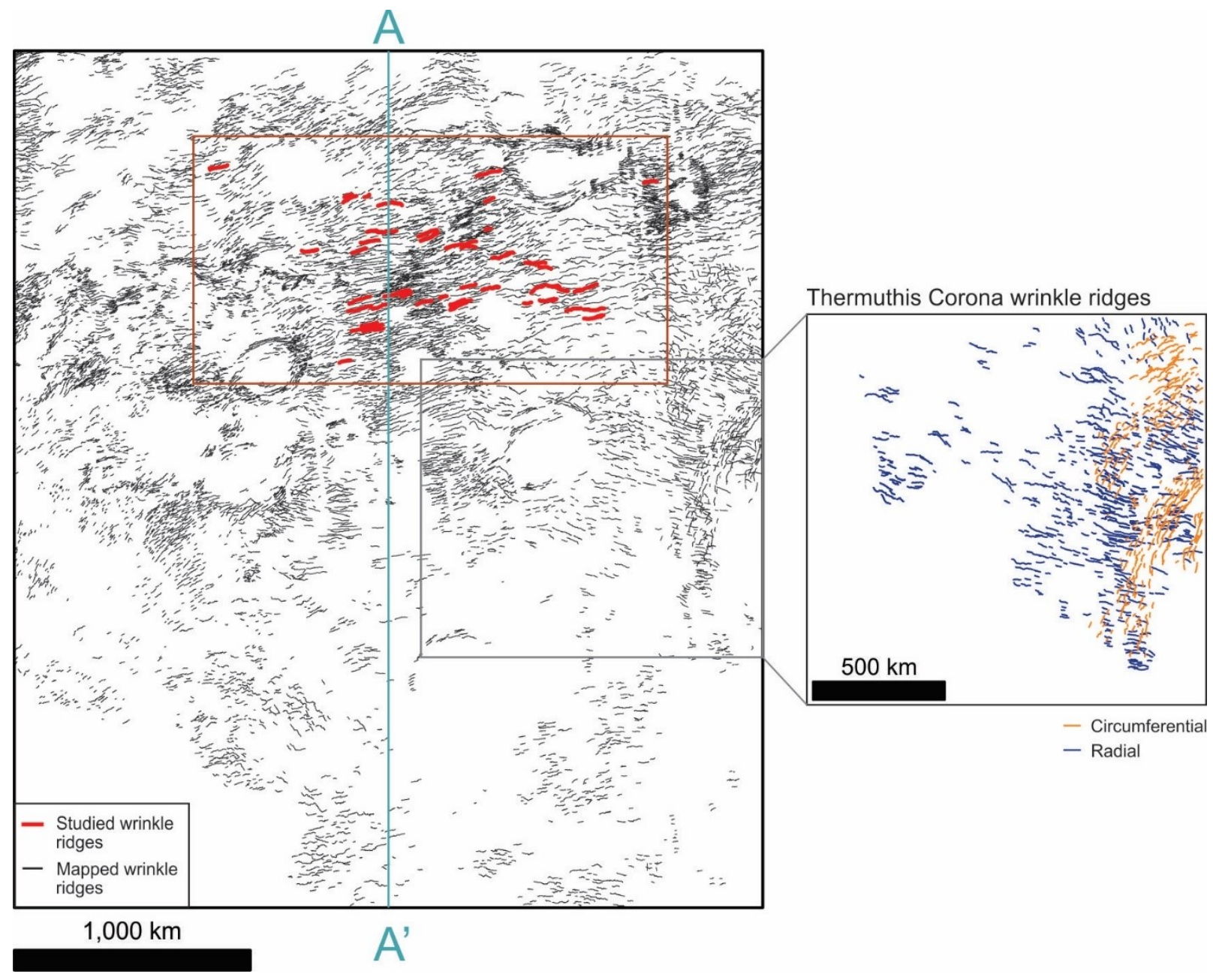

Figure 5.3: Wrinkle ridges mapped in the study area. The 40 wrinkle ridges selected for topographic analysis are outlined in red. The green line (oriented N-S and constructed through the centre of the study area along $15^{\circ} \mathrm{E}, 14^{\circ} \mathrm{N}-25^{\circ} \mathrm{S}$ ) represents the line along which the profiles in Figure 5.6 were constructed (A-A' from north to south) and corresponds to the transect used for measuring wrinkle ridge spacing in Figure 5.7. The inset map to the right shows the distribution of circumferential (orange) and radial (blue) wrinkle ridges associated with Thermuthis Corona. The brown box shows the location of Figure 5.4. 


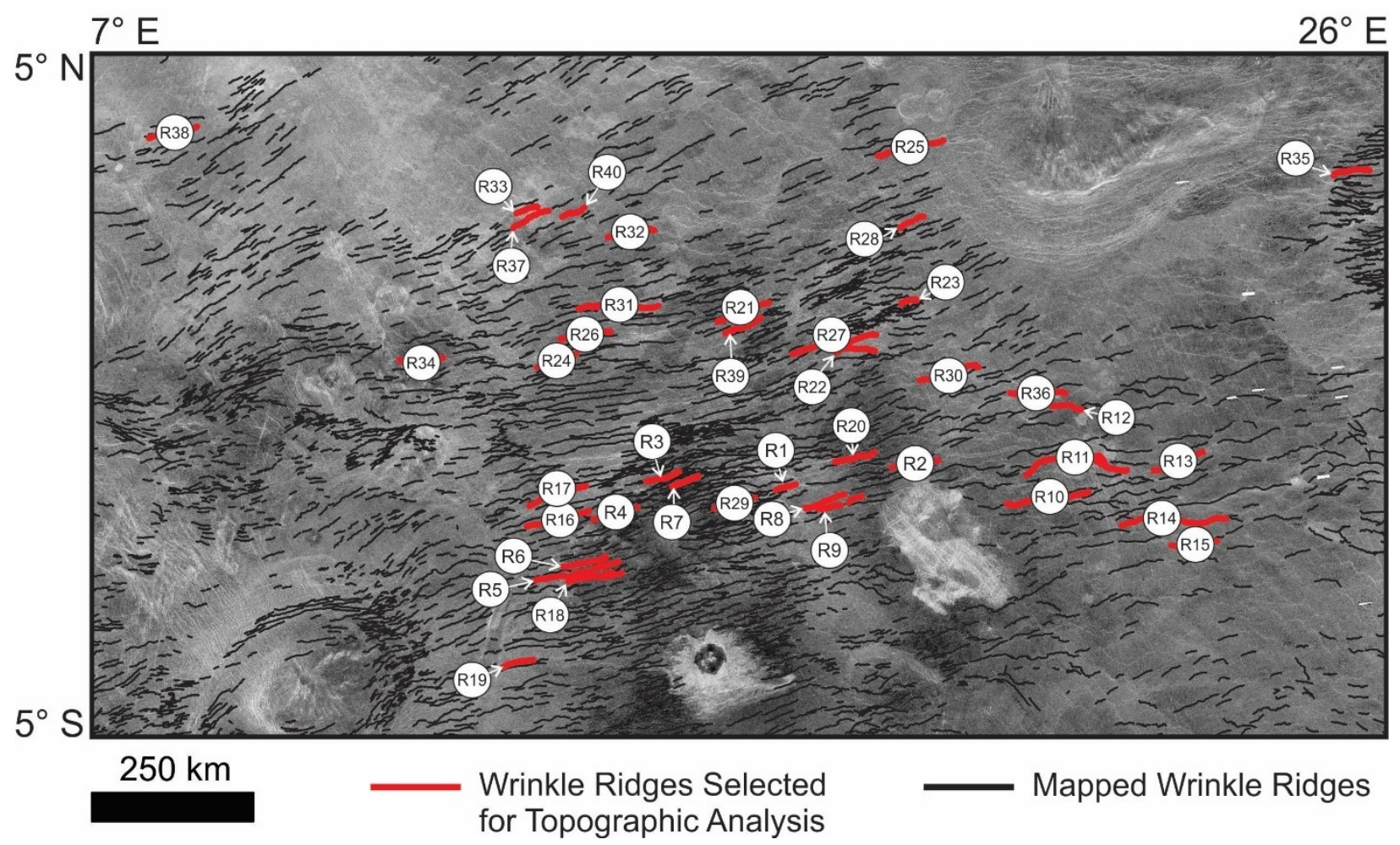

Figure 5.4: Map of the 40 wrinkle ridges selected for topographic analysis with superimposed labels. The location of this figure within the broader study area is shown in Figure 5.3. 

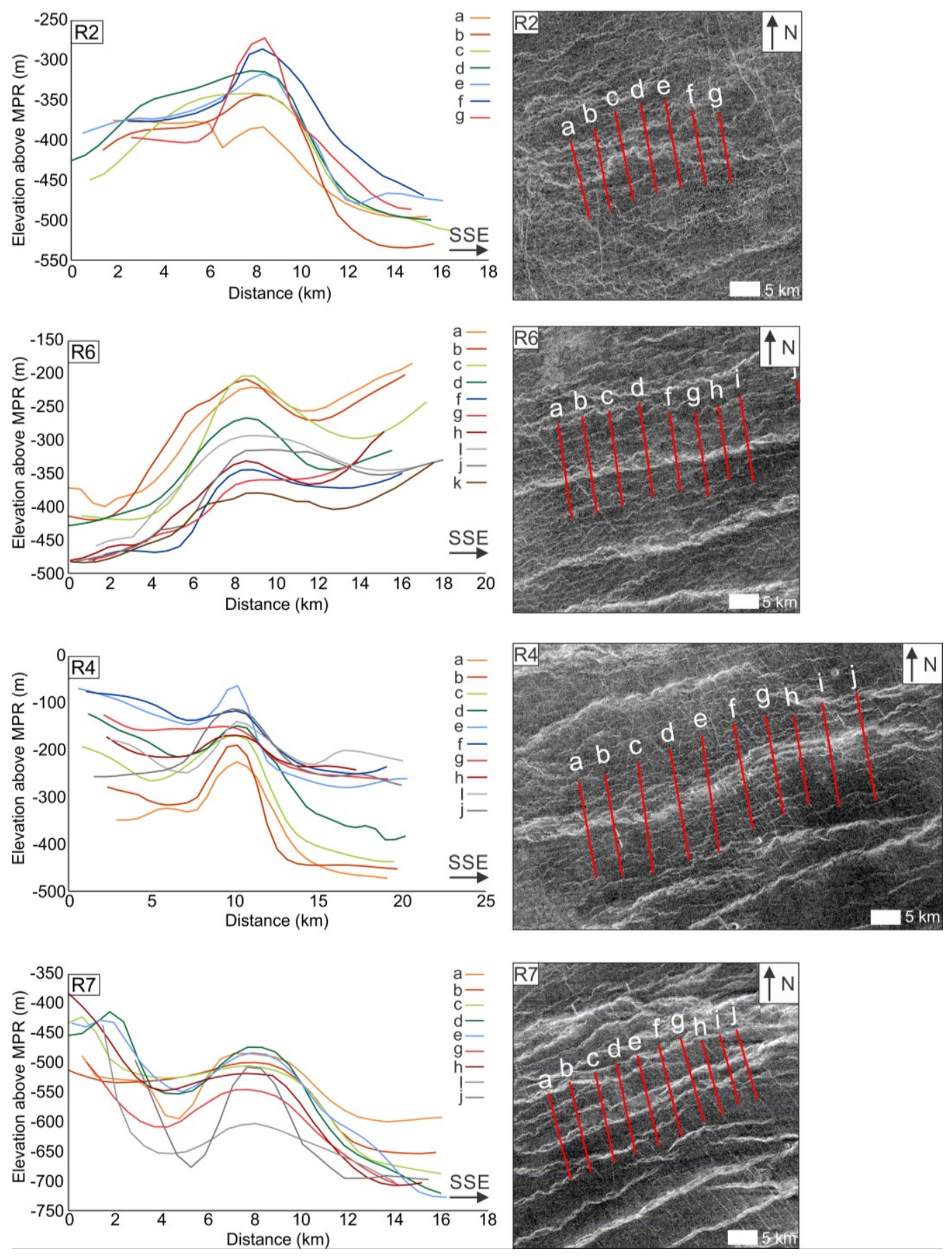

Figure 5.5: Examples of raw topographic profiles (left) and their locations on left-looking SAR images (right) for four of the studied wrinkle ridges (R2, R4, R6, and R7). All profiles are oriented with the right side toward the southeast. Vertical exaggerations (VE) for the profiles are as follows: $\mathrm{R} 2=34.6 x \mathrm{VE}, \mathrm{R} 4=28.6 x \mathrm{VE}, \mathrm{R} 6=33 \mathrm{xVE}$, and $\mathrm{R} 7=26.1 \mathrm{x} \mathrm{VE}$. 


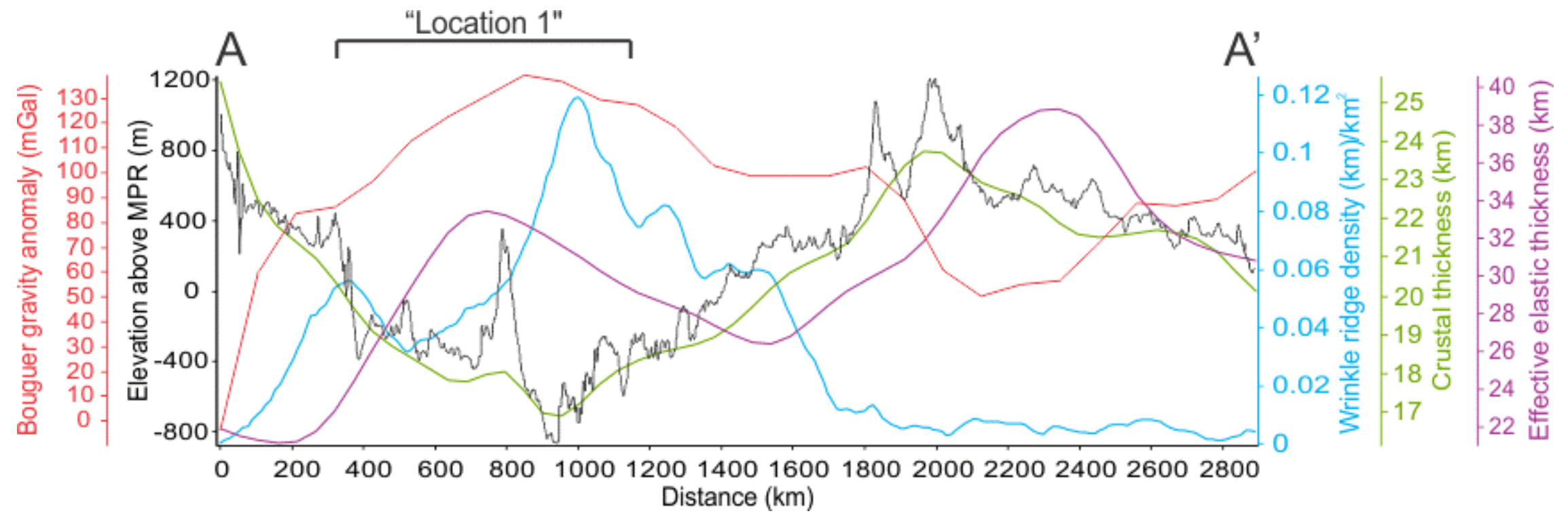

Figure 5.6: Profiles of various parameters across the study area: stereo-derived topography (black), Bouguer gravity anomaly (red), mapped wrinkle ridge density (blue), crustal thickness (green), and effective elastic thickness (purple). 


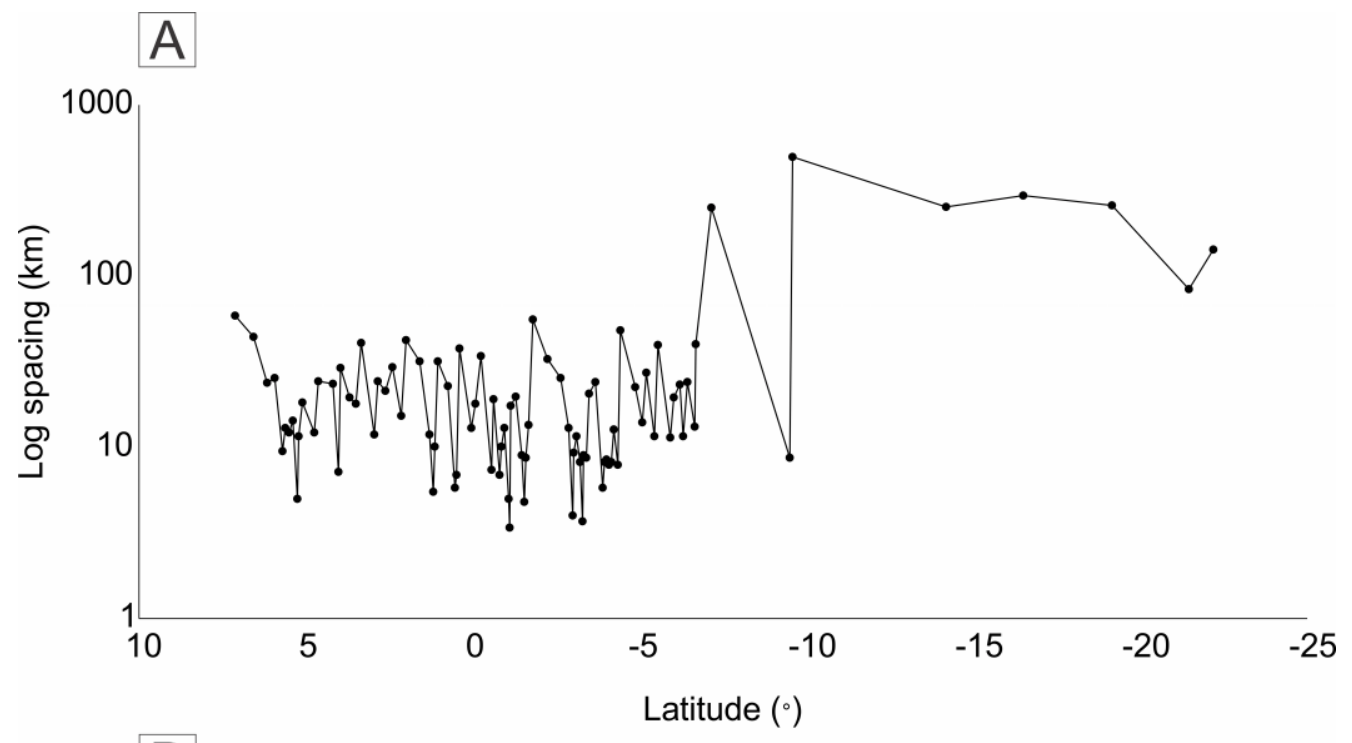

\section{B}

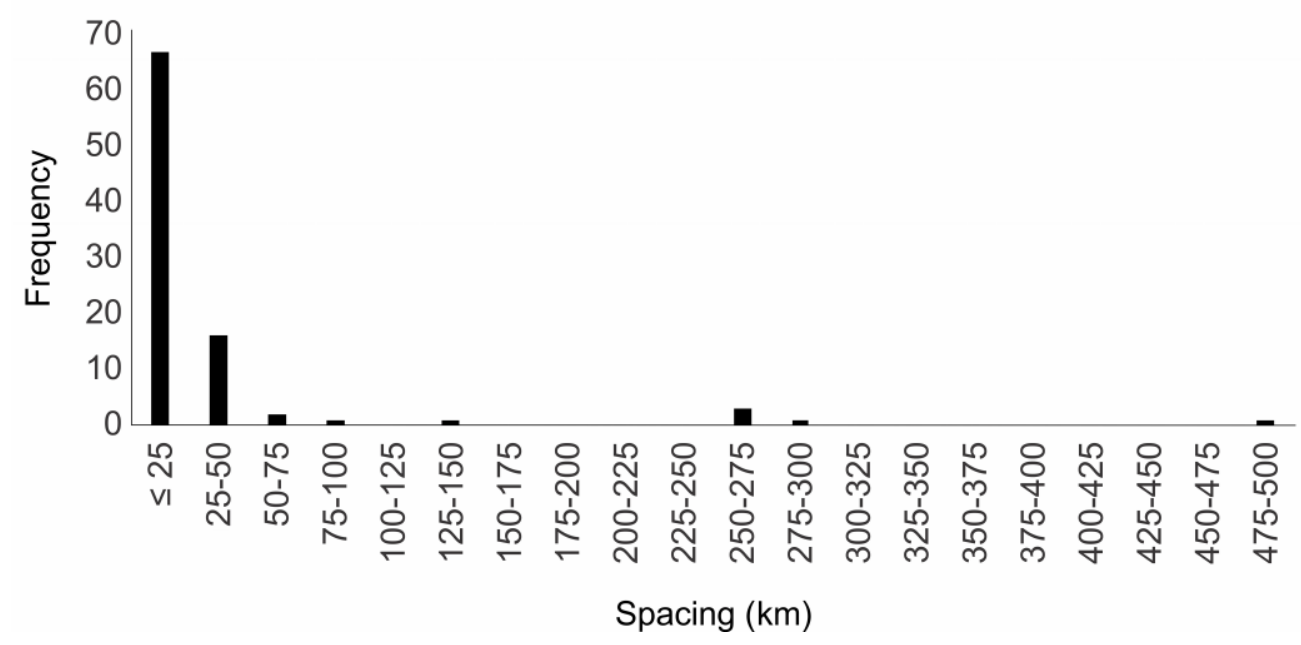

Figure 5.7: Distribution of wrinkle ridge spacing: A) wrinkle ridge spacing against latitude, and B) frequency histogram of wrinkle ridge spacing measurements. 


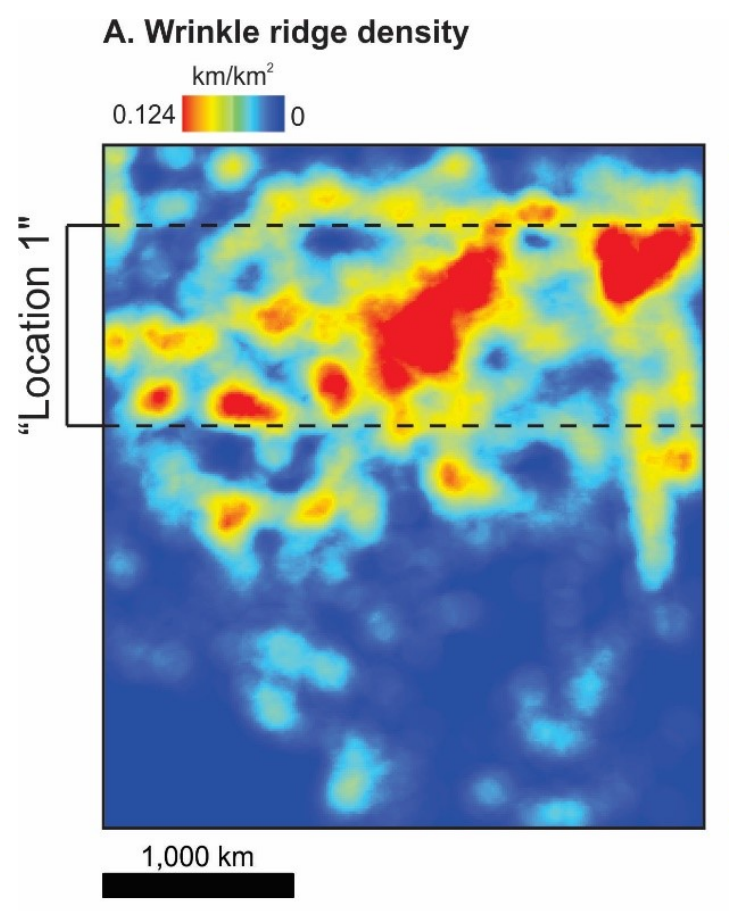

B. Bouguer gravity anomaly

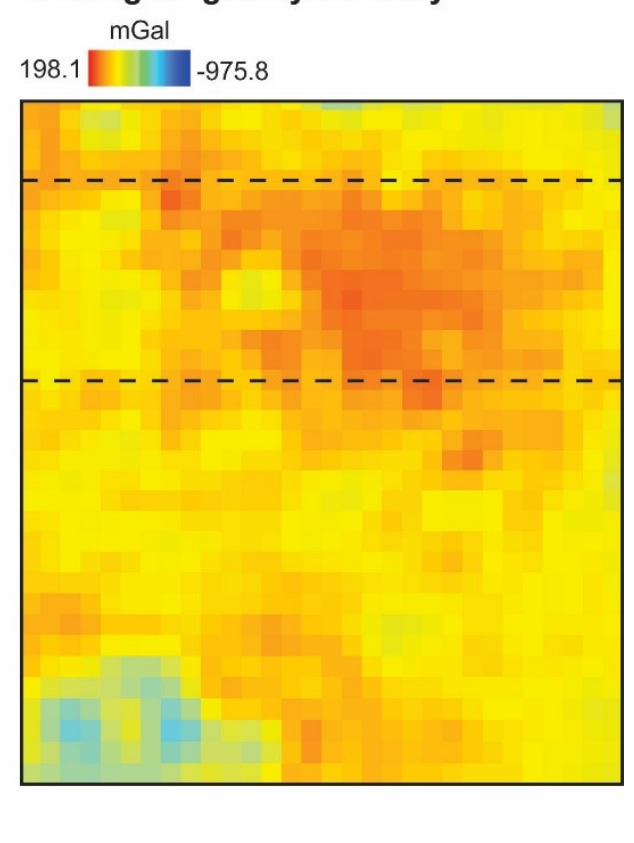

C. Location of geological features

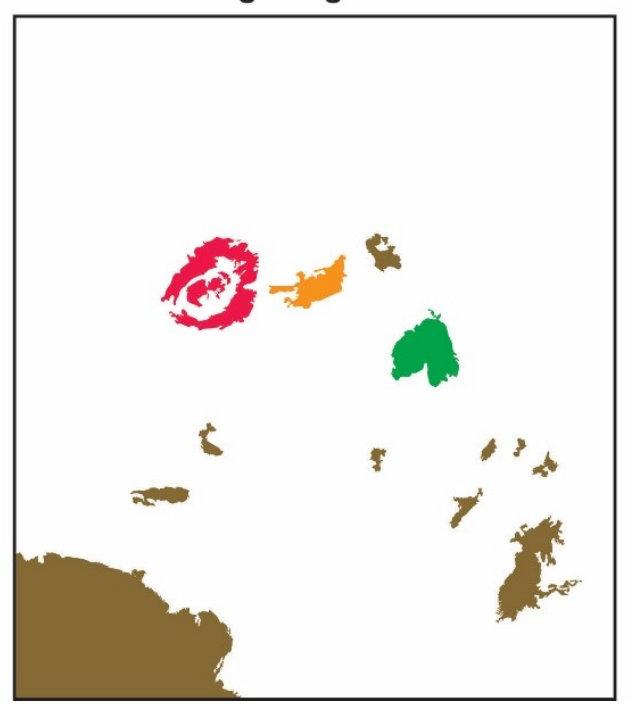

Kuan-Yin Corona

- Cybele Corona

- Carreno Crater

- Tessera terrain

Figure 5.8: Comparison between A) the density of mapped wrinkle ridges (in $\mathrm{km} / \mathrm{km}^{2}$ ), B) the Bouguer gravity anomaly (in $\mathrm{mGal}$ ) in the study area, and $\mathrm{C}$ ) the location of salient geological features. Location 1, the corridor of high wrinkle ridge density, is shown by the dashed lines on $A$ and $B$. 


\section{Width}

Profiles $=503$

Average

$10 \pm 1$

$\begin{array}{ccr}\text { IQR } & \text { Min } & \text { Max } \\ 8,11 & 7 \pm 1 & 18 \pm 3\end{array}$

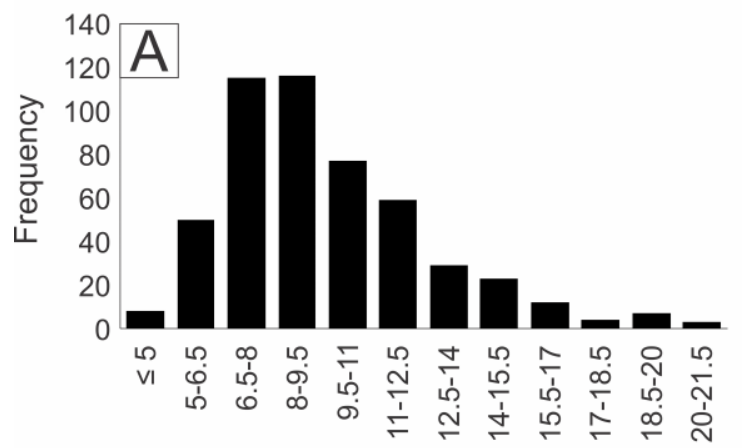

Width $(\mathrm{km})$

Elevation offset

Profiles $=30$

\begin{tabular}{lccr} 
Average & IQR & Min & Max \\
\hline 72 & 36,105 & 14 & 203
\end{tabular}

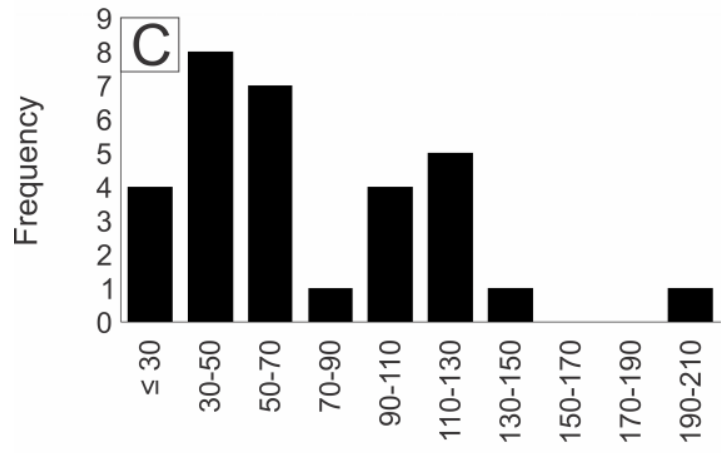

Elevation offset (m)

\section{Height}

Profiles $=503$

\begin{tabular}{lccr} 
Average & IQR & Min & Max \\
\hline $87 \pm 30$ & 52,105 & $39 \pm 1$ & $178 \pm 63$
\end{tabular}

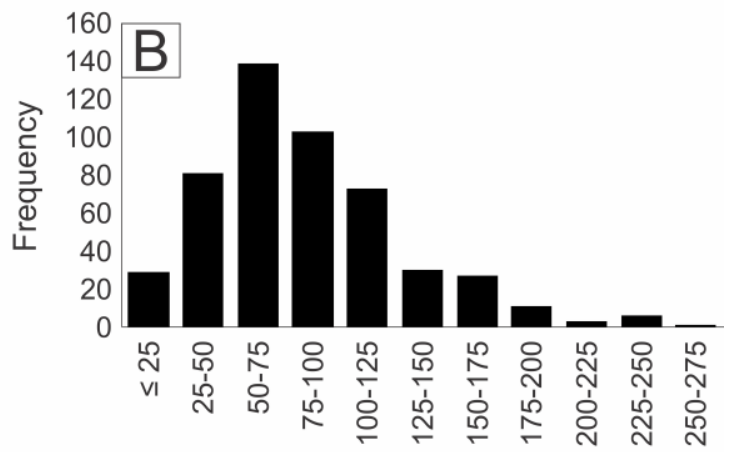

Height (m)

\section{Skewness}

Profiles $=503$

\begin{tabular}{llll} 
Average & IQR & Min & Max \\
\hline-0.13 & $-0.32,0.09$ & -1.25 & 0.80
\end{tabular}

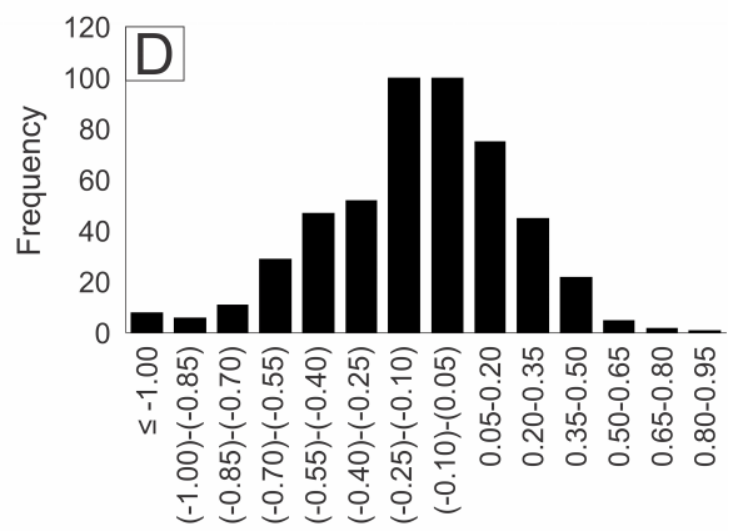

Skewness

Figure 5.9: Histograms and statistics for morphometric parameters of wrinkle ridges: A) width, B) height, C) elevation offset, and D) skewness. Reported for each parameter are the number of profiles studied, the average value, the interquartile range (IQR), and minimum (min) and maximum (max) values. 


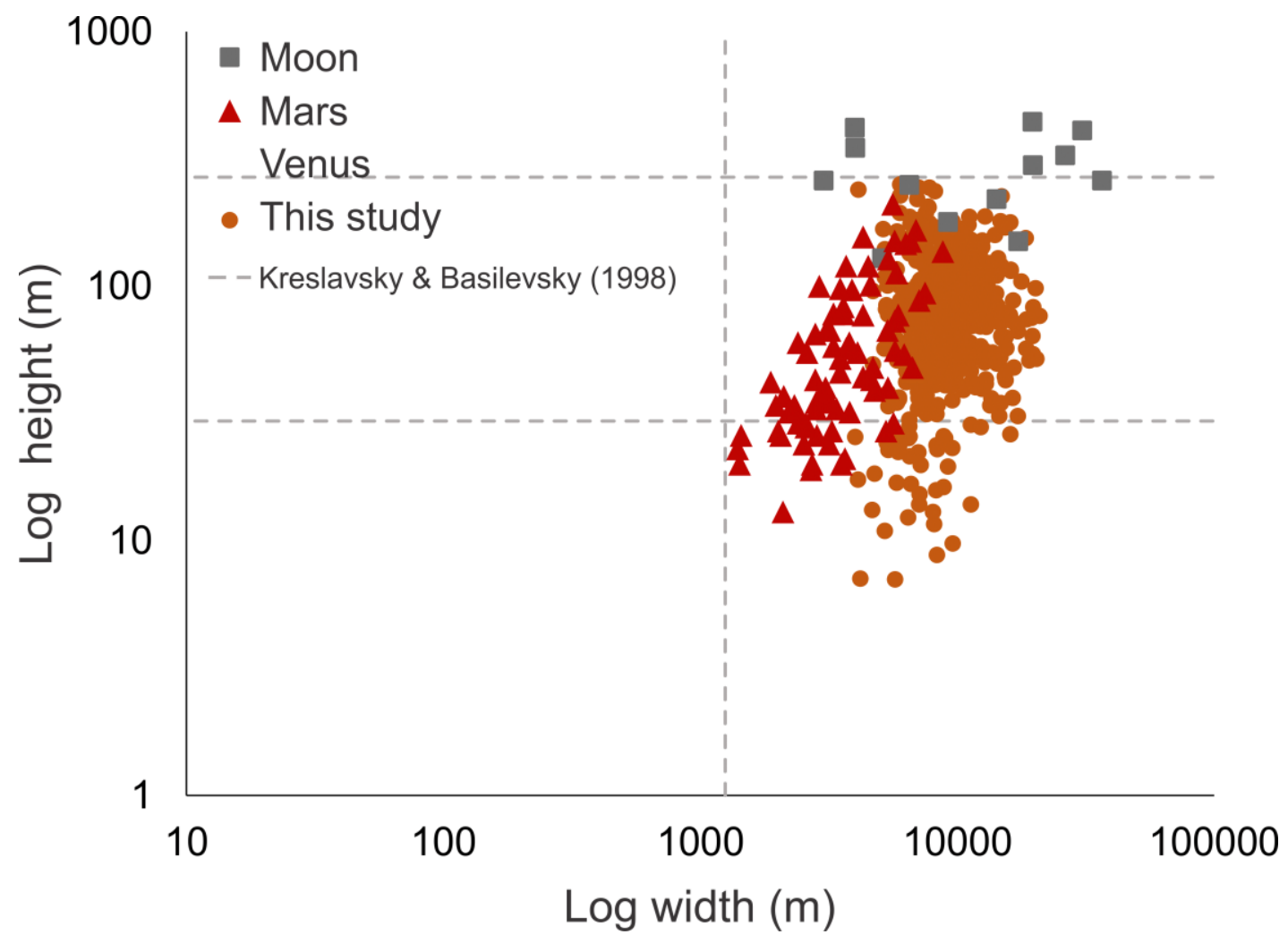

Figure 5.10: Comparison of morphometric data for wrinkle ridges on Venus (from this study and Kreslavsky and Basilevsky (1998)) with morphometric data for wrinkle ridges on the Moon and Mars. Data for Lunar wrinkle ridges are from Golombek et al. (1991) and Yue et al. (2015). Data for Martian wrinkle ridges are from Golombek et al. (1991), Plescia (1993), and Plescia (1991). 


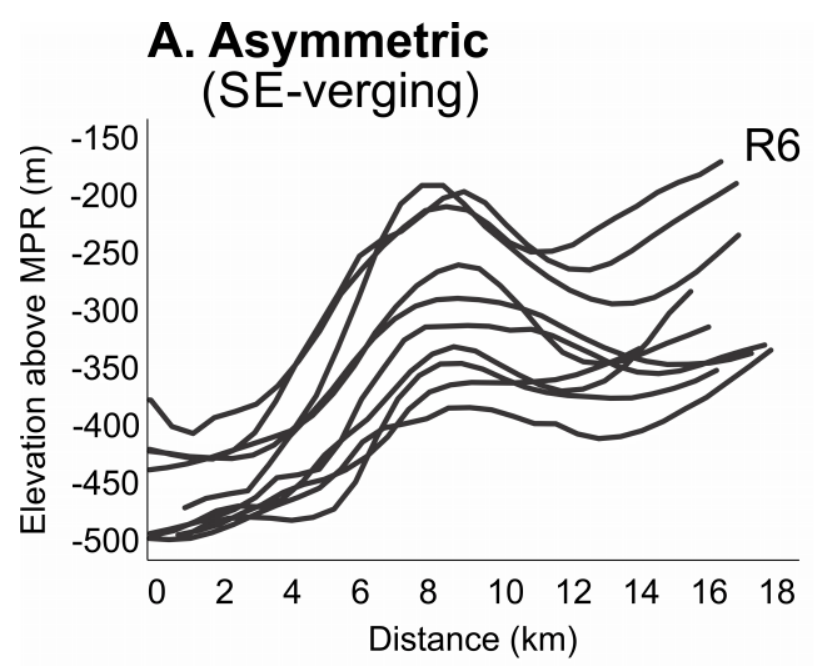

B. Symmetric

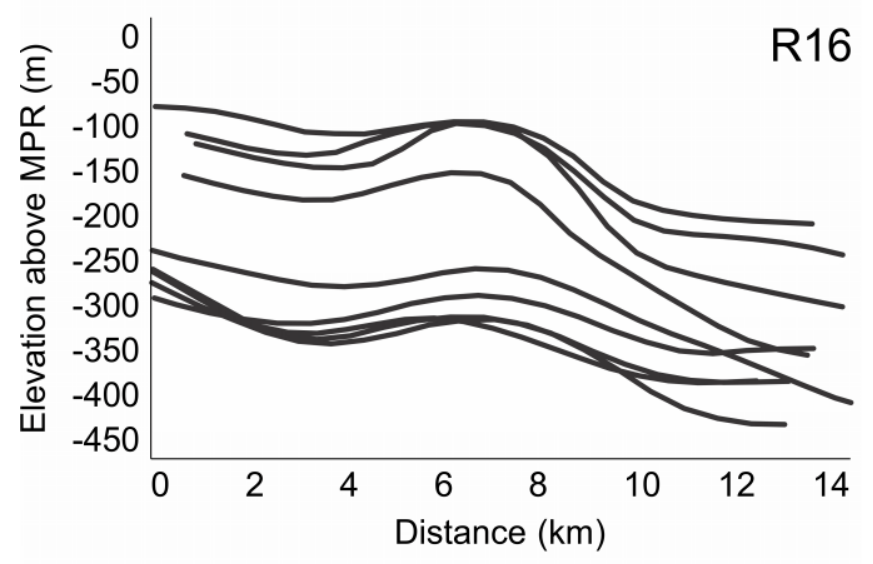

C. Double

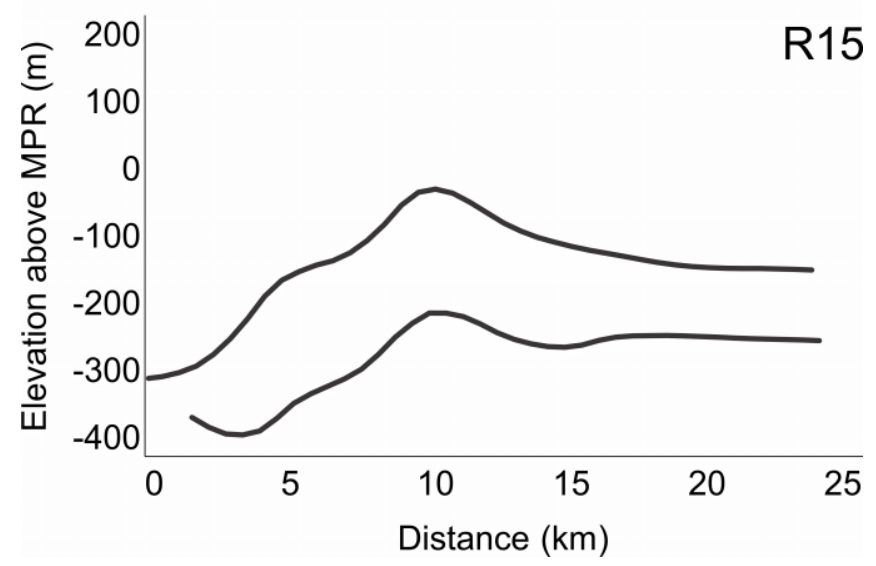

Figure 5.11: Examples of topographic profiles of wrinkle ridges illustrating the three shape categories: A) asymmetric (R6, verging to the southeast), B) symmetric (R16), and C) double (R15). 


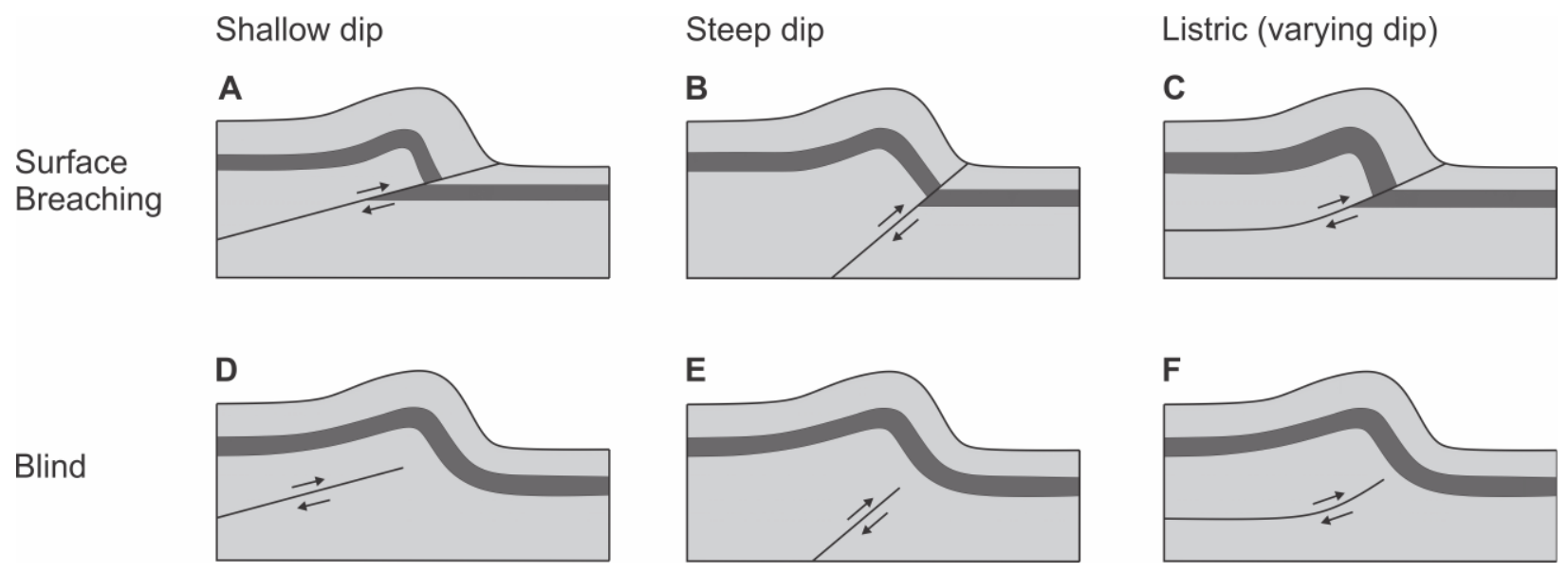

Figure 5.12: Schematic diagrams showing the range of faulting parameters considered in this study: A) a surface-breaching fault with a shallow dip; B) a surface-breaching fault with a steep dip; C) a surface-breaching fault with a listric geometry; D) a blind fault with a shallow dip; E) a blind fault with a steep dip; and F) a blind fault with a listric geometry. 

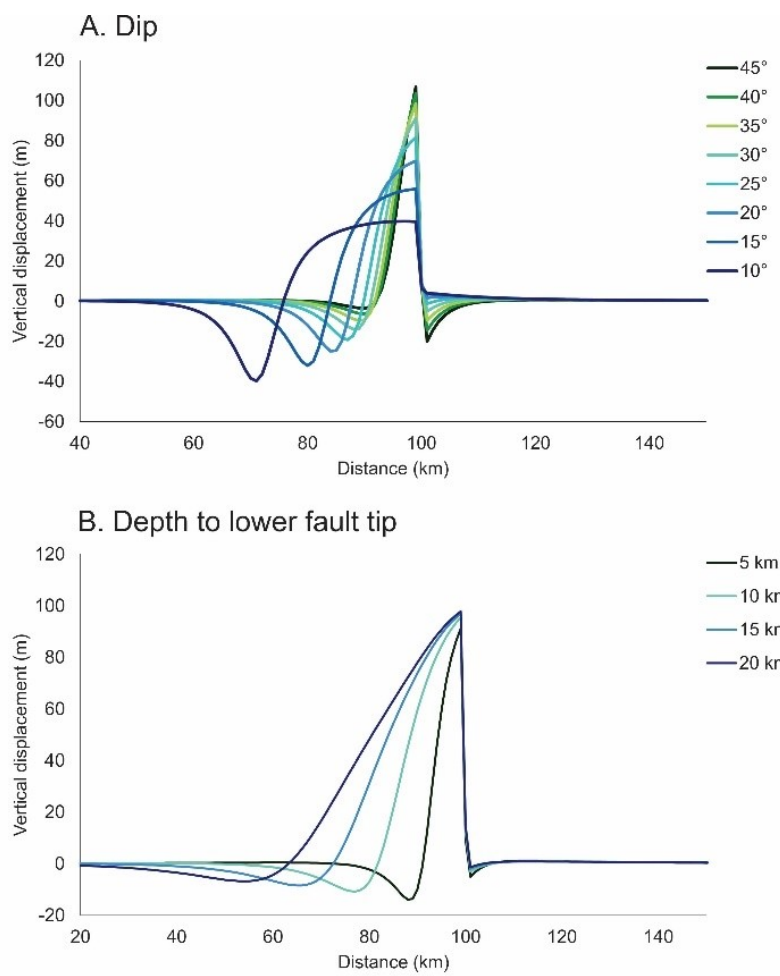

C. Depth to upper fault tip

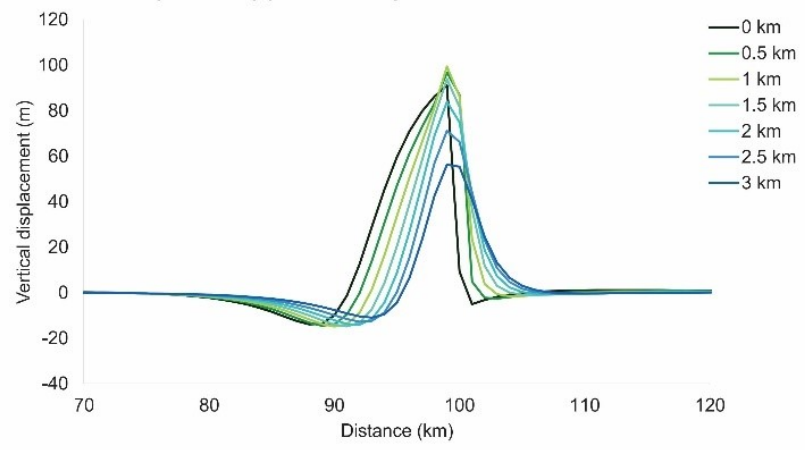

D. Geometry

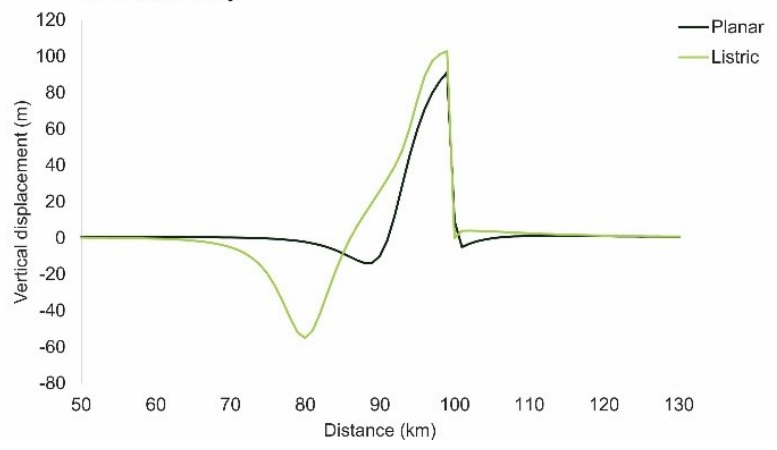

Figure 5.13: Sensitivity diagrams for the different faulting parameters: A) dip, B) depth to the lower fault tip, C) depth to the upper fault tip, and D) planar versus listric geometries. Unless otherwise stated, faulting parameters are set to a dip of $30^{\circ}$, a depth to the upper fault tip of $0 \mathrm{~km}$, a depth to the lower fault tip of $5 \mathrm{~km}$, a slip magnitude of $200 \mathrm{~m}$ and a planar fault geometry. 


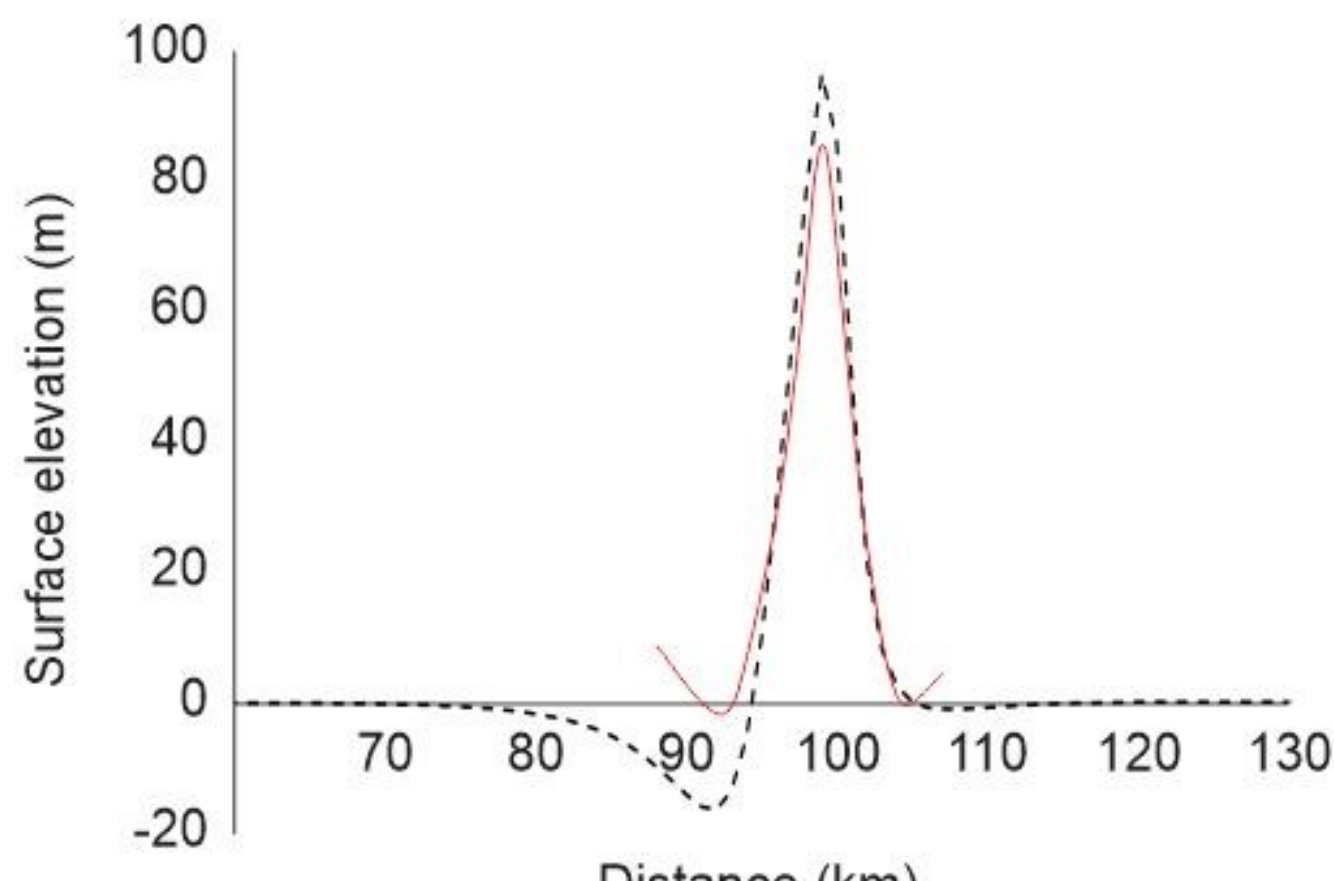

Distance $(\mathrm{km})$

Figure 5.14: Comparison between the average topographic wrinkle ridge profile (red) and the best fitting modeling result (dashed line). The average topographic profile is shown only in the immediate vicinity of the wrinkle ridge where de-trending was conducted. 


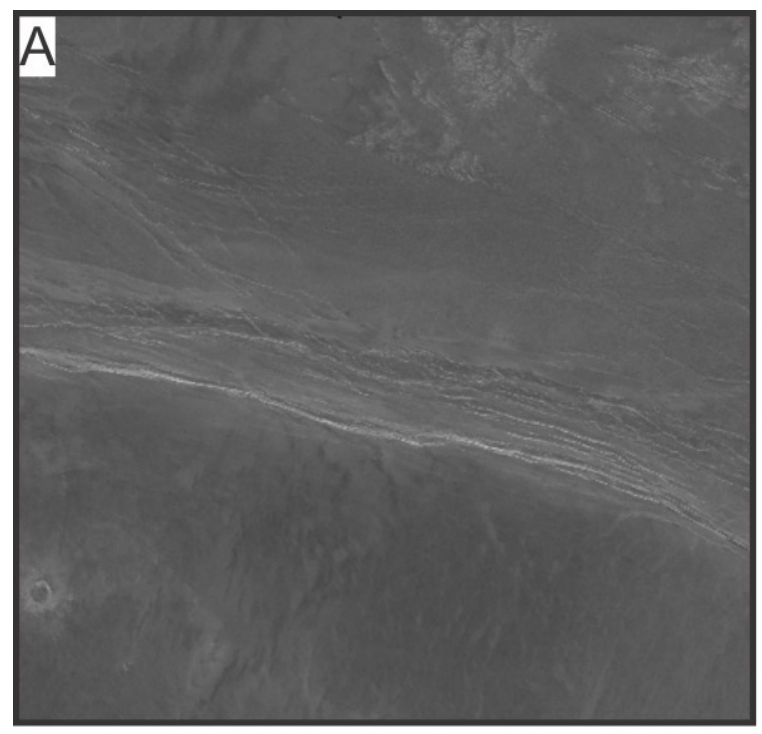

$100 \mathrm{~km}$

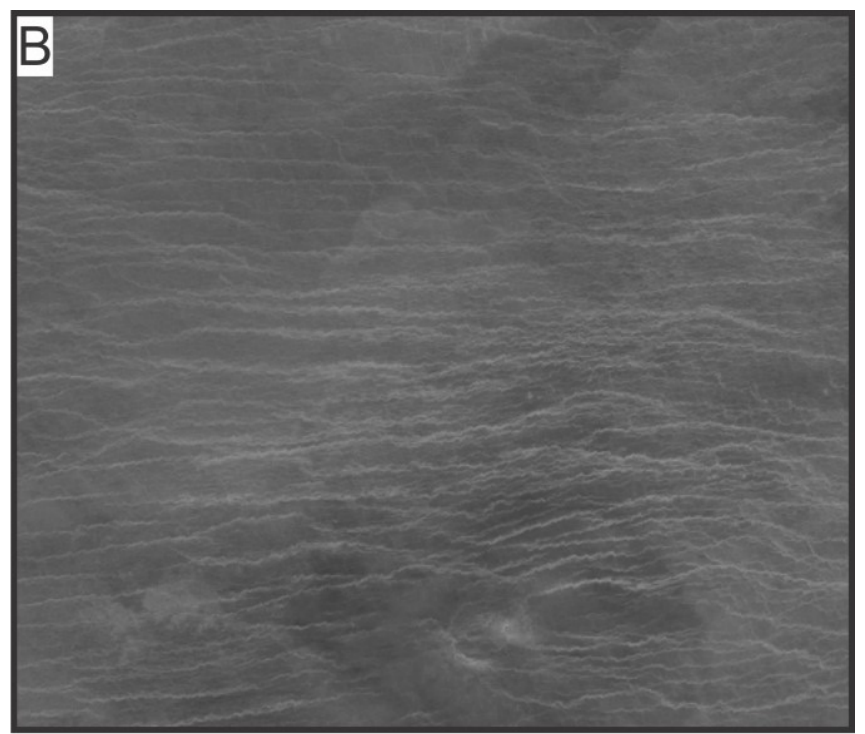

$100 \mathrm{~km}$

Figure 5.15: Comparison between left-looking SAR images of ridge belt and wrinkle ridge deformation: A) Lukelong Dorsa ((Frank and Head, 1989); image centred at $180^{\circ}$ $\mathrm{E}, 71^{\circ} \mathrm{N}$ ), and $\mathrm{B}$ ) wrinkle ridges deforming volcanic plains in the study area (image centred at $\left.15.5^{\circ} \mathrm{E}, 0.6^{\circ} \mathrm{N}\right)$. 


\section{CHAPTER 6: EVALUATION OF LANDING SITE TARGETS IN THE V-32 QUADRANGLE}

\subsection{The Venera-D Mission}

In preparation for future lander missions to Venus, potential landing site targets in the V-32 quadrangle have been evaluated using previously defined landing site criteria for Venus (e.g., Venera-D Joint Science Definition Team, 2019; Basilevsky et al., 2007), with a focus on the upcoming joint Roscosmos-NASA Venera-D mission to Venus. The main components of the mission are an orbiter and a lander with an attached LongLived In-Situ Solar System Explorer (LLISSE). The lander will be designed based on the VEGA lander architecture, but with modern instruments. It has an expected lifetime of 23 hours on the surface. The overall objectives of the lander component of the mission are to: 1) characterize the surface structure and morphology, 2) determine the

elemental composition of surface rocks, 3 ) identify mineral phases, 4) assess global and regional seismic activity, internal structure, and heat flow, and 5) study electromagnetic fields. Detailed information about the design and objectives of the Venera-D mission can be found in the Venera-D Joint Science Definition Team Report (Venera-D Joint Science Definition Team, 2019).

The V-32 quadrangle represents an attractive landing site for the upcoming Venera-D mission for the following reasons: 1) a variety of geological features and terrains are present, including those assigned high scientific priority, 2) the geology of the quadrangle has been characterized in detail, 3) datasets of limited global extent have high local coverage within the quadrangle (e.g., stereo-looking SAR and stereoderived topography (Herrick et al., 2012)), and 4) the Venera-D landing site attainability 
arc for December $5^{\text {th }}, 2026$ (one of the proposed launch dates) transects the quadrangle (Figure 6.1; Venera-D Joint Science Definition Team, 2019).

Landing site footprints were set to $300 \mathrm{~km}$ diameter circles. The choice of landing site targets has been made to attempt to maximize mission safety by avoiding regions that are highly tectonized or contain steep topographic gradients. As a result, units categorized as structural terrains or tessera material were not considered (Venera-D Joint Science Definition Team, 2019).

\subsection{Plains Material}

Plains material, inferred to be volcanic in origin, is the most widespread type of geological terrain on Venus (Basilevsky and Head, 2003). Units grouped as plains material in the V-32 quadrangle are typically of regional extent with no identified source(s), covering $55 \%$ of the surface area of the quadrangle. Areas covered by plains material are favourable landing site targets from a mission safety viewpoint, due to their generally smooth topography and low surface roughness. Although the Venera landers all landed in plains material, the geochemical data collected have large uncertainties (Nikolayeva et al., 1990; Kargel et al., 1993; Treiman, 2007). A future lander would reduce this uncertainty by providing geochemical data for a larger suite of elements using modern instrumentation. Therefore, plains material remains an important target as it covers most of Venus' surface (Venera-D Joint Science Definition Team, 2019).

Many previous geological mapping studies have grouped plains material into a small number of globally or regionally correlated units (e.g., Ivanov and Head, 2011). However, detailed mapping of the V-32 quadrangle revealed numerous sub-units within 
the plains that were recognized from subtle variations in radar properties and intricate analysis of interactions with structures. A total of 27 units and sub-units were identified. This approach to mapping indicates that plains material may not be as homogeneous as commonly thought and may, at local scales, display variations in surface properties and relative ages. This inhomogeneity may also apply to compositions. The geology of any potential landing site candidates in plains material should therefore be carefully analyzed.

Two possible landing site targets within plains material in the V-32 quadrangle have been identified. Target $A$ is centred at $\left(25.0^{\circ} \mathrm{E}, 4.4^{\circ} \mathrm{S}\right)$. and is located within Ridged Plains Material Unit 4 (pr4) (Figure 6.2A). Unit pr4 is characterized by intermediate radar backscatter and the presence of numerous wrinkle ridges. The landing circle for target $A$ is, however, centred on a region of unit pr4 that contains a relatively low density of wrinkle ridges (with an average spacing on the order of 20-30 $\mathrm{km})$. Additionally, analysis of wrinkle ridge topography in this region using stereoderived topography has demonstrated that the topographic slope of these ridges is not likely to be more than a few degrees (Table 5.1; refer to Section 5.4.5).

Target $\mathrm{B}$ is centred at $\left(6.5^{\circ} \mathrm{E}, 11.1^{\circ} \mathrm{S}\right)$ and encompasses a contact between Intermediate Plains Material Unit 3 (pi3) and Smooth Plains Material Unit 1 (ps1) (Figure 6.2B). Unit pi3 is characterized by intermediate radar backscatter, whereas unit ps 1 is characterized by moderately dark radar backscatter. As discussed above, the difference in radar properties between these two units could indicate compositional differences. The landing circle also contains both wrinkle ridges and extensional structures. 


\subsection{Digitate Volcanic Flows}

The Digitate Flow Material (fd) unit comprises an approximately 1400 km long series of overlapping volcanic flows that have defined, lobate margins with a digitate morphology. This unit is located in the central western area of the quadrangle and covers $5 \%$ of its surface area. The fd unit was divided into four sub-units that reflect varying levels of radar brightness within the flows, possibly representing differences in composition (e.g., basalt vs. andesite) and/or surface texture (e.g., pahoehoe vs. a'a).

While the fd unit has only been mapped in detail within the V-32 quadrangle here, it can also be recognized in the neighbouring $\vee-43$ (Carson) quadrangle, to the west. The flows may originate in the V-43 quadrangle, as the overall flow direction has been interpreted to be eastward, however, a source has not yet been identified. This unit may therefore be at the scale of a fluctus, or great flow field. Fluctüs are commonly interpreted to be analogous to flood basalt provinces on Earth (Roberts et al., 1992). Geochemical data returned from Venusian flood basalts would be able to provide information on the primitive upper mantle of Venus. Additionally, the fd unit has been interpreted as one of the most geologically young units in the V-32 quadrangle and is cross-cut by very few structures. It is therefore less likely than other units to have undergone significant weathering and/or alteration by the atmosphere.

Two possible landing site targets within the unit fd are suggested. Target $\mathrm{C}$, centred at $\left(11.5^{\circ} \mathrm{E}, 17.5^{\circ} \mathrm{S}\right)$ and Target $\mathrm{D}$, centred at $\left(1.4^{\circ} \mathrm{E}, 16.5^{\circ} \mathrm{S}\right)$ (Figure 6.2C,D). The landing circle for Target $\mathrm{C}$ contains few structures, except for wrinkle ridges, which in this area are relatively minor features with spacings on the order of $15-20 \mathrm{~km}$. Target 
D is located just north of the margin of the Alpha Regio highland and contains minor wrinkle ridges and extensional structures, as well as some small outcrops of tessera terrain.

\subsection{Coronae}

Coronae are quasi-circular tectono-magmatic structures that are typically hundreds of kilometres in diameter (refer to Section 2.3.4 for a detailed description). Coronae represent a major class of geological feature on Venus, with over 500 currently identified (Stofan et al., 2001). Analysis on the geochemistry of corona-related materials could provide insight into the processes involved in their formation, the details of which are still strongly debated.

The central regions of coronae, which are frequently highly tectonized and contain steep topographic gradients, would not be safe for landing. However, a landing site within a corona-sourced volcanic flow that extends sufficiently beyond the corona's central region may be an option. There is at least one such suitable area within the V-32 quadrangle, Target $\mathrm{E}$, centred at $\left(20.5^{\circ} \mathrm{E}, 20.5^{\circ} \mathrm{S}\right)$ and located to the southeast of Fatua Corona (Figure 6.2E). The landing circle contains minor wrinkle ridges and four prominent graben, which are spaced 50-100 km apart.

\subsection{Recommendations}

A recently completed detailed geological map of the $\mathrm{V}-32$ quadrangle has been used to evaluate potential landing site targets for the future Venera-D mission. Five potential targets have been identified: two in plains material, two in a relatively young digitate volcanic flow field (resembling a fluctus), and one in a corona-sourced volcanic 
flow. Sampling plains material would provide improved data from the early Venera and VEGA landers, whereas sampling terrains such as a digitate volcanic flow field or corona-sourced volcanic flow would return entirely new data on materials that have not yet been sampled. Additionally, sampling a relatively recent terrain (such as the digitate volcanic flow material unit (fd)) would decrease the likelihood of potential weathering and/or alteration by Venus' atmosphere. 


\subsection{Figures}

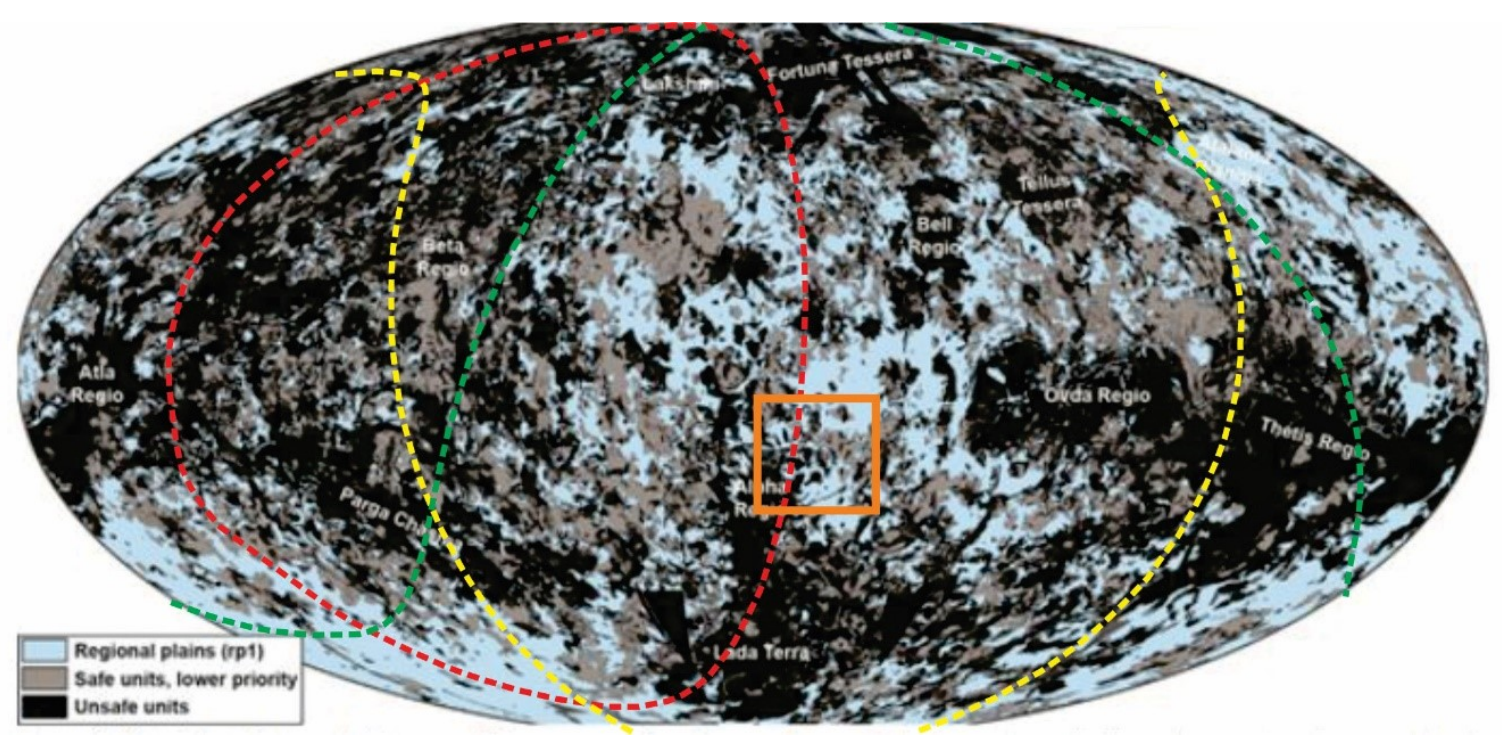

Figure 6.1: Landing site attainability arcs for the Venera-D mission. The attainability arc for December $5^{\text {th }}, 2026$ is shown by the dashed red line, and the outline of the V-32 quadrangle is shown by the orange box. Attainability arcs for December $9^{\text {th }}, 2026$, and December $17^{\text {th }}, 2026$, are shown by the green and yellow dashed lines, respectively. The map is in a Mollweide projection with a central meridian of $0^{\circ}$. Modified after Venera-D Phase II Final Report (2019). 

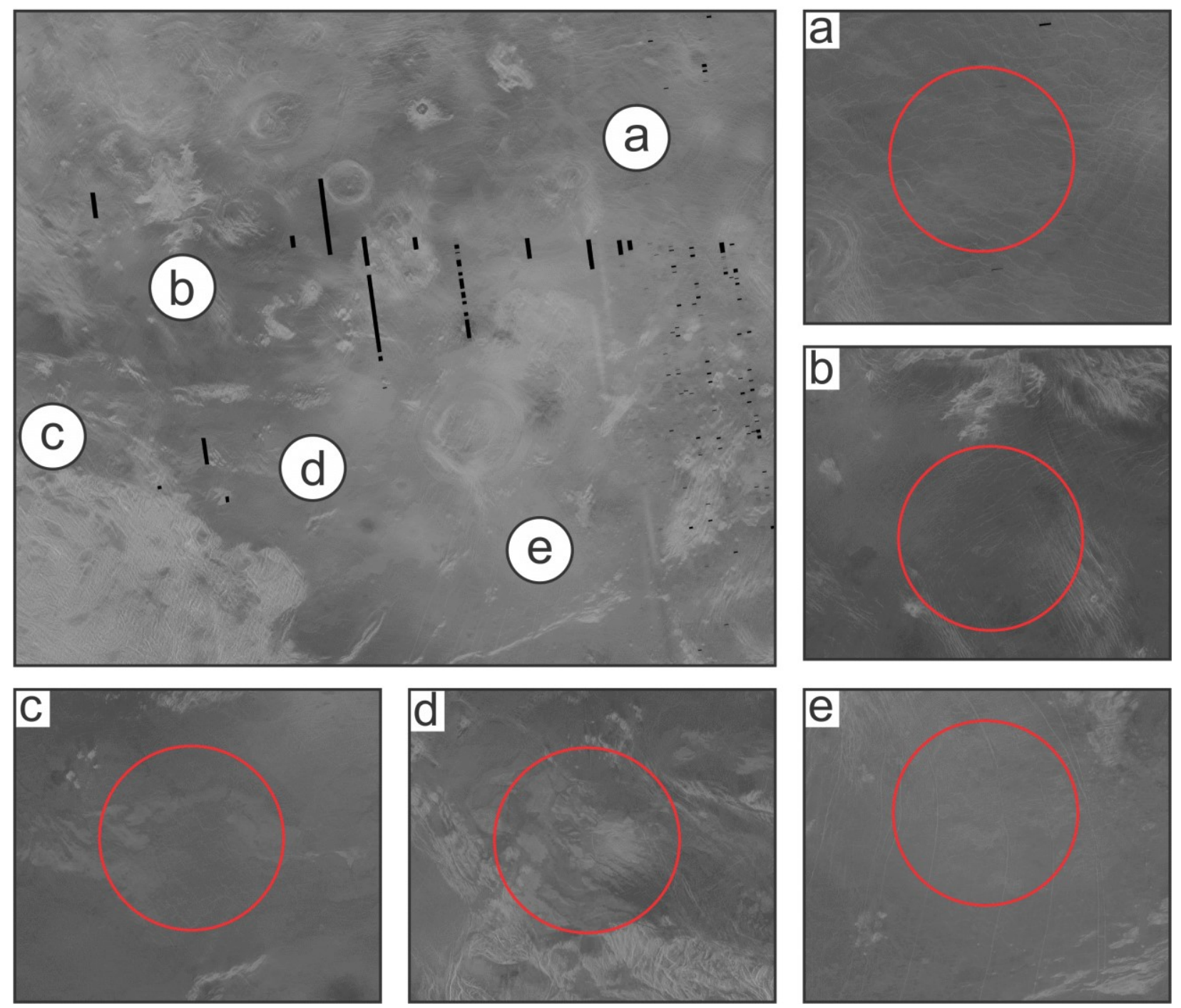

Figure 6.2 Landing site targets and their locations in the V-32 quadrangle. Targets $A$ (centred on $25.0^{\circ} \mathrm{E}, 4.4^{\circ} \mathrm{S}$ ) and $\mathrm{B}$ (centred on $6.5^{\circ} \mathrm{E}, 11.1^{\circ} \mathrm{S}$ ) are located in plains material. Targets $\mathrm{C}$ (centred on $11.5^{\circ} \mathrm{E}, 17.5^{\circ} \mathrm{S}$ ) and $\mathrm{D}$ (centred on $1.4^{\circ} \mathrm{E}, 16.5^{\circ} \mathrm{S}$ ) are located in a digitate volcanic flow field, and Target $\mathrm{E}$ (centred on $20.5^{\circ} \mathrm{E}, 20.5^{\circ} \mathrm{S}$ ) is located in a corona-sourced volcanic flow. Red circles outline $300 \mathrm{~km}$ diameter landing circles. 


\section{CHAPTER 7: CONCLUSIONS}

\subsection{Summary}

In this thesis, I present a 1:2,500,000 scale geological map of the Alpha Regio (V-32) quadrangle, Venus, that constitutes the first detailed mapping study in this area (Chapter 2). Nearly 40,000 lineaments were mapped and grouped into 27 extensional and 5 contractional systems based on their geometry and interpreted origin. A total of 77 units (including sub-units) were identified, including 23 units characterized as volcanic edifice and flow material, 17 units characterized as corona material, 27 units characterized as plains material, 6 units characterized as structural terrains, 2 units characterized as tessera material, and 2 units characterized as impact material. Two significant and distinct extensional zones were characterized and identified as fracture belts. Structures, including circumferential and radiating graben-fissures, and units associated with the five coronae and one corona-like feature contained within the quadrangle were identified and mapped, including several volcanic flows attributed to coronae that had previously been grouped into regional plains units. Mapping of the plains material in this quadrangle through careful analysis of radar properties and relationships with structures at the full resolution of the SAR data (maximum of 75 $\mathrm{m} / \mathrm{pixel}$ ) revealed numerous sub-units within the plains, which were previously grouped together and mapped as regionally or globally correlated units. Thousands of wrinkle ridges belonging to a regionally pervasive and extensive system circumscribing Eistla Regio were also mapped. I performed a detailed analysis of cross-cutting relationships between geological units and structural systems that revealed a complex geological 
history for the quadrangle involving numerous tectono-magmatic events, many of which overlapped in time.

The 1:2,500,000 scale geological mapping presented in this thesis has allowed for a more detailed characterization of features contained within the V-32 quadrangle. This is particularly true for coronae (Chapters 3 and 4 ) and wrinkle ridges (Chapter 5).

The mapping results of this thesis have revealed a radiating graben-fissure system originating from Fatua Corona that is interpreted to overly a radiating dyke swarm and extends for over $1700 \mathrm{~km}$ southward from the corona's annulus (Chapter 3 ). The volume of magma contained within these dykes is estimated herein to be at least $57,000 \mathrm{~km}^{3}$. Combining the dyke volume with an estimated $3,275 \mathrm{~km}^{3}$ of volcanic flows associated with the corona leads to a total igneous volume of $60,275 \mathrm{~km}^{3}$. This estimate does not consider other intrusive magmatic components, and the true igneous volume may thus be much greater. Therefore, the results of this thesis suggest its associated magmatic activity is LIP-scale and is comparable in size to the largest dyke swarm on Earth, the Mackenzie swarm.

The radiating dykes from Fatua swing in trend with distance from the centre of the corona to align with the regional stress field. This has enabled the determination herein of the orientation of the stress field at the time of emplacement of the dykes. From the dyke orientation, the regional stress field is inferred to have $\sigma_{1}$ oriented NNESSW. Based on the spatial association between the terminations of the dykes and the Alpha-Lada (trending NW-SE) and Derceto-Quetzalpetlatl (trending NNE-SSW) extensional belts, it is suggested here that the stress field at the time of dyke 
emplacement is thought to be dominated by extension in one or both of the belts. If extension in the Derceto-Quetzalpetlatl belt was dominant when the dykes were emplaced, $\sigma_{1}$ would align with the trend of the belt, consistent with dyke swarm orientations associated with rifting in the BAT region on Venus. However, this hypothesis requires that the radiating dykes were emplaced during a period of time when extension in the Derceto-Quetzalpetlatl belt was active, but largely before extension in the Alpha-Lada belt was established. This is inconsistent with cross-cutting relationships that suggest that the stress field of the Alpha-Lada extension was already in place when the Derceto-Quetzalpetlatl belt formed (Bridges and McGill, 2002). Alternatively, if Alpha-Lada extension was the dominant force when the dykes were emplaced, the stress field must have changed from a belt-parallel orientation of $\sigma_{1}$ within the belt, to a belt-orthogonal orientation of $\sigma_{1}$ at its margins. This type of stress field orientation is observed around divergent plate boundaries on Earth and is thought to be a result of ridge push forces. This research suggests that the Alpha-Lada extensional belt could therefore represent an insipient Earth-like divergent boundary.

Comparison between Venusian coronae and LIPs on Earth demonstrates that they share many characteristics in common, including major volcanic flows and giant radiating dyke swarms (Chapter 4). Other magmatic provinces typically associated with LIPs such as sill provinces, mafic-ultramafic intrusions and magmatic underplates are potentially also associated with coronae but are more difficult to recognize at the surface. Giant circumferential dyke swarms are a specific component of some LIPs on Earth that warrant a detailed comparison with coronae on Venus as they may be analogous to the circumferential graben-fissure systems associated with them. A list of 
characteristics that is useful in such a comparison has been compiled and discussed herein, and estimates have been derived for coronae in the V-32 quadrangle. A detailed comparison between these features will result in a greater understanding of the plumbing systems associated with coronae on Venus and LIPs on Earth.

One particular aspect that is fundamental to understanding coronae, and their possible counterparts on Earth, is their size. The average corona size of $200-300 \mathrm{~km}$ described in the literature is significantly smaller than what has been observed for giant circumferential dyke swarms on Earth. My mapping of corona structures in the V-32 quadrangle has resulted in larger size estimates for these coronae than previously described in global catalogues. Thermuthis Corona, whose structures extend into the V-32 quadrangle, may be nearly $1000 \mathrm{~km}$ larger in diameter than previously recognized. At $1250 \mathrm{~km}$ in diameter it is potentially the second largest corona on Venus (after Artemis).

The analysis presented in this thesis of the morphometry of 40 wrinkle ridges in southern Eistla Regio (including the V-32 quadrangle and part of the V-20 quadrangle) using stereo-derived topography data has determined that these wrinkle ridges have widths and heights on the order of $10 \mathrm{~km}$ and $100 \mathrm{~m}$, respectively (Chapter 5). The majority of these wrinkle ridges were found to have slight vergence towards the southeast, but a subset were relatively symmetric. A portion of the wrinkle ridges also had secondary peaks along the backslope and these have been interpreted to represent backthrust faults. The morphometry observed here is generally consistent with wrinkle ridges on Mars and the Moon. Width measurements obtained here, however, are nearly an order of magnitude greater than previous estimates of wrinkle ridge widths using 
SAR data on Venus. This is hypothesized to be due to the inherent difficulty of measuring the widths of topographic features with low slopes using SAR data, and the estimates presented here using topography data are likely more accurate. Elastic dislocation modeling of thrust faulting performed to match the average wrinkle ridge width, height and shape returned results that are consistent with shallowly penetrating, $30^{\circ}$ dipping blind faults that have accommodated approximately $200 \mathrm{~m}$ of slip. These results are consistent with thin-skinned deformation models for wrinkle ridges.

The detailed mapping of wrinkle ridges in this region presented here demonstrates that their distribution is non-uniform at a regional scale. Wrinkle ridge density is negatively correlated with the gradient of the geoid and the crustal thickness. These observations support previous hypotheses which link the magnitude of contractional strain to mantle dynamics coupled with the thickness of the crust. In this region, the driving force of this contraction appears to be mantle downwelling from the edges of Eistla Regio.

Lastly, the results of this thesis are used to suggest several landing site targets in the V-32 quadrangle for future missions to Venus (Chapter 6). Particular emphasis is given to the joint Roscosmos-NASA Venera-D mission. Five landing site targets are suggested in a variety of terrains, including relatively geologically recent digitate volcanic flows, volcanic flows sourced from coronae, and plains material.

\subsection{Recommendations for Future Work}

The results of this thesis have revealed multiple themes for future research to explore that will be discussed in the following sections. 


\subsubsection{Detailed Geological Mapping of Venus}

Although global geological mapping of Venus has been ongoing at various scales since the Magellan mission, a significant portion of the planet has not been mapped in detail. Global (Ivanov and Head (2011)) and large-scale regional (e.g., USGS quadrangle maps; Hansen and Lopéz, 2018; Hansen and Lopéz, 2020; Lopéz and Hansen, 2020) geological maps have been fundamental in understanding the geology of Venus, but a large amount of information can be obtained by mapping at smaller scales at the full resolution of the SAR data (e.g., Hansen and Phillips, 1993; Copp et al., 1998; Ernst et al., 2003; Grindrod and Guest, 2006; Studd et al., 2011; Graff et al., 2018). Additionally, maps for 28 of the 62 1:5,000,000 scale quadrangles have not yet been published (USGS, n.d.).

A specific point of interest for future geological mapping efforts will be to investigate if the volcanic plains of Venus are as homogeneous as commonly thought. The mapping techniques used for mapping plains material in this project, and in other detailed mapping studies elsewhere on Venus (e.g., Stofan and Guest, 2003; Grindrod et al., 2006; Grindrod et al., 2010), were able to parse out multiple separate units that were previously grouped together and in other cases have assigned discrete sources to some units. Future work should make use of the full resolution SAR data to complete analysis of cross-cutting relationships with other units and structures. If this heterogeneity in the volcanic plains is observed in many locations across the planet, it would have implications for the debate on resurfacing styles and would contradict the idea of a directional geological history of Venus (cf. Grindrod et al., 2006; Grindrod et al., 2010). 


\subsubsection{Stress and Relative Age Indicators in the Vicinity of the Alpha-Lada and Derceto-Quetzalpetlatl Extensional Belts}

Although the regional stress field in the region between Fatua Corona and the Alpha-Lada and Derceto-Quetzalpetlatl extensional belts has been determined from the orientations of radiating dykes originating from Fatua Corona, the controlling factors on the orientation of the stress field from the two extensional belts is not known with certainty. Analysis of cross-cutting relationships within the belts and with the radiating structures suggests that the formation of the two belts overlapped in time, with extension in the Alpha-Lada belt continuing to occur after cessation of extension in the Derceto-Quetzalpetlatl belt (Baer et al., 1994; McGill, 2002). To better understand the relative timing and influence of the features in this area, additional stress and relative age indicators (e.g., wrinkle ridges) should be mapped throughout the region.

\subsubsection{Comparisons Between Coronae and Giant Circumferential Dyke Swarms}

The similarities noted in this thesis and by previous studies (e.g., Buchan and Ernst, 2018, 2019) between Venus' coronae and LIPs on Earth are intriguing. Many previous studies have emphasized the apparent uniqueness of coronae to Venus. However, mantle plume-associated LIPs on Earth are analogous to coronae in many ways. In particular, the circumferential graben-fissure systems observed in the annuli of coronae resemble the giant circumferential dyke swarms recognized in association with some LIPs (Buchan and Ernst, 2019). In order to investigate the analogy between these features in greater detail, characteristics of coronae must be catalogued from a LIP 
perspective (as detailed in Section 4.1.3). Further modeling is also needed to better understand the magmatic plumbing system dynamics of LIPs and coronae.

\subsubsection{Analysis of Wrinkle Ridge Morphometry Using Stereo-Derived Topography}

The results of the morphometric analysis of wrinkle ridges in southern Eistla Regio presented in this thesis represent the first characterization of Venusian wrinkle ridges obtained directly from topography data. In order to gain a more comprehensive knowledge of wrinkle ridge morphometry across Venus, more regions with coverage by the stereo-topography dataset should be investigated to see if wrinkle ridges are observable in these data. Analyzing the morphometry of wrinkle ridges in different regions of the planet will shed more insight on whether the wrinkle ridges studied here are representative of the wrinkle ridges across the entire planet, or whether there are regional variations in their morphometry. 


\section{REFERENCES}

Allemand, P., and Thomas, P. (1992). A Brittle Model for Martian Ridges Constrained by Surface Geometry. Academie des Sciences (Paris), Comptes Rendus, Serie II Mecanique, Physique, Chimie, Sciences de la Terre et de l'Univers, 315 (11), p. $1397-1402$.

Anderson, F.S., and Smrekar, S.E. (1999). Tectonic Effects of Climate Change on Venus. Journal of Geophysical Research: Planets, 104 (E12), p. 30743-30756.

Andrews-Hanna, J.C. (2019). A Taxonomy of Wrinkle Ridges on Mars. Lunar and Planetary Science Conference L, abstract 2132.

Andrews-Hanna, J.C. (2020). The Tectonic Architecture of Wrinkle Ridges on Mars. Icarus, 351, p. 1-19.

Anguita, F., and Chiccaro, A.F. (1991). Ovoid Structures in the Solar System: The Coronae of Venus and Miranda, and the Domes on the Earth. Earth, Moon, and Planets, 53, p. 109-116.

Baer, G., Schubert, G., Bindschadler, D.L., and Stofan, E.R. (1994). Spatial and Temporal Relations Between Coronae and Extensional Belts, Northern Lada Terra, Venus. Journal of Geophysical Research, 99(E4), p. 8355-8369.

Barsukov, V.L., Basilevsky, A.T., Burba, G.A., Bobina, N.B., Kryuchkov, V.P., Kuzmin, R.O., Nikolaeva, O.V., Pronin, A.A., Ronca, L.B., Chernaya, I.M., Shashkina, V.P., Garanin, A.V., Kushky, E.R., Markov, M.S., Sukhanov, A.L., Kotelnikov, V.A., Rzhiga, O.N., Petrov, G.M., Alexandrov, YU.N., Sidorenko, A.I., 
Bogolomov, A.R., Skyrpnik, G.I., Bergman, M.YU., Kudrin, L.V., Bokshtein, I.M., Kronrod, M.A., Chochia, P.A., Tyuflin, YU.S., Kadnichansky, S.A., and Akim, E.L. (1986). The Geology and Geomorphology of the Venus Surface as Revealed by the Radar Images Obtained by Veneras 15 and 16. Journal of Geophysical Research: Solid Earth, 91, p. 378-398.

Barsukov, V.L., Bazilevskii, A.T., Kuzmin, R.O., Pronin, A.A., Kriuchkov, V.P., Nikolaeva, O.V., Chernaia, I.M., Burba, G.A., Bobina, N.N., and Shashkina, V.P. (1984). The Geology of Venus According to the Results of An Analysis of Radar Images Obtained by Venera-15 and Venera-16 Preliminary Data. Geokhimiia, p. $13091-13102$.

Basilevsky, A.T., and Head, J.W. (1995). Regional and Global Stratigraphy of Venus: A Preliminary Assessment and Implications for the Geological History of Venus. Planetary and Space Science, 45 (12), p. 1523-1553.

Basilevsky, A.T., and Head, J.W. (1998). The Geologic History of Venus: A Stratigraphic View. Journal of Geophysical Research: Planets, 103 (E4), p. 8531-8544.

Basilevsky, A.T., and Head, J.W. (2000a). Geologic Units on Venus: Evidence for their Global Correlation. Planetary and Space Science, 48, p. 75-111.

Basilevsky, A.T., and Head, J.W. (2000b). Rifts and Large Volcanoes on Venus: Global Assessment of their Age Relations with Regional Plains. Journal of Geophysical Research: Planets, 105, p. 24583-24611.

Basilevsky, A.T., and Head, J.W. (2002). Venus: Timing and Rates of Geologic Activity. Geology, 30 (11), p. 1015-1018. 
Basilevsky, A.T., and Head, J.W. (2003). The Surface of Venus. Reports on Progress in Physics, 66, p. 1699-1734.

Basilevsky, A.T., and Schaber, G.G. (1991). Cleopatra Crater on Venus: Happy Solution of the Volcanic vs. Impact Crater Controversy. Lunar and Planetary Science Conference XXII, p. 59-60.

Basilevsky, A.T., Head, J.W., Schaber, G.G., and Strom, R.G. (1997) The Resurfacing History of Venus. In S.W. Bougher, D.M. Hunten, and R.J. Phillips (Eds.), Venus II: Geology, Geophysics, Atmosphere, and Solar Wind Environment (pp. 10471086). Tucson, AZ: University of Arizona Press.

Basilevsky, A.T., Ivanov, M.A., Head, J.W., Aittola, M., and Raitala, J. (2007). Landing on Venus: Past and Future. Planetary and Space Science, 55(14), p. 2097-2112.

Basilevsky, A.T., Pronin, A.A., Ronca, L.B., and Kryuchkov, V.P. (1986). Styles of Tectonic Deformation on Venus: Analysis of Venera 15 and 16 Data. Journal of Geophysical Research, 91, p. D399-D411.

Bender, K.C., Senske, D.A., and Greeley, R. (2000). Geologic Map of the Carson (V-43) Quadrangle, Venus, Scale 1:5 M. U.S. Geological Survey Geologic Investigations Series I-2620.

Bethell, E., Ernst, R.E., and Samson, C. (2019c). Evaluation of Landing Site Targets in the Alpha Regio (V-32) Quadrangle. Venera-D Landing Site Selection and Cloud Habitability Workshop, Space Research Institute (IKI), Russia. 
Bethell, E.M, Ernst, R.E., Samson, C., and Buchan, K.L. (2016). Circumferential Graben-Fissure Systems of Venusian Coronae as Possible Analogues of Giant Circumferential Dyke Swarms on Earth. Lunar and Planetary Science Conference XLVII, abstract 1471.

Bethell, E.M., Ernst, R.E., and Samson, C. (2019a). Re-Evaluating the Structure of Thermuthis Corona Through Detailed Geological Mapping: The Second Largest Corona on Venus? Lunar and Planetary Science Conference L, abstract 1462.

Bethell, E.M., Ernst, R.E., and Samson, C. (2019b). Geology of the Alpha Regio (V-32) Quadrangle, Venus. Journal of Maps, 15(2), p. 474-486.

Bethell, E.M., Ernst, R.E., and Samson, C. (2020). Morphometry of Wrinkle Ridges, Southern Eistla Regio, Venus. Lunar and Planetary Science Conference LI, abstract 1278.

Bethell, E.M., Ernst, R.E., Samson, C., and Buchan, K.L. (2015). Giant Circumferential Graben-Fissure Systems: A Key to the Recognition of Venusian Corona Analogues on Earth. AGU-GAC-MAC-CGU Joint Assembly Meeting, Montréal, Canada.

Bethell, E.M., Ernst, R.E., Samson, C., and Buchan, K.L. (2017). Detailed Mapping of Graben-Fissure Systems Associated with Fatua Corona, Venus: Implications for Magmatism and the Regional Stress Field. Lunar and Planetary Science Conference XLVIII, abstract 2177.

Bilotti, F., and Suppe, J. (1999). The Global Distribution of Wrinkle Ridges on Venus. Icarus, 139 (1), p. 137-157. 
Bilotti, F.D. (1997). Venus Wrinkle Ridges: Structure, Distribution and Implication for Global Tectonic Evolution (Ph.D. Thesis). Princeton University, Princeton, New Jersey, United States of America.

Bindschadler, D.L., DeCharon, A., Beratan, K.K., Smrekar, S.E., and Head, J.W. (1992). Magellan Observations of Alpha Regio: Implications for Formation of Complex Ridged Terrains on Venus. Journal of Geophysical Research: Planets, 97, p. $13563-13577$.

Bjonnes, E.E., Hansen, V.L., James, B., and Swenson, J.B. (2012). Equilibrium Resurfacing of Venus: Results from New Monte Carlo Modeling and Implications for Venus Surface Histories. Icarus, 217, p. 451-461.

Blanchard, J.A., Ernst, R.E., and Samson, C. (2017). Gravity and Magnetic Modelling of Layered Mafic-Ultramafic Intrusions in Large Igneous Province Plume Centre Regions: Case Studies from the 1.27 Ga Mackenzie, 1.38 Ga Kunene-Kibaran, 0.06 Ga Deccan, 0.13-0.08 Ga High Arctic Events. Canadian Journal of Earth Sciences, 54(3), p. 290-310.

Bleamaster, L.F.I.I.I, and Hansen, V.L. (2001). The Kuanja/Vir-Ava Chasmata: A Coherent Intrusive Complex on Venus. Lunar and Planetary Science Conference XXXII, abstract 1316 .

Bridges, N.T., and McGill, G.E. (2002). Geologic Map of the Kaiwan Fluctus Quadrangle (V-44), Venus, Scale 1:5 M. U.S. Geological Survey Geologic Investigations Series I-2747. 
Bryan, S.E., and Ernst, R.E. (2008). Revised Definition of Large Igneous Provinces (LIPs). Earth Science Reviews, 86, p. 175-202.

Buchan, K.L., and Ernst, R.E. (2016). Giant Circumferential Dyke Swarms on Earth as Possible Analogues of Coronae on Venus. Lunar and Planetary Science Conference XLVII, abstract 1183.

Buchan, K.L., and Ernst, R.E. (2018). A Giant Circumferential Dyke Swarm Associated with the High Arctic Large Igneous Province (HALIP). Gondwana Research, 58, p. 39-57.

Buchan, K.L., and Ernst, R.E. (2019). Giant Circumferential Dyke Swarms: Catalogue and Characteristics. In R.K. Srivastava, R.E. Ernst, P. Peng (Eds.), Dyke Swarms of the World: A Modern Perspective (pp. 1-44). Springer Geology.

Bullock, M.A., Grinspoon, D.H., and Head, J.W. (1993). Venus Resurfacing Rates: Constraints Provided by 3-D Monte Carlo Simulations. Geophysical Research Letters, 20, p. 2783.

Burba, G.A., and Shashkina, V.P. (1992). Topographic Comparison of Coronae on Venus and Transylvanian Ring Structure on the Earth. Lunar and Planetary Science Conference XXIII, p. 184-184.

Burgess, S.D., Bowring, S.A., Fleming, T.H., and Elliot, D.H. (2015). High-Precision Geochronology Links the Ferrar Large Igneous Province with Early-Jurassic Ocean Anoxia and Biotic Crisis. Earth and Planetary Science Letters, 415(1), p. 90-99. 
Byrne, P.K., Ghail, R.C., Gilmore, M.S., Sengor, A.M.C, Klimczak, C., Senske, D.A., Whitten, J.L., Khawja, S., Ernst, R.E., and Solomon, S.C. (2020). Venus Tesserae Feature Layered, Folded, and Eroded Rocks. Geology, 49(1), p. 81-85.

Byrne, P.K., Klimczak, C., McGovern, P.J., Mazarico, E., James, P.B., Neumann, G.A., Zuber, M.T., and Solomon, S.C. (2015). Deep-seated Thrust Faults Bound the Mare Crisium Lunar Mascon. Earth and Planetary Science Letters, 427 (1), p. 183-190.

Campbell, I.H. (2005). Large Igneous Provinces and the Mantle Plume Hypothesis. Elements, 1(5), p. 265-269.

Campbell, I.H. (2007). Testing the Plume Theory. Chemical Geology, 241(3-4), p. 153176.

Campbell, I.H., and Griffiths, R.W. (1990). Implications of Mantle Plume Structure for the Evolution of Flood Basalts. Earth and Planetary Science Letters, 99(1-2), p. 79-93.

Casale, G., and Pratt, T.L. (2015). Thin- or Thick-Skinned Faulting in the Yakima Fold and Thrust Belt (WA)? Constraints from Kinematic Modeling of the Saddle Mountains Anticline. Bulletin of the Seismological Society of America, 105(2A), p. 745-752.

Chadwick Jr., W.W., and Dieterich, J.H. (1995). Mechanical Modelling of Circumferential and Radial Dike Intrusion on Galapagos Volcanoes. Journal of Volcanology and Geothermal Research, 66, p. 37-52. 
Chesner, C.A., and Rose, W.I. (1991). Stratigraphy of the Toba Tuffs and the Evolution of the Toba Caldera Complex, Sumatra, Indonesia. Bulletin of Volcanology, 53, p. 343-356.

Coffin, M.F., and Eldholm, O. (1994). Large Igneous Provinces: Crustal Structure, Dimensions, and External Consequences. Reviews of Geophysics, 32, p. 1-36.

Cole, H.M., and Andrews-Hanna, J.C. (2017). The Anatomy of a Wrinkle Ridge Revealed in the Wall of Melas Chasma, Mars. Journal of Geophysical Research: Planets, 122 (5), p. 889-900.

Colin, I. (1983). Basic Facts About Venus. In D.M. Hunten, L. Colin, T.M. Donahue, and V.I. Moroz (Eds.), Venus (pp. 10-26). Tucson, AZ: University of Arizona Press.

Colin, L. (1980). The Pioneer Venus Program. Journal of Geophysical Research: Planets, 85(A13), p. $7575=7598$.

Collins, G.S., Elbeshausen, D., Davison, T.M., Robbins, S.J., and Hynek, B.M. (2011). The Size-Frequency Distribution of Elliptical Impact Craters. Earth and Planetary Science Letters, 310(1-2), p. 1-8.

Colton, G.W., Howard, K.A., and Moore, H.J. (1972). Mare Ridges and Arches in Southern Oceanus Procellarum. Apollo 16: Preliminary Science Report, NASA SP-315, p. 29-90.

Copp, D.L., Guest, J.E., and Stofan, E.R. (1998). New Insights into Coronae Evolution: Mapping on Venus. Journal of Geophysical Research: Planets, 103, p. 1940119417. 
Crane, K.T., and Klimczak, C. (2019). A 3-D Structural Model of the Saddle Mountains, Yakima Fold Province, Washington, USA: Implications for Late Tertiary Tectonic Evolution of the Columbia River Flood Basalt Province. Tectonophysics, 766, p. $1-13$.

Crumpler, L.S., and Aubele, J.C. (2000). Volcanism on Venus. In H. Sigurdsson, B. Houghton, S.R. McNutt, H. Rymer, and J. Stix (Eds.), Encyclopedia of Volcanoes (pp. 728-769). Academic Press.

Davaille, A., Smrekar, S.E., and Tomlinson, S. (2017). Experimental and Observational Evidence for Plume-Induced Subduction on Venus. Nature Geoscience, 10, p. 349-355.

Davey, S.C., Ernst, R.E., Samson, C., and Grosfils, E.B. (2012). Hierarchical Clustering of Pit Crater Chains on Venus. Canadian Journal of Earth Sciences, 50(1), p. $109-126$.

Delaney, P.T., Pollard, D.D., Ziony, J.I., and McKee, E.H. (1986). Field Relations Between Dikes and Joints: Emplacement Processes and Paleostress Analysis. Journal of Geophysical Research: Solid Earth, 91(B5), p. 4920-4938.

Dobretsov, N.L. (2008). Geological Implications of the Thermomechanical Plume Model. Russian Geology and Geophysics, 49(7), p. 441-454.

Dombard, A.J., Johnson, C.L., Richards, M.A., and Solomon, S.C. (2007). A Magmatic Loading Model for Coronae on Venus. Journal of Geophysical Research: Planets, 112, p. 2156-2202. 
Donahue, T.M., and Russell, C.T. (1997). The Venus Atmosphere and lonosphere and their Interaction with the Solar Wind: An Overview. In S.W. Bougher, D.M. Hunten, and R.J. Phillips (Eds.), Venus II: Geology, Geophysics, Atmosphere, and Solar Wind Environment (pp. 3-31). Tucson, AZ: University of Arizona Press.

Donahue, T.M., Hoffman, J.H., Hodges Jr., R.R., and Watson, A.J. (1982). Venus Was Wet: A Measurement of the Ratio of Deuterium to Hydrogen. Science, 216(4546), p. 630-633.

Dragoni, M., and Piombo, A. (2003). A Model for the Formation of Wrinkle Ridges in Volcanic Plains on Venus. Physics of the Earth and Planetary Interiors, 135 (2-3), p. $161-171$.

Egea-González, I., Ruiz, J., Fernández, C., Williams, J.-P., Márquez, Á., and Lara, L.M. (2012). Depth of Faulting and Ancient Heat Flows in the Kuiper Region of Mercury from Lobate Scarp Topography. Planetary and Space Science, 60 (1), p. 193-198.

Elbeshausen, D., Wünnemann, K., and Collins, G.S. (2013). The Transition from Circular to Elliptical Impact Craters. Journal of Geophysical Research: Planets, 118(11), p. 2295-2309.

Ernst, R.E. (2014). Large Igneous Provinces (pp. 653). Cambridge, United Kingdom: Cambridge University Press.

Ernst, R.E., and Buchan, K.L. (1998). Arcuate Dyke Swarms Associated with Mantle Plumes on Earth: Implications for Venusian Coronae. Lunar and Planetary Science Conference XXIX, abstract 1021. 
Ernst, R.E., and Buchan, K.L. (2001). The Use of Mafic Dyke Swarms in Identifying and Locating Mantle Plumes. Geological Society of America Special Paper, 352, p. 247-265.

Ernst, R.E., Desnoyers, D.W., Head, J.W., and Grosfils, E.B. (2003). Graben-Fissure Systems in Guinevere Planitia and Beta Regio $\left(254^{\circ}-312^{\circ} \mathrm{E}, 24^{\circ}-60^{\circ} \mathrm{N}\right)$, Venus, and Implications for Regional Stratigraphy and Mantle Plumes. Icarus, 164, p. 282-316.

Ernst, R.E., Head, J.W., Parfitt, E., Grosfils, E.B., and Wilson, L. (1995). Giant Radiating Dyke Swarms on Earth and Venus. Earth Science Reviews, 39, p. 1-58.

Ernst, R.E., Liikane, D.A., Jowitt, S.M., Buchan, K.L., and Blanchard, J.A. (2019). A New Plumbing System Framework for Mantle Plume-Related Continental Large Igneous Provinces and their Mafic-Ultramafic Intrusions. Journal of Volcanology and Geothermal Research, 384, p. 75-84.

Ernst, R.E., Samson, C., Bethell, E., Lee, J., Khawja, S., Graff, J.R., and Davey, S. (2018). Venera-D Landing Site Selection Based on Detailed Geological Mapping Using Magellan Radar Images. Proceedings of the Venera-D Venus Modeling Workshop, p. 139-143.

Fahrig, W.R. (1987). The Tectonic Settings of Continental Mafic Dyke Swarms: Failed Arm and Early Passive Margin. Geological Association of Canada Special Paper, 34, p. 331-348. 
Ford, J.P., Plaut, J.J., Weitz, C.M., Farr, T.G., Senske, D.A., Stofan, E.R., Michaels, G., and Parker, T.J. (1993). Guide to Magellan Image Interpretation (pp. 148). Pasadena, CA: Jet Propulsion Laboratory (JPL) Publication.

Ford, P.G., and Pettengill, G.H. (1992). Venus Topography and Kilometer-Scale Slopes. Journal of Geophysical Research: Planets, 97, p. 13-114.

Frank, S.L., and Head, J.W. (1989). Lukelong Dorsa as a Zone of Underthrusting and Possible Subduction on Venus. Lunar and Planetary Science Conference XX, p. 309-310.

Frank, S.L., and Head, J.W. (1990). Ridge Belts on Venus: Morphology and Origin. Earth, Moon, and Planets, 50, p. 421-470.

Gault, D.E., and Wedekind, J.A. (1978). Experimental Studies of Oblique Impact. Proceedings of Lunar and Planetary Science Conference IX, p. 3843-3875.

Gilmore, M.S., and Head, J.W. (1994). Intratessera Volcanism of Alpha and Tellus Tesserae on Venus. Lunar and Planetary Science Conference XXV, p. 425-426.

Gilmore, M.S., and Head, J.W. (2000). Sequential Deformation of Plains at the Margins of Alpha Regio, Venus: Implications for Tessera Formation. Meteoritics and Planetary Science, 35, p. 667-687.

Glaze, L.S., Stofan, E.R., Smrekar, S.E., and Baloga, S.M. (2002). Insights Into Corona Formation Through Statistical Analyses. Journal of Geophysical Research: Planets, 107(E12), p. 18-1-18-12. 
Golombek, M.P., Anderson, F.S., and Zuber, M.T. (2001). Martian Wrinkle Ridge Topography: Evidence for Subsurface Faults from MOLA. Journal of Geophysical Research: Planets, 106(E10), p. 23811-23821.

Golombek, M.P., Plescia, J.B., and Franklin, B.J. (1991). Faulting and Folding in the Formation of Planetary Wrinkle Ridges. Proceedings of Lunar and Planetary Science, 21, p. 679-693.

Graff, J.R., Ernst, R.E., and Samson, C. (2018). Evidence for Triple-Junction Rifting Focussed on Local Magmatic Centres Along Parga Chasma, Venus. Icarus, 306, p. $122-138$.

Greeley, R., Arvidson, R.E., Elachi, C., Geringer, M.A., Plaut, J.J., Saunders, R.S., Schubert, G., Stofan, E.R., Thouvenot, E.J.P., Wall, S.D., and Weitz, C.M. (1992). Aeolian Features on Venus: Preliminary Magellan Results. Journal of Geophysical Research: Planets, 97(E8), p. 13319-13345.

Grimm, R.E., and Phillips, R.J. (1992). Anatomy of a Venusian Hot Spot: Geology, Gravity, and Mantle Dynamics of Eistla Regio. Journal of Geophysical Research: Planets, 97(E10), p. 16035-16054.

Grindrod, P.M., and Guest, J.E. (2006). 1:1,500,000 Geological Map of the Aglaonice Region on Venus. Journal of Maps, 2(1), p. 103-117.

Grindrod, P.M., and Hoogenboom, T. (2006). Venus: The Corona Conundrum. Astronomy \& Geophysics, 47, p. 3.16-3.21. 
Grindrod, P.M., Nimmo, F., Stofan, E.R., and Guest, J.E. (2005). Strain at Radially Fractured Centers on Venus. Journal of Geophysical Research: Planets, 110(E12), p. E12002.

Grindrod, P.M., Stofan, E.R., Brian, A.W., and Guest, J.E. (2006). The Geological Evolution of Atai Mons, Venus: A Volcano-Corona 'Hybrid'. Journal of the Geological Society, 163(2), p. 265-275.

Grosfils, E.B., and Head, J.W. (1991). Relationship of Volcanism and Fracture Patterns in a Volcano-Tectonic Structure West of Alpha Regio. Lunar and Planetary Science Conference XXII, p. 499-500.

Grosfils, E.B., and Head, J.W. (1994a). The Global Distribution of Giant Radiating Dike Swarms on Venus: Implications for the Global Stress State. Geophysical Research Letters, 21, p. 701-704.

Grosfils, E.B., and Head, J.W. (1994b). Emplacement of a Radiating Dike Swarm in Western Vinmara Planitia, Venus: Interpretation of the Regional Stress Field Orientation and Subsurface Magmatic Configuration. Earth, Moon, and Planets, 66, p.153-171.

Grosfils, E.B., and Head, J.W. (1995). Radiating Dike Swarms on Venus: Evidence for Emplacement at Zones of Neutral Buoyancy. Planetary and Space Science, 43(12), p. 1555-1557, 1559-1560.

Grosfils, E.B., and Head, J.W. (1996). The Timing of Giant Radiating Dike Swarm Emplacement on Venus: Implications for Resurfacing of the Planet and its 
Subsequent Evolution. Journal of Geophysical Research: Planets, 101(E2), p. 4645-4656.

Gudmundsson, A. (1995). Infrastructure and Mechanics of Volcanic Systems in Iceland. Journal of Volcanology and Geothermal Research, 64, p. 1-22.

Guest, J.E., and Stofan, E.R. (1999). A New View of the Stratigraphic History of Venus. Icarus, 139(1), p. 55-66.

Guest, J.E., Bulmer, M.H., Aubele, J., Beratan, K., Greeley, R., Head, J.W., Michaels, G., Weitz, C., and Wiles, C. (1992). Small Volcanic Edifices and Volcanism in the Plains of Venus. Journal of Geophysical Research, 97, p. 15949-15966.

Gülcher, A.J.P., Gerya, T.V., Montèsi, L.G.J., and Munch, J. (2020). Corona Structures Driven by Plume-Lithosphere Interactions and Evidence for Ongoing Plume Activity on Venus. Nature Geoscience, 13, p. 547-554.

Hamilton, V.E., and Stofan, E.R. (1996). The Geomorphology and Evolution of Hecate Chasma, Venus. Icarus, 121, p. 171-194.

Hamilton, W.B. (2005). Plumeless Venus Preserves an Ancient Impact-Accretionary Surface. Geological Society of America Special Papers, 388, p. 781-814.

Hansen, V.L., and López, I. (2018). Mapping of Geologic Structures in the NiobeAphrodite Map Area of Venus: Unraveling the History of Tectonic Regime Change. Journal of Geophysical Research: Planets, 123, p. 1760-1790.

Hansen, V.L., and Olive, A. (2010). Artemis, Venus: The Largest Tectonomagmatic Feature in the Solar System? Geology, 38, p. 467-470. 
Hansen, V.L., and Phillips, R.J. (1993). Tectonics and Volcanism of Eastern Aphrodite Terra, Venus: No Subduction, No Spreading. Science, 260, p. 526-530.

Hansen, V.L., and Willis, J.J. (1996). Structural Analysis of a Sampling of Tesserae: Implications for Venus Geodynamics. Icarus, 123, p. 296-312.

Hansen, V.L., and Willis, J.J. (1998). Ribbon Terrain Formation, Southwestern Fortuna Tessera, Venus: Implications for Lithosphere Evolution. Icarus, 132, p. 321-343.

Hansen, V.L., Willis, J.J., and Banerdt, W.B. (1997). Tectonic Overview and Synthesis. In S.W. Bougher, D.M. Hunten, and R.J. Phillips (Eds.), Venus II: Geology, Geophysics, Atmosphere, and Solar Wind Environment (pp. 797-844). Tucson, AZ: University of Arizona Press.

Head, J.W., and Basilevsky, A.T. (1998). Sequence of Tectonic Deformation in the History of Venus: Evidence from Global Stratigraphic Relations. Geology, 26, p. 35-38.

Head, J.W., Campbell, D.B., Elachi, C., Guest, J.E., McKenzie, D.P., Saunders, R.S., Schaber, G.G., and Schubert, G. (1991). Venus Volcanism: Initial Analysis from Magellan Data. Science, 252(5003), p. 276-288.

Head, J.W., Crumpler, L.S., Aubele, J.C., Guest, J.E., and Saunders, R.S. (1992). Venus Volcanism: Classification of Volcanic Features and Structures, Associations, and Global Distribution from Magellan Data. Journal of Geophysical Research: Planets, 97(E8), p. 13153-13197. 
Herrick, R.R., Stahlke, D.L., and Sharpton, V.L. (2012). Fine-Scale Venusian Topography from Magellan Stereo Data. Eos, Transactions American Geophysical Union, 93, p. 125-126.

Hou, G., Kusky, T.M., Wang, C., and Wang, Y. (2010). Mechanics of the Giant Radiating Mackenzie Dyke Swarm: A Paleostress Field Modeling. Journal of Geophysical Research, 110, p. B02402.

Hou, G.T., Wang, C.C., Li, J.H., and Qian, X.L. (2006). Late Paleoproterozoic Extension and a Paleostress Field Reconstruction of the North China Craton. Tectonophysics, 422, p. 89-98.

Ivanov, M.A., and Head, J.W. (1996). Tessera Terrain on Venus: A Survey of the Global Distribution, Characteristics, and Relation to Surrounding Units from Magellan Data. Journal of Geophysical Research: Planets, 101, p. 14861-14908.

Ivanov, M.A., and Head, J.W. (2006). Alba Patera, Mars: Topography, Structure, and Evolution of a Unique Late Hesperian-Early Amazonian Shield Volcano. Journal of Geophysical Research: Planets, 111(E9), p. E09003.

Ivanov, M.A., and Head, J.W. (2011). Global Geological Map of Venus. Planetary and Space Science, 59, p. 1559-1600.

Janes, D.M., Squyres, S.W., Bindschadler, D.L., Baer, G., Schubert, G., Sharpton, V.L., and Stofan, E.R. (1992). Geophysical Models for the Formation and Evolution of Coronae on Venus. Journal of Geophysical Research: Planets, 97, p. 1605516067. 
Jiménez-Diaz, A., Ruiz, J., Kirby, J.F., Romeo, I., Tejero, R., and Capote, R. (2015). Lithospheric Structure of Venus from Gravity and Topography. Icarus, 260(1), p. 215-231.

Jourdan, F., Féraud, G., Bertrand, H., Watkeys, M.K., and Renne, P.R. (2007). Distinct Brief Major Events in the Karoo Large Igneous Province Clarified by New ${ }^{40} \mathrm{Ar} /{ }^{39} \mathrm{Ar}$ Ages on the Lesotho Basalts. Lithos, 98(1-4), p. 195-209.

Kargel, J.S., Komatsu, G., Baker, V.R., and Strom, R.G. (1993). The Volcanology of Venera and VEGA Landing Sites and the Geochemistry of Venus. Icarus, 103(2), p. $253-275$.

Kasbohm, J., Schoene, B., and Burgess, S. (2021). Radiometric Constraints on the Timing, Tempo, and Effects of Large Igneous Province Emplacement. Geophysical Monograph, 255, p. 27-82.

Khawja, S., Ernst, R.E., Samson, C., Byrne, P.K., Ghail, R.C., and MacLellan, L.M. (2020). Tesserae on Venus May Preserve Evidence of Fluvial Erosion. Nature Communications, 11, p. 5789.

Kiefer, W.S., and Hager, B.H. (1991). A Mantle Plume Model for the Equatorial Highlands of Venus. Journal of Geophysical Research: Planets, 96(E4), p. 20947-20966.

Kiefer, W.S., and Swafford, L.C. (2006). Topographic Analysis of Devana Chasma, Venus: Implications for Rift System Segmentation and Propagation. Journal of Structural Geology, 28(12), p. 2144-2155. 
Krassilnikov, A.S., and Head, J.W. (2003). Novae on Venus: Geology, Classification, and Evolution. Journal of Geophysical Research: Planets, 108, p. 5108.

Kreslavsky, M.A., and Basilevsky, A.T. (1998). Morphometry of Wrinkle Ridges on Venus: Comparison with Other Planets. Journal of Geophysical Research: Planets, 103(E5), p. 11103-11111.

Kreslavsky, M.A., and Head, J.W. (1999). Morphometry of Small Shield Volcanoes on Venus: Implications for the Thickness of Regional Plains. Journal of Geophysical Research: Planets, 104(E8), p. 18925-18932.

Kreslavsky, M.A., Head, J.W., Neumann, G.A., Zuber, M.T., and Smith, D.E. (2017). Low-Amplitude Topographic Features and Textures on the Moon: Initial Results from Detrended Lunar Orbiter Laser Altimeter (LOLA) Topography. Icarus, 283, p. $138-145$.

Kreslavsky, M.A., Ivanov, M.A., and Head, J.W. (2015). The Resurfacing History of Venus: Constraints from Buffered Crater Densities. Icarus, 250, p. 438-450.

Lang, N., and López, I. (2013). The Magmatic Evolution of Three Venusian Coronae. Geological Society of London Special Publication, 401, p. 77-95.

López, I., Marquez, A., and Oyarzun, R. (1999). Are Coronae Restricted to Venus? Corona-Like Tectonovolcanic Structures on Earth. Earth, Moon, and Planets, 77, p. $125-137$.

Lucchitta, B.K. (1976). Mare Ridges and Related Highland Scarps - Result of Vertical Tectonism? Proceedings of Lunar and Planetary Science, 7, p. 2761-2782. 
Lutter, W.J., Catchings, R.D., and Jarchow, C.M. (1994). An Image of the Columbia Plateau from Inversion of High-Resolution Seismic Data. Geophysics, 59, p. 1278-1289.

Maher, H.D. Jr. (2001). Manifestations of the Cretaceous High Arctic Large Igneous Province in Svalbard. The Journal of Geology, 109(1), p. 91-104.

Mangold, N., Allemand, P., and Thomas, P.G. (1998). Wrinkle Ridges of Mars:

Structural Analysis and Evidence for Shallow Deformation Controlled by Ice-Rich Décollements. Planetary and Space Science, 46(4), p. 345-356.

Marinoni, L.B., and Gudmundsson, A. (2000). Dykes, Faults, and Palaeostresses in the Teno and Anaga Massifs of Tenerife (Canary Islands). Journal of Volcanology and Geothermal Research, 103(1-4), p. 83-103.

Masursky, H. (1987). Geological Evolution of Coronae (Complex Circular Features) on Venus. Lunar and Planetary Science Conference XVIII, p. 598-599.

Masursky, H., Eliason, E., Ford, P.G., McGill, G.E., Pettengill, G.H., Schaber, G.G., and Schubert, G. (1980). Pioneer Venus Radar Results: Geology from Images and Altimetry. Journal of Geophysical Research: Space Physics, 85(A13), p. 82328260.

McGill, G.E. (1993). Wrinkle Ridges, Stress Domains, and Kinematics of Venusian Plains. Geophysical Research Letters, 20, p. 2407-2410.

McGill, G.E. (1998). Central Eistla Regio: Origin and Relative Age of Topographic Rise. Journal of Geophysical Research: Planets, 103(E3), p. 5889-5896. 
McGill, G.E. (2000). Geologic Map of the Sappho Patera Quadrangle (V-20), Venus, Scale 1:5 M. U.S. Geological Survey Geologic Investigations Series I-2637.

McGill, G.E. (2004). Tectonic and Stratigraphic Implications of the Relative Ages of Venusian Plains and Wrinkle Ridges. Icarus, 172, p. 603-612.

McKenzie, D., McKenzie, J.M., and Saunders, R.S. (1992). Dike Emplacement on Venus and Earth. Journal of Geophysical Research: Planets, 97, p. 1597715990.

McKinnon, W.B., Zahnle, K.J., Ivanov, B.A., and Melosh, H.J. (1997). Cratering on Venus: Models and Observations. In S.W. Bougher, D.M. Hunten, and R.J. Phillips (Eds.), Venus II: Geology, Geophysics, Atmosphere, and Solar Wind Environment (pp. 969-1014). Tucson, AZ: University of Arizona Press.

Mège, D., and Ernst, R.E. (2001). Contractional Effects of Mantle Plumes on Earth, Mars, and Venus. Geological Society of America Special Paper, 352, p. 103-140.

Mège, D., and Masson, P. (1996). A Plume Tectonics Model for the Tharsis Province, Mars. Planetary and Space Science, 44(12), p. 1499-1546.

Mège, D., and Reidel, S.P. (2001). A Method for Estimating 2D Wrinkle Ridge Strain from Application of Fault Displacement Scaling to the Yakima Folds, Washington. Geophysical Research Letters, 28(18), p. 3545-3548.

Montési, L.G.J., and Zuber, M.T. (2003). Clues to the Lithospheric Structure of Mars from Wrinkle Ridge Sets and Localization Instability. Journal of Geophysical Research: Planets, 108(E6), p. E001974. 
Moruzzi, S.A., and Kiefer, W.S. (2019). Thrust Faulting on Venus: Tectonic Modeling of the Vedma Dorsa Ridge Belt. $17^{\text {th }}$ Meeting of the Venus Exploration and Analysis Group, abstract 2193.

Moruzzi, S.A., and Kiefer, W.S. (2020). Thrust Faulting on Venus: Tectonic Modeling of the Vedma Dorsa Ridge Belt. Lunar and Planetary Science Conference LI, abstract 1430.

Mäkitie, H., Data, G., Isabirye, E., Mänttäri, I., Huhma, H., Klausen, M.B., Pakkanen, L., and Virransalo, P. (2014). Petrology, Geochronology, and Emplacement Model of the Giant $1.37 \mathrm{Ga}$ Arcuate Lake Victoria Dyke Swarm on the Margin of a Large Igneous Province in Eastern Africa. Journal of African Earth Sciences, 97, p. 273-296.

Nakamura, M., Imamura, T., Ishii, N., Abe, T., Satoh, T., Suzuki, M., Ueno, M., Yamazaki, A., Iwagami, N., Watanabe, S., Taguchi, M., Fukuhara, T., Takahashi, Y., Yamada, M., Hoshino, N., Ohtsuki, S., Uemizu, K., Hashimoto, G.L., Takagi, M., Matsuda, Y., Ogohara, K., Sato, N., Kasaba, Y., Kouyama, T., Hirata, N., Nakamura, R., Yamamoto, Y., Okada, N., Horinouchi, T., Yamamoto, M., and Hayashi, Y. (2011). Overview of Venus Orbiter, Akatsuki. Earth, Planets, and Space, 63 , p. $443-457$.

Nikolaeva, O.V., Ronca, L.B., and Basilevsky, A.T. (1986). Circular Features on the Plains of Venus as an Evidence of its Geologic History. Geokhimiya, 5, p. 579589. 
Nikolayeva, O.V. (1990). Geochemistry of the Venera 8 Material Demonstrates the Presence of Continental Crust on Venus. Earth, Moon, and Planets, 50-51, p. 329-341.

Nimmo, F., and McKenzie, D. (1998). Volcanism and Tectonics on Venus. Annual Review of Earth and Planetary Sciences, 26, p. 23-51.

North American Commission on Stratigraphic Nomenclature. (2005). North American Stratigraphic Code. AAPG Bulletin, 89, p. 1547-1591.

Oakey, G.N., and Saltus, R.W. (2016). Geophysical Analysis of the Alpha-Mendelev Ridge Complex: Characterization of the High Arctic Large Igneous Province. Tectonophysics, 691(Part A), p. 65-84.

Odé, H. (1957). Mechanical Analysis of the Dike Pattern of the Spanish Peaks Area, Colorado. Geological Society of America Bulletin, 68(5), p. 567-576.

Okubo, C.H., and Schultz, R.A. (2001). Elevation Offsets Across Wrinkle Ridges: Key to Structural Width. Lunar and Planetary Science Conference XXXII, abstract 2086.

Okubo, C.H., and Schultz, R.A. (2002). What Can the Topography of Thrust-Related Anticlines Tell Us About Mechanical Stratigraphy and Pore Fluid Pressure? American Geophysical Union Fall Meeting, abstract T12G-01.

Okubo, C.H., and Schultz, R.A. (2004). Mechanical Stratigraphy in the Western Equatorial Region of Mars Based on Thrust Fault-Related Fold Topography and Implications for Near-Surface Volatile Reservoirs. GSA Bulletin, 116(5-6), p. 594605. 
Okubo, C.H., and Schultz, R.A. (2006). Variability in Early Amazonian Tharsis Stress State Based on Wrinkle Ridges and Strike-Slip Faulting. Journal of Structural Geology, 28(12), p. 2169-2181.

Parfitt, E.A., and Head, J.W. (1993). Buffered and Unbuffered Dike Emplacement on Earth and Venus: Implications for Magma Reservoir Size, Depth, and Rate of Magma Emplacement. Earth, Moon, and Planets, 61, p. 249-281.

Patterson, C.W., Ernst, R.E., and Samson, C. (2016). Pit Chains Associated with Radiating Graben-Fissure Systems on Venus: Formation During Lateral Dyke Injection? Lunar and Planetary Science Conference XLVII, abstract 2097.

Pedersen, G.B.M., Head, J.W., and Wilson, L. (2010). Formation, Erosion, and Exposure of Early Amazonian Dikes, Dike Swarms and Possible Subglacial Eruptions in the Elysium Rise/Utopia Basin Region, Mars. Earth and Planetary Science Letters, 294(3-4), p. 424-439.

Peterfreund, A.R., Head, J.W., and Grieve, R.A.F. (1984). Cleopatra Patera: A Circular Structure in Maxwell Montes, Venus. Lunar and Planetary Science Conference $X V$, p. 641-642.

Phillips, R.J., and Hansen, V.L. (1994). Tectonic and Magmatic Evolution of Venus. Annual Review of Earth and Planetary Sciences, 22, p. 597-656.

Phillips, R.J., and Hansen, V.L. (1997). Venus: Now and Then. Lunar and Planetary Science Conference XXVIII, p. 1105-1106. 
Phillips, R.J., and Malin, M.C. (1983) The Interior of Venus and Tectonic Implications. In D.M. Hunten, L. Colin, T.M. Donahue, and V.I. Moroz (Eds.), Venus (pp. 159214). Tucson, AZ: University of Arizona Press.

Phillips, R.J., Raubertas, R.F., Arvidson, R.E., Sarkar, I.C., Herrick, R.R., Izenberg, N., and Grimm, R.E. (1992). Impact Craters and Venus Resurfacing History. Journal of Geophysical Research, 97, p. 15923-15948.

Plescia, J.B. (1991). Wrinkle Ridges in Lunae Planum Mars: Implications for Shortening and Strain. Geophysical Research Letters, 18(5), p. 913-916.

Plescia, J.B. (1993). Wrinkle Ridges of Arcadia Planitia, Mars. Journal of Geophysical Research: Planets, 98(E8), p. 15049-15059.

Plescia, J.B., and Golombek, M.P. (1986). Origin of Planetary Wrinkle Ridges Based on the Study of Terrestrial Analogs. GSA Bulletin, 97(11), p. 1289-1299.

Pollard, D.D., and Segall, P. (1987). Theoretical Displacements and Stresses Near Fractures and Rock: With Applications to Faults, Joints, Veins, Dikes, and Solution Surfaces. In B.K. Atkinson (Eds.) Fracture Mechanics of Rock (p. 277347). London, United Kingdom: Academic Press.

Pollard, D.D., Delaney, P.T., Duffield, W.A., Endo, E.T., and Okamura, A.T. (1983). Surface Deformation in Volcanic Rift Zones. Tectonophysics, 94, p. 541-584.

Price, M., and Suppe, J. (1996). Constraints on the Resurfacing History of Venus from the Hypsometry and Distribution of Volcanism, Tectonism, and Impact Craters. Earth, Moon, and Planets, 71, p. 99-145. 
Pronin, A.A., and Stofan, E.R. (1990). Coronae on Venus: Morphology, Classification, and Distribution. Icarus, 87, p. 452-474.

Reidel, S.P., Camp, V.E., Tolan, T.L., Kauffman, J.D., and Garwood, D.L. (2013). Tectonic Evolution of the Columbia River Flood Basalt Province. Geological Society of America Special Paper, 497, p. 293-324.

Richards, M.A., Duncan, R.A., and Courtillot, V.E. (1989). Flood Basalts and Hot-Spot Tracks: Plume Heads and Tails. Science, 246(4926), p. 103-107.

Rivalta, E., Taisne, B., Bunger, A.P., and Katz, R.F. (2015). A Review of Mechanical Models of Dike Propagation: Schools of Thought, Results and Future Directions. Tectonophysics, 638, p. 1-42.

Roberts, K.M., Guest, J.E., Head, J.W., and Lancaster, M.G. (1992). Mylitta Fluctus, Venus: Rift-Related, Centralized Volcanism and the Emplacement of LargeVolume Flow Units. Journal of Geophysical Research: Planets, 97(E10), p. $15991-16015$.

Romeo, I., and Turcotte, D.L. (2009). The Frequency-Area Distribution of Volcanic Units on Venus: Implications for Planetary Resurfacing. Icarus, 203, p. 13-19.

Rubin, A.M. (1992). Dike-Induced Faulting and Graben Subsidence in Volcanic Rift Zones. Journal of Geophysical Research: Solid Earth, 97, p. 1839-1858.

Sandwell, D.T., and Schubert, G. (1992). Flexural Ridges, Trenches, and Outer Rises around Coronae on Venus. Journal of Geophysical Research: Planets, 97, p. 16069-16083. 
Sandwell, D.T., Johnson, C.L., Bilotti, F., and Suppe, J. (1997). Driving Forces for Limited Tectonics on Venus. Icarus, 129(1), p. 232-244.

Saunders, R.S., Arvidson, R.E., Head, J.W., Schaber, G.G., Stofan, E.R., and Solomon, S.C. (1991). An Overview of Venus Geology. Science, 252(5003), p. 249-252.

Saunders, R.S., Spear, A.J., Allin, P.C., Austin, R.S., Berman, A.L., Chandlee, R.C., Clark, J., Decharon, A.V., De Jong, E.M., Griffith, D.G., Gunn, J.M., Hensley, S., Johnson, W.T.K., Kirby, C.E., Leung, K.S., Lyons, D.T., Michaels, G.A., Miller, J., Morris, R.B., Morrison, A.D., Piereson, R.G., Scott, J.F., Shaffer, S.J., Slonski, J.P., Stofan, E.R., Thompson, T.W., and Wall, S.D. (1992). Magellan Mission Summary. Journal of Geophysical Research, 97, p. 13067-13090.

Schaber, G.G., Strom, R.G., Moore, H.J., Soderblom, L.A., Kirk, R.L., Chadwick, D.J., Dawson, D.D., Gaddis, L.R., Boyce, J.M., and Russell, J. (1992). Geology and Distribution of Impact Craters on Venus: What Are They Telling Us? Journal of Geophysical Research: Planets, 97(E8), p. 13257-13301.

Schubert, G., Moore, W.B., and Sandwell, D.T. (1994). Gravity over Coronae and Chasmata on Venus. Icarus, 112, p. 130-146.

Schultz, R.A. (1993). Brittle Strength of Basaltic Rock Masses with Applications to Venus. Journal of Geophysical Research: Planets, 98(E6), p. 10883-10895.

Schultz, R.A. (2000). Localization of Bedding-Plane Slip and Backthrust Faults Above Blind Thrust Faults: Keys to Wrinkle Ridge Structure. Journal of Geophysical Research: Planets, 105(E5), p. 12035-12052. 
Schultz, R.A., and Watters, T.R. (2001). Forward Mechanical Modeling of the Amenthes Rupes Thrust Fault on Mars. Geophysical Research Letters, 28(24), p. 46594662.

Senske, D.A., Campbell, D.B., Head, J.W., Fisher, P.C., Hine, A.A., deCharon, A., Frank, S.L., Keddie, S.T., Roberts, K.M., Stofan, E.R., Aubele, J.C., Crumpler, L.S., and Stacy, N. (1991). Geology and Tectonics of the Themis Regio-Lavinia Planitia-Alpha Regio-Lada Terra Area, Venus: Results from Arecibo Image Data. Earth, Moon, and Planets, 55, p. 97-161.

Senske, D.A., Schaber, G.G., and Stofan, E.R. (1992). Regional Topographic Rises on Venus: Geology of Western Eistla Regio and Comparison to Beta Regio and Atla Regio. Journal of Geophysical Research: Planets, 97(E8), p. 13395-13420.

Sharpton, V.L., and Head, J.W. (1988). Lunar Mare Ridges: Analysis of Ridge-Crater Intersections and Implications for the Tectonic Origin of Mare Ridges. Proceedings of the Lunar and Planetary Science Conference XVIII, p. 307-317.

Shellnutt, J.G., Denyszyn, S.W., and Mundil, R. (2012). Precise Age Determination of Mafic and Felsic Intrusive Rocks from the Permian Emeishan Large Igneous Province (SW China). Gondwana Research, 22(1), p. 118-126.

Smrekar, S.E., and Stofan, E.R. (1997). Corona Formation and Heat Loss on Venus by Coupled Upwelling and Delamination. Science, 277, p. 1289-1294.

Solomon, S.C., Bullock, M.A., and Grinspoon, D.H. (1999). Climate Change as a Regulator of Tectonics on Venus. Science, 286(5437), p. 87-90. 
Solomon, S.C., Smrekar, S.E., Bindschadler, D.L., Grimm, R.E., Kaula, W.M., McGill, G.E., Phillips, R.J., Saunders, R.S., Schubert, G., Squyres, S.W., and Stofan, E.R. (1992). Venus Tectonics: An Overview of Magellan Observations. Journal of Geophysical Research: Planets, 97(E8), p. 13199-13255.

Sonett, C.P. (1963). A Summary Review of the Scientific Findings of the Mariner Venus Mission. Space Science Reviews, 2, p. 751-777.

Squyres, S.W., Janes, D.M., Baer, G., Bindschadler, D.L., Schubert, G., Sharpton, V.L., and Stofan, E.R. (1992). The Morphology and Evolution of Coronae on Venus. Journal of Geophysical Research, 97, p. 13611-13634.

Stofan, E.R., and Head, J.W. (1988). Arachnoid Structures on Venus: Morphology and Distribution. Lunar and Planetary Science Conference XIX, abstract 1127.

Stofan, E.R., and Head, J.W. (1990). Coronae of Mnemosyne Regio: Morphology and Origin. Icarus, 83, p. 216-243.

Stofan, E.R., and Saunders, R.S. (1990). Geologic Evidence of Hotspot Activity on Venus: Predictions for Magellan. Geophysical Research Letters, 17(9), p. 13771380.

Stofan, E.R., Bindschadler, D.L., Head, J.W., and Parmentier, E.M. (1991). Corona Structures on Venus: Models of Origin. Journal of Geophysical Research: Planets, 96, p. 20933-20946.

Stofan, E.R., Hamilton, V.E., Janes, D.M., and Smrekar, S.E. (1997). Coronae on Venus: Morphology and Origin. In S.W. Bougher, D.M. Hunten, and R.J. Phillips 
(Eds.), Venus II: Geology, Geophysics, Atmosphere, and Solar Wind Environment (pp. 931). Tucson, AZ: University of Arizona Press.

Stofan, E.R., Head, J.W., and Parmentier, E.M. (1987). Corona Structures on Venus: Models of Origin. Lunar and Planetary Science Conference XVIII, abstract 1488.

Stofan, E.R., Sharpton, V.L., Schubert, G., Baer, G., Bindschadler, D.L., Janes, D.M., and Squyres, S.W. (1992). Global Distribution and Characteristics of Coronae and Related Features on Venus: Implications for Origin and Relation to Mantle Processes. Journal of Geophysical Research, 97, p. 13347-13378.

Stofan, E.R., Smrekar, S.E., Bindschadler, D.L., and Senske, D.A. (1995). Large Topographic Rises on Venus: Implications for Mantle Upwelling. Journal of Geophysical Research: Planets, 100(E11), p. 23317-23327.

Stofan, E.R., Smrekar, S.E., Tapper, S.W., Guest, J.E., and Grindrod, P.M. (2001). Preliminary Analysis of an Expanded Corona Database for Venus. Geophysical Research Letters, 28, p. 4267-4270.

Studd, D., Ernst, R.E., and Samson, C. (2011). Radiating Graben-Fissure Systems in the Ulfrun Regio Area, Venus. Icarus, 215, p. 279-291.

Suppe, J., and Connors, C. (1992). Critical Taper Wedge Mechanics of Fold-and-Thrust Belts on Venus: Initial Results from Magellan. Journal of Geophysical Research, 97, p.13545-13561. 
Suppe, J., and Narr, W. (1989). Fault-Related Folding on the Earth with Application to Wrinkle Ridges on Mars and the Moon. MEVTV Workshop on Tectonic Features on Mars, LPI Technical Report 89-06, p. 55-56.

Svedhem, H., Titov, D., Taylor, F., and Witasse, O. (2009). Venus Express Mission. Journal of Geophysical Research: Planets, 114(E5), p. E00B33.

Svensen, H., Corfu, F., Polteau, S., Hammer, Ø., and Planke, S. (2012). Rapid Magma Emplacement in the Karoo Large Igneous Province. Earth and Planetary Science Letters, 325-326, p. 1-9.

Tanaka, K.L. (1994). The Venus Geologic Mappers' Handbook, $2^{\text {nd }}$ Edition (USGS open-file report, pp. 94-438). Reston, VA: U.S. Department of the Interior and the U.S. Geological Survey (USGS).

Tanaka, K.L., Senske, D.A., Price, M., and Kirk, R.L. (1997). Physiography, Geomorphic/Geologic Mapping, and Stratigraphy of Venus. In S.W. Bougher, D.M. Hunten, and R.J. Phillips (Eds.), Venus II: Geology, Geophysics, Atmosphere, and Solar Wind Environment (pp. 667-696). Tucson, AZ: University of Arizona Press.

Tate, A., Golombek, M.P., and Mueller, K.J. (2001). Morphology of Wrinkle Ridges on Lunae and Solis Plana, Mars, from MOLA Topography: Implications for their Kinematic Development. Lunar and Planetary Science Conference XXXII, abstract 1444 .

Toda, S., Stein, R.S., Sevilgen, V., and Lin, J. (2011). Coulomb 3.3 Graphic-Rich Deformation and Stress-Change Software for Earthquake, Tectonic, and Volcano 
Research and Teaching - User Guide. U.S. Geological Survey Open-File Report, 2011-1060, pp. 63.

Townsend, M.R., Pollard, D.D., and Smith, R.P. (2017). Mechanical Models for Dikes: A Third School of Thought. Tectonophysics, 703-704, p. 98-118.

Treiman, A.H. (2007). Geochemistry of Venus' Surface: Current Limitations as Future Opportunities. AGU Monograph Series, 176, p. 7-22.

Turcotte, D.L., Morein, G., Roberts, D., and Malamud, B.D. (1999). Catastrophic Resurfacing and Episodic Subduction on Venus. Icarus, 139, p. 49-54.

United States Geological Survey. (n.d.). Retrieved from https://planetarymapping.wr.usgs.gov/Target/project/2

Venera-D Joint Science Definition Team (2019). Venera-D: Expanding Our Horizon of Terrestrial Planet Climate and Geology Through the Comprehensive Exploration of Venus. Report of the Venera-D Joint Science Definition Team, pp. 165.

Vita-Finzi, C., Howarth, R.J., Tapper, S.W., and Robinson, C.A. (2005). Venusian Craters, Size Distribution, and the Origin of Coronae. Geological Society of America Special Papers, 388, p. 815-823.

Von Zahn, U., Kumar, S., Niemann, H., and Prinn, R. (1983). Composition of the Venus Atmosphere. In D.M. Hunten, I. Colin, T.M. Donahue, and V.I. Moroz (Eds.), Venus (pp. 299-430). Tucson, AZ: University of Arizona Press.

Watters, T.R. (1988). Wrinkle Ridge Assemblages on the Terrestrial Planets. Journal of Geophysical Research: Planets, 93(B9), p. 10236-10254. 
Watters, T.R. (1991). Origin of Periodically Spaced Wrinkle Ridges on the Tharsis Plateau of Mars. Journal of Geophysical Research: Planets, 96(E1), p. 1559915616.

Watters, T.R. (1992). System of Tectonic Features Common to Earth, Mars, and Venus. Geology, 20(7), p. 609-612.

Watters, T.R. (1993). Compressional Tectonism on Mars. Journal of Geophysical Research: Planets, 98(E9), p. 17049-17060.

Watters, T.R. (2004). Elastic Dislocation Modeling of Wrinkle Ridges on Mars. Icarus, 171(2), p. 284-294.

Watters, T.R., and Janes, D.M. (1995). Coronae on Venus and Mars: Implications for Similar Structures on Earth. Geology, 23, p. 200-204.

Watters, T.R., and Robinson, M.S. (1997). Radar and Photoclinometric Studies of Wrinkle Ridges on Mars. Journal of Geophysical Research: Planets, 102(E5), p. 10889-10903.

Watters, T.R., and Schultz, R.A. (2002). The Fault Geometry of Planetary Lobate Scarps: Listric Versus Planar. Lunar and Planetary Science Conference XXXIII, abstract 1668.

Way, M.J., and Del Genio, A.D. (2020). Venusian Habitable Climate Scenarios: Modeling Venus Through Time and Applications to Slowly Rotating Venus-Like Exoplanets. Journal of Geophysical Research: Planets, 125(5), p. E006276. 
Way, M.J., Del Genio, A.D., Kiang, N.Y., Sohl, L.E., Grinspoon, D.H., Aleinov, I., Kelley, M., and Clune, T. (2016). Was Venus the First Habitable World of our Solar System? Geophysical Research Letters, 43(16), p. 8376-8383.

Whitaker, E.A. (1966). The Surface of the Moon. 1965 IAU-NASA Symposium Proceedings, p. 79-97.

Williams, J., and Moore, W.B. (2003). Incipient Formation of Tharsis: A Lithospheric Flexure Model Using Venusian Coronae as an Analogue. American Geophysical Union Fall Meeting, abstract P12B-1060.

Williams, N.R., Watters, T.R., Pritchard, M.E., Banks, M.E., and Bell, J.F. (2013). Fault Dislocation Modeled Structure of Lobate Scarps from Lunar Reconnaissance Orbiter Camera Digital Terrain Models. Journal of Geophysical Research: Planets, 118, p. 224-233.

Williams, Z.W., Byrne, P.K., and Balcerski, J.A. (2019). A Global Study of Ridge Belt Morphology and Morphometry on Venus. $17^{\text {th }}$ Meeting of the Venus Exploration and Analysis Group, abstract 2193.

Williams, Z.W., Byrne, P.K., Balcerski, J.A., and Bohnenstiehl, D. (2020). A Global Study of Ridge Belt Morphology and Morphometry on Venus. Lunar and Planetary Science Conference LI, abstract 2375.

Williams-Jones, G., Williams-Jones, A.E., and Stix, J. (1998). The Nature and Origin of Venusian Canali. Journal of Geophysical Research: Planets, 103, p. 8545-8555. 
Wilson, L., and Head, J.W. (2002). Tharsis-Radial Graben Systems as the Surface Manifestation of Plume-Related Dike Intrusion Complexes: Models and Implications. Journal of Geophysical Research: Planets, 107(E8), p. 1-1-1-24.

Wyrick, D., Ferrill, D.A., Morris, A.P., Colton, S.L., and Sims, D.W. (2004). Distribution, Morphology, and Origins of Martian Pit Crater Chains. Journal of Geophysical Research: Planets, 109, E06005.

Yue, Z., Li, W., Di, K., Liu, Z., and Liu, J. (2015). Global Mapping and Analysis of Lunar Wrinkle Ridges. Journal of Geophysical Research: Planets, 120, p. 978-994.

Zoback, M.L. (1992). First- and Second Order Patterns of Stress in the Lithosphere: The World Stress Map Project. Journal of Geophysical Research: Solid Earth, 97(B8), p. $11703-11728$.

Zuber, M.T. (1995). Wrinkle Ridges, Reverse Faulting, and the Depth of Penetration of Lithospheric Strain in Lunae Planum, Mars. Icarus, 114(1), p. 80-92. 


\section{APPENDIX A}

This appendix includes the 1:2,500,000 scale geological map of the Alpha Regio (V-32) quadrangle discussed in Chapter 2. Due to the page size restrictions of the thesis document, the map is attached to the thesis as a supplementary PDF file.

The map can also be downloaded from the open access article published in the Journal of Maps at the following link:

https://doi.org/10.6084/m9.figshare.8163371.v1 


\section{APPENDIX B}

This appendix contains data for the wrinkle ridge topographic profiles discussed in Chapter 5. Included in the following table are the start and end coordinates for each topographic profile, as well as the measured widths, heights, and calculated skewness values. Following the table are plots of the topographic profiles for each of the 40 wrinkle ridges studied.

\begin{tabular}{|c|c|c|c|c|c|c|c|c|}
\hline $\begin{array}{l}\text { Wrinkle } \\
\text { Ridge }\end{array}$ & Profile & $\begin{array}{l}\text { Start } X \\
\left({ }^{\circ} \mathrm{E}\right)\end{array}$ & $\begin{array}{l}\text { Start } Y \\
\left({ }^{\circ} \mathrm{N}\right)\end{array}$ & $\begin{array}{l}\text { End } X \\
\left({ }^{\circ} \mathrm{E}\right)\end{array}$ & $\begin{array}{l}\text { End } \mathrm{Y} \\
\left({ }^{\circ} \mathrm{N}\right)\end{array}$ & $\begin{array}{l}\text { Width } \\
(\mathrm{km})\end{array}$ & $\begin{array}{l}\text { Height } \\
\text { (m) }\end{array}$ & Skewness \\
\hline \multirow[t]{5}{*}{$\mathrm{R} 1$} & $A$ & 17.09 & -1.30 & 17.12 & -1.45 & 8.39 & 59.5 & -0.22 \\
\hline & B & 17.14 & -1.29 & 17.17 & -1.44 & 7.65 & 80.2 & 0.17 \\
\hline & C & 17.18 & -1.28 & 17.22 & -1.42 & 7.74 & 203.9 & 0.24 \\
\hline & D & 17.22 & -1.27 & 17.25 & -1.42 & 6.00 & 251.3 & 0.48 \\
\hline & $E$ & 17.26 & -1.25 & 17.30 & -1.41 & 7.06 & 182.0 & 0.38 \\
\hline \multirow[t]{7}{*}{ R2 } & A & 19.15 & -0.92 & 19.18 & -1.05 & 4.70 & 49.4 & -0.15 \\
\hline & B & 19.19 & -0.90 & 19.21 & -1.03 & 6.53 & 134.7 & -0.78 \\
\hline & C & 19.22 & -0.87 & 19.25 & -1.02 & 10.78 & 136.9 & -0.46 \\
\hline & D & 19.26 & -0.86 & 19.29 & -1.01 & 12.51 & 151.2 & -0.25 \\
\hline & $E$ & 19.30 & -0.85 & 19.33 & -1.00 & 6.55 & 138.5 & -0.85 \\
\hline & $\mathrm{F}$ & 19.35 & -0.87 & 19.37 & -0.99 & 6.35 & 90.3 & -0.09 \\
\hline & G & 19.39 & -0.88 & 19.41 & -0.99 & 5.16 & 167.5 & 0.10 \\
\hline \multirow[t]{11}{*}{ R3 } & A & 15.05 & -1.20 & 15.09 & -1.32 & 9.60 & 75.0 & -0.08 \\
\hline & B & 15.09 & -1.18 & 15.12 & -1.31 & 7.07 & 88.5 & -1.00 \\
\hline & C & 15.14 & -1.18 & 15.17 & -1.30 & 5.38 & 77.6 & -0.48 \\
\hline & D & 15.17 & -1.15 & 15.20 & -1.29 & 5.28 & 81.4 & -0.70 \\
\hline & $\mathrm{E}$ & 15.21 & -1.15 & 15.24 & -1.28 & 4.71 & 95.7 & -0.14 \\
\hline & $\mathrm{F}$ & 15.25 & -1.14 & 15.29 & -1.29 & 5.22 & 139.8 & -0.81 \\
\hline & 1 & 15.39 & -1.10 & 15.42 & -1.24 & 8.69 & 85.9 & -0.03 \\
\hline & $\mathrm{J}$ & 15.44 & -1.08 & 15.47 & -1.24 & 9.88 & 102.6 & -0.06 \\
\hline & $\mathrm{K}$ & 15.49 & -1.07 & 15.51 & -1.21 & 5.23 & 108.7 & -0.55 \\
\hline & $\mathrm{L}$ & $15.53^{\circ}$ & -1.05 & 15.56 & -1.20 & 11.07 & 174.8 & 0.37 \\
\hline & M & 15.57 & -1.06 & 15.56 & -1.20 & 5.99 & 227.1 & 0.20 \\
\hline \multirow[t]{9}{*}{ R4 } & A & 14.42 & -1.71 & 14.45 & -1.86 & 7.77 & 177.6 & 0.09 \\
\hline & B & 14.47 & -1.70 & 14.50 & -1.86 & 5.97 & 194.3 & 0.00 \\
\hline & C & 14.52 & -1.68 & 14.55 & -1.86 & 9.32 & 168.3 & 0.17 \\
\hline & D & 14.57 & -1.65 & 14.61 & -1.84 & 8.29 & 123.1 & 0.17 \\
\hline & $E$ & 14.63 & -1.63 & 14.66 & -1.82 & 5.36 & 100.6 & 0.49 \\
\hline & $\mathrm{F}$ & 14.68 & -1.61 & 14.71 & -1.78 & 6.59 & 62.3 & 0.26 \\
\hline & G & 14.73 & -1.60 & 14.76 & -1.76 & 8.78 & 56.2 & 0.08 \\
\hline & $\mathrm{H}$ & 14.78 & -1.60 & 14.80 & -1.74 & 7.15 & 57.3 & 0.09 \\
\hline & 1 & 14.83 & -1.58 & 14.85 & -1.75 & 7.01 & 101.8 & 0.21 \\
\hline
\end{tabular}




\begin{tabular}{|c|c|c|c|c|c|c|c|c|}
\hline & $\mathrm{J}$ & 14.88 & -1.56 & 14.91 & -1.74 & 7.70 & 128.8 & 0.01 \\
\hline \multirow[t]{7}{*}{ R5 } & $A$ & 14.12 & -2.52 & 14.15 & -2.69 & 7.69 & 129.9 & -0.73 \\
\hline & $B$ & 14.17 & -2.50 & 14.20 & -2.67 & 6.52 & 187.4 & 0.13 \\
\hline & C & 14.23 & -2.48 & 14.26 & -2.66 & 7.79 & 244.3 & 0.25 \\
\hline & $D$ & 14.28 & -2.47 & 14.31 & -2.65 & 10.80 & 79.1 & -0.42 \\
\hline & $E$ & 14.33 & -2.45 & 14.36 & -2.64 & 12.00 & 94.0 & 0.38 \\
\hline & $\mathrm{F}$ & 14.38 & -2.44 & 14.41 & -2.61 & 12.31 & 101.6 & -0.16 \\
\hline & $G$ & 14.41 & -2.43 & 14.45 & -2.61 & 11.88 & 127.0 & -0.17 \\
\hline \multirow[t]{11}{*}{ R6 } & $A$ & 14.09 & -2.38 & 14.11 & -2.53 & 8.82 & 99.9 & -0.15 \\
\hline & $B$ & 14.13 & -2.37 & 14.16 & -2.53 & 10.50 & 120.8 & -0.15 \\
\hline & C & 14.18 & -2.36 & 14.20 & -2.51 & 8.71 & 154.9 & 0.33 \\
\hline & $D$ & 14.23 & -2.35 & 14.25 & -2.50 & 8.33 & 99.8 & 0.02 \\
\hline & $E$ & 14.28 & -2.36 & 14.29 & -2.49 & 8.28 & 69.1 & -0.30 \\
\hline & $\mathrm{F}$ & 14.32 & -2.36 & 14.34 & -2.50 & 5.84 & 88.8 & -0.09 \\
\hline & G & 14.36 & -2.35 & 14.37 & -2.47 & 7.80 & 34.9 & 0.08 \\
\hline & $\mathrm{H}$ & 14.39 & -2.33 & 14.41 & -2.47 & 7.80 & 61.4 & -0.34 \\
\hline & I & 14.49 & -2.31 & 14.50 & -2.46 & 11.69 & 110.1 & -0.21 \\
\hline & $J$ & 14.52 & -2.28 & 14.55 & -2.45 & 9.45 & 86.9 & -0.30 \\
\hline & $\mathrm{K}$ & 14.56 & -2.27 & 14.59 & -2.43 & 8.98 & 40.8 & -0.54 \\
\hline \multirow[t]{10}{*}{ R7 } & A & 15.56 & -1.23 & 15.59 & -1.37 & 8.89 & 111.8 & -0.07 \\
\hline & B & 15.59 & -1.21 & 15.63 & -1.36 & 10.70 & 93.7 & -0.07 \\
\hline & C & 15.63 & -1.19 & 15.66 & -1.34 & 8.86 & 95.4 & -0.28 \\
\hline & D & 15.67 & -1.18 & 15.70 & -1.33 & 7.68 & 136.7 & 0.02 \\
\hline & $E$ & 15.70 & -1.17 & 15.74 & -1.31 & 10.10 & 121.1 & 0.02 \\
\hline & $F$ & 15.74 & -1.15 & 15.78 & -1.30 & 9.94 & 105.9 & -0.17 \\
\hline & $G$ & 15.81 & -1.14 & 15.84 & -1.26 & 8.11 & 104.0 & -0.27 \\
\hline & $\mathrm{H}$ & 15.77 & -1.14 & 15.81 & -1.28 & 9.89 & 106.2 & 0.18 \\
\hline & I & 15.84 & -1.13 & 15.87 & -1.25 & 7.73 & 69.9 & -0.51 \\
\hline & j & 15.87 & -1.12 & 15.90 & -1.24 & 6.58 & 176.1 & 0.31 \\
\hline \multirow[t]{11}{*}{ R8 } & A & 17.57 & -1.56 & 17.61 & -1.70 & 7.02 & 83.3 & 0.06 \\
\hline & $B$ & 17.61 & -1.55 & 17.65 & -1.68 & 10.41 & 134.0 & -0.02 \\
\hline & C & 17.66 & -1.53 & 17.69 & -1.65 & 6.93 & 66.8 & -0.18 \\
\hline & $D$ & 17.70 & -1.50 & 17.73 & -1.63 & 7.56 & 40.1 & 0.22 \\
\hline & $E$ & 17.74 & -1.48 & 17.78 & -1.63 & 8.87 & 71.6 & 0.08 \\
\hline & $\mathrm{F}$ & 17.79 & -1.46 & 17.82 & -1.61 & 8.24 & 100.1 & 0.24 \\
\hline & G & 17.82 & -1.45 & 17.87 & -1.59 & 5.81 & 52.1 & 0.33 \\
\hline & $\mathrm{H}$ & 17.87 & -1.43 & 17.90 & -1.57 & 6.46 & 71.0 & 0.32 \\
\hline & $\mathrm{J}$ & 17.96 & -1.40 & 18.00 & -1.55 & 8.36 & 89.5 & -0.13 \\
\hline & $\mathrm{K}$ & 18.01 & -1.39 & 18.04 & -1.53 & 9.58 & 140.3 & 0.32 \\
\hline & $\mathrm{L}$ & 18.06 & -1.39 & 18.09 & -1.52 & 10.04 & 106.1 & -0.23 \\
\hline \multirow[t]{8}{*}{ R9 } & $A$ & 17.70 & -1.60 & 17.73 & -1.70 & 6.51 & 47.2 & -0.05 \\
\hline & $B$ & 17.74 & -1.59 & 17.77 & -1.69 & 7.12 & 57.5 & 0.21 \\
\hline & C & 17.79 & -1.57 & 17.81 & -1.68 & 8.88 & 97.5 & 0.46 \\
\hline & D & 17.83 & -1.56 & 17.86 & -1.67 & 8.24 & 60.3 & 0.58 \\
\hline & $E$ & 17.87 & -1.54 & 17.90 & -1.66 & 8.77 & 66.5 & 0.34 \\
\hline & $\mathrm{F}$ & 17.91 & -1.53 & 17.94 & -1.64 & 9.38 & 93.8 & 0.41 \\
\hline & $G$ & 17.95 & -1.51 & 17.99 & -1.64 & 8.29 & 71.5 & 0.50 \\
\hline & $\mathrm{H}$ & 18.00 & -1.50 & 18.03 & -1.63 & 10.16 & 63.6 & -0.06 \\
\hline
\end{tabular}




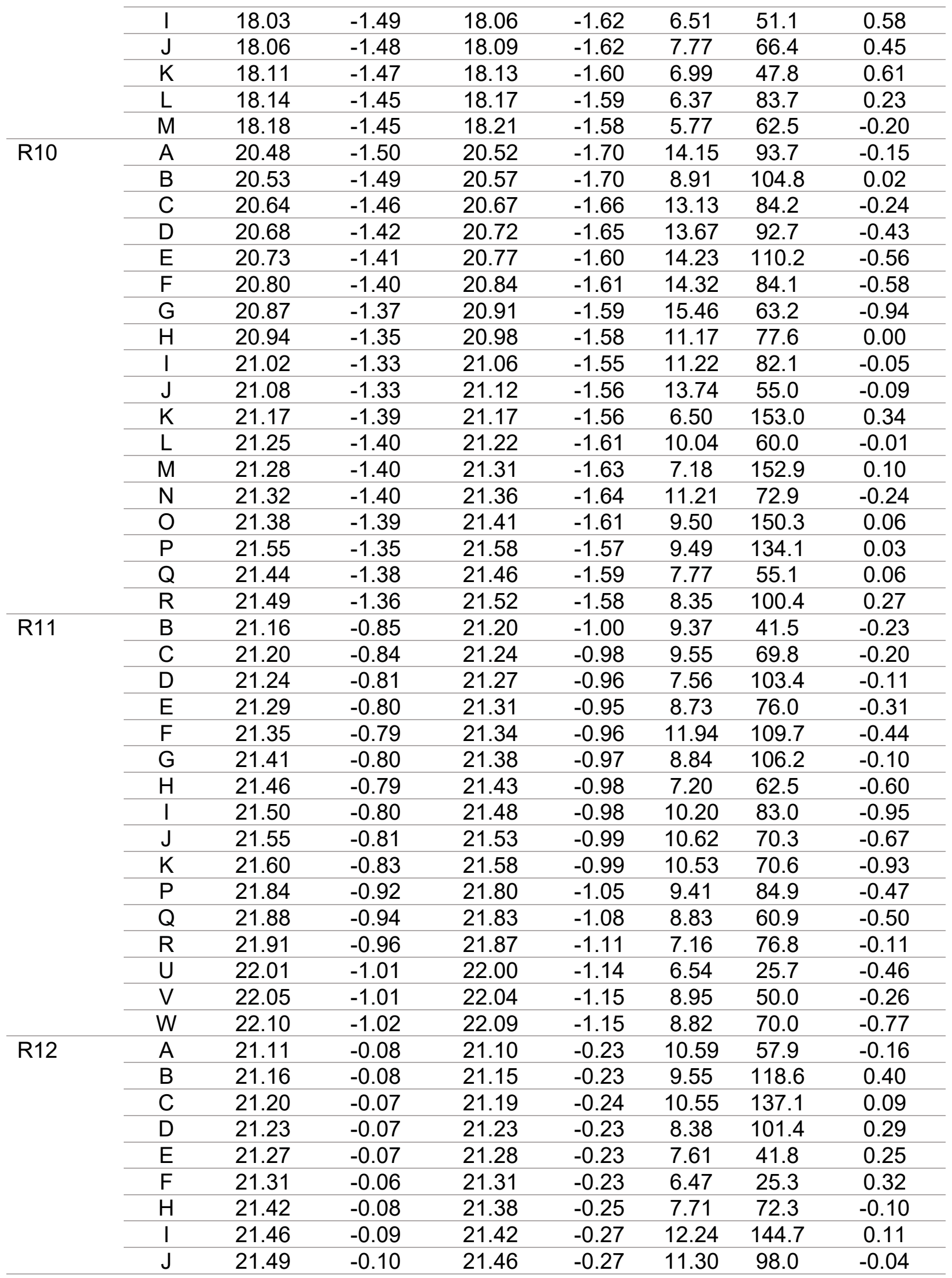




\begin{tabular}{|c|c|c|c|c|c|c|c|c|}
\hline \multirow[t]{9}{*}{ R13 } & $B$ & 22.60 & -0.99 & 22.63 & -1.16 & 9.45 & 156.5 & -0.66 \\
\hline & C & 22.64 & -0.98 & 22.68 & -1.16 & 10.19 & 101.2 & -0.12 \\
\hline & $D$ & 22.68 & -0.98 & 22.72 & -1.15 & 11.23 & 112.6 & -0.10 \\
\hline & $E$ & 22.73 & -0.97 & 22.76 & -1.15 & 10.16 & 125.0 & 0.02 \\
\hline & $F$ & 22.76 & -0.94 & 22.82 & -1.13 & 13.45 & 85.9 & -0.79 \\
\hline & $\mathrm{L}$ & 23.02 & -0.85 & 23.07 & -1.04 & 12.91 & 83.4 & 0.15 \\
\hline & $M$ & 23.06 & -0.84 & 23.10 & -1.02 & 7.79 & 111.5 & 0.01 \\
\hline & $\mathrm{N}$ & 23.10 & -0.83 & 23.15 & -1.01 & 7.58 & 91.0 & 0.24 \\
\hline & 0 & 23.15 & -0.82 & 23.19 & -0.99 & 8.38 & 64.0 & 0.06 \\
\hline \multirow[t]{12}{*}{ R14 } & $D$ & 22.68 & -1.73 & 22.67 & -1.89 & 14.77 & 121.0 & -0.30 \\
\hline & $E$ & 22.73 & -1.74 & 22.72 & -1.91 & 16.15 & 116.0 & -0.15 \\
\hline & $\mathrm{F}$ & 22.78 & -1.74 & 22.77 & -1.91 & 12.79 & 105.4 & -0.36 \\
\hline & $G$ & 22.83 & -1.74 & 22.82 & -1.92 & 12.00 & 107.9 & 0.10 \\
\hline & $\mathrm{H}$ & 22.88 & -1.75 & 22.87 & -1.94 & 11.30 & 97.3 & 0.36 \\
\hline & I & 22.93 & -1.75 & 22.92 & -1.94 & 10.70 & 169.1 & -0.19 \\
\hline & $\mathrm{J}$ & 22.99 & -1.76 & 22.97 & -1.94 & 12.82 & 188.1 & 0.07 \\
\hline & $\mathrm{K}$ & 23.04 & -1.76 & 23.02 & -1.94 & 14.89 & 225.8 & 0.08 \\
\hline & $\mathrm{L}$ & 23.09 & -1.76 & 23.08 & -1.95 & 14.73 & 180.0 & -1.21 \\
\hline & $M$ & 23.15 & -1.76 & 23.14 & -1.96 & 14.04 & 159.1 & -0.08 \\
\hline & $\mathrm{N}$ & 23.20 & -1.76 & 23.20 & -1.97 & 16.17 & 114.9 & 0.39 \\
\hline & $\mathrm{T}$ & 23.49 & -1.70 & 23.52 & -1.89 & 11.77 & 93.0 & -0.20 \\
\hline \multirow[t]{9}{*}{ R15 } & $A$ & 22.88 & -2.10 & 22.85 & -2.30 & 10.63 & 99.2 & 0.23 \\
\hline & $B$ & 22.93 & -2.10 & 22.91 & -2.31 & 9.52 & 155.5 & -0.01 \\
\hline & C & 22.99 & -2.10 & 22.97 & -2.32 & 16.07 & 178.2 & 0.04 \\
\hline & $\mathrm{D}$ & 23.03 & -2.09 & 23.03 & -2.32 & 15.39 & 170.0 & 0.17 \\
\hline & $E$ & 23.08 & -2.09 & 23.09 & -2.31 & 11.17 & 151.8 & 0.09 \\
\hline & $F$ & 23.13 & -2.08 & 23.15 & -2.30 & 11.72 & 111.8 & 0.00 \\
\hline & $G$ & 23.17 & -2.07 & 23.20 & -2.29 & 12.00 & 101.7 & -0.52 \\
\hline & $\mathrm{H}$ & 23.23 & -2.07 & 23.25 & -2.29 & 13.09 & 104.1 & -0.27 \\
\hline & I & 23.28 & -2.06 & 23.31 & -2.28 & 13.18 & 123.6 & -0.23 \\
\hline \multirow[t]{18}{*}{ R16 } & $A$ & 13.70 & -1.81 & 13.73 & -1.93 & 8.31 & 23.7 & -0.12 \\
\hline & B & 13.73 & -1.80 & 13.76 & -1.92 & 5.22 & 10.9 & 0.24 \\
\hline & C & 13.77 & -1.79 & 13.79 & -1.91 & 7.17 & 50.7 & 0.08 \\
\hline & $D$ & 13.80 & -1.79 & 13.82 & -1.91 & 7.16 & 68.1 & -0.19 \\
\hline & $E$ & 13.83 & -1.78 & 13.85 & -1.90 & 6.47 & 95.6 & -0.02 \\
\hline & $F$ & 13.85 & -1.77 & 13.88 & -1.89 & 8.32 & 87.6 & 0.21 \\
\hline & $G$ & 13.88 & -1.76 & 13.91 & -1.88 & 8.20 & 118.3 & -0.02 \\
\hline & $\mathrm{H}$ & 13.91 & -1.75 & 13.94 & -1.87 & 8.64 & 59.2 & 0.04 \\
\hline & 1 & 13.94 & -1.75 & 13.96 & -1.85 & 9.45 & 41.6 & -0.75 \\
\hline & $\mathrm{J}$ & 13.97 & -1.73 & 13.99 & -1.85 & 7.03 & 33.1 & 0.02 \\
\hline & $\mathrm{K}$ & 14.00 & -1.73 & 14.02 & -1.84 & 7.08 & 43.2 & 0.05 \\
\hline & $\mathrm{L}$ & 14.03 & -1.72 & 14.05 & -1.83 & 6.47 & 58.5 & -0.27 \\
\hline & $M$ & 14.06 & -1.71 & 14.08 & -1.82 & 6.33 & 42.0 & 0.09 \\
\hline & $\mathrm{N}$ & 14.09 & -1.70 & 14.11 & -1.81 & 7.20 & 19.8 & -0.20 \\
\hline & 0 & 14.12 & -1.69 & 14.14 & -1.80 & 5.39 & 22.7 & 0.18 \\
\hline & $\mathrm{P}$ & 14.14 & -1.68 & 14.16 & -1.79 & 6.00 & 25.8 & -0.12 \\
\hline & $\mathrm{T}$ & 14.26 & -1.65 & 14.27 & -1.76 & 7.07 & 22.2 & -0.19 \\
\hline & $A$ & 13.85 & -1.39 & 13.88 & -1.50 & 7.56 & 71.7 & -0.54 \\
\hline
\end{tabular}




\begin{tabular}{|c|c|c|c|c|c|c|c|c|}
\hline & B & 13.88 & -1.37 & 13.90 & -1.49 & 5.99 & 87.9 & -0.27 \\
\hline & C & 13.90 & -1.36 & 13.93 & -1.49 & 6.54 & 96.5 & 0.03 \\
\hline & $D$ & 13.93 & -1.34 & 13.96 & -1.49 & 6.51 & 68.4 & -0.11 \\
\hline & $E$ & 13.95 & -1.33 & 13.98 & -1.47 & 5.83 & 51.1 & 0.06 \\
\hline & $\mathrm{F}$ & 13.98 & -1.32 & 14.01 & -1.47 & 6.38 & 46.5 & -0.10 \\
\hline & $G$ & 14.01 & -1.31 & 14.04 & -1.46 & 9.43 & 87.5 & -0.52 \\
\hline & $\mathrm{H}$ & 14.04 & -1.31 & 14.07 & -1.46 & 9.46 & 103.1 & -0.26 \\
\hline & 1 & 14.08 & -1.30 & 14.10 & -1.44 & 9.89 & 77.1 & -0.67 \\
\hline & $\mathrm{J}$ & 14.11 & -1.30 & 14.14 & -1.44 & 9.43 & 76.7 & -0.72 \\
\hline & $\mathrm{K}$ & 14.14 & -1.30 & 14.17 & -1.43 & 10.76 & 58.6 & -0.05 \\
\hline & $\mathrm{L}$ & 14.18 & -1.29 & 14.20 & -1.41 & 10.01 & 67.5 & -0.08 \\
\hline R18 & B & 14.04 & -2.66 & 14.06 & -2.76 & 7.14 & 50.8 & -0.01 \\
\hline & C & 14.06 & -2.66 & 14.09 & -2.75 & 5.21 & 56.8 & -0.44 \\
\hline & $D$ & 14.09 & -2.65 & 14.11 & -2.75 & 8.19 & 236.4 & 0.35 \\
\hline & $E$ & 14.12 & -2.64 & 14.14 & -2.74 & 6.93 & 161.0 & -0.27 \\
\hline & $\bar{G}$ & 14.18 & -2.63 & 14.19 & -2.74 & 6.52 & 50.1 & 0.01 \\
\hline & $\mathrm{H}$ & 14.21 & -2.62 & 14.21 & -2.73 & 8.75 & 55.3 & -0.02 \\
\hline & 1 & 14.24 & -2.62 & 14.24 & -2.73 & 7.19 & 60.8 & -0.09 \\
\hline & $\mathrm{J}$ & 14.26 & -2.62 & 14.27 & -2.73 & 7.51 & 41.4 & -0.52 \\
\hline & $\mathrm{K}$ & 14.28 & -2.61 & 14.29 & -2.72 & 7.72 & 42.3 & -0.55 \\
\hline & $\mathrm{L}$ & 14.31 & -2.61 & 14.32 & -2.72 & 8.25 & 65.2 & -0.44 \\
\hline & $\bar{M}$ & 14.34 & -2.61 & 14.35 & -2.72 & 5.86 & 147.6 & -0.19 \\
\hline & $\mathrm{N}$ & 14.38 & -2.60 & 14.38 & -2.71 & 4.12 & 239.8 & 0.26 \\
\hline & 0 & 14.41 & -2.60 & 14.41 & -2.71 & 7.03 & 134.4 & -0.16 \\
\hline & $P$ & 14.44 & -2.60 & 14.44 & -2.71 & 8.29 & 168.5 & -0.23 \\
\hline & $Q$ & 14.47 & -2.59 & 14.47 & -2.71 & 7.07 & 244.1 & -0.50 \\
\hline & $\mathrm{R}$ & 14.50 & -2.59 & 14.50 & -2.71 & 7.70 & 205.9 & -0.66 \\
\hline & $\mathrm{S}$ & 14.54 & -2.58 & 14.54 & -2.71 & 7.67 & 106.0 & -0.08 \\
\hline & $\mathrm{T}$ & 14.57 & -2.58 & 14.58 & -2.71 & 5.99 & 99.9 & -1.17 \\
\hline & $U$ & 14.60 & -2.58 & 14.61 & -2.71 & 7.71 & 136.9 & -0.32 \\
\hline & $\mathrm{V}$ & 14.63 & -2.57 & 14.64 & -2.71 & 7.15 & 105.6 & -0.11 \\
\hline & W & 14.66 & -2.57 & 14.67 & -2.70 & 6.97 & 78.5 & -0.06 \\
\hline & $X$ & 14.68 & -2.57 & 14.71 & -2.70 & 7.60 & 31.5 & 0.12 \\
\hline & $Y$ & 14.72 & -2.56 & 14.75 & -2.68 & 4.67 & 13.2 & 0.07 \\
\hline R19 & A & 13.26 & -3.82 & 13.27 & -3.95 & 7.71 & 94.3 & -1.20 \\
\hline & $B$ & 13.29 & -3.82 & 13.30 & -3.93 & 8.31 & 105.4 & -0.84 \\
\hline & C & 13.33 & -3.81 & 13.33 & -3.93 & 6.94 & 126.0 & -0.04 \\
\hline & $\mathrm{D}$ & 13.36 & -3.81 & 13.37 & -3.93 & 7.20 & 106.3 & -0.29 \\
\hline & $E$ & 13.39 & -3.81 & 13.40 & -3.92 & 8.16 & 71.2 & -0.10 \\
\hline & $\bar{F}$ & 13.43 & -3.81 & 13.43 & -3.91 & 6.95 & 63.5 & -0.65 \\
\hline R20 & A & 18.12 & -0.87 & 18.12 & -0.99 & 5.83 & 164.0 & -0.15 \\
\hline & $B$ & 18.15 & -0.86 & 18.15 & -0.99 & 6.97 & 220.0 & 0.15 \\
\hline & C & 18.17 & -0.85 & 18.18 & -0.99 & 7.54 & 193.9 & 0.39 \\
\hline & $D$ & 18.19 & -0.83 & 18.21 & -0.97 & 8.36 & 101.2 & -0.45 \\
\hline & $E$ & 18.22 & -0.83 & 18.24 & -0.96 & 7.11 & 132.3 & -0.39 \\
\hline & $\mathrm{F}$ & 18.26 & -0.82 & 18.27 & -0.95 & 7.58 & 138.6 & 0.19 \\
\hline & $G$ & 18.29 & -0.82 & 18.29 & -0.95 & 8.10 & 171.1 & 0.45 \\
\hline & $\mathrm{H}$ & 18.33 & -0.83 & 18.32 & -0.95 & 6.44 & 78.2 & 0.24 \\
\hline
\end{tabular}




\begin{tabular}{|c|c|c|c|c|c|c|c|c|}
\hline & 1 & 18.36 & -0.84 & 18.34 & -0.95 & 7.05 & 44.8 & 0.01 \\
\hline \multirow{19}{*}{ R21 } & $A$ & 16.19 & 1.15 & 16.23 & 1.02 & 11.90 & 90.7 & -0.21 \\
\hline & $B$ & 16.24 & 1.16 & 16.28 & 1.04 & 12.81 & 103.3 & -0.19 \\
\hline & C & 16.29 & 1.18 & 16.34 & 1.03 & 9.27 & 88.0 & 0.22 \\
\hline & $D$ & 16.33 & 1.19 & 16.37 & 1.05 & 10.61 & 80.3 & -0.55 \\
\hline & $E$ & 16.36 & 1.21 & 16.40 & 1.07 & 10.07 & 54.6 & 0.06 \\
\hline & $\mathrm{F}$ & 16.40 & 1.23 & 16.44 & 1.09 & 9.93 & 44.9 & -0.47 \\
\hline & $G$ & 16.44 & 1.24 & 16.48 & 1.11 & 9.78 & 62.1 & -0.53 \\
\hline & $\mathrm{H}$ & 16.48 & 1.25 & 16.52 & 1.13 & 9.20 & 89.6 & -0.44 \\
\hline & 1 & 16.51 & 1.27 & 16.55 & 1.14 & 9.37 & 71.8 & -0.12 \\
\hline & $J$ & 16.54 & 1.29 & 16.58 & 1.17 & 10.17 & 47.8 & -0.09 \\
\hline & $\mathrm{K}$ & 16.57 & 1.31 & 16.61 & 1.19 & 7.50 & 32.1 & -0.25 \\
\hline & $\mathrm{L}$ & 16.61 & 1.33 & 16.65 & 1.20 & 7.60 & 85.9 & 0.09 \\
\hline & $M$ & 16.64 & 1.35 & 16.69 & 1.21 & 7.55 & 109.7 & -0.13 \\
\hline & $\mathrm{N}$ & 16.67 & 1.38 & 16.71 & 1.22 & 7.54 & 103.1 & 0.02 \\
\hline & 0 & 16.71 & 1.38 & 16.74 & 1.25 & 7.08 & 93.3 & -0.02 \\
\hline & $P$ & 16.75 & 1.39 & 16.78 & 1.25 & 8.37 & 120.8 & -0.20 \\
\hline & $Q$ & 16.80 & 1.39 & 16.82 & 1.26 & 8.71 & 142.0 & 0.12 \\
\hline & $\mathrm{R}$ & 16.84 & 1.41 & 16.87 & 1.27 & 7.60 & 158.0 & 0.78 \\
\hline & $S$ & 16.88 & 1.41 & 16.91 & 1.28 & 8.13 & 156.5 & 0.57 \\
\hline \multirow[t]{11}{*}{ R22 } & $A$ & 18.04 & 0.74 & 18.05 & 0.62 & 5.73 & 7.0 & -0.03 \\
\hline & $B$ & 18.08 & 0.75 & 18.08 & 0.62 & 6.33 & 46.5 & -0.06 \\
\hline & C & 18.11 & 0.75 & 18.11 & 0.62 & 7.11 & 13.9 & -0.22 \\
\hline & $D$ & 18.15 & 0.76 & 18.14 & 0.62 & 7.03 & 38.4 & 0.21 \\
\hline & $E$ & 18.19 & 0.76 & 18.18 & 0.62 & 7.18 & 33.4 & 0.02 \\
\hline & $\mathrm{F}$ & 18.31 & 0.76 & 18.29 & 0.61 & 12.33 & 58.1 & -0.02 \\
\hline & G & 18.34 & 0.76 & 18.33 & 0.61 & 12.92 & 77.4 & -0.17 \\
\hline & $\mathrm{H}$ & 18.37 & 0.76 & 18.36 & 0.61 & 13.37 & 74.0 & -0.24 \\
\hline & 1 & 18.41 & 0.75 & 18.39 & 0.62 & 10.61 & 54.8 & -0.12 \\
\hline & $J$ & 18.44 & 0.74 & 18.42 & 0.61 & 9.55 & 44.2 & -0.37 \\
\hline & K & 18.48 & 0.73 & 18.46 & 0.60 & 5.40 & 33.8 & -0.30 \\
\hline \multirow[t]{5}{*}{ R23 } & $A$ & 18.88 & 1.40 & 18.92 & 1.31 & 9.19 & 19.6 & -0.21 \\
\hline & $B$ & 18.92 & 1.42 & 18.97 & 1.32 & 5.93 & 36.6 & -0.10 \\
\hline & C & 18.97 & 1.45 & 19.01 & 1.33 & 7.16 & 124.8 & -0.15 \\
\hline & $D$ & 19.02 & 1.46 & 19.04 & 1.34 & 6.36 & 153.5 & 0.26 \\
\hline & $E$ & 19.07 & 1.47 & 19.07 & 1.35 & 5.81 & 116.7 & -0.13 \\
\hline \multirow[t]{12}{*}{ R24 } & $A$ & 13.53 & 0.49 & 13.58 & 0.36 & 8.29 & 31.4 & -0.56 \\
\hline & B & 13.57 & 0.51 & 13.62 & 0.38 & 8.22 & 41.0 & -0.44 \\
\hline & C & 13.62 & 0.53 & 13.66 & 0.39 & 10.10 & 41.2 & -0.04 \\
\hline & $D$ & 13.67 & 0.54 & 13.70 & 0.40 & 8.36 & 58.0 & 0.18 \\
\hline & $E$ & 13.71 & 0.54 & 13.74 & 0.41 & 8.38 & 58.6 & 0.19 \\
\hline & $F$ & 13.75 & 0.56 & 13.79 & 0.42 & 6.99 & 47.9 & 0.23 \\
\hline & $G$ & 13.79 & 0.57 & 13.82 & 0.43 & 6.96 & 79.7 & 0.06 \\
\hline & $\mathrm{H}$ & 13.82 & 0.58 & 13.86 & 0.45 & 7.64 & 56.4 & -0.50 \\
\hline & I & 13.86 & 0.59 & 13.90 & 0.46 & 7.64 & 34.9 & 0.06 \\
\hline & $\mathrm{J}$ & 13.89 & 0.60 & 13.94 & 0.46 & 8.11 & 50.9 & -0.21 \\
\hline & $\mathrm{K}$ & 13.93 & 0.61 & 13.97 & 0.48 & 8.24 & 33.1 & -0.36 \\
\hline & $\mathrm{L}$ & 13.96 & 0.63 & 14.00 & 0.50 & 6.50 & 28.2 & -0.02 \\
\hline
\end{tabular}




\begin{tabular}{|c|c|c|c|c|c|c|c|c|}
\hline & $M$ & 14.00 & 0.64 & 14.04 & 0.51 & 7.13 & 15.2 & 0.32 \\
\hline & $\mathrm{N}$ & 14.04 & 0.65 & 14.08 & 0.52 & 7.66 & 47.3 & -0.17 \\
\hline \multirow[t]{24}{*}{ R25 } & A & 18.58 & 3.60 & 18.58 & 3.41 & 18.58 & 74.1 & -0.33 \\
\hline & $B$ & 18.62 & 3.60 & 18.61 & 3.43 & 15.54 & 46.6 & -0.52 \\
\hline & C & 18.64 & 3.60 & 18.67 & 3.45 & 15.33 & 44.1 & -0.67 \\
\hline & $\mathrm{D}$ & 18.67 & 3.61 & 18.70 & 3.46 & 15.44 & 42.8 & -0.57 \\
\hline & $E$ & 18.71 & 3.63 & 18.74 & 3.48 & 9.50 & 55.0 & -0.49 \\
\hline & $\mathrm{F}$ & 18.75 & 3.64 & 18.75 & 3.48 & 6.60 & 90.3 & -1.25 \\
\hline & $G$ & 18.78 & 3.64 & 18.81 & 3.49 & 8.98 & 66.1 & -0.10 \\
\hline & $\mathrm{H}$ & 18.81 & 3.64 & 18.84 & 3.50 & 8.98 & 57.0 & 0.16 \\
\hline & I & 18.85 & 3.65 & 18.88 & 3.51 & 8.98 & 72.9 & -0.31 \\
\hline & $\mathrm{J}$ & 18.88 & 3.67 & 18.92 & 3.52 & 11.93 & 101.0 & -0.56 \\
\hline & $\mathrm{K}$ & 18.91 & 3.69 & 18.96 & 3.53 & 8.92 & 111.3 & -0.46 \\
\hline & $\mathrm{L}$ & 18.94 & 3.71 & 18.99 & 3.54 & 11.82 & 92.1 & -0.35 \\
\hline & $M$ & 18.98 & 3.72 & 19.03 & 3.56 & 10.65 & 74.2 & -0.64 \\
\hline & $\mathrm{N}$ & 19.02 & 3.73 & 19.07 & 3.59 & 10.52 & 72.2 & -0.23 \\
\hline & 0 & 19.07 & 3.74 & 19.09 & 3.58 & 11.29 & 69.6 & -0.59 \\
\hline & $P$ & 19.10 & 3.75 & 19.13 & 3.59 & 11.74 & 95.2 & -1.03 \\
\hline & $Q$ & 19.14 & 3.76 & 19.16 & 3.60 & 12.52 & 143.1 & -0.14 \\
\hline & $\mathrm{R}$ & 19.18 & 3.77 & 19.19 & 3.60 & 9.58 & 179.5 & -0.50 \\
\hline & $S$ & 19.22 & 3.77 & 19.23 & 3.61 & 9.60 & 85.5 & -0.69 \\
\hline & $\mathrm{T}$ & 19.26 & 3.77 & 19.27 & 3.61 & 11.18 & 59.6 & -0.34 \\
\hline & $U$ & 19.30 & 3.77 & 19.31 & 3.61 & 10.18 & 59.3 & -0.37 \\
\hline & V & 19.34 & 3.77 & 19.35 & 3.62 & 7.72 & 32.4 & -0.06 \\
\hline & W & 19.38 & 3.77 & 19.39 & 3.62 & 5.32 & 24.2 & -0.05 \\
\hline & $Y$ & 19.44 & 3.79 & 19.50 & 3.66 & 7.73 & 57.1 & -0.48 \\
\hline \multirow[t]{17}{*}{ R26 } & B & 13.95 & 0.90 & 13.95 & 0.76 & 5.80 & 16.9 & 0.14 \\
\hline & C & 13.97 & 0.91 & 13.99 & 0.78 & 4.76 & 18.4 & -0.01 \\
\hline & $D$ & 14.01 & 0.92 & 14.03 & 0.78 & 5.90 & 22.3 & 0.20 \\
\hline & $E$ & 14.05 & 0.92 & 14.07 & 0.80 & 8.80 & 70.5 & 0.07 \\
\hline & $F$ & 14.10 & 0.93 & 14.12 & 0.81 & 10.07 & 64.9 & -0.02 \\
\hline & $G$ & 14.16 & 0.95 & 14.16 & 0.81 & 8.37 & 22.9 & -0.47 \\
\hline & $\mathrm{H}$ & 14.19 & 0.95 & 14.22 & 0.83 & 7.56 & 34.1 & 0.32 \\
\hline & I & 14.23 & 0.96 & 14.25 & 0.84 & 5.96 & 23.8 & 0.36 \\
\hline & $\mathrm{J}$ & 14.26 & 0.96 & 14.28 & 0.85 & 8.04 & 13.0 & -0.62 \\
\hline & $\mathrm{K}$ & 14.30 & 0.97 & 14.32 & 0.85 & 9.17 & 51.9 & -0.18 \\
\hline & $\mathrm{L}$ & 14.34 & 0.98 & 14.36 & 0.86 & 6.50 & 29.9 & 0.09 \\
\hline & $M$ & 14.37 & 0.98 & 14.39 & 0.86 & 7.61 & 37.4 & -0.07 \\
\hline & $\mathrm{N}$ & 14.41 & 0.99 & 14.43 & 0.87 & 9.75 & 48.4 & 0.07 \\
\hline & 0 & 14.44 & 1.00 & 14.46 & 0.87 & 10.77 & 52.2 & 0.60 \\
\hline & $P$ & 14.48 & 1.00 & 14.49 & 0.88 & 8.37 & 72.5 & 0.14 \\
\hline & $Q$ & 14.52 & 1.00 & 14.53 & 0.88 & 5.87 & 56.6 & -0.74 \\
\hline & $\mathrm{R}$ & 14.56 & 1.01 & 14.57 & 0.89 & 4.01 & 25.6 & 0.11 \\
\hline \multirow[t]{5}{*}{ R27 } & A & 17.89 & 0.85 & 17.89 & 0.69 & 6.50 & 59.6 & 0.03 \\
\hline & $B$ & 17.93 & 0.86 & 17.93 & 0.69 & 5.93 & 36.1 & -0.66 \\
\hline & C & 17.97 & 0.85 & 17.97 & 0.69 & 8.30 & 126.3 & -0.02 \\
\hline & $D$ & 18.01 & 0.85 & 18.01 & 0.69 & 10.05 & 76.0 & -0.42 \\
\hline & $E$ & 18.05 & 0.86 & 18.06 & 0.69 & 7.78 & 96.6 & -0.37 \\
\hline
\end{tabular}




\begin{tabular}{|c|c|c|c|c|c|c|c|c|}
\hline & $\mathrm{F}$ & 18.09 & 0.86 & 18.12 & 0.70 & 8.90 & 80.8 & -0.08 \\
\hline & $\mathrm{G}$ & 18.13 & 0.87 & 18.16 & 0.71 & 12.43 & 71.6 & -0.16 \\
\hline & $\mathrm{H}$ & 18.16 & 0.87 & 18.20 & 0.73 & 13.67 & 73.2 & -0.24 \\
\hline & I & 18.21 & 0.88 & 18.24 & 0.74 & 12.76 & 55.9 & -0.18 \\
\hline & $\mathrm{J}$ & 18.25 & 0.89 & 18.29 & 0.75 & 12.79 & 50.3 & -0.18 \\
\hline R28 & $A$ & 18.85 & 2.52 & 18.93 & 2.43 & 11.31 & 83.6 & -0.23 \\
\hline & $B$ & 18.89 & 2.55 & 18.97 & 2.45 & 7.78 & 53.8 & 0.15 \\
\hline & C & 18.93 & 2.58 & 18.99 & 2.46 & 7.54 & 62.6 & -0.22 \\
\hline & D & 18.96 & 2.59 & 19.01 & 2.47 & 7.75 & 78.1 & -0.46 \\
\hline & $E$ & 19.01 & 2.60 & 19.05 & 2.49 & 7.75 & 113.3 & -0.14 \\
\hline & $\mathrm{F}$ & 19.07 & 2.63 & 19.11 & 2.51 & 6.51 & 94.3 & 0.39 \\
\hline & $G$ & 19.10 & 2.65 & 19.15 & 2.53 & 7.73 & 119.2 & -0.04 \\
\hline & $\mathrm{H}$ & 19.13 & 2.67 & 19.18 & 2.55 & 6.91 & 90.7 & -0.18 \\
\hline & I & 19.19 & 2.68 & 19.20 & 2.55 & 8.40 & 56.6 & 0.08 \\
\hline R29 & A & 16.39 & -1.44 & 16.40 & -1.59 & 7.69 & 64.8 & 0.03 \\
\hline & $B$ & 16.43 & -1.43 & 16.44 & -1.59 & 8.88 & 69.6 & 0.02 \\
\hline & C & 16.47 & -1.43 & 16.48 & -1.58 & 8.37 & 79.1 & -0.22 \\
\hline & $\mathrm{D}$ & 16.51 & -1.43 & 16.51 & -1.58 & 5.29 & 84.1 & -0.94 \\
\hline & $E$ & 16.55 & -1.43 & 16.55 & -1.58 & 8.74 & 62.8 & -0.28 \\
\hline & $\mathrm{F}$ & 16.59 & -1.44 & 16.58 & -1.58 & 10.00 & 100.6 & -0.32 \\
\hline & G & 16.63 & -1.44 & 16.63 & -1.58 & 7.54 & 162.5 & -0.23 \\
\hline & $\mathrm{H}$ & 16.67 & -1.44 & 16.67 & -1.58 & 7.55 & 83.0 & -0.46 \\
\hline & I & 16.70 & -1.44 & 16.73 & -1.56 & 8.12 & 92.2 & -0.41 \\
\hline & $\mathrm{J}$ & 16.35 & -1.46 & 16.39 & -1.59 & 7.50 & 119.5 & -0.51 \\
\hline & $\mathrm{K}$ & 16.31 & -1.49 & 16.37 & -1.61 & 5.78 & 79.6 & -0.36 \\
\hline R30 & A & 19.18 & 0.32 & 19.20 & 0.14 & 12.47 & 116.6 & 0.80 \\
\hline & $B$ & 19.23 & 0.33 & 19.25 & 0.15 & 10.18 & 70.3 & -0.64 \\
\hline & C & 19.28 & 0.34 & 19.28 & 0.14 & 9.57 & 102.7 & -0.18 \\
\hline & $D$ & 19.33 & 0.33 & 19.31 & 0.13 & 12.26 & 109.6 & 0.07 \\
\hline & $E$ & 19.38 & 0.33 & 19.36 & 0.13 & 12.27 & 136.8 & 0.21 \\
\hline & $\mathrm{F}$ & 19.41 & 0.33 & 19.40 & 0.13 & 11.82 & 121.2 & 0.24 \\
\hline & $G$ & 19.43 & 0.34 & 19.48 & 0.15 & 8.78 & 92.5 & -0.02 \\
\hline & $\mathrm{H}$ & 19.47 & 0.35 & 19.52 & 0.17 & 11.82 & 71.1 & -0.38 \\
\hline & 1 & 19.51 & 0.37 & 19.57 & 0.18 & 10.61 & 71.6 & -0.31 \\
\hline & $\mathrm{J}$ & 19.56 & 0.38 & 19.61 & 0.20 & 12.28 & 69.5 & -0.09 \\
\hline & $\mathrm{K}$ & 19.61 & 0.39 & 19.65 & 0.21 & 11.83 & 70.4 & -0.20 \\
\hline & $\mathrm{L}$ & 19.67 & 0.43 & 19.74 & 0.28 & 11.35 & 80.4 & -0.12 \\
\hline & $M$ & 19.70 & 0.46 & 19.78 & 0.30 & 11.12 & 93.3 & -0.16 \\
\hline & $\mathrm{N}$ & 19.74 & 0.49 & 19.81 & 0.32 & 12.24 & 142.2 & -0.08 \\
\hline & 0 & 19.79 & 0.51 & 19.84 & 0.33 & 11.79 & 40.1 & 0.35 \\
\hline & $P$ & 19.84 & 0.52 & 19.88 & 0.34 & 11.28 & 46.4 & -0.20 \\
\hline & $Q$ & 19.89 & 0.53 & 19.92 & 0.35 & 11.86 & 52.9 & -0.05 \\
\hline & $\mathrm{R}$ & 19.94 & 0.54 & 19.95 & 0.35 & 11.27 & 58.2 & -0.18 \\
\hline R31 & A & 14.17 & 1.37 & 14.21 & 1.20 & 8.96 & 50.1 & -0.15 \\
\hline & $B$ & 14.31 & 1.39 & 14.31 & 1.25 & 8.81 & 98.3 & 0.22 \\
\hline & C & 14.36 & 1.40 & 14.36 & 1.24 & 9.32 & 82.4 & -0.02 \\
\hline & D & 14.41 & 1.40 & 14.40 & 1.23 & 7.72 & 79.3 & 0.11 \\
\hline & $E$ & 14.43 & 1.41 & 14.46 & 1.23 & 8.90 & 64.6 & 0.13 \\
\hline
\end{tabular}




\begin{tabular}{|c|c|c|c|c|c|c|c|c|}
\hline & $\mathrm{F}$ & 14.48 & 1.42 & 14.50 & 1.24 & 7.71 & 54.0 & -0.18 \\
\hline & G & 14.56 & 1.41 & 14.51 & 1.23 & 5.38 & 38.2 & -0.05 \\
\hline & $\mathrm{H}$ & 14.59 & 1.37 & 14.55 & 1.20 & 4.19 & 7.1 & -0.37 \\
\hline & 1 & 14.61 & 1.37 & 14.63 & 1.18 & 6.54 & 21.5 & -0.46 \\
\hline & $\mathrm{J}$ & 14.66 & 1.37 & 14.65 & 1.18 & 8.23 & 42.3 & -0.09 \\
\hline & $\mathrm{K}$ & 14.70 & 1.37 & 14.69 & 1.17 & 7.05 & 36.4 & 0.11 \\
\hline & $\mathrm{L}$ & 14.74 & 1.36 & 14.73 & 1.18 & 8.86 & 16.2 & 0.45 \\
\hline & $M$ & 14.78 & 1.35 & 14.80 & 1.19 & 8.14 & 11.6 & -0.60 \\
\hline & $\mathrm{N}$ & 14.81 & 1.36 & 14.84 & 1.19 & 8.82 & 59.5 & 0.18 \\
\hline & 0 & 14.85 & 1.36 & 14.88 & 1.19 & 10.13 & 78.5 & 0.16 \\
\hline & $P$ & 14.88 & 1.37 & 14.93 & 1.21 & 9.35 & 56.0 & -0.41 \\
\hline & $Q$ & 14.94 & 1.38 & 14.94 & 1.23 & 7.64 & 112.5 & -0.02 \\
\hline & $\mathrm{R}$ & 14.98 & 1.39 & 14.97 & 1.22 & 7.74 & 91.2 & 0.10 \\
\hline & $S$ & 15.01 & 1.39 & 15.01 & 1.22 & 7.63 & 48.6 & -0.30 \\
\hline & $\mathrm{T}$ & 15.05 & 1.38 & 15.05 & 1.22 & 9.28 & 48.5 & -0.09 \\
\hline & $U$ & 15.09 & 1.38 & 15.09 & 1.23 & 8.90 & 66.4 & -0.02 \\
\hline & $\mathrm{V}$ & 15.12 & 1.38 & 15.14 & 1.22 & 9.44 & 50.0 & -0.27 \\
\hline & W & 15.16 & 1.39 & 15.17 & 1.23 & 8.77 & 52.2 & -0.50 \\
\hline & $X$ & 15.19 & 1.39 & 15.22 & 1.23 & 9.50 & 59.1 & -0.65 \\
\hline & $Y$ & 15.22 & 1.39 & 15.26 & 1.22 & 8.81 & 61.6 & 0.12 \\
\hline & Z & 15.26 & 1.39 & 15.30 & 1.24 & 7.19 & 52.7 & -0.23 \\
\hline R32 & $D$ & 14.68 & 2.44 & 14.72 & 2.28 & 16.42 & 36.5 & -0.53 \\
\hline & $E$ & 14.73 & 2.45 & 14.79 & 2.30 & 14.59 & 30.9 & -0.37 \\
\hline & $\mathrm{F}$ & 14.77 & 2.47 & 14.83 & 2.31 & 12.45 & 39.6 & -0.46 \\
\hline & G & 14.82 & 2.48 & 14.84 & 2.31 & 11.30 & 28.6 & -0.31 \\
\hline & $\mathrm{H}$ & 14.86 & 2.48 & 14.88 & 2.31 & 11.10 & 58.9 & -0.32 \\
\hline & 1 & 14.90 & 2.48 & 14.90 & 2.31 & 10.76 & 61.3 & -0.30 \\
\hline & $\mathrm{J}$ & 14.93 & 2.49 & 14.94 & 2.31 & 10.56 & 39.1 & -0.02 \\
\hline & $\mathrm{K}$ & 14.95 & 2.50 & 14.99 & 2.31 & 12.92 & 41.4 & 0.01 \\
\hline & $\mathrm{L}$ & 14.98 & 2.51 & 15.03 & 2.33 & 13.58 & 36.3 & -0.16 \\
\hline & $M$ & 15.02 & 2.53 & 15.05 & 2.35 & 11.30 & 13.9 & -0.18 \\
\hline & 0 & 15.13 & 2.54 & 15.14 & 2.37 & 6.59 & 16.7 & -0.09 \\
\hline & $\mathrm{P}$ & 15.16 & 2.54 & 15.16 & 2.36 & 7.78 & 34.2 & -0.39 \\
\hline & $Q$ & 15.20 & 2.54 & 15.19 & 2.34 & 6.48 & 72.9 & -0.09 \\
\hline & $\mathrm{R}$ & 15.24 & 2.54 & 15.23 & 2.34 & 7.66 & 69.0 & 0.04 \\
\hline & $S$ & 15.28 & 2.53 & 15.26 & 2.33 & 9.35 & 79.0 & -0.17 \\
\hline & $T$ & 15.32 & 2.53 & 15.30 & 2.33 & 12.98 & 69.4 & 0.10 \\
\hline & U & 15.36 & 2.52 & 15.34 & 2.32 & 11.86 & 74.7 & 0.09 \\
\hline & $\mathrm{V}$ & 15.40 & 2.52 & 15.38 & 2.31 & 8.95 & 61.2 & -0.58 \\
\hline & W & 15.45 & 2.51 & 15.43 & 2.31 & 10.12 & 116.0 & -0.12 \\
\hline & $X$ & 15.49 & 2.51 & 15.47 & 2.30 & 11.26 & 80.3 & -0.12 \\
\hline R33 & $A$ & 13.23 & 2.77 & 13.28 & 2.59 & 13.45 & 34.1 & -0.34 \\
\hline & $B$ & 13.27 & 2.78 & 13.32 & 2.60 & 8.33 & 8.8 & -0.85 \\
\hline & C & 13.31 & 2.80 & 13.36 & 2.61 & 12.92 & 43.1 & -0.16 \\
\hline & $D$ & 13.35 & 2.81 & 13.40 & 2.63 & 12.25 & 71.5 & -0.27 \\
\hline & $E$ & 13.39 & 2.81 & 13.44 & 2.64 & 11.21 & 60.1 & -0.05 \\
\hline & $\mathrm{F}$ & 13.42 & 2.82 & 13.47 & 2.66 & 9.46 & 40.8 & -0.10 \\
\hline & G & 13.46 & 2.84 & 13.49 & 2.66 & 8.40 & 34.1 & -0.14 \\
\hline
\end{tabular}




\begin{tabular}{|c|c|c|c|c|c|c|c|c|}
\hline & $\mathrm{H}$ & 13.49 & 2.85 & 13.53 & 2.67 & 10.02 & 48.9 & -0.18 \\
\hline \multirow{14}{*}{ R34 } & $A$ & 11.58 & 0.60 & 11.53 & 0.39 & 11.70 & 70.2 & 0.10 \\
\hline & $B$ & 11.62 & 0.60 & 11.58 & 0.38 & 18.51 & 56.9 & -0.09 \\
\hline & C & 11.67 & 0.59 & 11.63 & 0.36 & 16.60 & 47.9 & 0.21 \\
\hline & $D$ & 11.69 & 0.59 & 11.71 & 0.37 & 15.55 & 57.1 & -0.48 \\
\hline & $E$ & 11.72 & 0.60 & 11.75 & 0.39 & 17.00 & 70.9 & -1.04 \\
\hline & $\mathrm{F}$ & 11.80 & 0.60 & 11.78 & 0.39 & 12.34 & 27.9 & -0.64 \\
\hline & $G$ & 11.82 & 0.60 & 11.86 & 0.39 & 16.49 & 87.9 & -0.51 \\
\hline & $\mathrm{H}$ & 11.86 & 0.61 & 11.91 & 0.40 & 18.47 & 154.7 & 0.49 \\
\hline & 1 & 11.90 & 0.61 & 11.94 & 0.40 & 10.67 & 86.2 & -0.66 \\
\hline & $\mathrm{J}$ & 11.94 & 0.62 & 11.99 & 0.41 & 14.80 & 34.8 & 0.00 \\
\hline & $\mathrm{K}$ & 11.98 & 0.62 & 12.03 & 0.41 & 14.93 & 62.5 & 0.22 \\
\hline & $\mathrm{L}$ & 12.02 & 0.63 & 12.07 & 0.42 & 9.49 & 54.6 & -0.23 \\
\hline & $M$ & 12.06 & 0.64 & 12.12 & 0.43 & 13.05 & 94.1 & 0.17 \\
\hline & $\mathrm{N}$ & 12.11 & 0.65 & 12.16 & 0.45 & 10.09 & 85.8 & -0.02 \\
\hline \multirow[t]{13}{*}{ R35 } & $A$ & 25.19 & 3.30 & 25.30 & 3.18 & 8.97 & 25.3 & 0.75 \\
\hline & $B$ & 25.22 & 3.32 & 25.33 & 3.20 & 8.82 & 63.5 & 0.35 \\
\hline & C & 25.30 & 3.35 & 25.33 & 3.19 & 8.29 & 44.9 & 0.18 \\
\hline & $D$ & 25.33 & 3.35 & 25.36 & 3.20 & 9.58 & 35.6 & 0.03 \\
\hline & $E$ & 25.37 & 3.35 & 25.38 & 3.19 & 4.11 & 17.4 & -0.55 \\
\hline & $\mathrm{F}$ & 25.43 & 3.35 & 25.48 & 3.23 & 10.98 & 116.4 & -0.97 \\
\hline & G & 25.47 & 3.37 & 25.51 & 3.24 & 10.79 & 169.3 & -0.41 \\
\hline & $\mathrm{H}$ & 25.51 & 3.38 & 25.53 & 3.24 & 9.33 & 125.6 & 0.25 \\
\hline & 1 & 25.56 & 3.38 & 25.56 & 3.24 & 12.41 & 140.5 & 0.39 \\
\hline & $J$ & 25.59 & 3.39 & 25.60 & 3.24 & 12.01 & 104.5 & -0.12 \\
\hline & $\mathrm{K}$ & 25.63 & 3.39 & 25.63 & 3.24 & 10.67 & 72.7 & -0.17 \\
\hline & $\mathrm{L}$ & 25.66 & 3.40 & 25.67 & 3.24 & 8.72 & 80.7 & 0.02 \\
\hline & $\mathrm{M}$ & 25.69 & 3.41 & 25.73 & 3.26 & 8.91 & 116.8 & 0.04 \\
\hline \multirow[t]{19}{*}{ R36 } & A & 20.52 & 0.12 & 20.51 & -0.05 & 8.77 & 121.9 & -0.34 \\
\hline & $B$ & 20.56 & 0.12 & 20.55 & -0.06 & 11.32 & 152.3 & -0.46 \\
\hline & C & 20.60 & 0.12 & 20.59 & -0.06 & 8.87 & 142.7 & -0.41 \\
\hline & $D$ & 20.64 & 0.12 & 20.63 & -0.06 & 10.20 & 124.3 & 0.16 \\
\hline & $E$ & 20.69 & 0.12 & 20.68 & -0.07 & 13.72 & 115.8 & -0.34 \\
\hline & $\mathrm{F}$ & 20.74 & 0.11 & 20.71 & -0.08 & 11.90 & 96.6 & -0.18 \\
\hline & $G$ & 20.78 & 0.10 & 20.75 & -0.10 & 10.05 & 88.4 & 0.23 \\
\hline & $\mathrm{H}$ & 20.82 & 0.09 & 20.79 & -0.11 & 10.67 & 101.2 & 0.10 \\
\hline & 1 & 20.84 & 0.11 & 20.86 & -0.10 & 12.58 & 107.8 & 0.09 \\
\hline & $\mathrm{J}$ & 20.88 & 0.11 & 20.90 & -0.09 & 8.76 & 95.6 & 0.03 \\
\hline & $\mathrm{K}$ & 20.94 & 0.14 & 20.93 & -0.07 & 11.12 & 187.5 & 0.07 \\
\hline & $\mathrm{L}$ & 20.99 & 0.13 & 20.95 & -0.08 & 8.87 & 153.0 & 0.01 \\
\hline & $\mathrm{M}$ & 21.02 & 0.13 & 20.99 & -0.09 & 9.99 & 169.2 & 0.13 \\
\hline & $\mathrm{N}$ & 21.05 & 0.14 & 21.08 & -0.07 & 10.67 & 139.0 & -0.10 \\
\hline & $\mathrm{O}$ & 21.08 & 0.14 & 21.11 & -0.06 & 13.09 & 100.9 & -0.29 \\
\hline & $\mathrm{P}$ & 21.12 & 0.15 & 21.15 & -0.05 & 10.15 & 128.7 & 0.08 \\
\hline & $Q$ & 21.17 & 0.15 & 21.19 & -0.05 & 9.43 & 95.3 & 0.27 \\
\hline & $\mathrm{R}$ & 21.22 & 0.15 & 21.22 & -0.05 & 14.88 & 79.4 & -0.12 \\
\hline & $S$ & 21.26 & 0.15 & 21.25 & -0.06 & 14.74 & 52.8 & -0.34 \\
\hline R37 & A & 13.19 & 2.62 & 13.31 & 2.37 & 14.28 & 83.9 & -0.31 \\
\hline
\end{tabular}




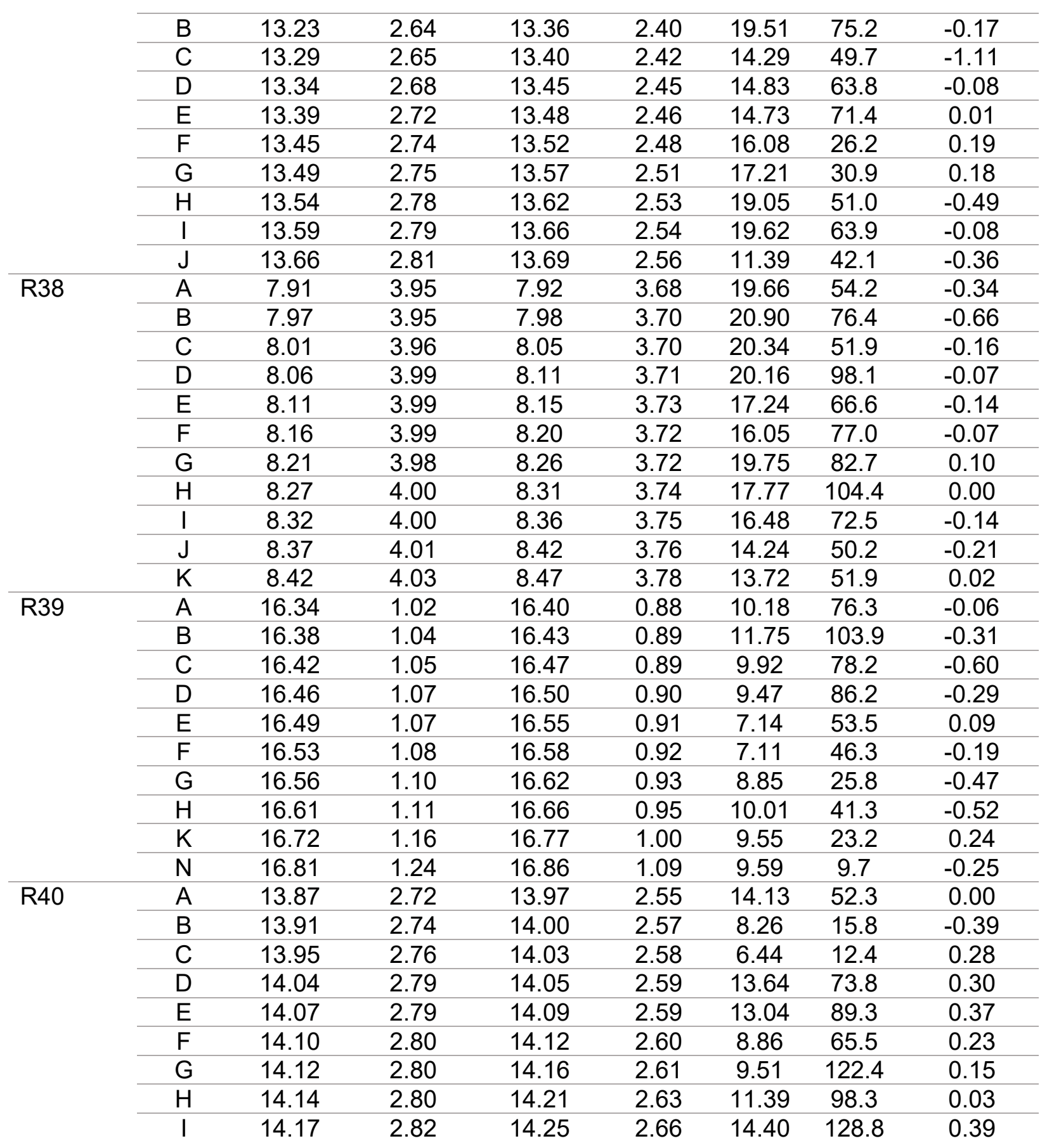



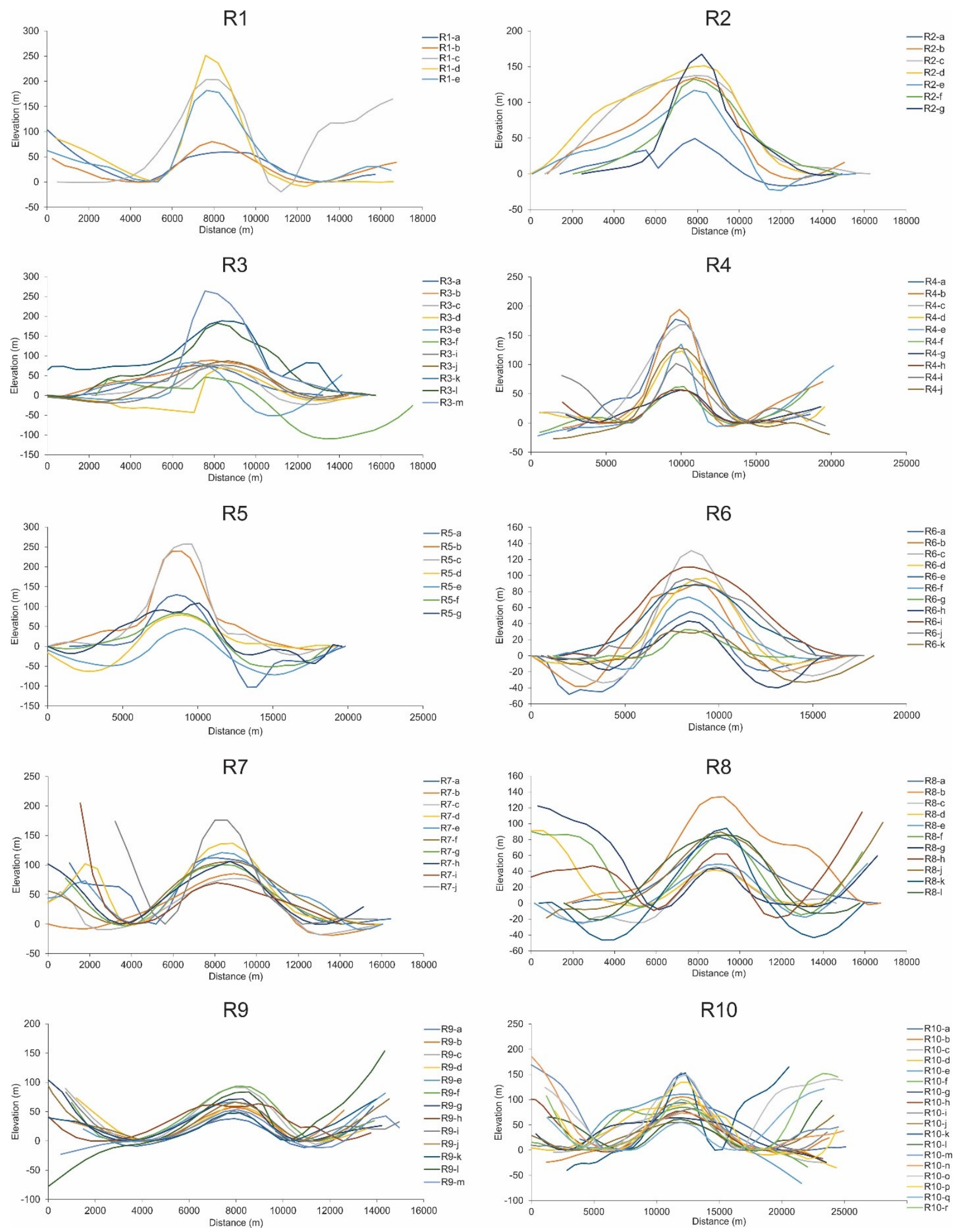

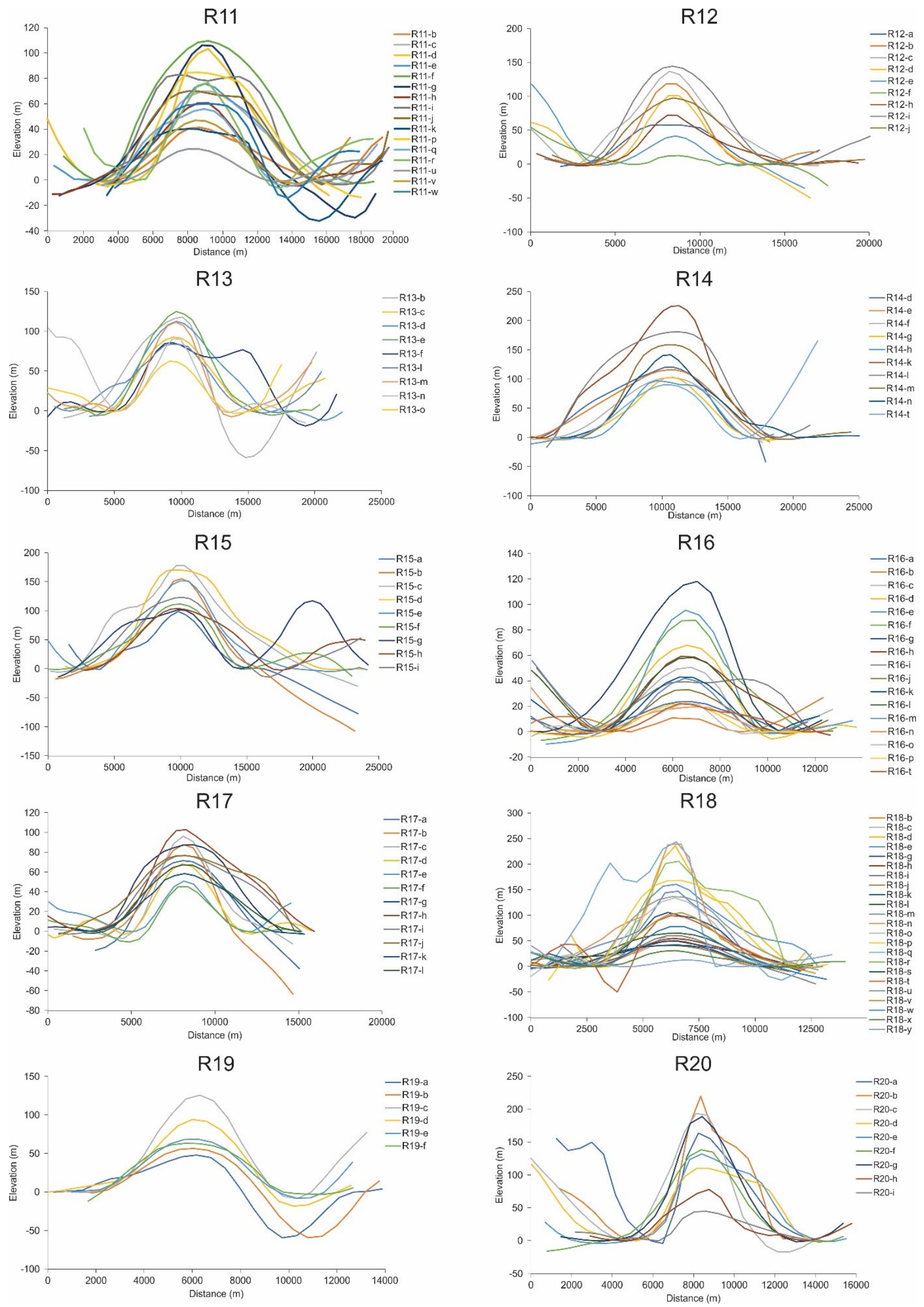

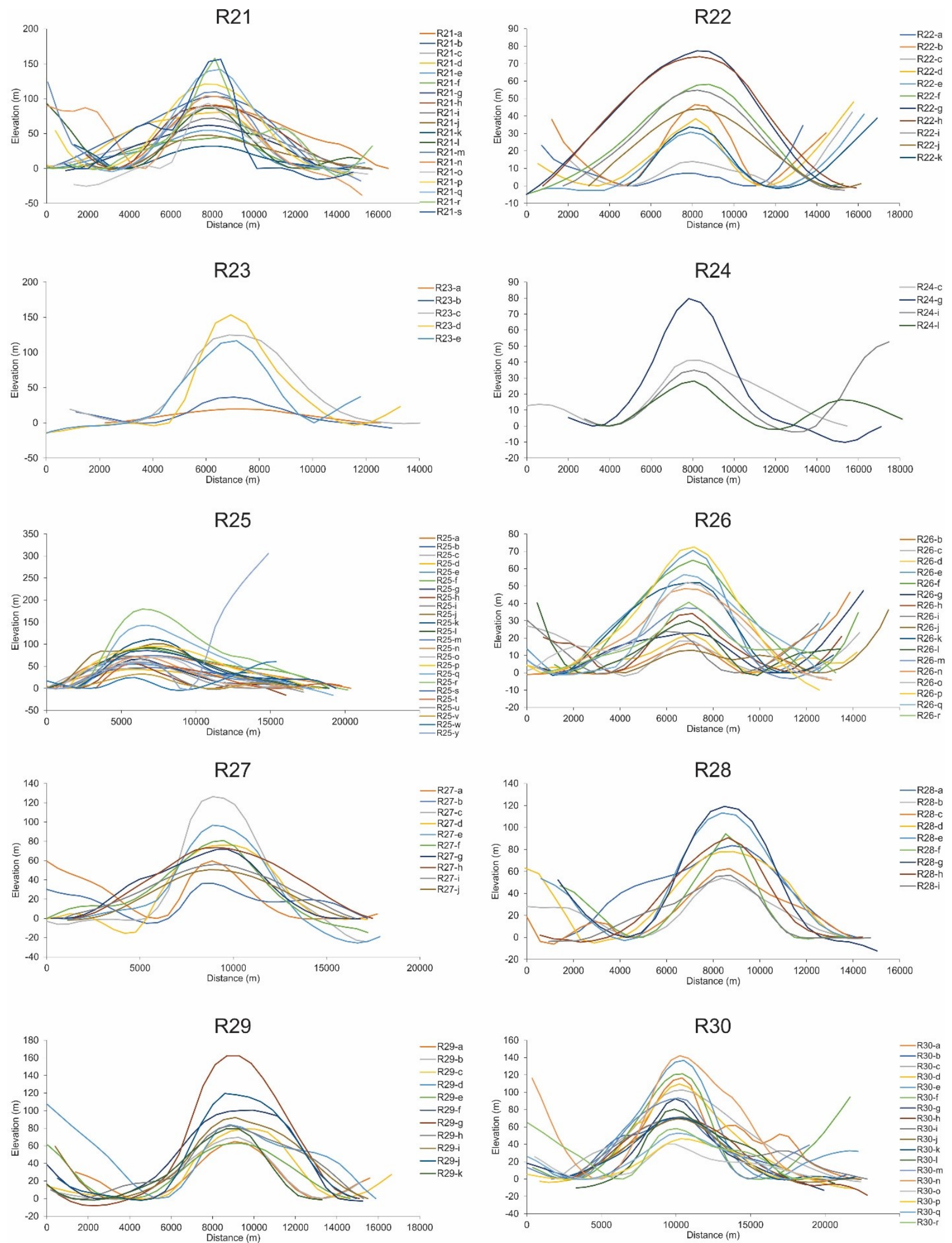


\section{APPENDIX C}

This appendix contains information about the elastic dislocation models in COULOMB 3.3 discussed in Chapter 5. Included in the tables below, divided into separate tables for planar and listric models, are the faulting parameters for each model. The following parameters were kept constant for all models and are not included in the table below: slip tapering (100 $\mathrm{m}$ in 5 increments from the edges of the fault plane), along-strike fault length (20 km), Young's modulus (80 GPa), Poisson's ratio (0.25), and coefficient of friction (0.8). For simplicity the amount of dip-slip has been fixed at $200 \mathrm{~m}$. Following the tables are plots of the vertical displacement of the models.

\section{Planar fault models}

\begin{tabular}{lcccc}
\hline Model & Dip & $\begin{array}{c}\text { Depth to upper } \\
\text { fault tip }(\mathrm{km})\end{array}$ & $\begin{array}{c}\text { Depth to lower } \\
\text { fault tip }(\mathrm{km})\end{array}$ & Amount of slip $(\mathrm{m})$ \\
\hline 1 & 45 & 0 & 5 & 200 \\
\hline 2 & 40 & 0 & 5 & 200 \\
\hline 3 & 35 & 0 & 5 & 200 \\
\hline 4 & 30 & 0 & 5 & 200 \\
\hline 5 & 25 & 0 & 5 & 200 \\
\hline 6 & 20 & 0 & 5 & 200 \\
\hline 7 & 15 & 0 & 5 & 200 \\
\hline 8 & 10 & 0 & 5 & 200 \\
\hline 9 & 45 & 0 & 10 & 200 \\
\hline 10 & 40 & 0 & 10 & 200 \\
\hline 11 & 35 & 0 & 10 & 200 \\
\hline 12 & 30 & 0 & 10 & 200 \\
\hline 13 & 25 & 0 & 10 & 200 \\
\hline 14 & 20 & 0 & 10 & 200 \\
\hline 15 & 15 & 0 & 10 & 200 \\
\hline 16 & 10 & 0 & 10 & 200 \\
\hline 17 & 45 & 0 & 15 & 200 \\
\hline 18 & 40 & 0 & 15 & 200 \\
\hline 19 & 35 & 0 & 15 & 200 \\
\hline 20 & 30 & 0 & 15 & 200 \\
\hline 21 & 25 & 0 & 15 & 200 \\
\hline 22 & 20 & 0 & 15 & 200 \\
\hline 23 & 15 & 0 & 15 & 200 \\
\hline 24 & 10 & 0 & 15 & 200 \\
\hline 25 & 45 & 0 & 20 & 200 \\
\hline 26 & 40 & 0 & 20 & \\
\hline & & 0 & & \\
\hline
\end{tabular}




\begin{tabular}{|c|c|c|c|c|}
\hline 27 & 35 & 0 & 20 & 200 \\
\hline 28 & 30 & 0 & 20 & 200 \\
\hline 29 & 25 & 0 & 20 & 200 \\
\hline 30 & 20 & 0 & 20 & 200 \\
\hline 31 & 15 & 0 & 20 & 200 \\
\hline 32 & 10 & 0 & 20 & 200 \\
\hline 33 & 45 & 0.5 & 5 & 200 \\
\hline 34 & 40 & 0.5 & 5 & 200 \\
\hline 35 & 35 & 0.5 & 5 & 200 \\
\hline 36 & 30 & 0.5 & 5 & 200 \\
\hline 37 & 25 & 0.5 & 5 & 200 \\
\hline 38 & 20 & 0.5 & 5 & 200 \\
\hline 39 & 15 & 0.5 & 5 & 200 \\
\hline 40 & 10 & 0.5 & 5 & 200 \\
\hline 41 & 45 & 0.5 & 10 & 200 \\
\hline 42 & 40 & 0.5 & 10 & 200 \\
\hline 43 & 35 & 0.5 & 10 & 200 \\
\hline 44 & 30 & 0.5 & 10 & 200 \\
\hline 45 & 25 & 0.5 & 10 & 200 \\
\hline 46 & 20 & 0.5 & 10 & 200 \\
\hline 47 & 15 & 0.5 & 10 & 200 \\
\hline 48 & 10 & 0.5 & 10 & 200 \\
\hline 49 & 45 & 0.5 & 15 & 200 \\
\hline 50 & 40 & 0.5 & 15 & 200 \\
\hline 51 & 35 & 0.5 & 15 & 200 \\
\hline 52 & 30 & 0.5 & 15 & 200 \\
\hline 53 & 25 & 0.5 & 15 & 200 \\
\hline 54 & 20 & 0.5 & 15 & 200 \\
\hline 55 & 15 & 0.5 & 15 & 200 \\
\hline 56 & 10 & 0.5 & 15 & 200 \\
\hline 57 & 45 & 0.5 & 20 & 200 \\
\hline 58 & 40 & 0.5 & 20 & 200 \\
\hline 59 & 35 & 0.5 & 20 & 200 \\
\hline 60 & 30 & 0.5 & 20 & 200 \\
\hline 61 & 25 & 0.5 & 20 & 200 \\
\hline 62 & 20 & 0.5 & 20 & 200 \\
\hline 63 & 15 & 0.5 & 20 & 200 \\
\hline 64 & 10 & 0.5 & 20 & 200 \\
\hline 65 & 45 & 0.75 & 5 & 200 \\
\hline 66 & 40 & 0.75 & 5 & 200 \\
\hline 67 & 35 & 0.75 & 5 & 200 \\
\hline 68 & 30 & 0.75 & 5 & 200 \\
\hline 69 & 25 & 0.75 & 5 & 200 \\
\hline 70 & 20 & 0.75 & 5 & 200 \\
\hline 71 & 15 & 0.75 & 5 & 200 \\
\hline 72 & 10 & 0.75 & 5 & 200 \\
\hline 73 & 45 & 0.75 & 10 & 200 \\
\hline 74 & 40 & 0.75 & 10 & 200 \\
\hline
\end{tabular}




\begin{tabular}{|c|c|c|c|c|}
\hline 75 & 35 & 0.75 & 10 & 200 \\
\hline 76 & 30 & 0.75 & 10 & 200 \\
\hline 77 & 25 & 0.75 & 10 & 200 \\
\hline 78 & 20 & 0.75 & 10 & 200 \\
\hline 79 & 15 & 0.75 & 10 & 200 \\
\hline 80 & 10 & 0.75 & 10 & 200 \\
\hline 81 & 45 & 0.75 & 15 & 200 \\
\hline 82 & 40 & 0.75 & 15 & 200 \\
\hline 83 & 35 & 0.75 & 15 & 200 \\
\hline 84 & 30 & 0.75 & 15 & 200 \\
\hline 85 & 25 & 0.75 & 15 & 200 \\
\hline 86 & 20 & 0.75 & 15 & 200 \\
\hline 87 & 15 & 0.75 & 15 & 200 \\
\hline 88 & 10 & 0.75 & 15 & 200 \\
\hline 89 & 45 & 0.75 & 20 & 200 \\
\hline 90 & 40 & 0.75 & 20 & 200 \\
\hline 91 & 35 & 0.75 & 20 & 200 \\
\hline 92 & 30 & 0.75 & 20 & 200 \\
\hline 93 & 25 & 0.75 & 20 & 200 \\
\hline 94 & 20 & 0.75 & 20 & 200 \\
\hline 95 & 15 & 0.75 & 20 & 200 \\
\hline 96 & 10 & 0.75 & 20 & 200 \\
\hline 97 & 45 & 1 & 5 & 200 \\
\hline 98 & 40 & 1 & 5 & 200 \\
\hline 99 & 35 & 1 & 5 & 200 \\
\hline 100 & 30 & 1 & 5 & 200 \\
\hline 101 & 25 & 1 & 5 & 200 \\
\hline 102 & 20 & 1 & 5 & 200 \\
\hline 103 & 15 & 1 & 5 & 200 \\
\hline 104 & 10 & 1 & 5 & 200 \\
\hline 105 & 45 & 1 & 10 & 200 \\
\hline 106 & 40 & 1 & 10 & 200 \\
\hline 107 & 35 & 1 & 10 & 200 \\
\hline 108 & 30 & 1 & 10 & 200 \\
\hline 109 & 25 & 1 & 10 & 200 \\
\hline 110 & 20 & 1 & 10 & 200 \\
\hline 111 & 15 & 1 & 10 & 200 \\
\hline 112 & 10 & 1 & 10 & 200 \\
\hline 113 & 45 & 1 & 15 & 200 \\
\hline 114 & 40 & 1 & 15 & 200 \\
\hline 115 & 35 & 1 & 15 & 200 \\
\hline 116 & 30 & 1 & 15 & 200 \\
\hline 117 & 25 & 1 & 15 & 200 \\
\hline 118 & 20 & 1 & 15 & 200 \\
\hline 119 & 15 & 1 & 15 & 200 \\
\hline 120 & 10 & 1 & 15 & 200 \\
\hline 121 & 45 & 1 & 20 & 200 \\
\hline 122 & 40 & 1 & 20 & 200 \\
\hline
\end{tabular}




\begin{tabular}{|c|c|c|c|c|}
\hline 123 & 35 & 1 & 20 & 200 \\
\hline 124 & 30 & 1 & 20 & 200 \\
\hline 125 & 25 & 1 & 20 & 200 \\
\hline 126 & 20 & 1 & 20 & 200 \\
\hline 127 & 15 & 1 & 20 & 200 \\
\hline 128 & 10 & 1 & 20 & 200 \\
\hline 129 & 45 & 1.25 & 5 & 200 \\
\hline 130 & 40 & 1.25 & 5 & 200 \\
\hline 131 & 35 & 1.25 & 5 & 200 \\
\hline 132 & 30 & 1.25 & 5 & 200 \\
\hline 133 & 25 & 1.25 & 5 & 200 \\
\hline 134 & 20 & 1.25 & 5 & 200 \\
\hline 135 & 15 & 1.25 & 5 & 200 \\
\hline 136 & 10 & 1.25 & 5 & 200 \\
\hline 137 & 45 & 1.25 & 10 & 200 \\
\hline 138 & 40 & 1.25 & 10 & 200 \\
\hline 139 & 35 & 1.25 & 10 & 200 \\
\hline 140 & 30 & 1.25 & 10 & 200 \\
\hline 141 & 25 & 1.25 & 10 & 200 \\
\hline 142 & 20 & 1.25 & 10 & 200 \\
\hline 143 & 15 & 1.25 & 10 & 200 \\
\hline 144 & 10 & 1.25 & 10 & 200 \\
\hline 145 & 45 & 1.25 & 15 & 200 \\
\hline 146 & 40 & 1.25 & 15 & 200 \\
\hline 147 & 35 & 1.25 & 15 & 200 \\
\hline 148 & 30 & 1.25 & 15 & 200 \\
\hline 149 & 25 & 1.25 & 15 & 200 \\
\hline 150 & 20 & 1.25 & 15 & 200 \\
\hline 151 & 15 & 1.25 & 15 & 200 \\
\hline 152 & 10 & 1.25 & 15 & 200 \\
\hline 153 & 45 & 1.25 & 20 & 200 \\
\hline 154 & 40 & 1.25 & 20 & 200 \\
\hline 155 & 35 & 1.25 & 20 & 200 \\
\hline 156 & 30 & 1.25 & 20 & 200 \\
\hline 157 & 25 & 1.25 & 20 & 200 \\
\hline 158 & 20 & 1.25 & 20 & 200 \\
\hline 159 & 15 & 1.25 & 20 & 200 \\
\hline 160 & 10 & 1.25 & 20 & 200 \\
\hline 161 & 45 & 1.5 & 5 & 200 \\
\hline 162 & 40 & 1.5 & 5 & 200 \\
\hline 163 & 35 & 1.5 & 5 & 200 \\
\hline 164 & 30 & 1.5 & 5 & 200 \\
\hline 165 & 25 & 1.5 & 5 & 200 \\
\hline 166 & 20 & 1.5 & 5 & 200 \\
\hline 167 & 15 & 1.5 & 5 & 200 \\
\hline 168 & 10 & 1.5 & 5 & 200 \\
\hline 169 & 45 & 1.5 & 10 & 200 \\
\hline 170 & 40 & 1.5 & 10 & 200 \\
\hline
\end{tabular}




\begin{tabular}{|c|c|c|c|c|}
\hline 171 & 35 & 1.5 & 10 & 200 \\
\hline 172 & 30 & 1.5 & 10 & 200 \\
\hline 173 & 25 & 1.5 & 10 & 200 \\
\hline 174 & 20 & 1.5 & 10 & 200 \\
\hline 175 & 15 & 1.5 & 10 & 200 \\
\hline 176 & 10 & 1.5 & 10 & 200 \\
\hline 177 & 45 & 1.5 & 15 & 200 \\
\hline 178 & 40 & 1.5 & 15 & 200 \\
\hline 179 & 35 & 1.5 & 15 & 200 \\
\hline 180 & 30 & 1.5 & 15 & 200 \\
\hline 181 & 25 & 1.5 & 15 & 200 \\
\hline 182 & 20 & 1.5 & 15 & 200 \\
\hline 183 & 15 & 1.5 & 15 & 200 \\
\hline 184 & 10 & 1.5 & 15 & 200 \\
\hline 185 & 45 & 1.5 & 20 & 200 \\
\hline 186 & 40 & 1.5 & 20 & 200 \\
\hline 187 & 35 & 1.5 & 20 & 200 \\
\hline 188 & 30 & 1.5 & 20 & 200 \\
\hline 189 & 25 & 1.5 & 20 & 200 \\
\hline 190 & 20 & 1.5 & 20 & 200 \\
\hline 191 & 15 & 1.5 & 20 & 200 \\
\hline 192 & 10 & 1.5 & 20 & 200 \\
\hline 193 & 45 & 1.75 & 5 & 200 \\
\hline 194 & 40 & 1.75 & 5 & 200 \\
\hline 195 & 35 & 1.75 & 5 & 200 \\
\hline 196 & 30 & 1.75 & 5 & 200 \\
\hline 197 & 25 & 1.75 & 5 & 200 \\
\hline 198 & 20 & 1.75 & 5 & 200 \\
\hline 199 & 15 & 1.75 & 5 & 200 \\
\hline 200 & 10 & 1.75 & 5 & 200 \\
\hline 201 & 45 & 1.75 & 10 & 200 \\
\hline 202 & 40 & 1.75 & 10 & 200 \\
\hline 203 & 35 & 1.75 & 10 & 200 \\
\hline 204 & 30 & 1.75 & 10 & 200 \\
\hline 205 & 25 & 1.75 & 10 & 200 \\
\hline 206 & 20 & 1.75 & 10 & 200 \\
\hline 207 & 15 & 1.75 & 10 & 200 \\
\hline 208 & 10 & 1.75 & 10 & 200 \\
\hline 209 & 45 & 1.75 & 15 & 200 \\
\hline 210 & 40 & 1.75 & 15 & 200 \\
\hline 211 & 35 & 1.75 & 15 & 200 \\
\hline 212 & 30 & 1.75 & 15 & 200 \\
\hline 213 & 25 & 1.75 & 15 & 200 \\
\hline 214 & 20 & 1.75 & 15 & 200 \\
\hline 215 & 15 & 1.75 & 15 & 200 \\
\hline 216 & 10 & 1.75 & 15 & 200 \\
\hline 217 & 45 & 1.75 & 20 & 200 \\
\hline 218 & 40 & 1.75 & 20 & 200 \\
\hline
\end{tabular}




\begin{tabular}{|c|c|c|c|c|}
\hline 219 & 35 & 1.75 & 20 & 200 \\
\hline 220 & 30 & 1.75 & 20 & 200 \\
\hline 221 & 25 & 1.75 & 20 & 200 \\
\hline 222 & 20 & 1.75 & 20 & 200 \\
\hline 223 & 15 & 1.75 & 20 & 200 \\
\hline 224 & 10 & 1.75 & 20 & 200 \\
\hline 225 & 45 & 2 & 5 & 200 \\
\hline 226 & 40 & 2 & 5 & 200 \\
\hline 227 & 35 & 2 & 5 & 200 \\
\hline 228 & 30 & 2 & 5 & 200 \\
\hline 229 & 25 & 2 & 5 & 200 \\
\hline 230 & 20 & 2 & 5 & 200 \\
\hline 231 & 15 & 2 & 5 & 200 \\
\hline 232 & 10 & 2 & 5 & 200 \\
\hline 233 & 45 & 2 & 10 & 200 \\
\hline 234 & 40 & 2 & 10 & 200 \\
\hline 235 & 35 & 2 & 10 & 200 \\
\hline 236 & 30 & 2 & 10 & 200 \\
\hline 237 & 25 & 2 & 10 & 200 \\
\hline 238 & 20 & 2 & 10 & 200 \\
\hline 239 & 15 & 2 & 10 & 200 \\
\hline 240 & 10 & 2 & 10 & 200 \\
\hline 241 & 45 & 2 & 15 & 200 \\
\hline 242 & 40 & 2 & 15 & 200 \\
\hline 243 & 35 & 2 & 15 & 200 \\
\hline 244 & 30 & 2 & 15 & 200 \\
\hline 245 & 25 & 2 & 15 & 200 \\
\hline 246 & 20 & 2 & 15 & 200 \\
\hline 247 & 15 & 2 & 15 & 200 \\
\hline 248 & 10 & 2 & 15 & 200 \\
\hline 249 & 45 & 2 & 20 & 200 \\
\hline 250 & 40 & 2 & 20 & 200 \\
\hline 251 & 35 & 2 & 20 & 200 \\
\hline 252 & 30 & 2 & 20 & 200 \\
\hline 253 & 25 & 2 & 20 & 200 \\
\hline 254 & 20 & 2 & 20 & 200 \\
\hline 255 & 15 & 2 & 20 & 200 \\
\hline 256 & 10 & 2 & 20 & 200 \\
\hline 257 & 45 & 2.25 & 5 & 200 \\
\hline 258 & 40 & 2.25 & 5 & 200 \\
\hline 259 & 35 & 2.25 & 5 & 200 \\
\hline 260 & 30 & 2.25 & 5 & 200 \\
\hline 261 & 25 & 2.25 & 5 & 200 \\
\hline 262 & 20 & 2.25 & 5 & 200 \\
\hline 263 & 15 & 2.25 & 5 & 200 \\
\hline 264 & 10 & 2.25 & 5 & 200 \\
\hline 265 & 45 & 2.25 & 10 & 200 \\
\hline 266 & 40 & 2.25 & 10 & 200 \\
\hline
\end{tabular}




\begin{tabular}{|c|c|c|c|c|}
\hline 267 & 35 & 2.25 & 10 & 200 \\
\hline 268 & 30 & 2.25 & 10 & 200 \\
\hline 269 & 25 & 2.25 & 10 & 200 \\
\hline 270 & 20 & 2.25 & 10 & 200 \\
\hline 271 & 15 & 2.25 & 10 & 200 \\
\hline 272 & 10 & 2.25 & 10 & 200 \\
\hline 273 & 45 & 2.25 & 15 & 200 \\
\hline 274 & 40 & 2.25 & 15 & 200 \\
\hline 275 & 35 & 2.25 & 15 & 200 \\
\hline 276 & 30 & 2.25 & 15 & 200 \\
\hline 277 & 25 & 2.25 & 15 & 200 \\
\hline 278 & 20 & 2.25 & 15 & 200 \\
\hline 279 & 15 & 2.25 & 15 & 200 \\
\hline 280 & 10 & 2.25 & 15 & 200 \\
\hline 281 & 45 & 2.25 & 20 & 200 \\
\hline 282 & 40 & 2.25 & 20 & 200 \\
\hline 283 & 35 & 2.25 & 20 & 200 \\
\hline 284 & 30 & 2.25 & 20 & 200 \\
\hline 285 & 25 & 2.25 & 20 & 200 \\
\hline 286 & 20 & 2.25 & 20 & 200 \\
\hline 287 & 15 & 2.25 & 20 & 200 \\
\hline 288 & 10 & 2.25 & 20 & 200 \\
\hline 289 & 45 & 2.5 & 5 & 200 \\
\hline 290 & 40 & 2.5 & 5 & 200 \\
\hline 291 & 35 & 2.5 & 5 & 200 \\
\hline 292 & 30 & 2.5 & 5 & 200 \\
\hline 293 & 25 & 2.5 & 5 & 200 \\
\hline 294 & 20 & 2.5 & 5 & 200 \\
\hline 295 & 15 & 2.5 & 5 & 200 \\
\hline 296 & 10 & 2.5 & 5 & 200 \\
\hline 297 & 45 & 2.5 & 10 & 200 \\
\hline 298 & 40 & 2.5 & 10 & 200 \\
\hline 299 & 35 & 2.5 & 10 & 200 \\
\hline 300 & 30 & 2.5 & 10 & 200 \\
\hline 301 & 25 & 2.5 & 10 & 200 \\
\hline 302 & 20 & 2.5 & 10 & 200 \\
\hline 303 & 15 & 2.5 & 10 & 200 \\
\hline 304 & 10 & 2.5 & 10 & 200 \\
\hline 305 & 45 & 2.5 & 15 & 200 \\
\hline 306 & 40 & 2.5 & 15 & 200 \\
\hline 307 & 35 & 2.5 & 15 & 200 \\
\hline 308 & 30 & 2.5 & 15 & 200 \\
\hline 309 & 25 & 2.5 & 15 & 200 \\
\hline 310 & 20 & 2.5 & 15 & 200 \\
\hline 311 & 15 & 2.5 & 15 & 200 \\
\hline 312 & 10 & 2.5 & 15 & 200 \\
\hline 313 & 45 & 2.5 & 20 & 200 \\
\hline 314 & 40 & 2.5 & 20 & 200 \\
\hline
\end{tabular}




\begin{tabular}{|c|c|c|c|c|}
\hline 315 & 35 & 2.5 & 20 & 200 \\
\hline 316 & 30 & 2.5 & 20 & 200 \\
\hline 317 & 25 & 2.5 & 20 & 200 \\
\hline 318 & 20 & 2.5 & 20 & 200 \\
\hline 319 & 15 & 2.5 & 20 & 200 \\
\hline 320 & 10 & 2.5 & 20 & 200 \\
\hline 321 & 45 & 2.75 & 5 & 200 \\
\hline 322 & 40 & 2.75 & 5 & 200 \\
\hline 323 & 35 & 2.75 & 5 & 200 \\
\hline 324 & 30 & 2.75 & 5 & 200 \\
\hline 325 & 25 & 2.75 & 5 & 200 \\
\hline 326 & 20 & 2.75 & 5 & 200 \\
\hline 327 & 15 & 2.75 & 5 & 200 \\
\hline 328 & 10 & 2.75 & 5 & 200 \\
\hline 329 & 45 & 2.75 & 10 & 200 \\
\hline 330 & 40 & 2.75 & 10 & 200 \\
\hline 331 & 35 & 2.75 & 10 & 200 \\
\hline 332 & 30 & 2.75 & 10 & 200 \\
\hline 333 & 25 & 2.75 & 10 & 200 \\
\hline 334 & 20 & 2.75 & 10 & 200 \\
\hline 335 & 15 & 2.75 & 10 & 200 \\
\hline 336 & 10 & 2.75 & 10 & 200 \\
\hline 337 & 45 & 2.75 & 15 & 200 \\
\hline 338 & 40 & 2.75 & 15 & 200 \\
\hline 339 & 35 & 2.75 & 15 & 200 \\
\hline 340 & 30 & 2.75 & 15 & 200 \\
\hline 341 & 25 & 2.75 & 15 & 200 \\
\hline 342 & 20 & 2.75 & 15 & 200 \\
\hline 343 & 15 & 2.75 & 15 & 200 \\
\hline 344 & 10 & 2.75 & 15 & 200 \\
\hline 345 & 45 & 2.75 & 20 & 200 \\
\hline 346 & 40 & 2.75 & 20 & 200 \\
\hline 347 & 35 & 2.75 & 20 & 200 \\
\hline 348 & 30 & 2.75 & 20 & 200 \\
\hline 349 & 25 & 2.75 & 20 & 200 \\
\hline 350 & 20 & 2.75 & 20 & 200 \\
\hline 351 & 15 & 2.75 & 20 & 200 \\
\hline 352 & 10 & 2.75 & 20 & 200 \\
\hline 353 & 45 & 3 & 5 & 200 \\
\hline 354 & 40 & 3 & 5 & 200 \\
\hline 355 & 35 & 3 & 5 & 200 \\
\hline 356 & 30 & 3 & 5 & 200 \\
\hline 357 & 25 & 3 & 5 & 200 \\
\hline 358 & 20 & 3 & 5 & 200 \\
\hline 359 & 15 & 3 & 5 & 200 \\
\hline 360 & 10 & 3 & 5 & 200 \\
\hline 361 & 45 & 3 & 10 & 200 \\
\hline 362 & 40 & 3 & 10 & 200 \\
\hline
\end{tabular}




\begin{tabular}{lllll}
\hline 363 & 35 & 3 & 10 & 200 \\
\hline 364 & 30 & 3 & 10 & 200 \\
\hline 365 & 25 & 3 & 10 & 200 \\
\hline 366 & 20 & 3 & 10 & 200 \\
\hline 367 & 15 & 3 & 10 & 200 \\
\hline 368 & 10 & 3 & 10 & 200 \\
\hline 369 & 45 & 3 & 15 & 200 \\
\hline 370 & 40 & 3 & 15 & 200 \\
\hline 371 & 35 & 3 & 15 & 200 \\
\hline 372 & 30 & 3 & 15 & 200 \\
\hline 373 & 25 & 3 & 15 & 200 \\
\hline 374 & 20 & 3 & 15 & 200 \\
\hline 375 & 15 & 3 & 15 & 200 \\
\hline 376 & 10 & 3 & 15 & 200 \\
\hline 377 & 45 & 3 & 20 & 200 \\
\hline 378 & 40 & 3 & 20 & 200 \\
\hline 379 & 35 & 3 & 20 & 200 \\
\hline 380 & 30 & 3 & 20 & 200 \\
\hline 381 & 25 & 3 & 20 & 200 \\
\hline 382 & 20 & 3 & 20 & 200 \\
\hline 383 & 15 & 3 & 20 & 200 \\
\hline 384 & 10 & 3 & 20 & \\
\hline & & 3 & & \\
\hline
\end{tabular}

Listric fault models

\begin{tabular}{|c|c|c|c|c|c|}
\hline Model & Segment & Dip & $\begin{array}{l}\text { Depth to upper } \\
\text { fault tip }(\mathrm{km})\end{array}$ & $\begin{array}{l}\text { Depth to lower } \\
\text { fault tip }(\mathrm{km})\end{array}$ & Slip (m) \\
\hline \multirow[t]{4}{*}{385} & 1 & 30 & 0 & 2.88675 & 200 \\
\hline & 2 & 10 & 2.88675 & 3.76838 & 200 \\
\hline & 3 & 5 & 3.76838 & 4.20582 & 200 \\
\hline & 4 & 0.01 & 4.20582 & 4.20669 & 200 \\
\hline \multirow[t]{4}{*}{386} & 1 & 30 & 0 & 5.77350 & 200 \\
\hline & 2 & 10 & 5.77350 & 7.53677 & 200 \\
\hline & 3 & 5 & 7.53677 & 8.41166 & 200 \\
\hline & 4 & 0.01 & 8.41166 & 8.41341 & 200 \\
\hline \multirow[t]{4}{*}{387} & 1 & 30 & 0 & 8.66025 & 200 \\
\hline & 2 & 10 & 8.66025 & 11.30515 & 200 \\
\hline & 3 & 5 & 11.30515 & 12.61748 & 200 \\
\hline & 4 & 0.01 & 12.61748 & 12.62010 & 200 \\
\hline \multirow[t]{4}{*}{388} & 1 & 30 & 0 & 11.54701 & 200 \\
\hline & 2 & 10 & 11.54701 & 15.07354 & 200 \\
\hline & 3 & 5 & 15.07354 & 16.82332 & 200 \\
\hline & 4 & 0.01 & 16.82332 & 16.82681 & 200 \\
\hline \multirow[t]{4}{*}{389} & 1 & 30 & 0.5 & 3.38675 & 200 \\
\hline & 2 & 10 & 3.38675 & 4.26838 & 200 \\
\hline & 3 & 5 & 4.26838 & 4.70582 & 200 \\
\hline & 4 & 0.01 & 4.70582 & 4.70669 & 200 \\
\hline 390 & 1 & 30 & 0.5 & 6.2735 & 200 \\
\hline
\end{tabular}




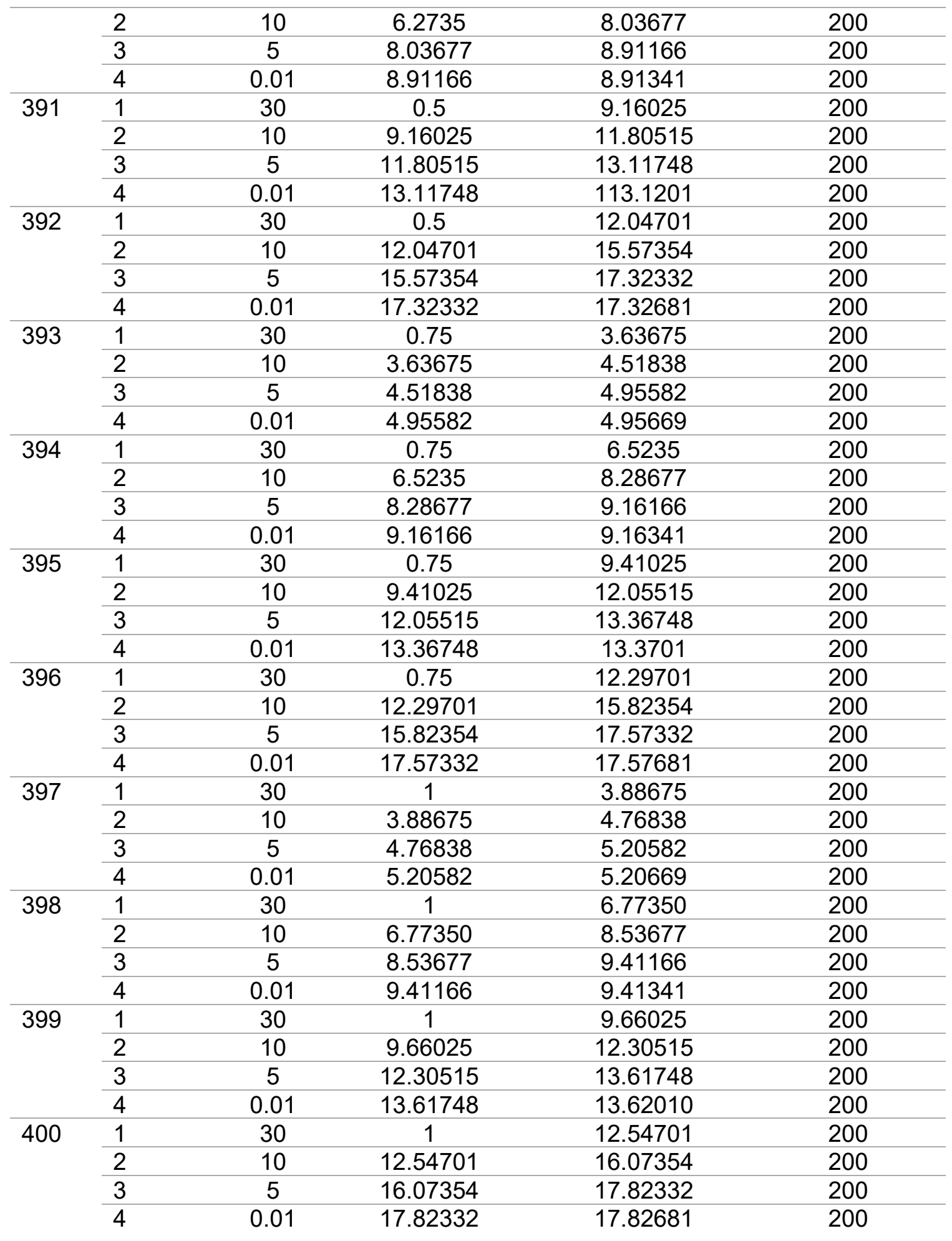



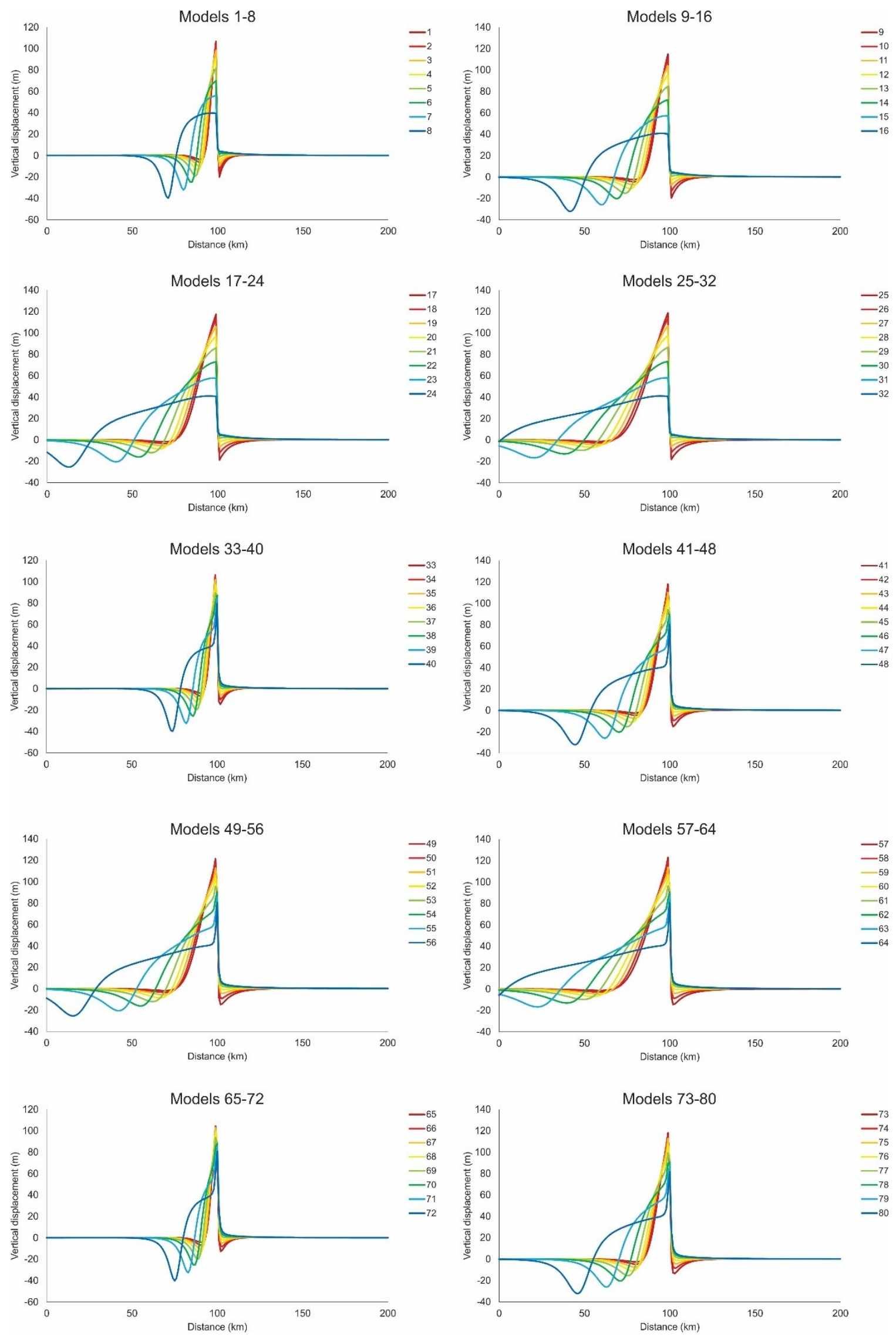

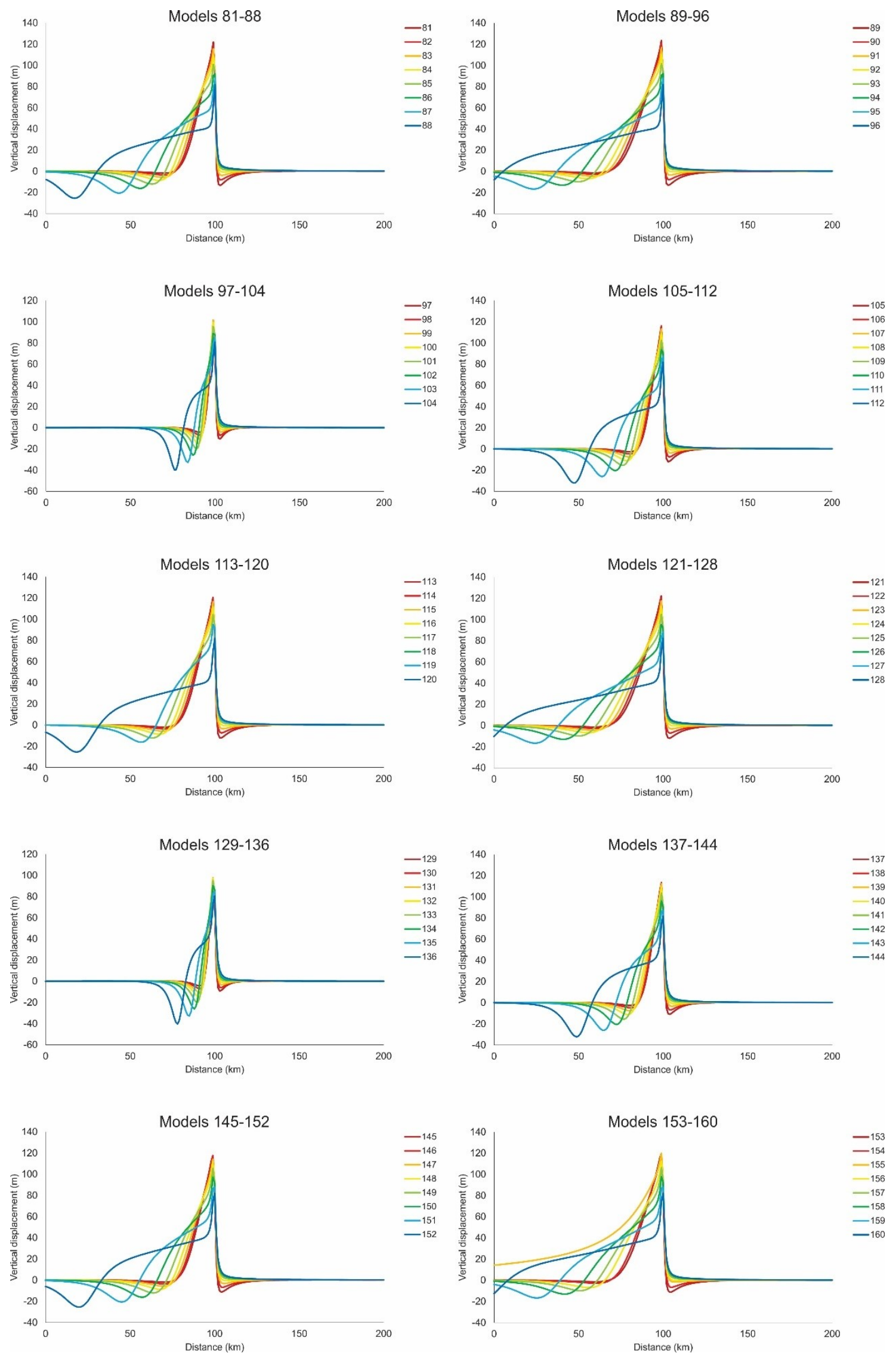

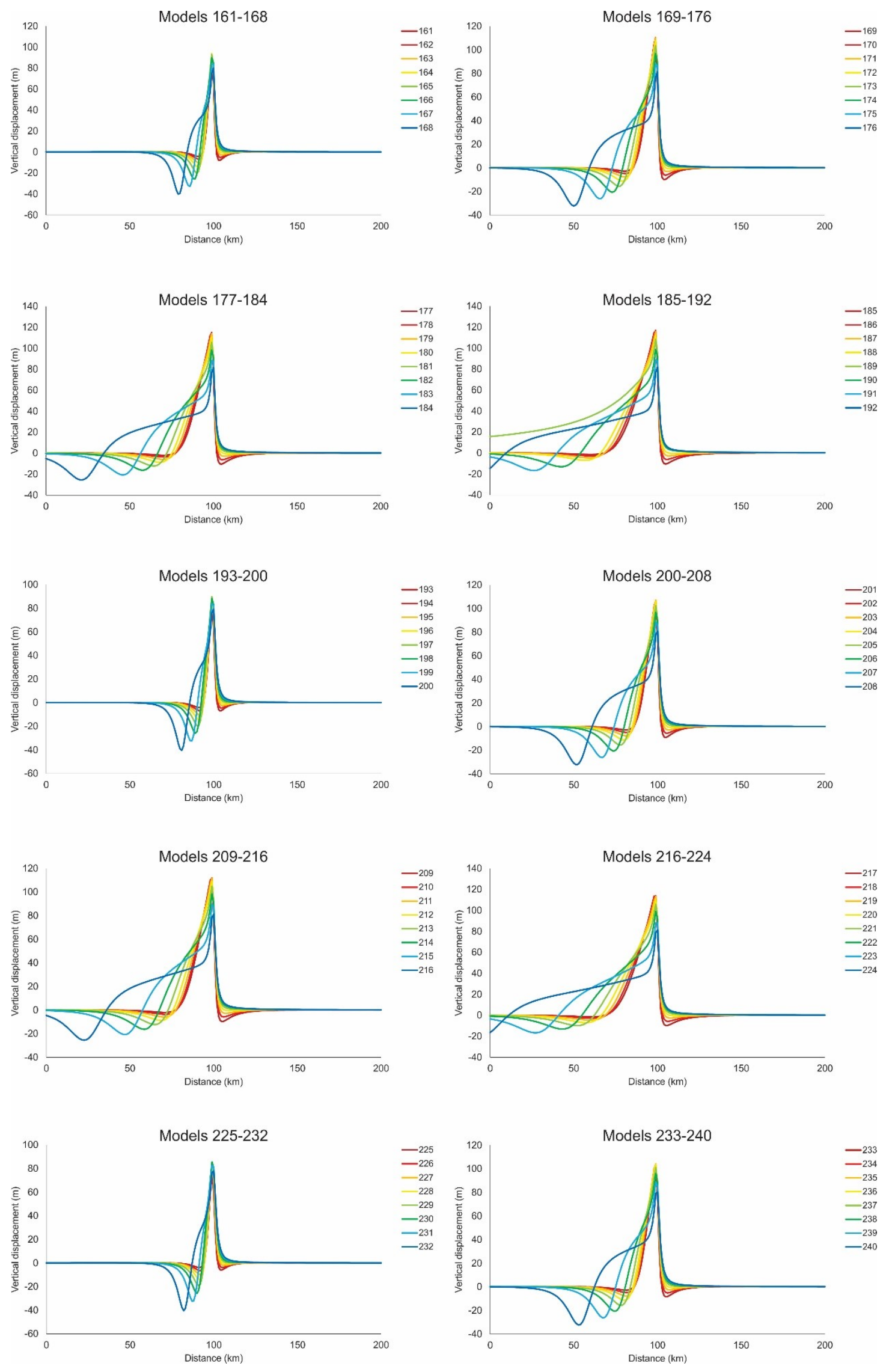

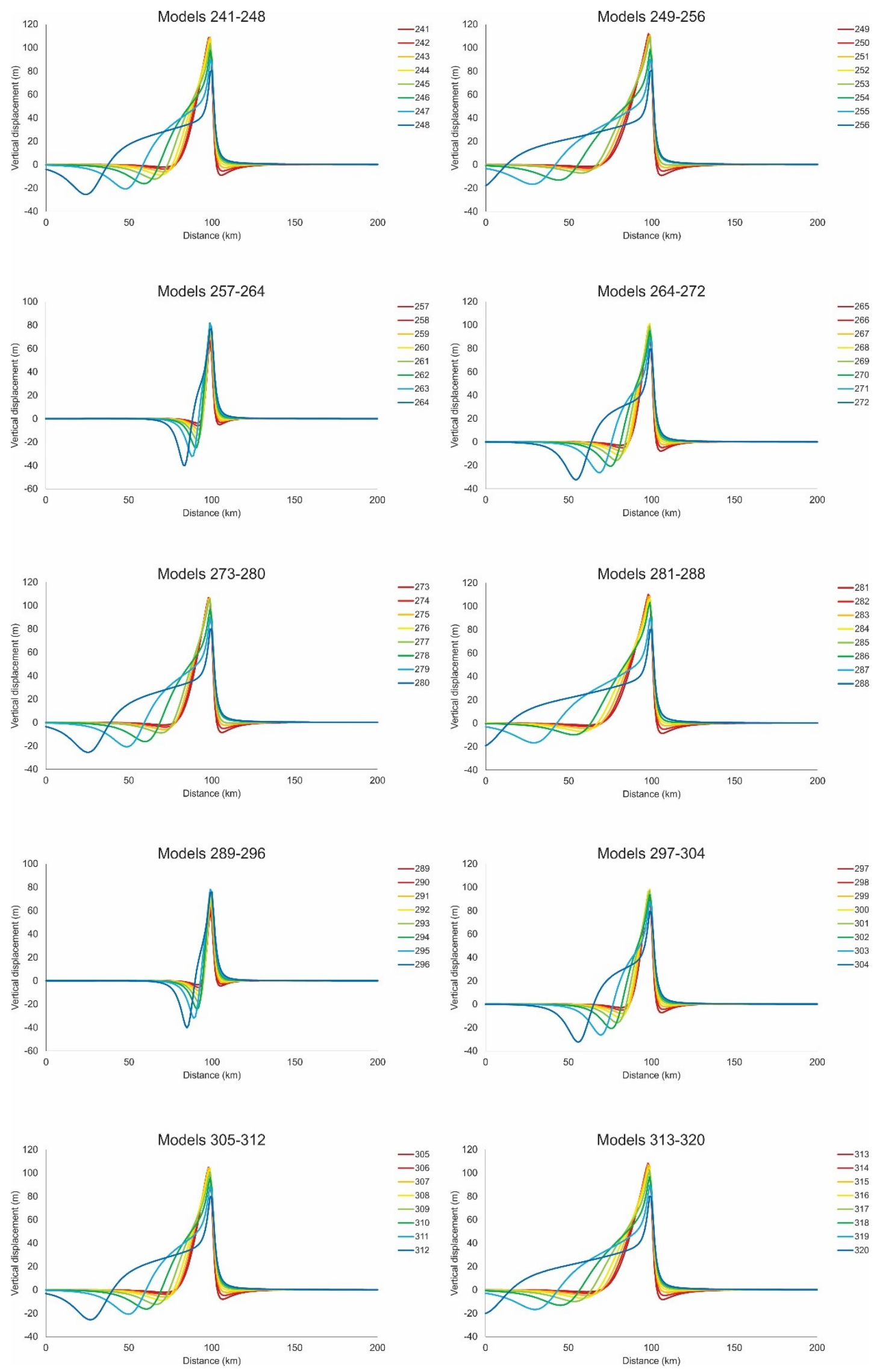

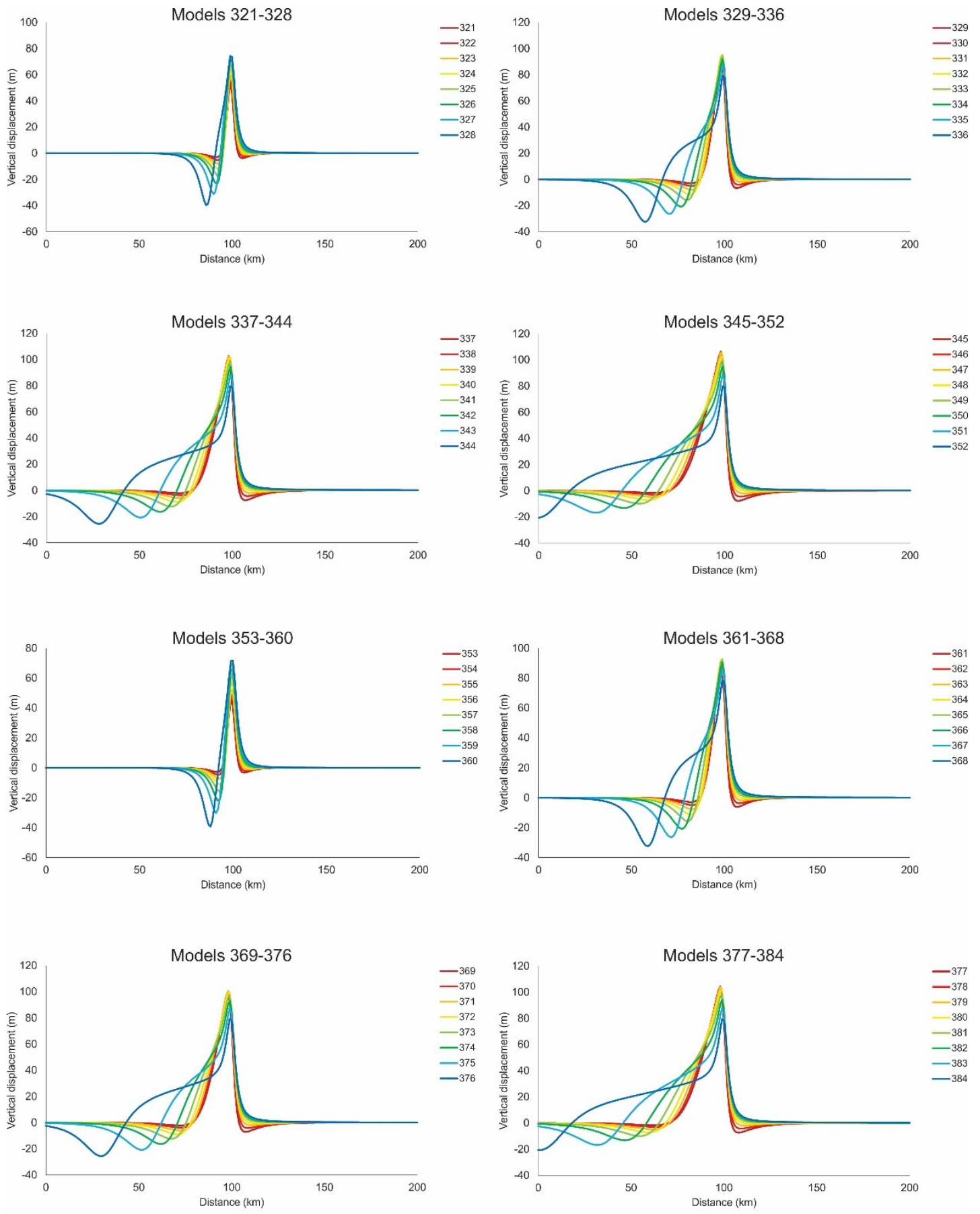

$$
\begin{aligned}
& -361 \\
& -362 \\
& -363 \\
& -364 \\
& -365 \\
& -366 \\
& -367 \\
& -368
\end{aligned}
$$
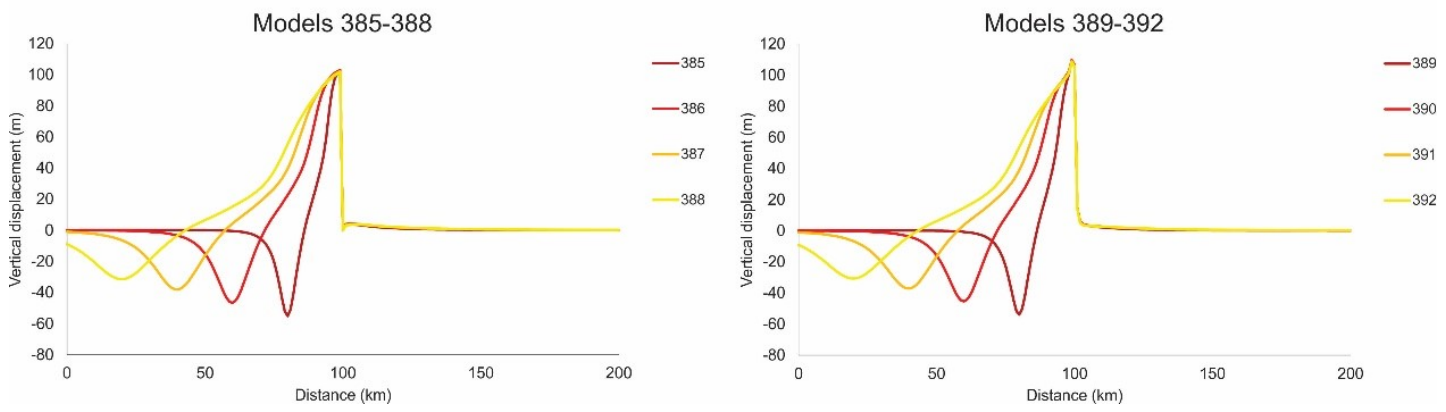

281 

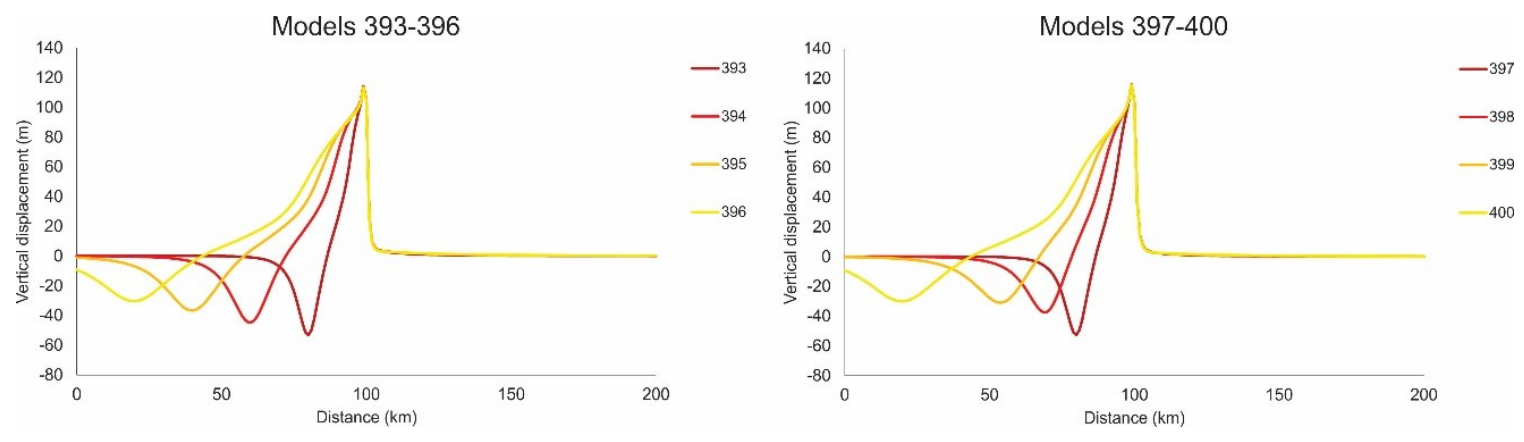